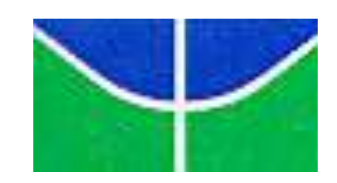

Universidade de Brasília - UnB

Faculdade de Economia, Administração e Contabilidade - FACE

Programa de Pós-Graduação em Administração - PPGA

\title{
SUPORTE À APRENDIZAGEM, IMPACTO DE TREINAMENTO EM PROFUNDIDADE E EM AMPLITUDE E DESENVOLVIMENTO DE COMPETENCIAS GERENCIAIS NO INSS
}

LEOVANIR DIETER DOCKHORN RICHTER

Brasília, DF

2017 


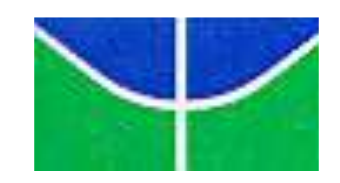

Universidade de Brasília - UnB

Faculdade de Economia, Administração e Contabilidade - FACE

Programa de Pós-Graduação em Administração - PPGA

\section{SUPORTE À APRENDIZAGEM, IMPACTO DE TREINAMENTO EM PROFUNDIDADE E EM AMPLITUDE E DESENVOLVIMENTO DE COMPETÊNCIAS GERENCIAIS NO INSS}

LEOVANIR DIETER DOCKHORN RICHTER

Dissertação apresentada ao
Programa de Pós-Graduação em
Administração - PPGA/FACE/UnB,
como requisito parcial à obtenção
do título de Mestre em
Administração.

Orientador: Prof. Dr. Francisco Antônio Coelho Junior

Brasília, DF

Abril de 2017 
Leovanir Dieter Dockhorn Richter

Suporte à Aprendizagem, Impacto de treinamento em Profundidade e em Amplitude e Desenvolvimento de Competências Gerenciais no INSS

Dissertação de Mestrado defendida diante e avaliado pela banca examinadora constituída por:

$\overline{\text { Professor Dr. Francisco Antônio Coelho Júnior (Presidente) }}$ Universidade de Brasília (UnB)

Professora Dra. Helga Cristina Hedler (Membro) Universidade Católica de Brasília (UCB)

Professor Dr. Rodrigo Ferreira (Membro) Universidade de Brasília (UnB)

$\overline{\text { Professora Dra. Tatiane Paschoal (Membro) }}$ Universidade de Brasília (UnB)

Brasília - DF

2017 


\section{Agradecimentos}

A Deus por mais uma vez abrir às portas e me abençoar, permitindo-me realizar mais um sonho em minha vida.

A minha querida e amada esposa Ligia, minha resiliente filha Letícia e meu abençoado filho Leonardo pela compreensão de minha ausência, pelo incentivo, apoio, amor e carinho a mim dedicados durante esta árdua jornada.

Ao Professor Francisco por sua perseverança, foco, paciência e entusiasmo em me orientar com respeito, sabedoria e ética para atingir os objetivos definidos.

Aos colegas do Grupo de Pesquisas e Estudos Avançados sobre Comportamento Organizacional - GEPACO pela colaboração e disposição em incrementar o referencial teórico e auxiliar a validar os instrumentos de pesquisa.

Aos servidores e gestores do INSS, em especial a Auditoria Geral e a Diretoria de Gestão de Pessoas, que permitiram e efetivamente apoiaram a realização da pesquisa nessa Autarquia. Aos servidores e gestores da CGU, em especial a Coordenação de Gestão de Pessoas, que permitiram conciliar os trabalhos profissionais com esta produção intelectual.

Aos Professores do PPGA, em especial à Professora Gardênia que me desafiou a avançar nos estudos, bem como ao Professor Rodrigo, a Professora Helga e a Professora Tatiane que fizeram grandes contribuições na avaliação desta pesquisa. E por fim, agradeço a todos os que acreditam que as pessoas são o que há de mais importante em uma organização e que é por meio do desenvolvimento destas que a organização atingirá seus objetivos.

O meu muito obrigado e eterno reconhecimento. 


\section{LISTA DE TABELAS}

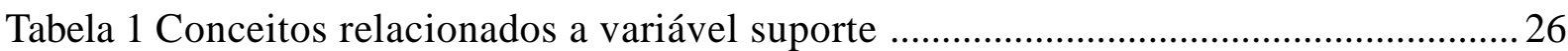

Tabela 2 Conceitos relacionados a competência .................................................................. 30

Tabela 3 Definições constitutivas e operacionais das variáveis nos modelos teóricos

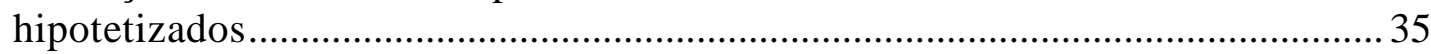

Tabela 4 Quantidade de Gerências Executivas e Agências da Previdência Social por Superintendência no Brasil ................................................................................. 42

Tabela 5 Detalhamento dos cargos em comissão e das funções gratificadas do INSS ....... 43

Tabela 6 Quantitativo de Cursos de Gestão ......................................................................... 45

Tabela 7 Cursos de gestão selecionados para avaliação do impacto em profundidade ...... 47

Tabela 8 Características do questionário .............................................................................. 49

Tabela 9 Dados biográficos e funcionais dos respondentes da pesquisa ............................54

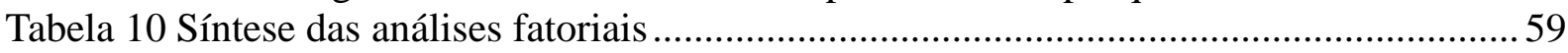

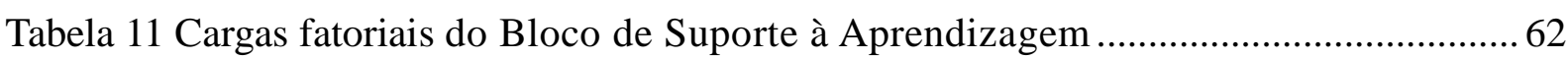

Tabela 12 Análises fatoriais dos 4 fatores - Suporte a Aprendizagem .............................. 63

Tabela 13 Cargas fatoriais da solução unifatorial da escala de Impacto de treinamento em amplitude

Tabela 14 Cargas da solução do bloco de Impacto em Profundidade - Curso de Gestão Estratégica

Tabela 15 Cargas da solução do bloco de Impacto em Profundidade - Curso de Gestão de Equipes

Tabela 16 Cargas da solução unifatorial do bloco de Impacto de treinamento em amplitude sobre Competências do gerente de APS - escalas Importância e Contribuição

Tabela 17 Resultados Regressão Múltipla Impacto de treinamento em amplitude

Tabela 18 Resultados Regressão Múltipla Impacto de treinamento em profundidade (curso Gestão Estratégica, importância do curso à aquisição e domínio de competências profissionais do gestor)

Tabela 19 Resultados Regressão Múltipla Impacto de treinamento em profundidade (curso Gestão Estratégica, contribuição percebida do curso à aquisição e domínio de competências profissionais do gestor)

Tabela 20 Resultados Regressão Múltipla Impacto de treinamento em profundidade (curso Gestão de Equipes, importância percebida do curso à aquisição e domínio de competências profissionais do gestor)

Tabela 21 Resultados Regressão Múltipla Impacto de treinamento em profundidade (curso Gestão de Equipes, contribuição percebida do curso à aquisição e domínio de competências profissionais do gestor)

Tabela 22 Resultados Regressão Múltipla Impacto do treinamento em amplitude sobre competência do gerente de APS, importância percebida do curso à aquisição e domínio de competências profissionais do gestor

Tabela 23 Resultados Regressão Múltipla Impacto do treinamento em amplitude sobre competência do gerente de APS, contribuição percebida do curso à aquisição e domínio de competências profissionais do gestor.... 


\section{LISTA DE FIGURAS}

Figura 1. Níveis de avaliação em modelos tradicionais de Kirkpatrick (1976) e Hamblin (1978). Fonte: Vitoria, D.M. (2014).

Figura 2. Representação esquemática dos componentes do Modelo IMPACT, proposto por Abbad, G.S. (2014)

Figura 3. Modelo geral de avaliação da transferência de treinamento via web no trabalho proposto por Zerbini e Abbad (2010) .................................................................. 23

Figura 4. Modelo téorico hipotetizado de impacto de treinamento, de suporte a aprendizagem e de características pessoais e profissionais.................................... 36

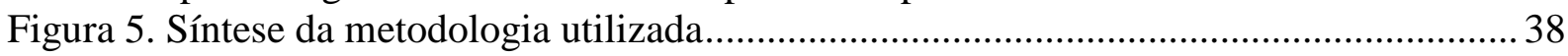

Figura 6. Estrutura do INSS no Brasil ............................................................................... 41

Figura 7. Gráfico de sedimentação do Suporte à Aprendizagem .......................................... 61

Figura 8. Gráfico comparativo de médias entre gerentes executivos e gerentes de APS quanto avaliações de contribuição e importância do curso de Gestão Estratégica .. 78 


\section{RESUMO}

As ações de capacitação, nas organizações, são planejadas e ofertadas com vistas à resolução de lacunas de desempenho identificadas nos indivíduos em situação laboral. Estas ações precisam ser investigadas, especialmente quanto ao impacto gerado, pelas mesmas, à melhoria da performance. Na literatura científica disponível usualmente se pesquisa a aplicação de treinamento como impacto, e seu principal preditor encontra-se em variáveis de contexto. $\mathrm{O}$ suporte à transferência vem sendo apontado como principal preditor de impacto. Pouco se sabe, empiricamente, como se dá o impacto (tanto em profundidade quanto em amplitude) sobre o desenvolvimento e expressão de competências relacionadas ao trabalho. Torna-se premente, assim, identificar qual é a importância da capacitação sobre o desenvolvimento de competências profissionais, e quanto tal capacitação, de fato, propicia valor final nas rotinas laborais. Assim, o objetivo geral consistiu em verificar a influência do suporte à aprendizagem e dos treinamentos gerenciais ofertados a gestores do Instituto Nacional do Seguro Social (INSS) sobre a expressão de competências requeridas para o desempenho de suas funções. Para o alcance deste objetivo, foi elaborado o modelo teórico hipotetizado de pesquisa tendo como variáveis critério impactos de treinamento no trabalho, medido tanto em profundidade e em amplitude, mensurado sobre qual foi a importância e contribuição de dois cursos avaliados para a aquisição e expressão das competências laborais gerenciais. Quanto à metodologia, foram investigados dois cursos ofertados na modalidade a distância, no INSS, que tratavam sobre gestão estratégica e de equipes. A coleta de dados foi realizada a distância. A amostra final $(\mathrm{N}=291)$ era predominantemente masculina, entre 31 a 50 anos e com ensino superior completo. Os resultados sinalizaram evidências de validade e de construto para as medidas utilizadas, bem como apontaram que suporte à aprendizagem foi importante preditora nos modelos empíricos finais. Tendo constante investimento em ações de melhoria do suporte à aprendizagem no ambiente organizacional, tais gestores podem aplicar em suas rotinas as competências adquiridas em situação de treinamento, de uma forma mais perene, impactante e alinhada com os objetivos estratégicos da autarquia.

Palavras-chave: Impacto do treinamento no trabalho, Suporte à aprendizagem, Competências Gerenciais, Resultados de treinamento. 


\begin{abstract}
The training actions, in the organizations, are planned and offered with a view to solving the identified performance gaps in the individuals in labor situation. These actions need to be investigated, especially with respect to the impact of these actions on improving performance. In the available scientific literature, the application of training as impact is usually researched, and its main predictor lies in context variables. The transfer support has been pointed as the main impact predictor. Little is known, empirically, as the impact (both in depth and breadth) on the development and expression of work-related competencies. It is therefore imperative to identify the importance of training on the development of professional competences, and how such training, in fact, provides final value in the work routines. Thus, the general objective was to verify the influence of the learning support and the managerial training offered to managers of the Instituto Nacional do Seguro Social (INSS) on the expression of competencies required for the performance of their duties. In order to reach this objective, the hypothesized theoretical model of research was elaborated, having as variables the criteria of training in the work, measured both in depth and in amplitude, measured on what was the importance and contribution of two courses evaluated for the acquisition and expression of the Management competences. As for the methodology, two courses were offered in the distance modality, in the INSS, which dealt with strategic management and teams. Data collection was carried out at a distance. The final sample $(\mathrm{N}=291)$ was predominantly male, between 31 and 50 years old, and with complete higher education. The results showed evidence of validity and construct for the measures used, as well as pointed out that learning support was an important predictor in the final empirical models. Having a constant investment in actions to improve learning support in the organizational environment, these managers can apply their acquired competences in a training situation in a more perennial, impactful way and in line with the organization strategic objectives.
\end{abstract}

\title{
Keywords:
}

Impact of training at work, Support to learning, Management competences, Training results. 
SUMÁRIO

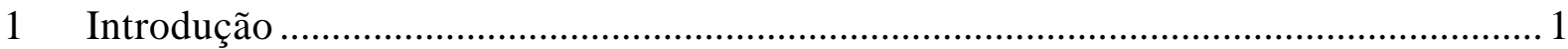

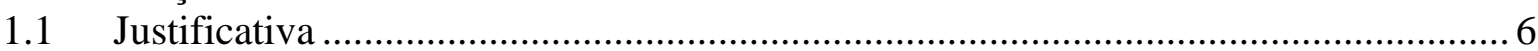

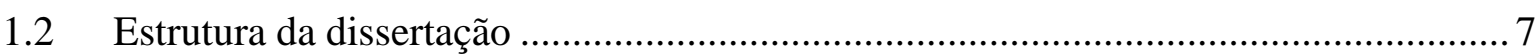

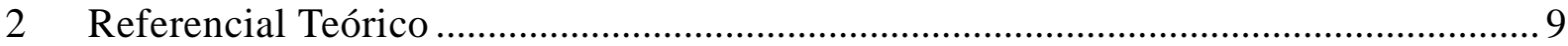

2.1 Critérios e procedimentos de construção do referencial teórico .............................9

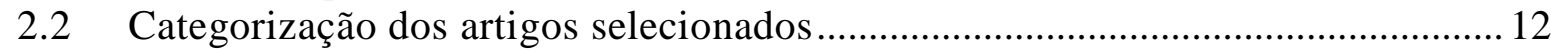

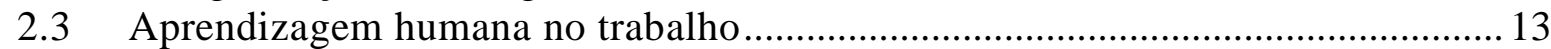

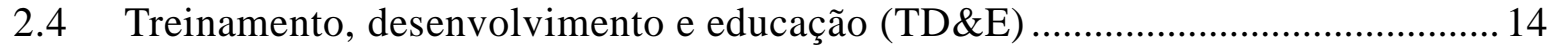

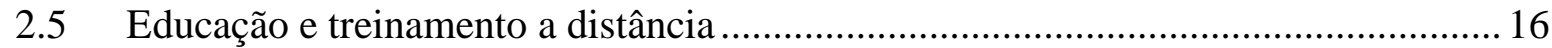

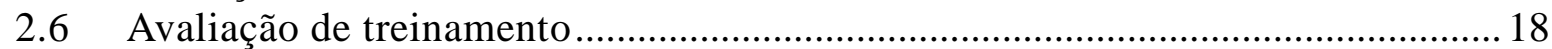

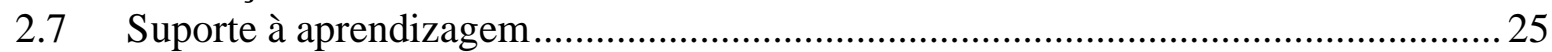

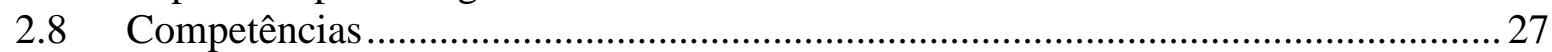

3 Modelo Teórico Hipotetizado de Pesquisa ..................................................................... 33

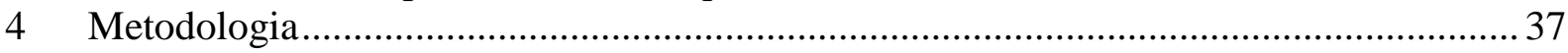

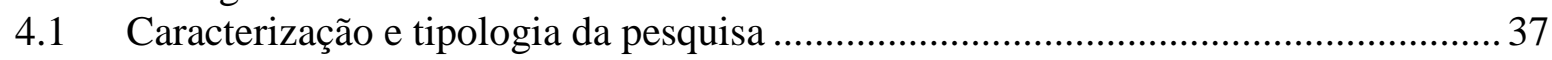

4.2 Caracterização da organização estudada.................................................................. 39

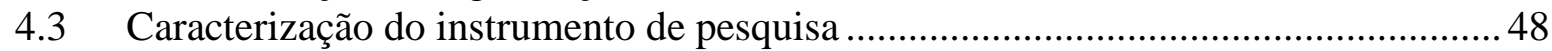

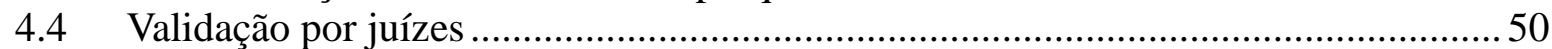

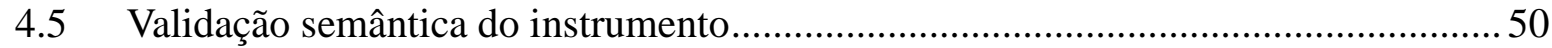

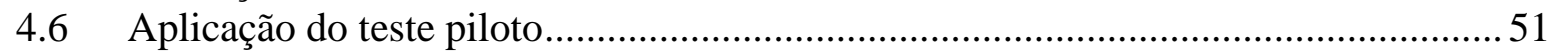

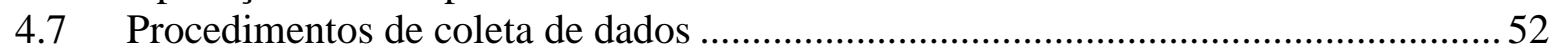

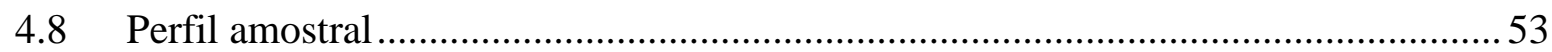

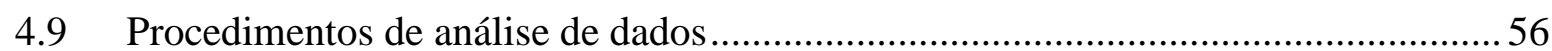

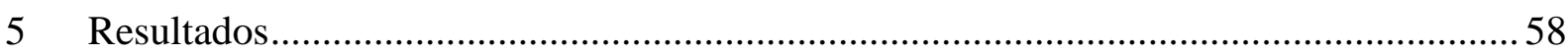

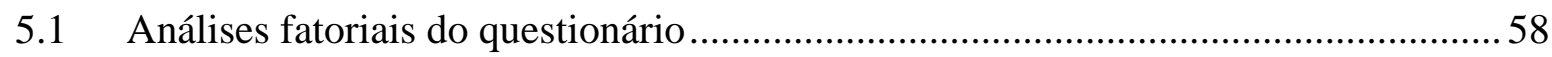

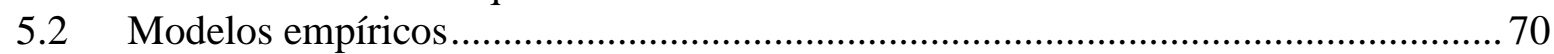

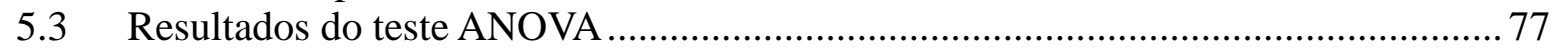

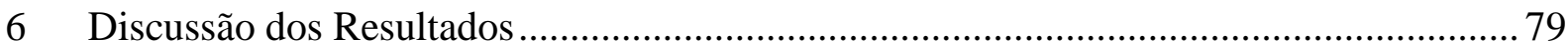

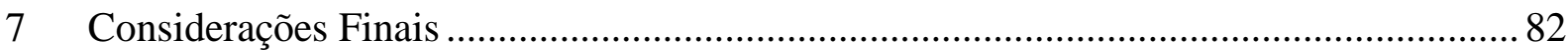

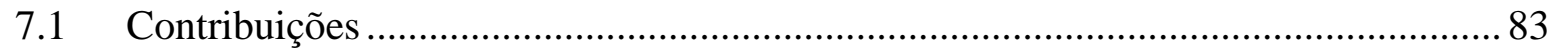

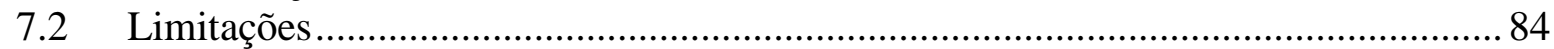

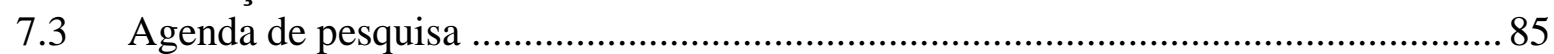

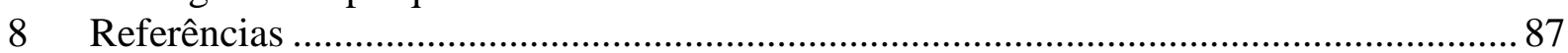

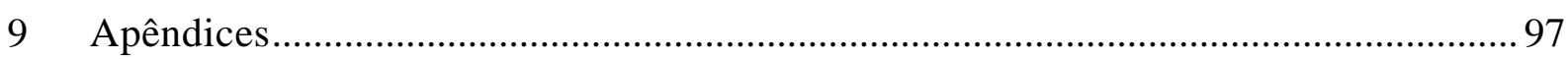

Apêndice I - Pesquisas nacionais selecionadas sobre suporte à aprendizagem, competências organizacionais e impacto do treinamento no trabalho.............................. 97

Apêndice II - Pesquisas internacionais selecionadas sobre suporte à aprendizagem, competências organizacionais e impacto do treinamento no trabalho ............................. 113

Apêndice III - Questionário aos gerentes executivos e gerentes de Agência da

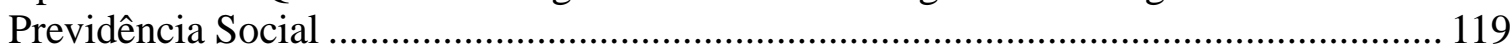

Apêndice IV - Conceitos relacionados a Competência .................................................... 128

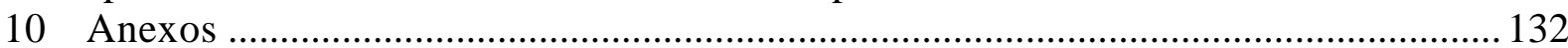

Anexo I - Competências do gerente de Agência da Previdência Social (APS) ......... 132

Anexo II - Competências do gerente executivo ........................................................ 134 


\section{Introdução}

Na sociedade do conhecimento a aprendizagem se tornou variável imprescindível para que os indivíduos consigam desempenhar mais e melhor. $\mathrm{O}$ ambiente laboral, em que crenças são compartilhadas e comportamentos são socialmente aprendidos, é capaz de incentivar a incidência de ações de aprendizagem entre os colaboradores. O apoio psicossocial da chefia e dos colegas é imprescindível neste contexto (Galanou \& Priporas, 2009).

Aprender, hoje, torna-se uma exigência contínua aos indivíduos em situação laboral. A referência é ao desempenho competente, alinhado aos resultados esperados do cargo e aos objetivos organizacionais. Sem aprendizagem os conhecimentos se tornam obsoletos, e as competências podem vir a se tornar desatualizadas (Alfandi, 2016).

Historicamente, ações de capacitação são recomendadas nas organizações com o objetivo de sanar lacunas de performance. Maximizar a eficiência na realização do trabalho aliado à busca por melhores resultados é uma das premissas fundamentais que justificam a ação de aprendizagem nas organizações (Salas; Cannon-Bowers, 2001).

No contexto brasileiro, a denominada Nova Administração Pública, segundo BresserPereira (1998), também conhecida como administração pública gerencial, emergiu como um modelo ideal para o gerenciamento do Estado focado no gerenciamento de resultados. Este modelo orientou as organizações públicas brasileiras à investirem no mapeamento e desenvolvimento de competências de seus quadros gerenciais, impactando nas rotinas de trabalho e gerando melhoria do desempenho individual e institucional.

Um desafio gerencial na administração pública é o desenvolvimento de lideranças. Este tem sido tema particularmente importante no desenvolvimento do novo serviço público, segundo Denhardt (2012). Espera-se das lideranças competências alinhadas ao compromisso com os valores e missão organizacionais, foco na excelência de prestação de serviços 
públicos, empoderamento e dedicação ao serviço público, dentre outros, refletindo um modelo de negócio que torna o serviço público eficaz ao atendimento das demandas dos usuárioscidadãos. São princípios-chave para o novo serviço público servir cidadãos; dar mais valor à cidadania; agir estrategicamente; dar valor às pessoas, não apenas à produtividade é também outro importante preceito defendido neste novo contexto da administração pública gerencial.

Neste contexto, a política de capacitação e de desenvolvimento de pessoas, publicada no Decreto $n^{\circ}$ 5.707, de 23 de fevereiro de 2006, em implantação no governo federal, assenta-se entre outros aspectos em um tripé estratégico: gestão por competências; democratização das relações de trabalho para gerar ambientes adequados à inovação; e qualificação intensiva das equipes de trabalho, incluindo o uso de tecnologia da informação. Tal política tem diretrizes que estimulam a aprendizagem contínua e ampla disseminação do conhecimento. Ainda, atribui, ao conhecimento, a chave para a inovação e a melhoria da gestão pública. Por fim, busca a qualidade de vida no trabalho (saúde física e emocional); valoriza a informação compartilhada; e, finalmente, busca gerar alto grau de envolvimento de dirigentes e de servidores no ambiente de trabalho.

É salutar destacar, também, ainda em termos legais, a vigência da Lei no 13.346 , de 10 de outubro de 2016, que dispõe sobre a extinção de cargos em comissão do Grupo-Direção e Assessoramento Superiores e a criação de funções de confiança denominadas Funções Comissionadas do Poder Executivo. Nessa Lei fica determinado que os órgãos e entidades do Poder Executivo Federal deverão incluir em seus planos de capacitação ações destinadas à habilitação de seus servidores para o exercício das FCPE e para a ocupação de cargos em comissão do Grupo-DAS, com base no perfil profissional e nas competências desejadas e compatíveis com a responsabilidade e complexidade inerentes à função ou ao cargo. Também determina que se estabeleça um programa de desenvolvimento gerencial para os ocupantes das FCPE e de cargos em comissão do Grupo-DAS. Tal fundamentação legal vem ao encontro 
do objeto em análise e valoriza tal temática de desenvolvimento gerencial dentro da realidade da administração pública federal.

Ao considerar o modelo vigente da nova administração pública, o desafio é transformar sólidos normativos em exemplares modelos referenciais de gestão pública na formação de pessoas, sendo algo que exige de todas as partes interessadas um maior compromisso, muito além do basilar controle nas ações educacionais das organizações públicas brasileiras. Inclusive o Tribunal de Contas da União (TCU) já se pronunciou sobre o assunto por meio do Acórdão $n^{\circ} 3.023 / 2013$ - TCU - Plenário, destacando, entre outros aspectos, que na Governança e Gestão de Pessoas da Administração Pública Federal há falta de critérios de qualificação para ocupação de cargos de gestão e de assessoramento, bem como, falta de capacitação dos gestores e carência de programas de desenvolvimento gerencial.

Sobre governança pública é salutar enfatizar que tal termo entrou no vocabulário da gestão pública nas três últimas décadas, onde Peci, Pieranti e Rodrigues (2008) enfatizam que o conceito de governança pode ser utilizado na teoria de administração pública para qualificar as relações que o Estado (domínio dos políticos e burocratas) desenvolve com o setor privado (domínio das empresas e consumidores) e o terceiro setor (domínio da cidadania organizada em torno dos seus interesses).

Recentemente, em 08 de março de 2017, o TCU retornou sobre o mesmo tema no Acórdão no 358/2017 - TCU - Plenário reafirmando que a governança de pessoas é a aplicação de um conjunto de princípios e práticas no principal viabilizador de resultados organizacionais: os recursos humanos. Nesse Acórdão nº 358/2017 - TCU - Plenário também consta a afirmação de que a ausência de profissionalização na gestão de pessoas deixa as organizações com critérios frágeis de tomada de decisões, permitindo que importantes deliberações decorram de critérios subjetivos, interesses individuais ou relações sociais existentes entre atores da organização, em detrimento da orientação ao interesse público. Mais 
uma vez ressalta-se a importância de serem desenvolvidas ações de capacitação orientadas à aquisição e expressão de competências relacionadas ao contínuo desenvolvimento gerencial.

Borges-Andrade (2006) destaca que a demanda por avaliação em treinamento nos setores público e privado é crescente e generalizada, visto que tradicionalmente realizam elevados investimentos nas atividades de treinamento, desenvolvimento e educação. Também muitas organizações, segundo tal autor, descobriram os valores estratégicos do conhecimento e do esforço na contínua qualificação de seu pessoal.

Neste ínterim, e considerando a relevância de se avaliar as ações instrucionais desenvolvidas no lócus da administração pública brasileira, esta pesquisa foi desenvolvida junto ao Instituto Nacional do Seguro Social (INSS), caracterizada como autarquia federal, tendo público alvo os ocupantes de função comissionada de gerente executivo e gerente de Agência da Previdência Social (APS). Ressalta-se que esta Organização foi selecionada por desempenhar atividades gerenciais nas diversas unidades administrativas e de atendimento à população brasileira mais carente, econômica e socialmente, e por apresentarem necessidades e características que precisam ser consideradas nos treinamentos realizados por aquela autarquia.

Isto posto, o objetivo geral é verificar a influência do suporte à aprendizagem e dos treinamentos gerenciais ofertados a gestores do INSS sobre a expressão de competências requeridas para o desempenho de suas funções.

Dispondo do objetivo geral, os seguintes objetivos específicos foram definidos:

a. Construir instrumento de autoavaliação de mensuração do impacto em profundidade vinculado a cursos a distância ofertados aos gestores do INSS;

b. Buscar evidências de validação do instrumento de autoavaliação de medida de impacto em amplitude frente a cursos a distância ofertados e as competências requeridas aos gestores do INSS; 
c. Buscar evidências de validação do instrumento de suporte psicossocial à aprendizagem vinculado a cursos a distância ofertados aos gestores do INSS; e

d. Testar relações preditivas entre suporte à aprendizagem, impactos de treinamentos em profundidade e em amplitude junto à aquisição e desenvolvimento de competências de gestão a gestores do INSS.

Nos objetivos algumas definições se fazem necessárias, onde suporte à aprendizagem vem a ser as medidas de avaliação de fatores externos ao treinamento, não ligados ao apoio direto à realização do evento instrucional, conforme destacam Abbad, Coelho Jr, Freitas e Pilati (2006). Já verificar a influência ou impacto de treinamento, desenvolvimento e educação (TD\&E) significa avaliar em que medida os esforços despendidos nestas ações efetivamente geraram os efeitos desejados, segundo Freitas, Borges-Andrade, Abbad e Pilati (2006). A expressão de competências requeridas assume uma dimensão estratégica, segundo Bastos (2006), onde o profissional necessita lidar com cada situação ou evento organizacional e mobilizar recursos adequados para oferecer respostas a situação presente ou futura em determinado ambiente.

Formulou-se a seguinte pergunta de pesquisa a partir de tais objetivos estabelecidos: qual a influência do suporte à aprendizagem e dos treinamentos gerenciais ofertados a gestores do INSS sobre a aquisição e expressão de competências gerenciais requeridas para o desempenho de suas funções?

Para responder tal pergunta, pesquisou-se, aqui, a importância atribuída a cada um dos dois (2) cursos analisados sobre o desenvolvimento de competências gerenciais no âmbito dos indivíduos pesquisados. Ainda, mediu-se o quanto cada curso em específico contribuiu, efetivamente, para o desenvolvimento destas competências gerenciais. O impacto dos dois cursos foi medido sobre a importância dos mesmos ao desenvolvimento das competências 
gerenciais e ao quanto, de fato, sob a percepção dos respondentes, estes cursos contribuíram para o desenvolvimento destas competências.

As capacitações realizadas junto a gestores do INSS também foram objeto de verificação de pesquisa, em especial quanto ao alcance de êxito na expressão de competências de liderança nos mesmos. Foi estudado se o contexto de aprendizagem e de expressão de competências estavam convergindo nesta autarquia, por meio da análise do suporte psicossocial provido à aprendizagem por parte das próprias chefias e dos colegas e pares.

Esta perspectiva (considerar os efeitos do impacto de uma capacitação sobre o desenvolvimento de competências profissionais) pode ser considerada relativamente inovadora, pois pouca tecnologia instrucional faz referência ao posterior desenvolvimento e expressão das competências, especialmente as de nível gerencial. A perspectiva teórica assumida nesta Dissertação se baseia em Elnaga e Imran (2013) e Alfandi (2016).

\subsection{Justificativa}

Considerando a questão estabelecida e seus objetivos, a construção da justificativa deste Estudo é assentada pelas suas relevâncias social, teórica, gerencial e organizacional.

A relevância social encontra na literatura um reforço, onde Aguinis e Kraiger (2009) enfatizam que a melhoria dos serviços prestados por uma organização por meio do aperfeiçoamento profissional e humano dos seus integrantes pode ser obtido por meio da realização de ações de Treinamento, Desenvolvimento e Educação (TD\&E). Ao considerar tal possibilidade de melhoria do desempenho das atribuições por meio de ações formais de capacitação, avaliar as ações educacionais voltadas para a formação de gestores previdenciários poderá propiciar o aperfeiçoamento dos cursos ministrados, o incremento da qualidade dos serviços previdenciários prestados pelo INSS. Tal fato é imprescindível 
principalmente em razão da importância destes serviços sociais prestados visando garantir proteção ao trabalhador e sua família, por meio de sistema público de política previdenciária solidária, inclusiva e sustentável, com o objetivo de promover o bem-estar social.

No tocante à relevância organizacional, a realização desta pesquisa contribuiu para aprimorar as ações de TD\&E desta autarquia federal, justificando, inclusive, o recurso financeiro destinado às suas realizações. Espera-se que este trabalho possibilite a racionalização de recursos públicos no âmbito do INSS, bem como a melhoria dos serviços prestados a população brasileira (especialmente a de baixa renda, foco das ações do INSS em geral), assim como pode incentivar o incremento e consolidação de uma cultura de avaliação do impacto dos cursos promovidos no âmbito desta Instituição.

Além de tais relevâncias, este estudo tem justificativas teóricas, como verificar relações entre a percepção de suporte à aprendizagem, impacto de treinamentos gerenciais em amplitude e profundidade, inclusive a importância e contribuição das competências requeridas aos gerentes executivos e gerentes de APS do INSS. Destaca-se que pouco se investigou empiricamente sobre o impacto de capacitações sobre o desenvolvimento de competências profissionais.

O trabalho também auxilia no cumprimento das agendas de pesquisa voltadas para ampliar e diversificar amostras de treinamentos e organizações, possibilitando aumentar a generalização dos resultados de pesquisa nacionais em TD\&E (Coelho Junior \& Abbad, 2010).

\subsection{Estrutura da dissertação}

A dissertação está estruturada em sete Capítulos. O primeiro o da introdução apresentou a Introdução, que contextualizou a temática em análise, os objetivos e pergunta de pesquisa. 
O Capítulo 2 apresenta o referencial teórico que orientou a análise e discussão acerca dos construtos investigados e dos modelos empíricos que foram obtidos. Foram elencados os conceitos e pressupostos apontados pela literatura nacional e internacional como importantes e necessários para a compreensão acerca dos fenômenos de suporte à aprendizagem e de impacto de treinamentos em amplitude e profundidade sobre a percepção de competências.

O Capítulo 3 apresenta o modelo teórico hipotetizado de pesquisa, que foi testado empiricamente com a finalidade de se permitir a visualização da pesquisa proposta, sintetizando os objetivos do estudo e apresentando as variáveis antecedentes e critérios que foram investigadas na presente pesquisa.

O Capítulo 4 descreve o método, procedimentos e técnicas de pesquisa que foram utilizados para a realização do trabalho, especificando o tipo e a descrição geral da pesquisa, bem como apresentando as informações sobre a organização locus do estudo e a descrição dos cursos em estudo. O perfil amostral também é demonstrado neste Capítulo.

O Capítulo 5 traz os resultados obtidos. São apresentados os dados sobre análises fatoriais e regressões estatísticas múltiplas sobre cada variável critério estabelecida.

No Capítulo 6 ocorre a discussão dos resultados. No Capítulo 7 tem-se as considerações finais, onde são reforçadas as contribuições, destacadas as limitações e sugerida uma agenda de pesquisa. 


\section{Referencial Teórico}

De início são apresentados quais os critérios e procedimentos que foram utilizados para a construção do presente referencial teórico. Em seguida são apresentados os conceitos adotados sobre o tema treinamento, desenvolvimento e educação (TD\&E), bem como destaques para educação e treinamento a distância; avaliação de treinamento; suporte à aprendizagem; competências; impacto do treinamento no trabalho, o que compõe um arcabouço sistêmico e adequado para dar suporte à pesquisa proposta.

\subsection{Critérios e procedimentos de construção do referencial teórico}

Foram pesquisadas teses e dissertações, aprovadas no âmbito da Academia brasileira, e artigos científicos, publicados em revistas de reconhecida qualidade e potencial de impacto na divulgação da produção científica. Para tanto, foram utilizadas as bases de dados da Biblioteca Digital Brasileira de Teses e Dissertações (BDTD), do Instituto Brasileiro de Informação em Ciência e Tecnologia (IBICT) e do Sistema WebQualis, gerido pela Coordenação de Aperfeiçoamento de Pessoal de Nível Superior (CAPES).

O levantamento dos principais periódicos publicados no Brasil foi realizado nas áreas de Administração e Psicologia. Também foram utilizados os artigos e pesquisas publicadas nos Anais dos Encontros da Associação Nacional dos Programas de Pós-Graduação em Administração (EnANPAD), nos Anais dos Encontros da Sociedade Brasileira de Psicologia Organizacional e do Trabalho (CBPOT), nos Anais dos Encontros de Gestão de Pessoas e Relações de Trabalho (EnGPR) e nos Resumos de Comunicação Científica da Sociedade Brasileira de Psicologia (SBP).

As buscas iniciais realizadas no BDTD e nos periódicos brasileiros utilizaram as palavras-chave: "treinamento desenvolvimento e educação". Em razão da múltipla utilização 
destes termos em várias áreas do conhecimento científico para as mais diversas finalidades, foi necessário o refinamento da busca. O limite temporal de busca para construção do referencial teórico foram 17 (dezessete) anos, além de se citarem as publicações mais clássicas da área que ultrapassaram este período.

Adotou-se então, para o levantamento nacional, as palavras-chave "impacto do treinamento no trabalho", "suporte à aprendizagem" e "competências organizacionais". Na busca internacional, as palavras-chave foram: support to learning, professional competences, and impact of training at work.

Com estes critérios de levantamento da literatura foram adotados procedimentos para construção do referencial teórico, construído a partir das teses, dissertações e artigos, dando arrimo à coleta e interpretação dos dados sobre o fenômeno objeto de estudo.

Tal arrimo de pesquisa também direcionou a busca por revisões periódicas da literatura sobre o que se tem produzido na área de treinamento, desenvolvimento e educação corporativa, verificando as características temáticas da área, bem como a forma como ela tem evoluído como ciência. Assim selecionou-se o artigo referencial internacional de Aguinis e Kraiger (2009), e o nacional de Meneses, Coelho Junior, Ferreira, Paschoal e Silva Filho (2014).

Ao considerar tal referencial, o Treinamento, Desenvolvimento e Educação (TD\&E) possui no Brasil uma evolução quantitativa de pesquisas empíricas sobre impacto de treinamento no trabalho. Usualmente são estudos de caso, baseados em ações instrucionais de organizações específicas. Assim, é importante a testagem do efeito preditivo de variáveis já pesquisadas em outros contextos organizacionais, de forma a verificar convergências ou divergências com estudos anteriores a fim de se chegar a uma teoria geral sobre os principais preditores de impacto de treinamento no trabalho e posterior desenvolvimento de competências. Contudo, existem variáveis que serão mais promissoras do que outras, por 
razões teóricas ou constatadas por experiências anteriores.

Colquitt, LePine e Noe (2000) sugerem que um passo importante na construção de uma teoria é se perguntar sobre quais construtos devem ser considerados e como o pesquisador deve equilibrar a necessidade de ser abrangente, por meio da inclusão de todas os construtos relevantes, com o desejo de ser parcimonioso, omitindo variáveis que agregam pouco valor incremental.

Há um número crescente de estudos de caso qualitativos que podem gerar contribuições substantivas para uma variedade de diferentes áreas de pesquisa, tais como as capacidades dinâmicas, a estratégia como prática, ou de negócios internacionais. Ocorre que há pouca acumulação de conhecimento a partir desses estudos de caso primários. Esta desatenção pode advir do fato de que a maioria dos pesquisadores projeta seus estudos para recolher novos dados primários, assim ocorre um detrimento da acumulação de resultados que poderiam ser convergentes e cumulativos (Hoon, 2013).

Tendo por parâmetro as considerações de Aguinis e Kraiger (2009), Meneses et al (2014), Colquitt et al (2000) e Hoon (2013), investigou-se a produção acadêmica sobre as palavras-chave suporte à aprendizagem (support to learning), competências organizacionais (organizational competences), impacto do treinamento no trabalho (impact of training at work).

A busca por artigos foi feita em periódicos científicos das bases de dados Scielo, Pepsic, Scopus, Spell, Redalyc, Emerald, Eric e Periódicos Capes. Considerou-se que as bases mencionadas abarcam os periódicos de maior impacto nacional nas áreas visadas pelo presente plano de pesquisa, que foram ampliadas em nível internacional conforme necessidades de pesquisa.

As palavras-chave foram selecionadas nas bases de dados por meio de três tentativas de busca, com delimitação aos últimos dezessete anos (2000 a 2016) para área 
temática de ciências humanas e ciências sociais aplicadas, ordenando a busca por fator de impacto, onde os maiores retornos de artigos ocorreram na Scielo e Periódicos Capes.

Para fins de realização desta dissertação, além das referências utilizadas e citadas no Capítulo 8, foram selecionados pelo critério de afinidade temática e lócus em organizações públicas 42 (quarenta e dois) artigos nacionais e 18 (dezoito) artigos internacionais. Estes artigos foram categorizados de acordo com sua semelhança temática, por meio da identificação de três variáveis, isoladamente ou em interação: suporte à aprendizagem (support to learning), competências profissionais (profesional competences) e impacto do treinamento no trabalho (impact of training at work). Informações sobre os procedimentos adotados em cada um dos 60 artigos encontram-se disponíveis nos Apêndices I e II.

\subsection{Categorização dos artigos selecionados}

Os 60 (sessenta) artigos selecionados foram agrupados nestas três categorias (suporte à aprendizagem, competências profissionais, impacto do treinamento no trabalho) de acordo com seu conteúdo e similaridade temática. Segundo Lima (2010) a categorização é o reconhecimento das similaridades e diferenças e que levam à criação de um conhecimento novo, pelo agrupamento de entidades, de acordo com as similaridades e diferenças observadas.

Na Categoria 1 - Suporte à aprendizagem - os 30 (trinta) artigos agrupados trazem à tona a contextualização e abrangência do suporte à aprendizagem em organizações, que podem gerar maiores ganhos de qualidade, produtividade e conhecimento no ambiente de trabalho. 
Na Categoria 2 - Competências profissionais - os 12 (doze) artigos agrupados nos fazem refletir sobre o processo e importância das competências organizacionais alinhada com os objetivos estratégicos e educacionais.

Na Categoria 3 - Impacto do treinamento no trabalho - os 18 (dezoito) artigos tratam da análise e mensuração deste impacto no ambiente de trabalho que permitem a realização dos serviços públicos com maior qualidade, eficiência, eficácia e efetividade.

Tendo estas categorizações comuns foi possível situar o referencial teórico em torno de conceitos centrais, fundamentais para a realização e conclusão desta pesquisa.

\subsection{Aprendizagem humana no trabalho}

A aprendizagem no mundo do trabalho responde pelo desenvolvimento dos indivíduos e pela sustentabilidade das organizações (Coelho Jr e Borges-Andrade, 2008). Corresponde a um fenômeno complexo e difícil de mensurar, havendo uma diversidade conceitual de fato onde decidiu-se utilizar o conceito de aprendizagem individual de competências adotado por Abbad et al (2013), que afirmam ser um estudo que compreende quatro estágios: aquisição de conhecimento, habilidades e atitudes (CHAs); retenção desses CHAs na memória; generalização, utilização dos CHAs em outras situações similares; e a transferência da aprendizagem, utilização dos CHAs em condições distintas daquelas em que foram adquiridos.

Ao observar a importância da transferência de aprendizagem no trabalho com utilização dos CHAs, em termos de efetividade no desempenho da competência treinada, verifica-se que há fatores a serem explicados, segundo Noe, Clarke e Klein (2014, a saber: (i) se a avaliação da transferência realiza-se algum tempo após o treinamento ou se é logo após o treinamento; (ii) se a avaliação da transferência é fruto de percepção dos próprios treinandos ou dos seus pares; (iii) se o conceito de transferência é operacionalizado como aplicação no 
trabalho daquilo que foi aprendido pelo indivíduo ou em termos de efetividade de desempenho da competência treinada.

Segundo Loiola, Néris e Bastos (2006), o aprendizado é fenômeno localizado em territórios e em organizações. Sustentam tais autores que a aprendizagem de indivíduos nas organizações e sua transformação em aprendizagem organizacional dependem da variedade, do grau de interação da intensidade de uso de fontes internas e externas de conhecimento, assim como da variedade, intensidade de uso e de interação entre os diferentes mecanismos de socialização e de codificação do que foi aprendido pelos indivíduos nas organizações.

Com base nesse cenário, considerando que a aprendizagem humana no trabalho tem uma pluralidade de conceitos e definições, será focado a seguir a questão de treinamento, desenvolvimento e educação corporativa. Serão contemplados termos atuais, que estão incorporados ao cotidiano das organizações.

\subsection{Treinamento, desenvolvimento e educação (TD\&E)}

O treinamento é considerado uma atividade materializada por ritmos diferentes, com visões distintas, implantados de acordo com vários fins e regulamentadas pela dinâmica da concorrência econômica, segundo Alfandi (2016). Como um serviço institucionalizado, o treinamento é estruturado sobre a atividade laboral, sendo um objeto transcendente que tem percorrido as sociedades, contingências, sistemas políticos, e condições econômicas.

O treinamento sempre foi um meio obrigatório para promover a qualificação dos trabalhadores necessários para cada uma dessas lógicas de gestão. Malvezzi (2015) enfatiza que ao longo de sua trajetória histórica, o treinamento tem enfrentado vários tipos de desafios que só têm servido para enriquecê-lo e lhe permitido evoluir, integrado em torno do desempenho no trabalho e na emancipação do indivíduo como ser humano e não mero recurso humano nas organizações. 
Abbad e Borges-Andrade (2014) destacam que treinamento tem como objetivo melhorar o desempenho do empregado no cargo que ocupa. Treinamento é indicado para a resolução de uma lacuna atual identificada no exercício de uma função. Os resultados de uma avaliação de desempenho poderão ser utilizados para a identificação de insumos para treinamento.

O tema de treinamento e desenvolvimento pessoal é considerado, conforme Kraiger e Cavanagh (2015), um processo sistemático gerido pelas organizações, com mudanças constantes no conhecimento, habilidades e atitudes de seus ocupantes. Este processo sistemático está incorporado em um sistema educacional mais amplo, onde Kraiger e Cavanagh (2015) desenvolveram o modelo de design sob o olhar da psicologia organizacional. Tal processo ocorre por meio de: (1) gestão do sistema de ensino (como processo), (2) realização de um treinamento de avaliação das necessidades para definir o conteúdo do treinamento, (3) projeto de treinamento, (4) fornecimento de treinamento, (5) gestão da transferência de treinamento de volta para o trabalho, e (6) avaliação do impacto do treinamento e revisão do sistema de ensino com base nesses dados.

A medição dos resultados e avaliação dos treinamentos, segundo Kraiger e Cavanagh (2015), deve geralmente ser feito para: (1) tomar uma decisão sobre o treinamento (por exemplo, se deve ou não continuar um programa de treinamento já existente); (2) fornecer feedback para instrutores, treinandos, ou designers de formação; e / ou (3) comercializar o programa de treinamento para futuros formandos. Ao identificar a finalidade de avaliação e seleção de medidas compatíveis com o objeto, há uma maior probabilidade de que os dados podem afetar a mudança dentro da organização.

Com a sensibilização para a medição dos resultados de treinamentos gerenciais no INSS, esta pesquisa foi delineada teoricamente em medidas de auto percepção do impacto de treinamento, suporte à aprendizagem e das competências requeridas às funções de gerente executivo e gerente de agência da Previdência Social. Tais treinamentos foram realizados 
totalmente na modalidade à distância no INSS, daí surge a necessidade de se conceituar tal estratégia de capacitação.

\subsection{Educação e treinamento a distância}

A educação a distância (EAD) é uma modalidade voltada usualmente à aprendizagem de adultos. Essa modalidade está vinculada a vários princípios educacionais, entre os quais o de aprendizagem aberta, aprendizagem ao longo de toda vida ou educação permanente. No Brasil, a EAD está sendo adotada na educação, em programas de qualificação e formação profissional, e em educação corporativa (Abbad, 2007).

A educação à distância está crescendo rapidamente, calcada na oferta de cursos por meio de ambientes virtuais de aprendizagem que possibilitam ao estudante e ao professor a interação assíncrona, a qual permite aos participantes interagirem a qualquer momento, independente da sincronia de ações, e a veiculação de objetos de aprendizagem pela internet (Abbad, Carvalho \& Zerbini, 2006).

O apoio de novas tecnologias da comunicação e informação possibilitou a adoção de $e$ learning e blended learning em grande escala pelas universidades corporativas e pelas instituições de ensino. A American Society for Training and Development (ASTD) define $e$ learning como um termo que cobre uma ampla variedade de aplicações e processos, como web-based training (WBT), computer-based training (CBT), salas de aula virtuais, e colaboração digital, objetivando permitir o treinamento a distância por meios eletrônicos. Inclui a disponibilização de conteúdo via internet, fitas de áudio e vídeo, difusão por satélite, TV interativa, CD-ROM e outras mídias (Jóia \& Costa, 2007). Blended learning é uma modalidade que combina a aprendizagem face a face com a aprendizagem mediada pela internet. Os cursos híbridos são aqueles em que uma parte significativa das atividades de ensino-aprendizagem foi transferida para ambientes online. Por isso, adoção do blended 
learning requer o redesenho de cursos e a redução do tempo gasto em sala de aula. Tais cursos não eliminam completamente a sala de aula, apenas reduzem bastante a sua ocorrência (Abbad, Zerbini, \& Souza, 2010).

Escolas de Governo de diversos países como França, Espanha, Canadá e Brasil estão implementando a educação a distância, em todas as suas formas, na oferta de cursos para servidores públicos e para a comunidade. De acordo com Burgess e Russel (2003), muitas organizações após a tragédia do 11/09/2001 nos Estados Unidos (EUA), cancelaram viagens para treinamento e intensificaram a utilização da modalidade de treinamento a distância. Os treinamentos têm sido oferecidos a milhares de pessoas simultaneamente, por meio de diversas tecnologias, entre as quais a transmissão via satélite. Pesquisas analisadas pelos autores Burgess e Russel (2003) mostraram que aproximadamente 24\% das companhias estadunidenses estavam destinando recursos financeiros especialmente para programas de treinamento a distância.

O treinamento a distância (TaD), segundo Zerbini e Abbad (2010), pode ser entendido como um conjunto de ações educacionais, sistematicamente planejadas, desenvolvidas na maior parte do tempo no contexto de flexibilidade espacial e temporal entre professor e aluno, de sincronidade e assincronidade, de interação e interatividade e de abertura dos espaços físicos. Utiliza-se de recursos e meios tecnológicos que facilitam o aperfeiçoamento e a aquisição de conhecimentos, habilidades e atitudes (CHAs) por meio do autogerenciamento da aprendizagem do indivíduo. $\mathrm{O}$ aluno se torna mais autônomo em relação a própria aprendizagem.

Ao considerar a EAD necessária e viável a sua utilização para as capacitações gerenciais na estrutura do INSS, os conceitos relativos à avaliação de treinamento são apresentados a seguir. Avaliar as ações de treinamento, especialmente à distância, torna-se tarefa imprescindível até mesmo para se justificar os elevados gastos financeiros com a oferta deste 
tipo de capacitação.

\subsection{Avaliação de treinamento}

Esta Seção apresenta alguns modelos desenvolvidos para realização da avaliação de treinamento, explica conceitos e detalha o modelo teórico de avaliação de treinamento escolhido para nortear este estudo.

De acordo com os estudos de Bloom, Hastings e Madaus (1983) a avaliação do processo ensino-aprendizagem, apresenta três tipos de funções: diagnóstica (analítica), formativa (controladora) e somativa (classificatória).

A avaliação somativa que é o objeto desta pesquisa, vem a ser segundo Borges-Andrade $(2006,344)$ “o processo de planejar, obter e analisar informações visando fornecer subsídios úteis para decidir sobre a adoção ou rejeição de um programa ou evento isolado de TD\&E, pensado como um sistema instrucional".

Vários são os níveis de critérios de avaliação somativa encontrados na literatura. Em geral, os modelos abordam três níveis de avaliação: (1) Reação; (2) Aprendizagem; e (3) Impacto do Treinamento no Trabalho.

Reação, conforme Abbad, Gama e Borges-Andrade (2000, p.26) é compreendida como “o nível de satisfação dos participantes com a programação, o apoio ao desenvolvimento do curso, a aplicabilidade, a utilidade e os resultados do treinamento".

Aprendizagem, segundo Abbad e Borges-Andrade (2014), é um processo psicológico que faz referência a mudanças que ocorrem no comportamento do indivíduo, não resultantes unicamente da maturação, mas de sua interação com o contexto. A aprendizagem é facilitadora da aquisição de competências, esperando-se que estas sejam capazes de gerar efeito sobre o desempenho dos indivíduos em situação laboral. 
Impacto do Treinamento no Trabalho, segundo Abbad (1999), compreende o conceito de transferência de treinamento, que se refere à aplicação correta, no ambiente de trabalho, de conhecimentos, habilidades ou atitudes adquiridas em situações de treinamento. O impacto precisa ser observável e passível de mensuração, normalmente quando se supre a lacuna de competência previamente identificada na etapa de avaliação de necessidades de capacitação.

Na revisão da literatura internacional, Salas e Cannon-Bowers (2001) destacaram a evolução nas pesquisas de treinamento da década de 90 e consideraram que há ferramentas avaliativas para analisar a aquisição de conhecimentos e habilidades. Hoje investiga-se mais sobre variáveis que influenciam a efetividade do treinamento (como o valor final agregado do mesmo, por exemplo). Salas e Cannon-Bowers (2001) assinalam ainda uma importante mudança: as organizações trocaram suas visões sobre treinamento, passando de um evento separado, isolado, para um componente completamente integrado e estratégico às organizações.

Na literatura científica aponta-se para dois modelos de avaliação de treinamento, conforme a Figura 1: o de Kirkpatrick (1976) sugere quatro níveis de avaliação: a) reações; b) aprendizagem; c) desempenho no cargo; d) resultados. O modelo de Hamblin (1978) subdivide o item de resultados, tendo a seguinte apresentação: a) reações; b) aprendizagem; c) desempenho no cargo; d) mudança organizacional; e) valor final.

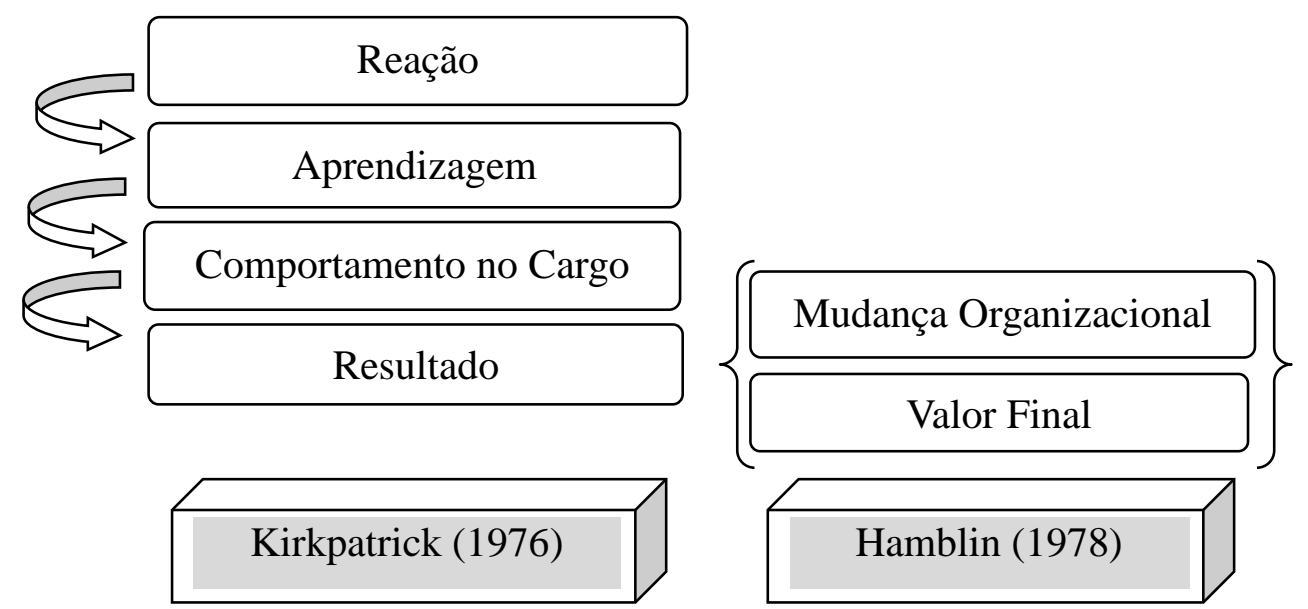

Figura 1. Níveis de avaliação em modelos tradicionais de Kirkpatrick (1976) e Hamblin (1978). Fonte: Vitoria, D.M. (2014). 
"A dificuldade para mensurar os Níveis "d" e "e" do modelo de Hamblin (1978) é uma das principais razões para que a maior parte das avaliações de TD\&E ainda se limita à avaliação de reação e, em alguns casos, de aprendizagem", segundo Borges-Andrade et al (2006, p. 506). Destaca que mesmo a avaliação da performance dos treinados não indica em que medida essa alteração no desempenho individual afeta a organização. Afirma que o problema não está em saber da necessidade de se medir o impacto nos níveis de resultado, mas na dificuldade para fazê-lo.

Estes dois modelos clássicos foram questionados por Alliger e Janak (1989), Tannenbaum e Yukl (1992) e Goldstein (1991). Este último sustenta que as medidas de reação são pouco úteis para explicar fatores de aprendizagem e só fazem sentido se estiverem alinhadas com as necessidades de treinamento. Um dos aspectos que ainda não foram devidamente testados, segundo tais autores, é a percepção da utilidade do treinamento, que está muito correlacionada ao impacto do treinamento e menos intensamente com o processo de aprendizagem, devido ao fato da forte influência pelos conhecimentos dos participantes acerca dos ambientes de trabalho onde se inserem.

Os modelos mais contemporâneos mesclam resultados de treinamentos com variáveis dos ambientes. Nesta linha, pode-se citar o CIRO (Warr, Bird e Rackham, 1970), o CIPP 48 (Stufflebeam, 1978), o MAIS (Borges-Andrade, 1982) e o IMPACT (Abbad, 1999; Abbad, 2014).

O modelo CIRO é formado por quatro componentes: contexto, insumo, reações e resultados. O modelo CIPP 48 é composto também por quatro componentes, sendo os dois primeiros iguais ao CIRO e os dois últimos foram modificados para processo e produto.

O primeiro modelo brasileiro sistematizado de avaliação de treinamento foi criado por Borges-Andrade (1982) e revisado recentemente pelo mesmo Autor. O Modelo de Avaliação Integrado e Somativo (MAIS) de Borges-Andrade (2006) acrescenta aos modelos tradicionais, 
variáveis do indivíduo, do curso e do ambiente na avaliação de resultados de treinamento. $\mathrm{O}$ modelo é formado por cinco componentes: insumo, procedimentos, processo, resultados e ambiente, que se subdivide em: necessidades, suporte, disseminação e efeitos em longo prazo.

O Modelo Integrado de Avaliação do Impacto do Treinamento (IMPACT) foi elaborado por Abbad (1999) e revisto em 2014, a partir do MAIS, e é constituído por dez componentes: (1) ambiente externo; (2) suporte; (3) necessidades; (4) características da clientela; (5) características do treinamento; (6) reações; (7) aprendizagem, (8) impacto do treinamento no trabalho; (9) mudança na organização; (10) valor final. Os sete primeiros componentes são variáveis preditoras do impacto do treinamento no trabalho. A Figura 2 traz uma representação esquemática dos componentes do modelo IMPACT. Este modelo foi o escolhido para nortear esta pesquisa na utilização da variável critério impacto de treinamento (em amplitude), abarcando também variáveis de contexto. Suporte à aprendizagem é a variável de contexto que foi testado nesta pesquisa, como parte integrante do processo de se transferir o conteúdo aprendido em treinamento para as rotinas laborais.

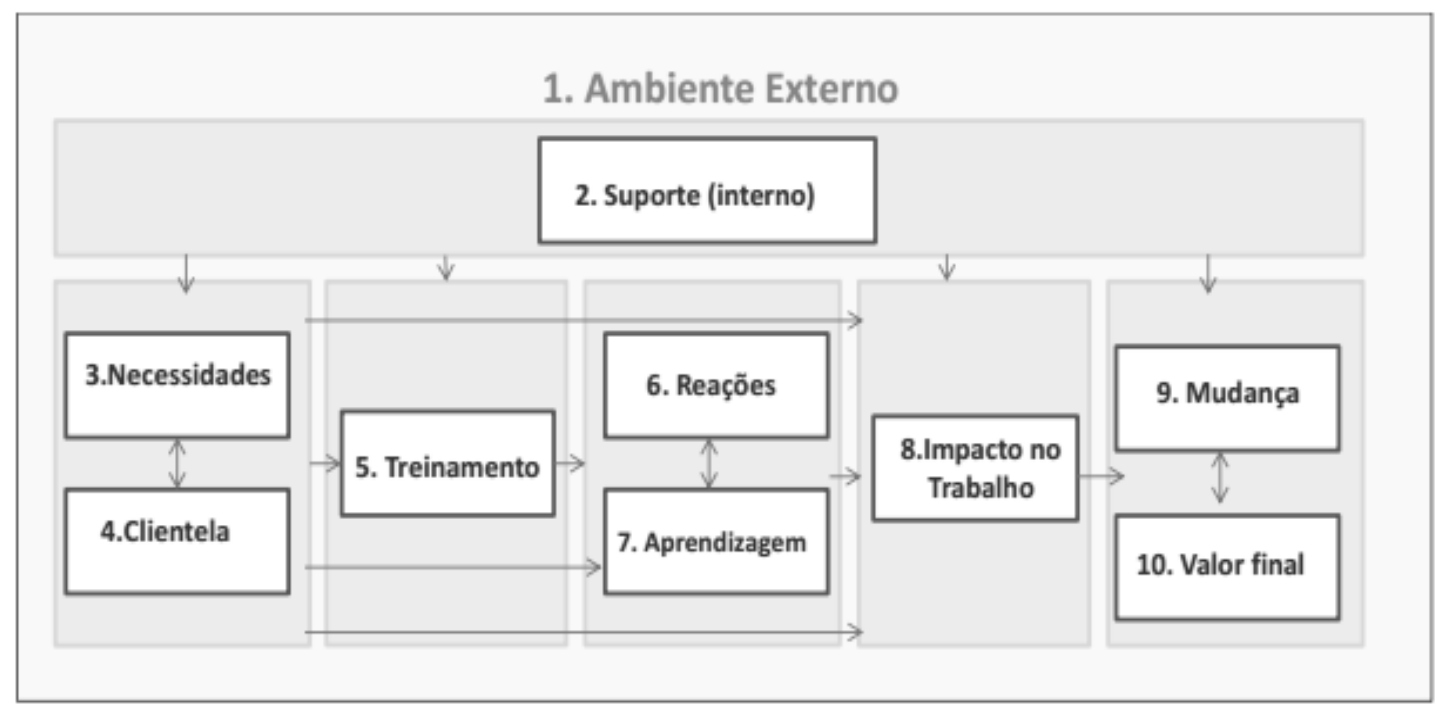

Figura 2. Representação esquemática dos componentes do Modelo IMPACT. Fonte: Abbad, G. S. (2014).

Abbad (1999) concluiu que os efeitos do treinamento no desempenho e nas atitudes dos participantes dependem fortemente de um ambiente organizacional propício ao uso das novas 
habilidades. Para esta autora, as implicações práticas desses resultados são muitas. Não basta garantir o comprometimento das chefias com o levantamento de necessidades, o apoio à participação no treinamento e o encorajamento do participante (subordinado) a aplicar no trabalho as novas habilidades. É preciso que a organização (chefes, pares, colegas de outras unidades e áreas profissionais) propiciem o suporte à aprendizagem e à transferência a partir de um ambiente organizacional facilitador da aprendizagem contínua, no qual os membros tenham múltiplas oportunidades e muita autonomia para buscarem o próprio crescimento profissional. A construção desse ambiente compreende uma mudança cultural nas relações entre os integrantes da organização, os quais necessitarão uns dos outros para otimizar o crescimento profissional.

As pesquisas brasileiras, segundo Abbad, Pilati e Pantoja (2003), definem que o impacto do treinamento no trabalho é o efeito de longo prazo exercido pelo treinamento nos níveis de desempenho, motivação e atitudes do participante. São utilizados dois tipos de medidas: a) avaliação de impacto em amplitude, que mede os efeitos gerais do evento instrucional sobre o desempenho das tarefas relacionadas diretamente ou não ao conteúdo aprendido no curso; b) avaliação de impacto em profundidade, que mensura o efeito do treinamento em tarefas estritamente relacionadas aos conteúdos específicos ensinados nos cursos.

A avaliação de impacto em amplitude contém itens relacionados a frequência de utilização do aprendizado, melhoria da qualidade do desempenho de tarefas, diminuição de erros na execução da tarefa e itens que avaliam o impacto do treinamento na motivação e auto-eficácia do profissional treinado. A avaliação de impacto em profundidade tem itens elaborados a partir dos objetivos instrucionais (transformados em objetivos esperados de desempenho) específicos de cada treinamento.

Zerbini e Abbad (2010) apresentam mais um modelo de avaliação de treinamento a distância visando identificar variáveis preditoras da Transferência de Treinamento, entre as 
variáveis de características da clientela (estratégias de aprendizagem), de reações ao curso (procedimentos instrucionais e desempenho do tutor) e de contexto (ambiente de estudo do aluno e procedimentos de interação do curso), conforme Figura 3.

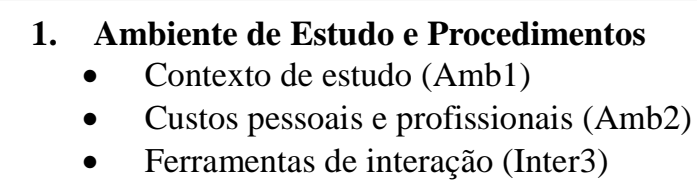

\section{Estratégias de Aprendizagem}

- Controle da emoção (Est1)

- Busca de ajuda interpessoal (Est2)

- Repetição e organização (Est3)

- Controle da motivação (Est4)

- Elaboração (Est5)

- Busca de ajuda ao material didático (Est6)

- Monitoramento da compreensão (Est7)

3. Reações ao Curso

- Procedimentos tradicionais (Proc1)

- $\quad$ Recursos da web (Proc2)

- Desempenho do tutor (Tutor)

Figura 3. Modelo geral de avaliação da transferência de treinamento via web no trabalho, proposto por Zerbini e Abbad (2010).

A discussão da qualidade dos instrumentos de medidas existentes é feita por Zerbini e Abbad (2010), bem como o relacionamento entre variáveis de interesse em treinamento, desenvolvimento e educação de pessoas - TD\&E, por meio de pesquisas realizadas na literatura nacional de Psicologia Organizacional e de TD\&E no período de 1980 a 2008. Destacam que a transferência de aprendizagem é o indicador mais utilizado em pesquisas de TD\&E para verificar a aplicação de conhecimentos, habilidades e atitudes - CHAs no trabalho. No artigo classificam os indicadores de impacto do treinamento no trabalho em: comportamentos e resultados; complexidade da medida (profundidade ou largura); e nível a que se refere (indivíduo, grupos e organização).

Os resultados de Zerbini e Abbad (2010) destacam ser: a) Importante investigar as 
características da clientela e dos treinamentos, as reações e aprendizagem dos treinandos e as condições necessárias à expressão das competências no ambiente de trabalho do egresso, seja ele corporativo ou aberto. b) Fundamental garantir a efetividade de ações educacionais, e é por esse motivo que os profissionais envolvidos nesse processo precisam estar bem capacitados para promover avaliações que forneçam respostas rápidas e fidedignas às organizações. c) Esperar que esta análise crítica da literatura contribua para o subsistema de avaliação de ações de TD\&E no contexto das organizações e do trabalho, culminando com a construção, validação e aplicação de novos modelos explicativos da transferência de treinamento e do impacto do treinamento no trabalho.

É oportuno destacar que para avaliar o treinamento é importante observar as diferenças entre conceito ou constructo, medida e instrumento, conforme Borges-Andrade, Abbad, Mourão e Colaboradores (2006). Conceito ou constructo de interesse é a aprendizagem propriamente dita e seus componentes de retenção e generalização. As medidas são extraídas das definições operacionais de cada constructo e podem ser, por exemplo, a temperatura de uma pessoa com valor em graus Celsius. Os instrumentos são as ferramentas do avaliador: itens de verificação, questionários, inventários, testes, provas, roteiros; sendo um exemplo o termômetro utilizado para medir a respectiva temperatura corpórea.

Além do instrumento de impacto do treinamento, faz-se necessário conceituar as demais variáveis, objeto desta pesquisa, sendo o suporte à aprendizagem um dos fatores críticos para o efetivo aproveitamento do treinamento no ambiente de trabalho. A premissa teórica básica do conceito de suporte à aprendizagem é que a aprendizagem é um fenômeno social vívido e dinâmico, e que a postura de chefias e colegas é fundamental à sua aplicação nas rotinas laborais. Este conceito encontra-se discutido a seguir. 


\subsection{Suporte à aprendizagem}

A aprendizagem "é um processo psicológico entendido como as mudanças que ocorrem no comportamento do indivíduo em função da relação deste com o meio e não apenas mudanças resultantes unicamente da maturação", segundo Abbad e Borges-Andrade (2014, p. 244). Esses autores ressaltam que o conceito de aprendizagem em ambiente de trabalho envolve aquisição, retenção e generalização; que por sua vez estão diretamente relacionados à transferência de treinamento e impacto do treinamento no ambiente de trabalho.

Para efetivar a aprendizagem é fundamental a existência do suporte, e nesta pesquisa utilizou-se o conceito de suporte à aprendizagem formulado por Coelho Junior (2004, p. 56), assim formulado:

A avaliação de suporte psicossocial (colegas, pares e chefes) à aprendizagem e à aplicação de novas habilidades no ambiente de trabalho, adquiridas não somente por meio de treinamentos (aprendizagem induzida) específicos, previamente planejados, mas também por aprendizagens ocorridas em situações organizacionais não estruturadas ou não-intencionais (aprendizagem natural). Suporte à aprendizagem envolve a percepção do empregado sobre como e em que medida o ambiente organizacional favorece ou dificulta a aprendizagem e a aplicação de novas habilidades no trabalho. O nível de análise refere-se, portanto, à avaliação do apoio psicossocial de pares e chefias no desempenho do sujeito.

Para Abbad et al. (2012, p. 247), o suporte à aprendizagem é "avaliado em termos do estímulo do ambiente organizacional a novas aprendizagens espontâneas no trabalho por meio do contato com pessoas mais experientes, autodidatismo ou comportamento de imitação" e trata de dimensões de apoio como a criação de expectativas positivas sobre os benefícios da aprendizagem e sua aplicação, o fornecimento de feedback e a disseminação de informações relativas ao desempenho competente.

Os conceitos relacionados à variável "Suporte" são sintetizados por Balarin et al. (2014), conforme Tabela 1. 


\section{Tabela 1}

Conceitos relacionados a variável suporte

\begin{tabular}{|c|c|c|}
\hline Conceito & Definição & $\begin{array}{l}\text { Autor(es) citados } \\
\text { em Balarin, } \\
\text { Zerbini, e Martins } \\
\text { (2014). }\end{array}$ \\
\hline $\begin{array}{l}\text { Suporte } \\
\text { organizacional }\end{array}$ & $\begin{array}{l}\text { Percepção dos indivíduos a respeito do quanto a organização se } \\
\text { preocupa com o bem-estar e valoriza as contribuições dos } \\
\text { indivíduos que nela trabalham. }\end{array}$ & Abbad et al (1999) \\
\hline $\begin{array}{l}\text { Suporte gerencial } \\
\text { ao treinamento }\end{array}$ & $\begin{array}{l}\text { Indicadores de apoio gerencial à transferência de treinamento, } \\
\text { presentes no ambiente organizacional antes, durante e após o } \\
\text { treinamento. }\end{array}$ & Broad (1982) \\
\hline $\begin{array}{l}\text { Clima para } \\
\text { transferência }\end{array}$ & $\begin{array}{l}\text { Percepção do indivíduo sobre o apoio que recebe do ambiente } \\
\text { organizacional para transferir novas aprendizagens para o trabalho. } \\
\text { Este conceito inclui fatores situacionais antecedentes e } \\
\text { conseqüências associadas à transferência de treinamento. }\end{array}$ & $\begin{array}{l}\text { Rouller e Goldstein } \\
\text { (1993) }\end{array}$ \\
\hline $\begin{array}{l}\text { Suporte à } \\
\text { transferência }\end{array}$ & $\begin{array}{l}\text { Percepção do indivíduo sobre o apoio que recebe de colegas e } \\
\text { chefias para aplicar, no trabalho, novas habilidades adquiridas em } \\
\text { treinamentos. Além do suporte psicossocial, esse conceito enfoca o } \\
\text { apoio material à transferência de treinamento. }\end{array}$ & $\begin{array}{l}\text { Abbad e Sallorenzo } \\
(2001)\end{array}$ \\
\hline $\begin{array}{l}\text { Cultura de } \\
\text { aprendizagem } \\
\text { contínua }\end{array}$ & $\begin{array}{l}\text { Padrão compartilhado de significados e expectativas acerca de } \\
\text { quanto a organização maximiza os processos de inovação e a } \\
\text { competitividade, promovendo a aquisição constante de habilidades, } \\
\text { conhecimentos e comportamentos oriundos dos mais distintos } \\
\text { meios, a fim de modificar o ambiente de trabalho em algum } \\
\text { aspecto. }\end{array}$ & $\begin{array}{l}\text { Tracey, } \\
\text { Tannenbaum e } \\
\text { Kavanagh (1995) }\end{array}$ \\
\hline $\begin{array}{l}\text { Suporte à } \\
\text { aprendizagem }\end{array}$ & $\begin{array}{l}\text { É a avaliação de suporte psicossocial (colegas, pares e chefes) à } \\
\text { aprendizagem e à aplicação de novas habilidades no ambiente de } \\
\text { trabalho, adquiridas não somente por meio de treinamentos } \\
\text { (aprendizagem induzida) específicos, previamente planejados, mas } \\
\text { também por aprendizagens ocorridas em situações organizacionais } \\
\text { não estruturadas ou não-intencionais (aprendizagem natural). }\end{array}$ & $\begin{array}{l}\text { Coelho } \\
(2004)\end{array}$ \\
\hline $\begin{array}{l}\text { Suporte à } \\
\text { aprendizagem } \\
\text { contínua }\end{array}$ & $\begin{array}{l}\text { Percepção dos indivíduos sobre a presença de condições favoráveis } \\
\text { à aprendizagem no grupo de trabalho. }\end{array}$ & $\begin{array}{l}\text { Freitas } \quad(2005) ; \\
\text { Pantoja (2004) }\end{array}$ \\
\hline
\end{tabular}

Nota. Fonte: Balarin, Zerbini e Martins (2014). 
Nesta Dissertação será utilizado o conceito de Coelho Junior (2004), conforme será demonstrado no Capítulo 3 (apresentação do modelo teórico hipotetizado).

\subsection{Competências}

Ao tratar sobre o tema, é oportuno iniciar o embasamento teórico a partir das contribuições de McClelland (1973) e Boyatzis (1982), pois eles são considerados os precursores no debate acerca de competências. Eles partem da escola norte-americana e propõem as competências como inputs, ou seja, as qualidades requeridas ao exercício de um cargo, relacionadas unicamente ao conjunto de Conhecimentos, Habilidades e Atitudes CHAs.

Para Mertens (1996), o conceito de competência compreende conhecimento e habilidades constatadas. Existe diferença entre habilidades e conhecimentos mostrados no posto de trabalho e os resultados exigidos de uma pessoa que ocupa esse posto. A qualificação, por sua vez, se projeta no desempenho do posto, em saber cumprir as normas de conhecimento e habilidade, enquanto que a competência se projeta no resultado que deve cumprir a pessoa ligada ao posto, tais como conhecimentos e habilidades que assegurem um produto desejado. Enquanto a qualificação se circunscreve ao posto ocupacional, a competência se centra na pessoa, que pode chegar a ocupar um ou mais postos de trabalho, o que subjaz no conceito de multifunção.

Sandberg (1996) critica o conceito tradicional de competências: um conjunto de conhecimentos, habilidades e atitudes; ou seja, a aquisição de atributos (abordagem racionalista). Conforme argumenta tal autor: "Por meio da análise de competências, eu estou cada vez mais convencido que os aspectos essenciais da competência humana não podem ser reduzidos a uma lista externa de atributos relacionados ao trabalho" (Sandberg, 1996, p. 20). Para ele, o desenvolvimento de competências deve ser compreendido com base nas práticas 
organizacionais, focalizando sua análise no enriquecimento de experiências e vivências (abordagem interpretativa). "Mais especificamente, nós destacamos que o desenvolvimento de competências envolve a mudança na estrutura e no significado das práticas de trabalho" (Sandberg, 1996, p. 411). A questão, então, refere-se não apenas ao que constitui as competências, mas também em como as competências são desenvolvidas.

Sandberg (2000) propõe a compreensão do significado do trabalho como a primeira fase para a definição de competências. Para o autor, o desenvolvimento desse conjunto de conhecimentos e habilidades envolve a mudança na compreensão do trabalho. Para a definição da visão de competência parte-se da compreensão ou da forma como os gestores enxergam as competências. Com isso, deve-se tratar a questão como “visão compartilhada de competências".

Nesse contexto, as competências se desenvolvem por meio da interação entre as pessoas no ambiente de trabalho, privilegiando a questão da complementaridade; ou seja, não se limitam ao desenvolvimento de um perfil idealizado de gestor (“super-homem") nem a listas infindáveis de atributos irreais ou fantasiosos, mas se traduzem em práticas gerenciais complementares ou em ações gerenciais articuladas (consolidação de competências coletivas). O ciclo de competência é apresentado por Sandberg (2000) como uma maneira de unificar a compreensão e a aplicação das competências, quebrando a visão reducionista e racionalista do modelo tradicional.

Le Boterf (1997), por sua vez, afirma que a competência vale-se de três eixos principais, ao considerar a formação pessoal (biografia, socialização), a formação educacional e a experiência profissional. Ressalta, ainda, os aspectos referentes à responsabilidade e legitimidade na construção da noção de competência. A responsabilidade implica o domínio da expertise da competência e o engajamento responsável na atividade, enquanto a legitimidade se associa ao reconhecimento por parte dos superiores, pares, subordinados, em 
relação à capacidade de agir e de responder às situações.

As propostas de Sandberg (1996) e de Le Boterf (1997) ressaltam aspectos importantes que contribuem para a reflexão do tema. Os aspectos voltados à interação entre as pessoas, ao significado da competência e à experiência vêm da abordagem de Sandberg (1996). A ênfase na articulação, na legitimação e na formação vem da abordagem de Le Boterf (1997). As abordagens se complementam. Assim: (i) a interação entre as pessoas propicia uma melhor articulação das diretrizes e dos níveis organizacionais; (ii) a identificação do significado da competência permite a sua legitimação; e (iii) a experiência relaciona-se diretamente à formação, no sentido de capacitação, que implica visão pessoal, educacional e profissional. Portanto, a competência pode ser explicada com base em sua concepção, suas redes de trabalho e seus recursos.

O estudo sobre competências tem contribuído para a proposição de estratégias organizacionais bem-sucedidas, tendo como pano de fundo o desenvolvimento de lideranças capazes de mobilizar saberes e transpor conhecimentos as suas equipes. Estas lideranças devem visar alcançar o desempenho organizacional eficaz e efetivo, destacando-se aspectos como incentivo à autonomia e responsabilidade e fomentando valores como a iniciativa, urbanidade e a polivalência (Deluiz, 2004).

Dutra (2008) aponta que, embora teóricos e pessoas compreendam a competência como conjunto de CHAs, esse enfoque é pouco instrumental, pois o fato de algumas pessoas os possuírem não é garantia de que haverá agregação de valor à organização. Esta agregação de valor está relacionada a algo que a pessoa entrega de maneira efetiva à organização e que lá permanece independentemente de essa pessoa estar ou não lá. Então, a agregação de valor não é somente atingir metas, mas melhorar processos e introduzir inovações. A internalização deste novo modus operandi na realização das atividades e tarefas é função imprescindível da gestão por competências. 
O conceito de competência assume poder de decisão, influência e participação nas questões estratégicas da empresa, quando se refere à capacidade da pessoa de assumir iniciativas e ir além das atividades prescritas. A incorporação dessa noção mais dinâmica, flexível e estratégica das competências, ao tempo em que esvazia a noção de competência enquanto recurso (Sveiby, 1998) e qualificação (Ropé \& Tanguy, 1997), reforça as abordagens de "evento" (Zarifian, 2001), “competência em ação" (Le Boterf, 1997), e “entrega" (Dutra, 2008). Esses três conceitos, em oposição ao instrumentalismo mecanicista contido nas visões tradicionais de competência, emergem como uma nova moldura que sustenta a abordagem das competências individuais, permitindo maior flexibilidade na gestão das competências no âmbito das organizações.

Devido à importância de tal conceito de competências, observa-se que na literatura há muitas definições a respeito. Visando identificar diferenças e convergências no uso técnico de tal conceito, Campos (2015) realizou uma análise sistemática na literatura científica especializada. As principais definições de competências encontram-se na Tabela 2 e no Apêndice IV desta Dissertação.

Tabela 2

Conceitos relacionados a competência

Autor Definição de Competência(s)

Abbad e Borges-

Andrade (2004)

Boyatzis (1982)

Brandão e

BorgesAndrade (2007)

Ruas et al. (2005)

Sveiby (1998, como citado em Okimoto, 2004)
Competência é uma combinação de conhecimentos, habilidades e atitudes (CHAs) que um indivíduo mobiliza para alcançar um determinado propósito no trabalho.

Competência é uma característica subjacente de um indivíduo (que pode ser um motivo, traço, habilidade, aspecto de sua autoimagem, papel social, ou conjunto de conhecimentos) causalmente relacionados a efetividade e/ou desempenho superior no trabalho.

Competência representa um conjunto de conhecimentos, habilidades e atitudes necessários para exercer certa atividade e, também o desempenho expresso pelo indivíduo em termos de comportamentos adotados no trabalho e realizações decorrentes.

Competência é a capacidade de mobilizar, integrar e colocar em ação conhecimentos, habilidades e formas de atuar do indivíduo com a finalidade de atingir e/ou superar desempenhos esperados pela organização.

A competência de um indivíduo é formada por cinco elementos mutuamente dependentes: o conhecimento explícito, habilidades, experiências, julgamentos de valor e rede social. 
Autor Definição de Competência(s)

Vasconcelos, Cavalcante e Monte (2011)

Zarifian (2008)
Uma competência pode ser entendida como o conjunto de conhecimentos, habilidades e atitudes que contribuem para que haja resposta adequada às demandas do trabalho que um indivíduo exerce.

A competência é o "tomar iniciativa" e o "assumir responsabilidade" do indivíduo diante de situações profissionais com as quais se depara. A competência é um entendimento prático de situações que se apoia em conhecimentos adquiridos e os transforma na medida em que aumenta a diversidade das situações.

Nota. Fonte: Campos (2015).

Nessa análise, Campos (2015) identificou três dimensões junto ao conceito de competências em torno de características de atributos subjacentes na dimensão de conhecimentos, habilidades e atitudes, são eles: desempenho observável na dimensão de comportamentos e resultados; qualidade do desempenho na dimensão de excelência e reconhecimento.

Campos (2015, p. 34) destaca que:

O conceito de competência expressa atributos individuais dependentes do contexto, que variam de acordo com a situação (imprevistos, mudanças) e com o trabalho a ser realizado. Por esse motivo, avaliar apenas fatos ou ocorrências isoladas de desempenho e resultados do trabalho humano são estratégias metodológicas insuficientes e pouco adequadas para a mensuração de competências humanas. Além disso, o conceito para competência inclui padrões e valores de referência adotados por uma determinada unidade social (organização, equipe, outras pessoas) para julgar se um dado desempenho é ou não competente e se o resultado desse desempenho é ou não indicador de sucesso.

Para esta pesquisa, utilizou-se a definição apresentada por Carbone (2009), que se refere a competência como combinações sinérgicas de conhecimentos, habilidades e atitudes, expressas pelo desempenho profissional dentro de determinado contexto organizacional, que agregam valor a pessoas e organizações.

Ao observar a competência gerencial, Bitencourt (2004) enfatiza que a mesma está, de alguma forma, relacionada ao negócio da empresa. Parte-se da análise das competências essenciais para se chegar às competências gerenciais.

A dificuldade operacional e científica está exatamente na articulação do nível estratégico e operacional, e não na definição dos atributos necessários para cada um desses níveis. Segundo esta autora, a competência gerencial é tratada, ainda, com base em um perfil 
ideal previamente estabelecido. Existe uma tendência a construir atributos de competência ambiciosos, seja por sua abrangência, abstração e/ou diversidade (complexidade). A ênfase nessa construção é individual, o que dificulta a construção de competências coletivas.

Para Brandão, Borges-Andrade, Freitas e Vieira (2010) as competências gerenciais constituem uma categoria que tem despertado crescente interesse por parte de teóricos, organizações e pesquisadores, talvez por causa da suposição de que elas exercem considerável influência sobre o desempenho de equipes de trabalho e, por conseguinte, sobre os resultados organizacionais. Apesar dos esforços que têm sido realizados, sobretudo no campo teórico, para explicar a natureza da competência gerencial, muitas questões permanecem sem resposta, tendo carência de pesquisas destinadas a investigar antecedentes e consequentes da expressão de competências no trabalho, onde nesta pesquisa tal variável está contemplada.

À luz das teorias apresentadas sobre impacto do treinamento, suporte à aprendizagem e competências, no próximo Capítulo apresenta-se o modelo teórico aqui hipotetizado, bem como as hipóteses que serão testadas a partir da aplicação dos procedimentos metodológicos apresentados no Capítulo 4. 


\section{Modelo Teórico Hipotetizado de Pesquisa}

Nesta Dissertação o modelo teórico de pesquisa proposto teve como variáveis critério impactos de treinamento no trabalho tanto em profundidade quanto em amplitude, inclusive verificando seus efeitos sobre competências requeridas aos gestores do INSS. Espera-se que quanto maior for a influência percebida (impacto do treinamento em profundidade e em amplitude) haverá maior importância e contribuição dos dois cursos avaliados frente as competências requeridas a tais gestores.

Com a percepção favorável das influências do treinamento no ambiente de trabalho, mais competências podem ser agregadas e relacionadas às capacitações e ao dia a dia profissional. Já se ressalta aqui que a chamada medida de amplitude sobre competências foi construída por profissionais da própria Organização em estudo a partir da escala de competências gerenciais proposta por Brandão, Borges-Andrade, Freitas e Vieira (2010). Nesta pesquisa, diferentemente de Brandão et al (2010), foram utilizados somente medidas de autoavaliação.

O modelo teórico hipotetizado aqui desenvolvido (que tem como variáveis critério impactos de treinamento em profundidade e em amplitude sobre a aquisição e expressão de competências gerenciais no trabalho) foi concebido a partir de variáveis contidas no modelo IMPACT (Abbad, 1999).

Foram testadas as seguintes variáveis preditoras: a) perfil da clientela, que contém as informações biográficas e funcionais relativas aos participantes dos dois treinamentos em análise; b) suporte à aprendizagem (apoio psicossocial de colegas e chefia à aplicação de novas aprendizagens no desempenho laboral).

Destaca-se que o suporte à aprendizagem, segundo Abbad et al (2012), vem sendo considerado como principal preditor do impacto do treinamento, pois parte do pressuposto de 
que a existência de um contexto organizacional favorável ao uso de novas habilidades aprendidas em treinamento gera condições para o impacto.

Portanto, foi verificada, neste modelo, a relação das variáveis preditoras pessoais, profissionais e de suporte à aprendizagem junto as variáveis critério de impacto de treinamento em profundidade e em amplitude sobre aquisição e expressão de competências gerenciais junto a gerentes executivos e gerentes de APS, no âmbito do INSS.

Para operacionalizar a investigação empírica de tais variáveis teóricas, foi elaborado um único questionário dirigido a gestores do INSS (ver Apêndice III, e informações sobre o Instrumento de pesquisa no Capítulo 4), considerando-se todos os itens, de cada uma das medidas em estudo, devidamente agrupados. Este questionário contemplou, ainda, informações demográficas e funcionais.

O modelo teórico hipotetizado foi concebido com base na análise da literatura descrita no Capítulo 2. Considerou que em um ambiente de suporte de chefia e colegas, com o impacto em profundidade e em amplitude de capacitações gerenciais, haveria a aquisição e expressão (etapas concebidas, aqui, como equivalentes de domínio de competências) de habilidades e conhecimentos adquiridos a partir destes treinamentos na rotina laboral.

Impacto não foi mensurado apenas da forma como a literatura tradicional de TD\&E o faz, mas considerou ainda o resultado de cada um dos impactos relatados sobre o desenvolvimento das competências gerenciais. Foi considerado a importância atribuída a cada capacitação à melhoria do desempenho laboral pós-capacitação bem como o quanto, efetivamente, sob a ótica dos indivíduos, cada um dos dois cursos avaliados contribuiu para a melhoria deste desempenho profissional.

De forma sintética na Tabela 3 são apresentados exemplos de definições constitutivas, encontradas na literatura cientifica sobre TD\&E, bem como cada definição operacional das variáveis contempladas no modelo teórico hipotetizado de pesquisa. 
Tabela 3

Definições constitutivas e operacionais das variáveis nos modelos teóricos hipotetizados Variável Definição constitutiva Definição operacional

Características Informações demográficas, funcionais, Perfil pessoal e funcional dos gestores pessoais e motivacionais e atitudinais relativas aos selecionados, contendo dados de profissionais participantes dos treinamentos. (Abbad, 1999). experiência profissional, idade, gênero e da clientela lotação.

Suporte à Percepção dos indivíduos sobre o incentivo de aprendizagem pares e chefias à aprendizagem e à transferência de novas habilidades no trabalho. (Coelho Junior \& et al. 2005).
Autopercepção quanto ao estímulo do ambiente organizacional proporcionado por colegas e chefia para participação em treinamentos e uso de novos conhecimentos.
Impacto de treinamento em amplitude
Mede os efeitos gerais do evento instrucional sobre o desempenho das tarefas relacionadas diretamente ou não ao conteúdo aprendido no curso. (Abbad \& et al. 2003).
Impacto de treinamento em profundidade

Impacto de treinamento em amplitude sobre competências
Autopercepção de melhorias gerais no desempenho e atitudes do indivíduo após participação em treinamento. Autopercepção quanto ao domínio dos conteúdos relacionados especificamente a dois cursos obrigatórios aos gestores participantes. al. 2003).

Capacidade do profissional assumir iniciativas,
realizar além das atividades preestabelecidas, ter cada curso para a aquisição de
habilidade para compreender e dominar $\begin{aligned} & \text { competências orientadas ao desempenho } \\ & \text { situações novas no trabalho, com profissional e a contribuição real de cada } \\ & \text { responsabilidade e obter o reconhecimento um dos dois cursos para o } \\ & \text { disto. (Fleury \& Fleury, 2000). } \\ & \text { desenvolvimento destas competências } \\ & \text { gerenciais requeridas. }\end{aligned}$

Nota: Síntese elaborada pelo autor com adaptações dos autores citados em cada variável.

Para uma melhor visualização da pesquisa proposta, foi elaborado um modelo teórico hipotetizado, apresentado na Figura 4. 


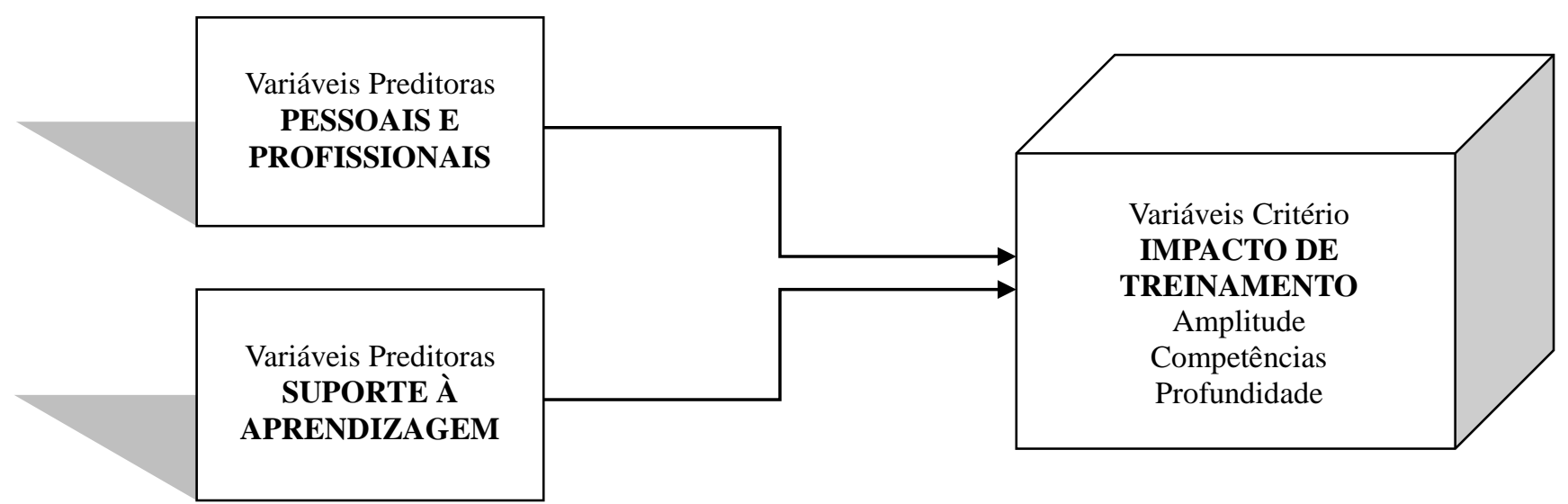

Figura 4. Modelo téorico hipotetizado de impacto de treinamento, de suporte a aprendizagem e de características pessoais e profissionais.

Será detalhado, no Capítulo 4, os procedimentos metodológicos de pesquisa utilizados para alcançar os objetivos estabelecidos. 


\section{$4 \quad$ Metodologia}

Neste Capítulo apresenta-se o tipo e descrição geral da pesquisa, bem como as informações sobre a organização locus da pesquisa, os eventos corporativos de educação a distância que foram objeto de estudo, o questionário de pesquisa e os instrumentos utilizados para coleta e análise dos dados. O perfil amostral também será apresentado. Tal delineamento segue diretrizes de Churchill (1999), Fachin (2006), Gil (2009), Creswell (2010).

\subsection{Caracterização e tipologia da pesquisa}

Esta pesquisa, teórico/empírica, teve natureza aplicada e delineamento de pesquisa descritiva correlacional. O escopo foi de caso junto ao INSS, por meio da avaliação de duas capacitações gerenciais quanto ao impacto e ao suporte à aprendizagem, verificando se promoveram, de fato, sob a ótica dos investigados, as competências estabelecidas aos ocupantes de funções comissionadas.

A abordagem enquadrou-se como quantitativa, tendo recorte transversal, com a coleta de dados realizada em um momento (de julho a agosto de 2016), não havendo a intenção de traçar a evolução ou identificar possíveis mudanças ocorridas ao longo do tempo. Foi feito por meio do uso de questionário eletrônico tipo survey (Apêndice III) em ambiente de campo, aplicado aos gerentes executivos e gerentes de APS distribuídos nas unidades do INSS no território brasileiro.

A técnica de survey pode ser descrita como a obtenção de dados ou informações sobre características, ações ou opiniões de determinado grupo de pessoas, indicado como representante de uma população-alvo, por meio de um instrumento de pesquisa, normalmente um questionário. Nesta pesquisa foram utilizados dados primários, coletados pelo próprio pesquisador. Como para participarem da pesquisa dever-se-ia atender ao critério de já ter 
participado de pelo menos uma das duas capacitações em estudo (pois só assim seria possível mensurar impacto), a amostra foi classificada como não-probabilística intencional, segundo Creswell (2010). Os gerentes que poderiam vir a se tornar participantes desta pesquisa realizaram capacitação entre janeiro/2013 a março/2016.

Na Figura 5 é apresentada uma síntese da metodologia utilizada nesta pesquisa.

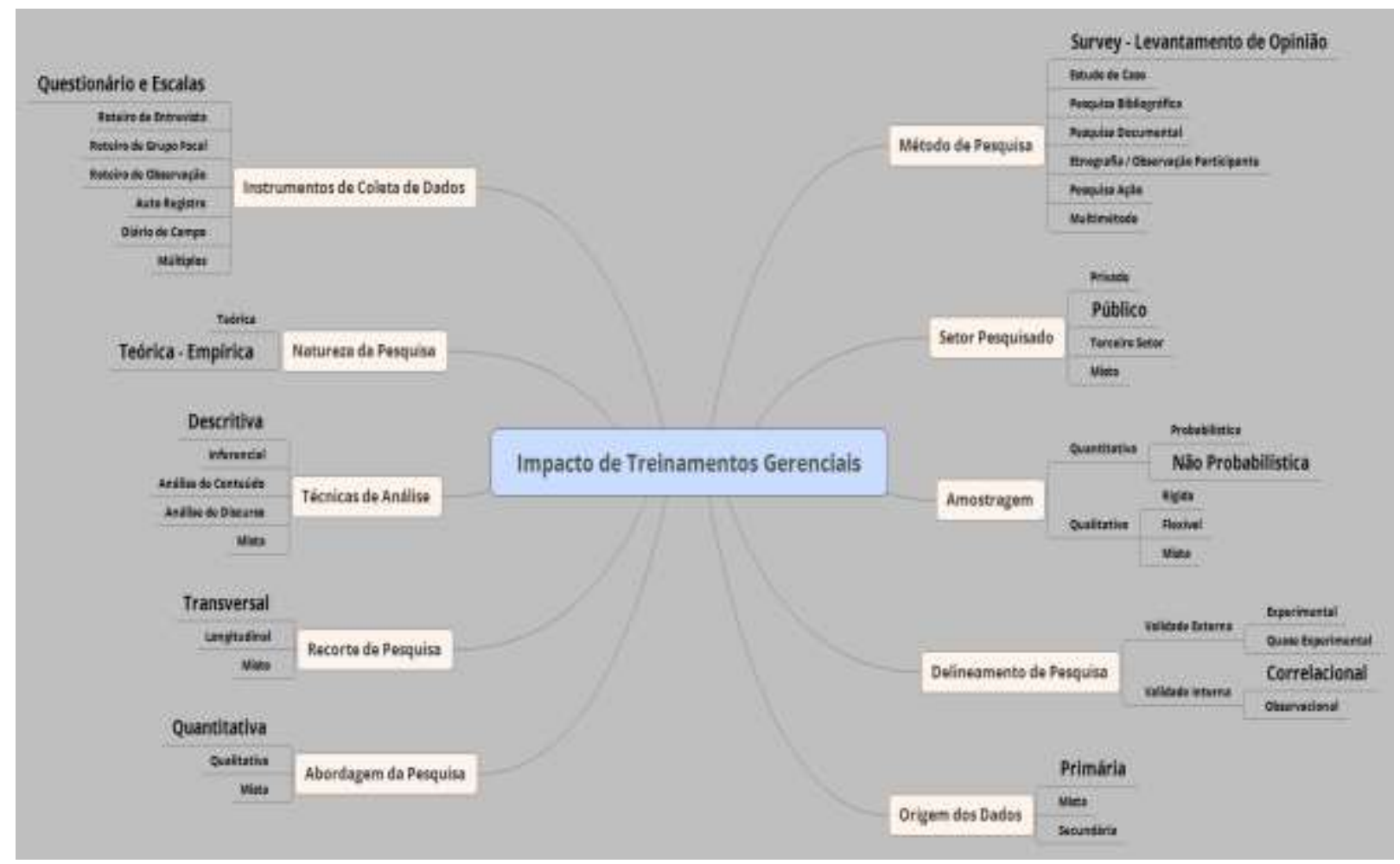

Figura 5. Síntese da metodologia utilizada

A síntese apresentada na Figura 5 contempla as diversas premissas para realização desta pesquisa, onde o método de pesquisa foi o Survey - levantamento de opinião; o setor pesquisado foi o público - INSS; a amostragem foi quantitativa e não probabilística, com a escolha dos participantes delimitados aos gerentes executivos e gerentes de APS; o delineamento da pesquisa tem validade interna à autarquia e é correlacional; possui a origem de dados primária; a abordagem da pesquisa é quantitativa; o recorte de pesquisa é transversal, visto que a escolha dos participantes foi somente em um determinado momento; 
a técnica de análise é descritiva; a natureza da pesquisa é teórica - empírica; e o instrumento de coleta de dados foi através de questionário dirigido ao público alvo estabelecido.

O perfil da Organização em análise é apresentado a seguir.

\subsection{Caracterização da organização estudada}

A pesquisa foi realizada no Instituto Nacional do Seguro Social (INSS), onde o pesquisador atuou até novembro de 2016. O INSS foi criado em 1990, durante a gestão do então presidente Fernando Collor de Melo, por meio do Decreto n. 99.350 (1990), a partir da fusão do Instituto de Administração Financeira da Previdência e Assistência Social - IAPAS com o Instituto Nacional de Previdência Social - INPS, sendo hoje uma autarquia vinculada ao Ministério do Trabalho e Previdência Social, instituída com fundamento no disposto no art. 17 da Lei de n. 8.029 (1990), e tem por finalidade promover o reconhecimento de direito ao recebimento de benefícios administrados pela Previdência Social, assegurando agilidade, comodidade aos seus usuários e ampliação do controle social.

Compete, ainda, ao INSS a operacionalização do reconhecimento dos direitos da clientela do Regime Geral de Previdência Social (RGPS), que em 2014 abrangia 51,6 milhões de contribuintes, segundo o Boletim estatístico gerencial do Instituto Nacional do Seguro Social (2015).

O art. 201 da Constituição Federal Brasileira, de 5 de outubro de 1988 (2016), organiza o RGPS, que tem caráter contributivo e filiação obrigatória. Enquadra toda a atuação do INSS respeitadas as políticas e estratégias governamentais oriundas dos órgãos hierarquicamente superiores.

O RGPS tem caráter universalista e o INSS oferece à sociedade, tanto a certeza de renda futura àqueles que contribuem regularmente, seja por meio de seus empregadores, seja por 
iniciativa própria, quanto mantém benefícios temporários ou permanentes por incapacidade, acidente do trabalho, entre outros.

O INSS dispõe de um sistema que provê benefícios previdenciários e operacionaliza o reconhecimento dos benefícios assistenciais. Ao proporcionar rendimento aos idosos e pessoas com necessidades especiais e outros brasileiros, realiza importante papel social no combate à pobreza e na melhoria da distribuição de renda entre diferentes grupos sociais, e contribui, assim, com expressiva parcela para a erradicação da miséria.

O INSS caracteriza-se, portanto, como uma organização pública prestadora de serviços previdenciários para a sociedade brasileira. É nesse contexto e procurando preservar a integridade da qualidade do atendimento a essa clientela que a autarquia federal vem buscando alternativas de melhoria contínua, com programas de modernização e excelência operacional, ressaltando a maximização e a otimização de resultados e de ferramentas que fundamentem o processo de atendimento ideal aos anseios da sociedade em geral.

O histórico da moderna gestão de desempenho no INSS teve início com o Programa de Melhoria do Atendimento (PMA) em 1997, onde se buscou uma nova forma de atendimento e com modificações nas Agências de atendimento. Em 2001, o INSS iniciou a modelagem de seus processos, com o projeto Novo Modelo de Gestão, que priorizou os processos de atendimento com ênfase no aperfeiçoamento do cadastro e no desenvolvimento de sistemas.

Em 2009 se iniciou a implementação do Escritório de Processos e Projetos. Com isto, surgiu a estratégia da gestão de processos, por meio da promoção do acesso à informação de forma transparente e tempestiva, fortalecendo os mecanismos de acesso à informação com o "foco do cidadão", ampliando a oferta de serviços de informações ao cidadão por meio de diversos canais de relacionamento, intensificando a utilização de canais remotos na prestação de serviços. Buscou-se estabelecer uma política de gestão da informação e documentação que pudesse propiciar e agilizar o acesso a informação por diversos meios, com vistas a 
implementação de processo digital, garantindo uma comunicação clara, objetiva, tempestiva, ágil, oportuna, consistente e acessível ao público interno e externo.

Também em 2009 a estratégia de simplificar e desburocratizar normas e uniformizar os processos previdenciários, assegurou a clareza e objetividade das normas institucionais. Com isto, busca-se promover a simplificação de procedimentos e garantir a uniformidade de decisões em todas as unidades e instâncias, efetivando o gerenciamento de processo de negócio na organização, seja finalístico, gerencial ou de apoio, que estabeleça como base essencial o "foco do cidadão", por meio da realização da modelagem, análise, desenho, transformação de processos e o gerenciamento de desempenho de processos.

Na Figura 6 é apresentada a estrutura de funcionamento do INSS a nível de Brasil.

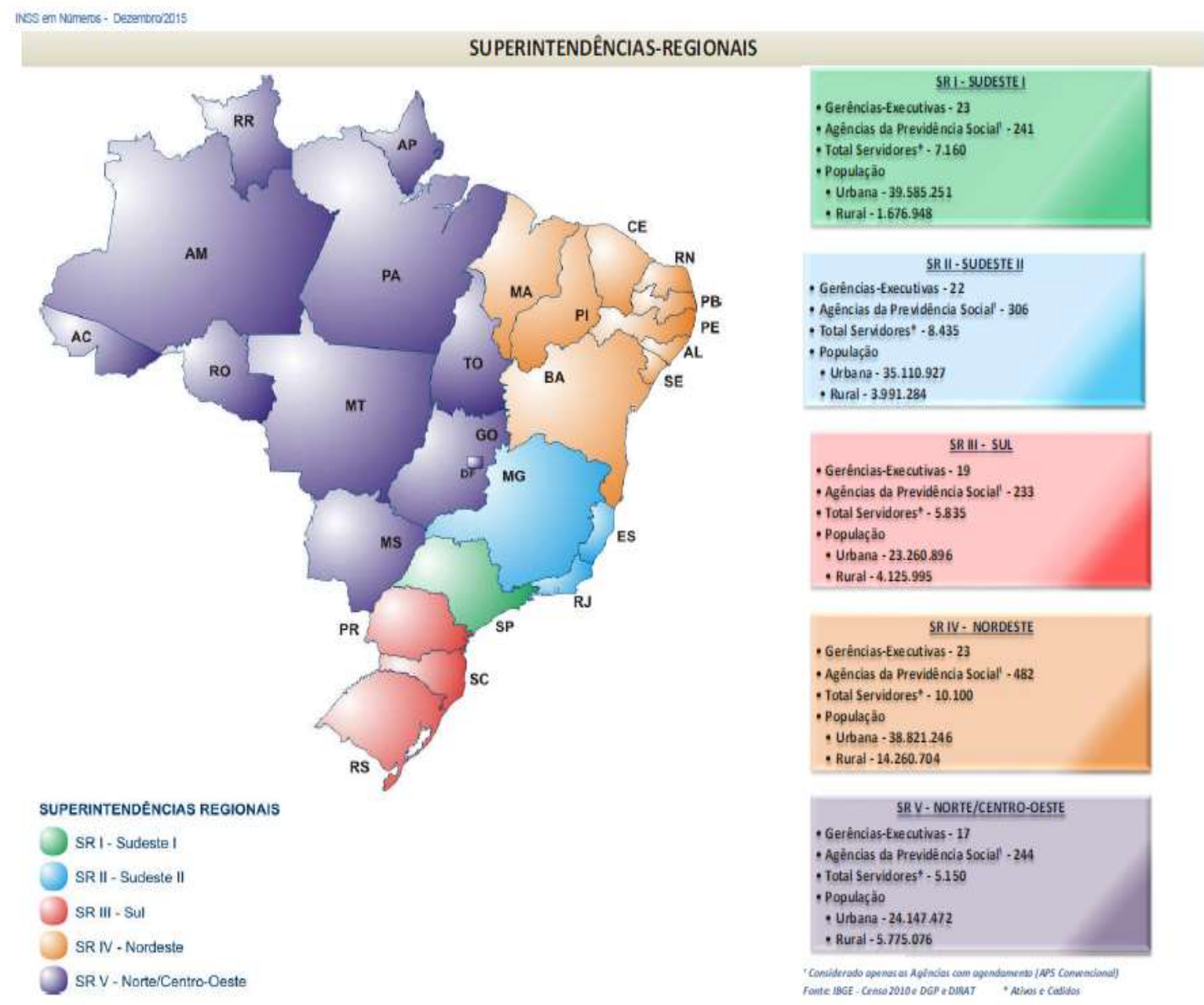

Figura 6. Estrutura do INSS no Brasil

Fonte: Boletim estatístico gerencial - INSS em Números Dezembro/2015 (2015). 
As cinco Superintendências do INSS coordenam as atividades das Gerências Executivas, que por sua vez coordenam as atividades das Agências da Previdência Social, sendo que em cada unidade há um gestor responsável, conforme Tabela 4, com posição em outubro/2016.

Tabela 4

Quantidade de Gerências Executivas e Agências da Previdência Social por Superintendência no Brasil

$\begin{array}{lcccc} & \text { Gerências } & \text { Agências da } & \\ \text { Superintendência - Unidades da Federação } & \text { Executivas } & \% \text { GEX } & \text { Previdência } & \% \text { APS } \\ & (\text { GEX) } & \text { Social (APS) } & \end{array}$

Sul - Rio Grande do Sul, Santa Catarina, Paraná.

19

23

Sudeste I - São Paulo.

Sudeste II - Minas Gerais, Espírito Santo, Rio de

Janeiro.

Norte e Centro Oeste - Mato Grosso do Sul, Mato

Grosso, Goiás, Distrito Federal, Tocantins, Rondônia,

Acre, Amazonas, Roraima, Pará, Amapá.

Nordeste - Bahia, Sergipe, Alagoas, Pernambuco,

Paraíba, Rio Grande do Norte, Ceará, Piauí, Maranhão.

\begin{tabular}{lllll}
\hline Total & 104 & 100,00 & 1.506 & 100,00 \\
\hline
\end{tabular}

15,47

$22,12 \quad 241 \quad 16,00$

$22 \quad 306 \quad 20,32$

17

16,35

244

16,20

23

22,12

482

32,01

A abrangência de atuação do INSS encontra-se em todas as unidades federativas do Brasil, conforme demonstrado na Figura $n^{\circ} 6$ e na Tabela $n^{\circ} 4$, tendo gestores que necessariamente realizam os cursos obrigatórios desta autarquia, cuja descrição será feita na próxima Seção.

\subsubsection{Descrição dos cursos em estudo}

A existência de 5.015 cargos em comissão e funções gratificadas (Tabela 5) demonstra a relevância do programa de formação continuada para gestores, implementado pelo Centro de Formação e Aperfeiçoamento do INSS (CFAI), cujo objetivo é o desenvolvimento das competências profissionais, técnicas e estruturantes, definidos em cinco (5) eixos: Gestão de 
Processos, de Equipe, de Atendimento, da Informação e do Conhecimento, fundamentado na

Carta de Princípios de Gestão e Governança do INSS. É importante destacar que na linha de comando organizacional o gerente de APS ocupa o $4^{\circ}$ nível hierárquico, o gerente executivo o $3^{\circ}$ nível hierárquico, o Superintendente o $2^{\circ}$ nível e a Presidência o $1^{\circ}$ nível hierárquico de poder, sendo que em cada nível existem subordinados com cargos em comissão e funções gratificadas.

Tabela 5

Detalhamento dos cargos em comissão e das funções gratificadas do INSS

\begin{tabular}{|c|c|c|c|c|}
\hline \multirow[b]{2}{*}{$\begin{array}{l}\text { TIPOLOGIAS DOS CARGOS EM COMISSÃO } \\
\text { E DAS FUNÇÕES GRATIFICADAS }\end{array}$} & \multicolumn{2}{|c|}{ LOTAÇÃO } & \multirow{2}{*}{$\begin{array}{c}\text { Ingressos } \\
\text { no } \\
\text { Exercício }\end{array}$} & \multirow{2}{*}{$\begin{array}{c}\text { Egressos } \\
\text { no } \\
\text { Exercício }\end{array}$} \\
\hline & Autorizada & Efetiva & & \\
\hline 1. Cargos em Comissão & 727 & 708 & 205 & 151 \\
\hline 1.1. Cargos Natureza Especial & 0 & 0 & 0 & 0 \\
\hline 1.2. Grupo Direção e Assessoramento Superior & 727 & 708 & 205 & 151 \\
\hline 1.2.1. Servidores de Carreira Vinculada ao Órgão & 727 & 563 & 150 & 96 \\
\hline 1.2.2. Servidores de Carreira em Exercício & 0 & 127 & 51 & 52 \\
\hline \multicolumn{5}{|l|}{ Descentralizado } \\
\hline 1.2.3. Servidores de Outros Órgãos e Esferas & 0 & 9 & 3 & 2 \\
\hline 1.2.4. Sem Vínculo & 0 & 9 & 1 & 1 \\
\hline 1.2.5. Aposentados & 0 & 0 & 0 & 0 \\
\hline 2. Funções Gratificadas & 4.686 & 4.307 & 1.323 & 968 \\
\hline 2.1. Servidores de Carreira Vinculada ao Órgão & 4.686 & 4.149 & 1.268 & 905 \\
\hline 2.2. Servidores de Carreira em Exercício & 0 & 156 & 54 & 62 \\
\hline \multicolumn{5}{|l|}{ Descentralizado } \\
\hline 2.3. Servidores de Outros órgãos e Esferas & 0 & 2 & 1 & 1 \\
\hline 3. Total de Servidores em Cargo e em Função (1+2) & 5.413 & 5.015 & 1.528 & 1.119 \\
\hline
\end{tabular}

Fonte: Relatório de Gestão INSS 2014. Instituto Nacional do Seguro Social (2015).

Obs.: 1- A lotação efetiva considerou os servidores ocupantes de cargos comissionados/funções gratificadas sem ocorrência de encerramento no exercício de 2014; 2- Os ingressos e egressos foram apurados tomando por base os dois últimos registros de provimento de funções mantidos na fita espelho do SIAPE para os servidores, computando apenas as ocorrências referentes ao exercício de 2014.

O projeto educacional do INSS, implementado pela Resolução n ${ }^{\circ} 291$ (2013), traz uma proposta educativa com vistas à formação, ao desenvolvimento, ao aperfeiçoamento e à qualificação dos servidores; e à disseminação dos conhecimentos previdenciários, num 
cenário de unificação e educação voltada aos servidores e à sociedade.

A proposta pedagógica buscou estabelecer uma política de educação que resgate a trajetória do fazer pedagógico no INSS e promova novas perspectivas de desenvolvimento e formação dos indivíduos, visto que o processo educativo, em uma instituição, extrapola os espaços físicos e acontece por meio das relações, das experiências e das práticas existentes.

Este projeto foi construído considerando o histórico do Instituto, e, mais especificamente, a trajetória educacional da organização; e embasado pela análise da atual situação do INSS, em suas diversas interfaces: instituição, servidor e sociedade.

A proposta educacional, em questão, teve como referência a missão, a visão e os objetivos estratégicos da instituição, bem como as suas peculiaridades regionais que caracterizam o Brasil. Objetivou delinear o pensar educacional em consonância com o Decreto $\mathrm{n}^{\circ} 5.707$ (2006), que instituiu a política e as diretrizes para o desenvolvimento de pessoal da administração pública federal direta, autárquica e fundacional.

O projeto educacional do INSS deve ser compreendido como uma escolha significativa de novos caminhos para a formação de cidadãos éticos e participativos, comprometidos com uma sociedade inclusiva, solidária e sustentável, uma vez que busca a sistematização de teorias e práticas educativas que nortearão as ações educacionais internas e externas, oportunizando a construção do conhecimento individual e coletivo, nos diversos ambientes educativos existentes.

Os cursos de gestão direcionados aos gerentes executivos e gerentes de APS tem amparo legal no Decreto $\mathrm{n}^{\circ} 5.707$ (2006) e em normativos internos, destacando-se o Memorando Circular Conjunto $n^{\circ}$ 4/CFAI/DGP/INSS de 09 de junho de 2015 que determina que tais gestores tenham os cursos à distância de Deveres e Proibições - 10 horas/aula; Disseminando Saúde e Qualidade de Vida no Trabalho (DSQVT) - 12 horas/aula; Ética no Serviço Público 10 horas/aula; Formação de Gestores - 10 horas/aula; Gestão Estratégica - 10 horas/aula; 
Gestão de Equipes - 15 horas/aula; e Sistema Sala de Monitoramento - 10 horas/aula. O quantitativo dos cursos de gestão realizados desde o início das turmas até 23 de junho de 2016 é apresentado na Tabela $n^{\circ} 6$ e o detalhamento do conteúdo dos dois cursos selecionados encontra-se na Tabela $n^{\circ} 7$.

O quantitativo de turmas concluídas e de participantes nos cursos de gestão promovidos pelo INSS é relevante, cujos cursos foram iniciados entre 2010 e 2014. Em 2016 foram 7 (sete) cursos obrigatórios aos ocupantes de funções comissionadas de gerente executivo e gerente de APS. A quantidade de participantes nestes cursos é formada por atuais gestores e servidores sem função comissionada ou cargo comissionado, conforme Tabela $\mathrm{n}^{\circ} 6$.

Tabela 6

Quantitativo de Cursos de Gestão

\begin{tabular}{llccc}
\hline \multicolumn{1}{c}{ CURSOS DE GESTÃo } & $\begin{array}{c}\text { Data de Início do } \\
\text { Curso - 1 }\end{array}$ & $\begin{array}{c}\text { Quantidade de } \\
\text { Turmas Concluídas } \\
\text { - até 23-06-2016 }\end{array}$ & $\begin{array}{c}\text { Quantidade de } \\
\text { Participantes - } \\
\text { Inscritos - até 23- } \\
\text { 06-2016 }\end{array}$ & $\begin{array}{c}\text { Quantidade de } \\
\text { Participantes - } \\
\text { Concluintes - até } \\
\mathbf{2 3 - 0 6 - 2 0 1 6}\end{array}$ \\
\hline DEVERES E PROIBIÇÕES & julho de 2014 & 25 & 5.304 & 4.360 \\
DSQVT & março de 2013 & 48 & 7.900 & 5.805 \\
ÉTICA & setembro de 2013 & 34 & 7.206 & 5.959 \\
FORMAÇÃO DE GESTORES junho de 2010 & 87 & 13.847 & 10.821 \\
GESTÃO ESTRATÉGICA & maio de 2010 & 79 & 11.872 & 9.038 \\
GESTÃO DE EQUIPES & novembro de 2011 & 55 & 7.519 & 5.652 \\
SALA DE & março de 2014 & 34 & 6.072 & 4.432 \\
MONITORAMENTO & & 362 & 59.720 & 46.067 \\
\hline TOTAL & & & & \\
\hline
\end{tabular}

Fonte: INSS - Diretoria de Gestão de Pessoas - Centro de Formação e Aperfeiçoamento do INSS.

Nesta pesquisa decidiu-se investigar dois cursos quanto aos aspectos do impacto do treinamento em profundidade: curso de gestão estratégica e curso de gestão de equipes.

No Curso “Gestão Estratégica” apresentam-se, nos níveis taxonômicos de conhecimento, compreensão e análise, as principais características de modelos de gestão estratégica em geral particularizando-se a realidade do planejamento estratégico do INSS. Sua carga horária é de 10 horas, e foi um curso ofertado totalmente na modalidade a distância. 
O curso "Gestão de Equipes" teve carga horária de 15h, e objetivava apresentar as características de composição de uma equipe de trabalho, dando ênfase ao papel tático do gestor na condução da equipe. Também foi um curso ofertado totalmente na modalidade a distância. Informações gerais sobre estes dois cursos estão apresentadas na Tabela $n^{0} 7$. 
Tabela 7

Cursos de gestão selecionados para avaliação do impacto em profundidade

\begin{tabular}{|c|c|c|c|}
\hline Curso & Objetivo Geral & Objetivo Específico & Metodologia \\
\hline $\begin{array}{c}\text { Gestão } \\
\text { Estratégica }\end{array}$ & $\begin{array}{l}\text { Ao final do curso os } \\
\text { aprendizes serão } \\
\text { capazes de empregar os } \\
\text { conceitos e práticas da } \\
\text { Gestão e do } \\
\text { Planejamento } \\
\text { Estratégico da } \\
\text { Previdência Social. }\end{array}$ & $\begin{array}{l}\text { - Relacionar as fases e subfases dos processos de gestão estratégica, na ordem cronológica em que ocorrem e seu } \\
\text { conceitos. } \\
\text { - Selecionar, entre alternativas, o que é Planejamento Estratégico. } \\
\text { - Listar, de forma objetiva, os motivos pelos quais as organizações devem adotar o Planejamento Estratégico. } \\
\text { - Classificar os níveis e desdobramentos do Planejamento na organização; } \\
\text { - Indicar aspectos positivos do Planejamento Estratégico. } \\
\text { - Sintetizar o conceito da metodologia BSC. } \\
\text { - Relacionar, de forma objetiva, como foi realizado o processo de Planejamento Estratégico na Previdência Social. } \\
\text { - Identificar os direcionadores estratégicos da Previdência Social. } \\
\text { - Identificar de que forma ocorre o alinhamento e desdobramento das estratégias organizacionais. }\end{array}$ & $\begin{array}{l}\text { O curso é disponibilizado } \\
\text { na intranet e internet, } \\
\text { com o acompanhamento } \\
\text { de um Tutor On-line. }\end{array}$ \\
\hline $\begin{array}{c}\text { Gestão de } \\
\text { Equipes }\end{array}$ & $\begin{array}{l}\text { Sensibilizar o } \\
\text { participante acerca da } \\
\text { importância da } \\
\text { construção e da } \\
\text { mobilização da equipe } \\
\text { de trabalho, } \\
\text { contribuindo para a } \\
\text { melhoria dos processos } \\
\text { de gestão no INSS. }\end{array}$ & $\begin{array}{l}\text { - Diferenciar grupo, equipe e organização. } \\
\text { - Conhecer o histórico das relações entre organização e trabalho. } \\
\text { - Conhecer a contribuição das diferentes teorias da Administração. } \\
\text { - Compreender o conceito de motivação como elemento constituinte da equipe de trabalho. } \\
\text { - Compreender os aspectos que envolvem a transformação de um grupo em equipe. } \\
\text { - Compreender o conceito de liderança. } \\
\text { - Reconhecer a Gestão participativa como fator de mobilização da equipe para o trabalho. } \\
\text { - Reconhecer a ética como condição para viabilizar a gestão. } \\
\text { - Reconhecer a cultura organizacional como fator de mobilização da equipe ao trabalho. } \\
\text { - Identificar as condições ideais para a realização do trabalho em equipe. }\end{array}$ & $\begin{array}{l}\text { O curso é disponibilizado } \\
\text { na intranet e internet, } \\
\text { com o acompanhamento } \\
\text { de um Tutor On-line. } \\
\text { Público participante: } \\
\text { Servidores do INSS. }\end{array}$ \\
\hline
\end{tabular}


Tendo selecionado para avaliação do impacto em profundidade os cursos de gestão estratégica e getão de equipes, demonstra-se a seguir o instrumento de pesquisa selecionado para a coleta de dados aos gestores do INSS.

\subsection{Caracterização do instrumento de pesquisa}

O questionário de pesquisa, abrangendo todas as variáveis que foram pesquisadas neste trabalho, continha um total de 111 itens. Os itens concernentes à escala de suporte à aprendizagem já foram previamente testados e validados empiricamente (Coelho Jr., 2004), restando adotar procedimentos de validação semântica e de adequação destes itens à linguagem e cultura da Organização em estudo.

Já os itens relativos a impacto, tanto em profundidade quanto em amplitude, foram elaborados pelos responsáveis pela Área de Recursos Humanos da própria Organização, com o auxílio de assessoria externa, em 2010. Desde então não foi feito qualquer tipo de validação empírica desta medida. Em 2010 foram extraídos os objetivos instrucionais dos dois cursos selecionados, sendo tais objetivos transformados em objetivos de desempenho. Optou-se, por uma questão política visando facilitar o acesso à população em análise, por utilizar esta medida construída pela própria Organização. Ressalta-se que não foram utilizados, para fins de análise de dados para esta Dissertação, todos os itens contidos na medida disponibilizada pela Organização, por não se tratarem de interesse de pesquisa neste momento.

Na Tabela 8, apresentada a seguir, encontra-se uma síntese das dimensões teóricas de todos os itens que compuseram o instrumento de pesquisa disponibilizado eletronicamente aos egressos dos dois cursos pesquisados. 
Tabela 8

Características do questionário

\begin{tabular}{|c|c|c|c|}
\hline Nome da Escala & Dimensões do Instrumento & $\begin{array}{l}\text { Número de Itens } \\
\text { Correspondentes }\end{array}$ & Tipo de Resposta \\
\hline \multirow{3}{*}{$\begin{array}{l}\text { Impacto do } \\
\text { Treinamento em } \\
\text { Amplitude }\end{array}$} & $\begin{array}{l}\text { Impacto do treinamento em amplitude - } \\
\text { referência Modelo IMPACT }\end{array}$ & 13 & Itens Likert de 1 a 10 \\
\hline & Adequação a realidade & 3 & Itens Likert de 1 a 10 \\
\hline & Avaliação de reação & 1 & Sim ou Não \\
\hline \multirow{2}{*}{$\begin{array}{c}\text { Impacto do } \\
\text { Treinamento em } \\
\text { Profundidade }\end{array}$} & $\begin{array}{l}\text { Curso Gestão Estratégica - Escalas de } \\
\text { Importância e Contribuição }\end{array}$ & 10 & Itens Likert de 1 a 4 \\
\hline & $\begin{array}{l}\text { Curso Gestão de Equipes - Escalas de } \\
\text { Importância e Contribuição }\end{array}$ & 10 & Itens Likert de 1 a 4 \\
\hline \multirow{3}{*}{$\begin{array}{c}\text { Suporte à } \\
\text { Aprendizagem }\end{array}$} & Percepções sobre a Unidade de Trabalho & 9 & Itens Likert de 1 a 10 \\
\hline & Percepções sobre o Gestor Imediato & 9 & Itens Likert de 1 a 10 \\
\hline & Percepções sobre a Equipe de Trabalho & 5 & Itens Likert de 1 a 10 \\
\hline $\begin{array}{l}\text { Impacto do } \\
\text { Treinamento em }\end{array}$ & $\begin{array}{l}\text { Função de gerente executivo - Escalas de } \\
\text { Importância e Contribuição }\end{array}$ & 34 & Itens Likert de 1 a 4 \\
\hline $\begin{array}{l}\text { Amplitude sobre } \\
\text { Competências }\end{array}$ & $\begin{array}{l}\text { Função de gerente de APS - Escalas de } \\
\text { Importância e Contribuição }\end{array}$ & 34 & Itens Likert de 1 a 4 \\
\hline \multirow{3}{*}{$\begin{array}{l}\text { Solicitações de } \\
\text { Capacitação }\end{array}$} & Auto Formação & 1 & Sim ou Não \\
\hline & Equipe de Trabalho & 1 & Sim ou Não \\
\hline & Gestor Substituto & 1 & Sim ou Não \\
\hline \multirow{2}{*}{ Perfil do Gestor } & Funcionais & 11 & Variável \\
\hline & Biográficos & 3 & Variável \\
\hline
\end{tabular}

O questionário desenvolvido de forma abrangente foi objeto de considerações e validações que serão explicitadas na Seção seguinte. Entre as características do questionário, destaca-se que as escalas Likert são variáveis, tendo situações de 1 a 4 e outras de 1 a 10 para o participante ponderar e refletir na escolha de suas respostas. Para equilibrar tal situação projetou-se o uso do escore padronizado para posteriores comparações, porém ao realizar tal procedimento verificou-se a não necessidade de tal uso nesta pesquisa, visto que as análises fatoriais das variáveis preditoras e critério seriam por bloco, ou seja de forma isolada foram analisados os itens respondidos de suporte à aprendizagem, impacto do treinamento em amplitude, impacto do treinamento em profundidade e impacto do treinamento em amplitude sobre competências. 


\subsection{Validação por juízes}

A validação do questionário por juízes foi realizada entre os dias 08 a 10 de março de 2016, por 7 servidores federais lotados em 4 (quatro) regionais da auditoria interna do INSS no Brasil, especializados em gestão de pessoas. Também participaram servidores federais lotados na gerência executiva do INSS no Distrito Federal, Brasília, que atuam no Centro de Formação e Aperfeiçoamento do INSS.

Os juízes avaliaram a precisão, pertinência e adequação de cada um dos itens em relação ao objeto desta pesquisa. Considera-se que os mesmos contribuíram com a elaboração do instrumento de pesquisa, garantindo, também, que o questionário fosse adaptado à cultura do INSS bem como assegurando que a escala proposta estivesse apta a medir aquilo a que se propunha medir.

Após esta primeira validação por juízes da própria Organização em estudo realizou-se, também, validação com 3 professores dos Departamentos de Administração e Gestão de Políticas Públicas da Universidade de Brasília. Ainda, efetuou-se validação junto a 5 pesquisadores do Gepaco (Grupo de Pesquisas e Estudos Avançados sobre Comportamento Organizacional), coordenador pelo professor Orientador deste trabalho.

Durante esta etapa de validação por juízes foram examinados todos os itens do questionário, avaliando-se a clareza, a relevância e a adequação à linguagem utilizada no INSS. Além dos itens do questionário, foi validado também, pelos juízes, a mensagem que convidou os participantes para a realização da pesquisa e as instruções de preenchimento da escala.

\subsection{Validação semântica do instrumento}

A escala foi validada semanticamente com a finalidade de eliminar eventuais vieses e 
ambiguidades de interpretação teórica que poderiam estar presentes nos itens. Por meio da validação semântica, realizou-se a análise do instrumento quanto à sua clareza, parcimônia e objetividade (Pasquali, 2010), tanto dos itens como das instruções para o seu preenchimento, buscando minimizar a possibilidade de surgirem dúvidas no momento em que os itens estiverem sendo respondidos pelos participantes. Adaptou-se a linguagem dos itens à cultura gerencial predominante no INSS.

A etapa da validação semântica foi realizada junto a servidores federais lotados em 8 (oito) regionais da auditoria interna do INSS no Brasil, especializados em gestão de pessoas, em abril de 2016. As sugestões de melhoria foram adotadas pelo pesquisador. Em seguida, com o instrumento já adequado à realidade do INSS, iniciou-se os procedimentos de coleta de dados.

\subsection{Aplicação do teste piloto}

Após a realização das validações por juízes e semântica, o instrumento foi digitalizado eletronicamente, no ambiente virtual limesurvey. Procedeu-se, então, à realização de um teste piloto com o envio do link de acesso ao questionário via e-mail a uma amostra reduzida, com o objetivo de analisar aspectos operacionais, envolvidos na coleta de dados. Tal teste piloto permitiu acompanhar o número inicial de respostas oferecido em relação à quantidade de $e$ mails enviada (proporção entre quantidade de e-mails e quantidade de respondentes), bem como propiciou o aprendizado sobre a utilização desta ferramenta de coleta, permitindo a correção de eventuais problemas no momento da aplicação do instrumento em toda a população estudada.

Ressalta-se, aqui, que a ferramenta escolhida foi o LimeSurvey, software livre disponível na internet, que oferece a possibilidade de customização de pesquisa, por meio da 
construção e envio de questionários, bem como do monitoramento da quantidade de respondentes e da coleta de dados. O questionário foi totalmente transposto para a plataforma on line em abril de 2016.

A mensagem explicativa e o link de acesso ao questionário foram enviados por email para uma amostra formada por 20 (vinte) participantes da Gerência Executiva do Distrito Federal, composta por um gerente executivo e dezenove gerentes de APS.

Com as informações obtidas por meio do teste piloto, que geraram 5 questionários preenchidos completamente, 6 preenchidos parcialmente e 9 não preenchidos, foi verificada a necessidade de se ampliar o esforço de sensibilização da população alvo para participação da pesquisa, especialmente de gerentes de APS. A maior sensibilização da população foi buscada com o oferecimento de informações por meio da intranet do INSS e apoio dos demais gestores, em especial dos Superintendentes Regionais e da Auditoria Interna do INSS.

A aplicação do teste piloto possibilitou demonstrar o domínio da ferramenta LimeSurvey, que se mostrou adequada e confiável, o que permitiu a confirmação da sua utilização na execução dos procedimentos efetiva a coleta de dados à população de interesse (egressos de duas capacitações), descrita na próxima Seção.

\subsection{Procedimentos de coleta de dados}

Para a realização da pesquisa foram aplicados questionários aos servidores ocupantes de funções comissionadas de gerente executivo e gerentes de APS, distribuídos em todo o território nacional. Estes gestores foram convidados para participar da pesquisa por meio de um convite enviado para a caixa de mensagem eletrônica (e-mail) funcional, cuja listagem foi fornecida ao pesquisador pelo INSS, contando com o apoio da Auditoria Geral desta autarquia para realizar tal coleta de dados.

A coleta foi realizada entre os meses de julho e agosto de 2016. As instruções para 
preenchimento do instrumento eram auto-explicativas, visto que a coleta foi realizada à distância. Durante este período foram encaminhados e-mails renovando o convite para a participação na pesquisa. Procedeu-se a 5 reenvios dos e-mails convidativos à pesquisa. Ressalta-se que nos e-mails foram apresentados os objetivos da pesquisa, bem como foi garantido o anonimato e sigilo das respostas. Ao clicar para começar a pesquisa cada respondente preenchia o termo de consentimento livre e esclarecido de sua espontânea participação neste trabalho.

A população de interesse correspondeu a 104 gerentes executivos e 1.506 gerentes de APS. A amostra final contou com 291 respondentes. O perfil amostral é apresentado a seguir.

\subsection{Perfil amostral}

O envio dos questionários foi censitário. Considerando 1.610 gestores que poderiam participar desta pesquisa, obteve-se a participação de 291 respondentes (índice de retorno de 18\%). A margem de erro aceitável nesta pesquisa foi de $6 \%$ e o grau de confiança de $95 \%$, tendo um referencial necessário mínimo de 229 participantes, conforme orienta Santos (2016).

Dos 291 participantes, 30 se identificaram como gerentes executivos e 261 como gerentes de APS, com representatividade de $29 \%$ e $17 \%$ respectivamente frente a população de 104 gerentes executivos e 1.506 gerentes de APS.

Destes 291 participantes, 114 eram do sexo feminino e 177 do sexo masculino, tendo escolaridade distribuída em ensino médio (com 15 participantes), superior incompleto (36), superior completo (161), especialização (7)4 e mestrado (5).

O tempo de serviço público dos 291 participantes teve maior representatividade com $30 \%$ (trinta por cento) no período superior a 15 anos e na função gerencial com maior representatividade de $35 \%$ (trinta e cinco por cento) no período de 1 a 3 anos. 
A participação geográfica foi representativa e equilibrada pelo país. Na região Sudeste constatou-se $34 \%$ de participantes, na região Norte e Centro Oeste $28 \%$, Nordeste com $22 \%$ e Sul 16\%. A unidade federativa com maior participação foi Minas Gerais com 14\%.

Outra característica pontual foi a identificação do último curso obrigatório concluído pelos 291 participantes. O curso relativo a Deveres e Proibições com 25,8\% foi o mais citado, e o menos foi de Gestão de Equipes com 4,1\%. O tempo médio de conclusão destes cursos foi de 9,7 meses, tendo por data de referência o preenchimento deste questionário.

Na análise global, $84 \%$ dos participantes afirmam que preenchem a avaliação de reação do curso realizado, 59\% solicitam cursos para sua formação profissional, 69\% solicitam cursos para sua equipe de trabalho e $39 \%$ afirmam que seu substituto imediato realizou parcialmente os cursos obrigatórios aos gestores.

A Tabela 9 sintetiza o perfil amostral desta pesquisa.

Tabela 9

Dados biográficos e funcionais dos respondentes da pesquisa

\begin{tabular}{|c|c|c|c|}
\hline Variável & Descrição & $\begin{array}{c}\text { Frequência } \\
\text { Absoluta }\end{array}$ & $\begin{array}{l}\text { Frequência } \\
\text { Relativa \% }\end{array}$ \\
\hline Sexo & $\begin{array}{l}\text { Feminino } \\
\text { Masculino }\end{array}$ & $\begin{array}{l}114 \\
177\end{array}$ & $\begin{array}{l}39,2 \\
60,8\end{array}$ \\
\hline Idade & $\begin{array}{l}\text { De } 21 \text { a } 30 \text { anos } \\
\text { De } 31 \text { a } 40 \text { anos } \\
\text { De } 41 \text { a } 50 \text { anos } \\
\text { De } 51 \text { a } 60 \text { anos } \\
\text { Acima de } 60 \text { anos }\end{array}$ & $\begin{array}{r}17 \\
105 \\
86 \\
71 \\
12\end{array}$ & $\begin{array}{c}5,8 \\
36,1 \\
29,6 \\
24,4 \\
4,1\end{array}$ \\
\hline Escolaridade & $\begin{array}{l}\text { Ensino Médio } \\
\text { Superior Incompleto } \\
\text { Superior Completo } \\
\text { Especialização / MBA } \\
\text { Mestrado / Doutorado }\end{array}$ & $\begin{array}{r}15 \\
36 \\
161 \\
74 \\
5\end{array}$ & $\begin{array}{c}5,2 \\
12,4 \\
55,3 \\
25,4 \\
1,7\end{array}$ \\
\hline $\begin{array}{l}\text { Exerce o cargo de } \\
\text { Servidor Público no } \\
\text { INSS há quanto } \\
\text { tempo: }\end{array}$ & $\begin{array}{l}\text { Entre } 1 \text { e } 3 \text { anos } \\
\text { Entre } 3 \text { e } 5 \text { anos } \\
\text { Entre } 5 \text { e } 10 \text { anos } \\
\text { Entre } 10 \text { e } 15 \text { anos } \\
\text { Há mais de } 15 \text { anos }\end{array}$ & $\begin{array}{r}7 \\
30 \\
85 \\
82 \\
87\end{array}$ & $\begin{array}{c}2,4 \\
10,3 \\
29,2 \\
28,2 \\
29,9\end{array}$ \\
\hline $\begin{array}{l}\text { Exerce a função de } \\
\text { Gerente a quanto } \\
\text { tempo: }\end{array}$ & $\begin{array}{l}\text { Há menos de } 1 \text { ano } \\
\text { Entre } 1 \text { e } 3 \text { anos } \\
\text { Entre } 3 \text { e } 5 \text { anos } \\
\text { Entre } 5 \text { e } 10 \text { anos } \\
\text { Há mais de } 10 \text { anos }\end{array}$ & $\begin{array}{r}36 \\
101 \\
74 \\
41 \\
39\end{array}$ & $\begin{array}{l}12,4 \\
34,7 \\
25,4 \\
14,1 \\
13,4\end{array}$ \\
\hline
\end{tabular}




\begin{tabular}{|c|c|c|c|}
\hline Variável & Descrição & $\begin{array}{c}\text { Frequência } \\
\text { Absoluta } \\
\end{array}$ & $\begin{array}{l}\text { Frequência } \\
\text { Relativa \% }\end{array}$ \\
\hline Cargo & $\begin{array}{l}\text { Técnico do Seguro Social } \\
\text { Analista do Seguro Social } \\
\text { Outro(s) }\end{array}$ & $\begin{array}{r}264 \\
19 \\
7\end{array}$ & $\begin{array}{c}90,7 \\
6,5 \\
2,4\end{array}$ \\
\hline Função & $\begin{array}{l}\text { Gerente de APS } \\
\text { Gerente executivo }\end{array}$ & $\begin{array}{r}261 \\
30\end{array}$ & $\begin{array}{l}89,7 \\
10,3\end{array}$ \\
\hline 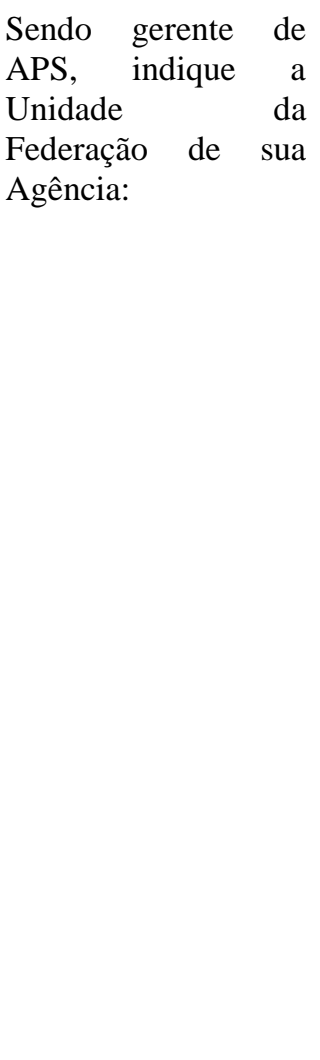 & $\begin{array}{l}\text { AC } \\
\text { AL } \\
\text { AM } \\
\text { BA } \\
\text { CE } \\
\text { DF } \\
\text { ES } \\
\text { GO } \\
\text { MA } \\
\text { MG } \\
\text { MS } \\
\text { MT } \\
\text { PA } \\
\text { PB } \\
\text { PE } \\
\text { PI } \\
\text { PR } \\
\text { RJ } \\
\text { RN } \\
\text { RO } \\
\text { RR } \\
\text { RS } \\
\text { SC } \\
\text { SE } \\
\text { SP } \\
\text { TO }\end{array}$ & $\begin{array}{r}4 \\
6 \\
5 \\
8 \\
7 \\
6 \\
4 \\
12 \\
6 \\
40 \\
9 \\
11 \\
12 \\
4 \\
15 \\
4 \\
13 \\
11 \\
6 \\
3 \\
2 \\
20 \\
10 \\
6 \\
31 \\
6\end{array}$ & $\begin{array}{l}1,4 \\
2,1 \\
1,7 \\
2,4 \\
2,1 \\
2,1 \\
1,4 \\
4,1 \\
2,1 \\
13,7 \\
3,1 \\
3,8 \\
4,1 \\
1,4 \\
5,2 \\
1,4 \\
4,5 \\
3,8 \\
2,1 \\
1,0 \\
0,7 \\
6,9 \\
3,4 \\
2,1 \\
10,7 \\
2,1\end{array}$ \\
\hline $\begin{array}{l}\text { Sendo gerente de } \\
\text { APS, indique o Tipo } \\
\text { de sua Agência: }\end{array}$ & $\begin{array}{l}\text { A } \\
\text { B } \\
\text { C } \\
\text { D }\end{array}$ & $\begin{array}{r}62 \\
122 \\
62 \\
15\end{array}$ & $\begin{array}{c}21,3 \\
41,9 \\
21,3 \\
5,2\end{array}$ \\
\hline $\begin{array}{l}\text { A Unidade onde } \\
\text { exerce o seu trabalho } \\
\text { é vinculada à qual } \\
\text { Superintendência: }\end{array}$ & $\begin{array}{l}\text { Sudeste I - São Paulo } \\
\text { Sudeste II - Belo Horizonte } \\
\text { Sul - Florianópolis } \\
\text { Nordeste - Recife } \\
\text { Norte e Centro-Oeste - Brasília }\end{array}$ & $\begin{array}{l}35 \\
65 \\
46 \\
65 \\
80\end{array}$ & $\begin{array}{l}12,0 \\
22,3 \\
15,8 \\
22,3 \\
27,5\end{array}$ \\
\hline $\begin{array}{l}\text { Último Curso à } \\
\text { Distância concluído: }\end{array}$ & $\begin{array}{l}\text { Deveres e Proibições } \\
\text { Disseminando Saúde e Qualidade de Vida no } \\
\text { Trabalho } \\
\text { Ética no serviço público } \\
\text { Formação de gestores } \\
\text { Gestão estratégica } \\
\text { Gestão de Equipes } \\
\text { Sistema Sala de Monitoramento } \\
\text { Outro }\end{array}$ & $\begin{array}{l}75 \\
25 \\
28 \\
48 \\
34 \\
12 \\
37 \\
32\end{array}$ & $\begin{array}{c}25,8 \\
8,6 \\
\\
9,6 \\
16,5 \\
11,7 \\
4,1 \\
12,7 \\
11,0\end{array}$ \\
\hline
\end{tabular}


Na próxima Seção serão explicados os procedimentos estatísticos que foram utilizados para a análise dos dados.

\subsection{Procedimentos de análise de dados}

A análise dos dados obtidos foi realizada apenas com a utilização dos questionários preenchidos integralmente e dentro do prazo estipulado para a coleta. Os questionários foram construídos de modo a impedir os casos omissos (não preenchimento de itens, que foram todos obrigatórios).

Com a finalidade de se assegurar a qualidade da análise, foi realizada limpeza do banco de dados, identificando outliers por meio do escore $\mathrm{Z}$ e distância mahalanobis. Realizou-se as análises de dados com e sem a presença dos outliers identificados. Não foram encontradas diferenças significativas entre os resultados, de modo que se optou por relatar os dados com a amostra total obtida $(\mathrm{N}=291)$.

A seguir, foram conduzidas análises descritivas, a fim de se analisar médias, freqüências, desvio-padrão e distribuição. A avaliação psicométrica da qualidade do instrumento utilizado foi feita a partir da análise fatorial exploratória e pela análise do coeficiente de consistência interna, cargas fatoriais, valor próprio, alfas de Cronbach, além de outros critérios citados por Pasquali (2010). Efetuou-se, para as análises preditivas, regressão linear múltipla.

Conforme apresentado por Corrar e et al (2007), a regressão linear é empregada em estudos organizacionais com o propósito de estimação de relações preditivas. Essa técnica consiste em determinar uma função matemática para descrever o comportamento de determinado indicador, dado os valores de outros indicadores já conhecidos (pode ser apenas um ou mais de um). O grande objetivo dessa técnica é alcançar valores previstos para o 
indicador alvo (variável critério) com maior precisão em relação à simples utilização da média.

Pelo estado da arte, são tradicionalmente reconhecidas as relações teóricas entre as variáveis antecedentes e critério. São apresentadas variáveis antecedentes com maior poder preditivo sobre impacto do treinamento, sendo esse critério teórico possível de ser adotado para a ordem de entrada das variáveis independentes no modelo de regressão, conforme orientam Tabachnick e Fidel (2007). Os procedimentos envolvendo a tabulação dos dados e cálculos foram realizados com a utilização do programa SPSS (Statistical Package for the Social Sciences).

Os resultados são apresentados no Capítulo 5, a seguir. 


\section{$5 \quad$ Resultados}

Apresentam-se, primeiramente, os dados de evidência de validade interna do questionário utilizado com foco na análise específica de suas dimensões teóricas subjacentes (suporte à aprendizagem e impacto de treinamento em amplitude e profundidade). Posteriormente, apresentam-se os modelos empíricos finais obtidos.

\subsection{Análises fatoriais do questionário}

Os dados foram submetidos à análise de componentes principais e fatoração do eixo principal. Essas análises permitiram examinar a estrutura fatorial do questionário e julgar a sua confiabilidade, onde os parâmetros comumente referendados pela literatura sobre psicometria são aqui apresentados.

A fatorabilidade foi testada pelo Indice de Kaiser-Meyer-Olkin, conhecido como índice de adequação da amostra, e pelo teste de esfericidade de Bartlett, conforme recomendação de Tabachnick e Fidell (2007). Depois disso, os dados foram submetidos a análises de componentes principais (ACP), a fatoração dos eixos principais (principal axis factoring PAF) e a fidedignidade dos fatores foi estimada pelo cálculo dos alfas de Cronbach, via SPSS.

O cálculo do índice de consistência interna, por meio do alfa de Cronbach ( $\alpha$ ), é o método mais utilizado em estudos transversais - quando as medições são realizadas em apenas um único momento (Sijtsma, 2009). George e Mallery (2003) sugerem que $\alpha>0,90=$ excelente; $\alpha>0,80=$ bom; $\alpha>0,70=$ aceitável; $\alpha>0,60=$ questionável; $\alpha>0,50=$ pobre; $\alpha<0,50=$ inaceitável.

A medida de Kaiser-Meyer-Olkin (KMO) indica a fatorabilidade da matriz. Para Palant (2007) um limite razoável deste índice. Field (2009) recomenda que um índice ótimo de KMO 
está entre 0,8 e 0,9. O teste de esfericidade de Bartlett, que corrobora para a realização da análise fatorial, aceito por Palant (2007) deve ser estatisticamente significante em $p<0,05>$.

$\mathrm{Na}$ análise da matriz de comunalidades, Hair et al (2006) sustenta que as mesmas necessitam exceder a 0,60 para a maior parte das variáveis estudadas, podendo variar entre 0 a 1. Valores próximos de 0 indicam que os fatores comuns não explicam a variância e valores próximos de 1 indicam que todas as variâncias são explicadas pelos fatores comuns.

$\mathrm{Na}$ análise para a identificação dos fatores e posterior seleção, segundo Hair et al (2006), é importante salientar que o critério utilizado dos valores próprios (eingenvalues) deve ter no mínimo um autovalor associado igual a 1. Hair et al (2006) recomenda o mínimo de 3\% de variância explicada por cada fator como sendo aceitável na explicação da variância do construto em análise. A rotação testada entre os fatores de cada dimensão (suporte à aprendizagem e impactos) foi Varimax.

Na Tabela 10 encontram-se sintetizados os indicadores psicométricos de cada um dos 4 fatores identificados agrupados em relação à suporte à aprendizagem, a solução unifatorial obtida para a variável "impacto em amplitude" e as estruturas bi-fatoriais para as medidas de impacto em profundidade.

Tabela 10

Síntese das análises fatoriais

\begin{tabular}{|c|c|c|c|c|c|}
\hline Bloco & Itens & KMO & $\begin{array}{l}\text { Cargas } \\
\text { Fatoriais }\end{array}$ & $\begin{array}{l}\text { Alfa de } \\
\text { Cronbach }\end{array}$ & $\begin{array}{l}\text { Variância } \\
\text { Explicada }\end{array}$ \\
\hline \multirow{4}{*}{$\begin{array}{l}\text { Suporte a } \\
\text { Aprendizagem }\end{array}$} & Local de trabalho -7 & \multirow{4}{*}{0,85} & \multirow{4}{*}{0,41 a 0,81} & 0,82 & \multirow{4}{*}{$54 \%$} \\
\hline & Chefia -5 & & & 0,85 & \\
\hline & Equipe -5 & & & 0,79 & \\
\hline & Falta de suporte - 6 & & & 0,65 & \\
\hline $\begin{array}{l}\text { Impacto em } \\
\text { amplitude }\end{array}$ & Impact - 16 & 0,96 & 0,75 a 0,90 & 0,95 & $66 \%$ \\
\hline $\begin{array}{l}\text { Impacto em } \\
\text { profundidade - }\end{array}$ & Importância - 5 & 0,89 & 0,85 a 0,92 & 0,93 & $78 \%$ \\
\hline
\end{tabular}




\begin{tabular}{|c|c|c|c|c|c|}
\hline Bloco & Itens & KMO & $\begin{array}{l}\text { Cargas } \\
\text { Fatoriais }\end{array}$ & $\begin{array}{l}\text { Alfa de } \\
\text { Cronbach }\end{array}$ & $\begin{array}{l}\text { Variância } \\
\text { Explicada }\end{array}$ \\
\hline $\begin{array}{l}\text { Gestão } \\
\text { Estratégica }\end{array}$ & Contribuição - 5 & 0,87 & 0,80 a 0,91 & 0,92 & $76 \%$ \\
\hline $\begin{array}{l}\text { Impacto em } \\
\text { profundidade - } \\
\text { Gestão de } \\
\text { Equipes }\end{array}$ & Importância - 5 & 0,87 & 0,82 a 0,90 & 0,92 & $76 \%$ \\
\hline $\begin{array}{l}\text { Impacto em } \\
\text { amplitude } \\
\text { sobre }\end{array}$ & Importância - 17 & 0,87 & 0,30 a 0,73 & 0,87 & $32 \%$ \\
\hline $\begin{array}{l}\text { Gerente de } \\
\text { APS }\end{array}$ & Contribuição - 17 & 0,87 & 0,43 a 0,73 & 0,88 & $34 \%$ \\
\hline
\end{tabular}

Tal síntese contida na Tabela 10 será detalhada a seguir, visando maior visibilidade e compreensão de tais informações.

\subsubsection{Análise fatorial de suporte à aprendizagem}

A fatorabilidade da amostra foi testada pelo Indice de Kaiser-Meyer-Olkin e pelo teste de esfericidade de Bartlett, conforme recomendação de Tabachnick e Fidell (2007). Depois disso, os dados foram submetidos a análises dos componentes principais (ACP), a fatoração dos eixos principais (PAF) e a fidedignidade dos fatores foi estimada pelo cálculo dos alfas de Cronbach, via SPSS. A carga fatorial mínima, critério adotado em todos os demais fatores dos demais agrupamentos teóricos, foi $>0,30$.

Observa-se que a medida de Kaiser-Meyer-Olkin é igual a 0,85, um valor satisfatório para a realização da análise fatorial. Além disto, o teste de esfericidade de Bartlett apresentou um p-valor aproximadamente 0 , um valor significativo, que indica a viabilidade da realização da análise fatorial.

Ao analisar a matriz de correlação verificou-se que a correlação média foi igual a 0,18 e o percentual de correlações com valores absolutos maiores que 0,3 é baixo (33\%), indicando 
condições para a fatorabilidade da matriz. A correlação média baixa é devido a existência de correlações negativas a positivas, estas que podem estar se anulando. O ideal seria que esta correlação média fosse superior a 0,5. Analisando a matriz anti-imagem, observa-se que os valores presentes na diagonal desta matriz são valores bem altos, pois há uma grande quantidade de valores acima de 0,8 .

A fim de verificar indicadores de validade da escala de Suporte a Aprendizagem, procedeu-se para a análise dos componentes principais. Mesmo que já existem estudos de validação da escala na literatura, decidiu-se pela análise fatorial exploratória a fim de identificar eventuais problemas na configuração fatorial ou em itens específicos à realidade do INSS.

Quatro componentes foram selecionados e apresentaram eigenvalues acima de um, conforme critério de Kaiser, sendo que o primeiro explicou 16,56\% da variância, o segundo $16,10 \%$, o terceiro $11,45 \%$ e o quarto $9,45 \%$.

Os 4 fatores explicaram $54 \%$ da variância dos itens sobre suporte à aprendizagem. A solução com 4 fatores apresentou sentido teórico e alinhamento com a literatura. O Scree plot pode ser visualizado a seguir na Figura 7.

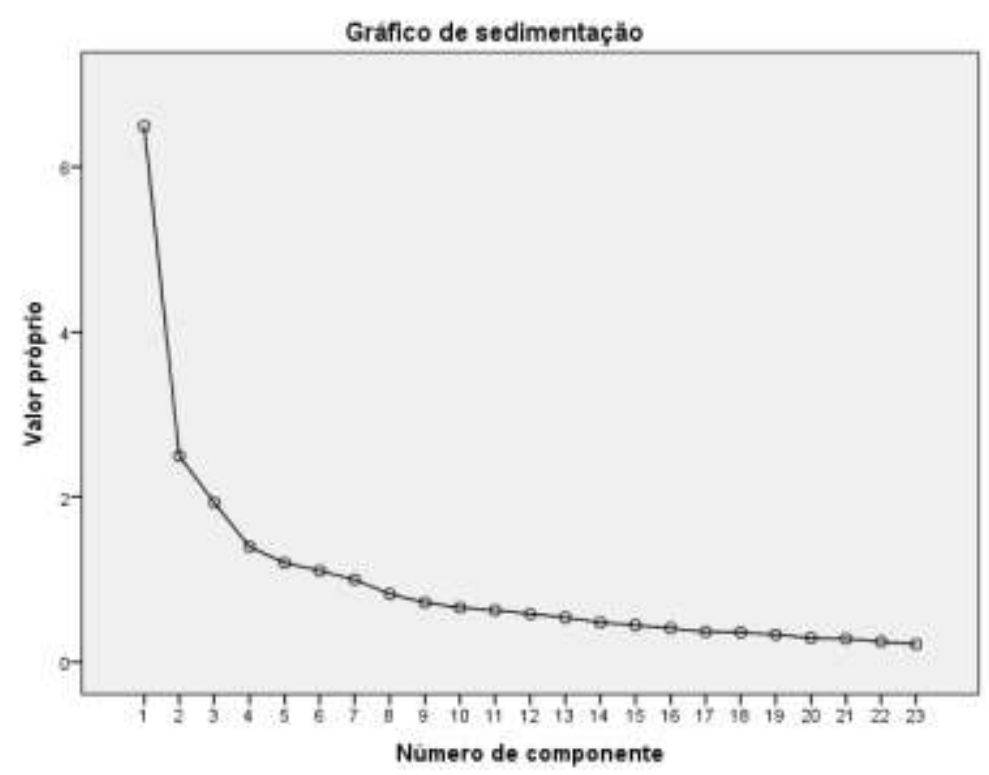

Figura 7. Gráfico de sedimentação do Suporte à Aprendizagem 
A análise da matriz de comunalidade apresenta valores não tão próximos de 0 e nem tão próximos de 1, caracterizando uma solução fatorial satisfatória. A matriz de componentes identificada no bloco de suporte à aprendizagem é formada pelos quatro fatores (1 - Local de Trabalho, 2 - Chefia, 3 - Equipe, 4 - Falta de Suporte) que explicam 54\% da variância já citada, gerando cargas fatoriais entre 0,13 e 0,81 ; cujos resultados se encontram na Tabela 11 .

\section{Tabela 11}

\section{Cargas fatoriais do Bloco de Suporte à Aprendizagem}

\begin{tabular}{llll}
\hline \multirow{2}{*}{ Item de Suporte à Aprendizagem } & \multicolumn{4}{c}{ Fator* } \\
& 1 & 2 & 3
\end{tabular}

1. Há oportunidade para exposição de idéias de cada servidor 0,68

2. Há tempo destinado para a busca de novas formas de executar o trabalho

0,61

3. O excesso de trabalho impede a participação em capacitações

4. Há autonomia para argumentar as demandas do Gestor imediato

$\mathbf{0 , 6 0}$

5. Há troca de informações sobre a aplicação de novos conhecimentos e habilidades

6. Há tolerância a erros quando se tenta aplicar novos conhecimentos e habilidades

7. As tentativas de aplicação de novos conhecimentos e habilidades são ignorados

8. Há incentivos a busca de novas aprendizagens

9. Há recursos materiais, humanos, financeiros e/ou informacionais suficientes para a aplicação de novos conhecimentos e habilidades

10. Estabelece objetivos de trabalho que me motivam a aplicar novos conhecimentos e habilidades

11. Me estimula a aplicar novos conhecimentos e habilidades no ambiente de trabalho

12. Assume comigo os riscos de tentar novas formas de realizar o trabalho

13. Leva em conta minhas ideias quando diferente das dele

14. Inibe o uso das minhas novas habilidades no trabalho

15. Me elogia quando aplico novos conhecimentos e habilidades

16. Ignora as mudanças que eu proponho em função do que aprendi em capacitação 
Item de Suporte à Aprendizagem

Fator*

\section{-}

(1)

12

$\mathbf{0 , 7 1}$

18. Está disponível para tirar minhas dúvidas sobre o uso de novos conhecimentos e habilidades

19. Há espaço para orientação quando existem dificuldades para aplicar novos conhecimentos e habilidades

0,62

20. Há reconhecimento quando aplicadas novas habilidades e conhecimentos

$\mathbf{0 , 6 0}$

21. Há estímulo para busca de novos conhecimentos e habilidades voltados ao $\quad \mathbf{0 , 4 9}$ trabalho

22. Me criticam negativamente quando erro ao aplicar novos conhecimentos e habilidades no trabalho

23. Sentem-se ameaçados quando aplico novos conhecimentos e habilidades no trabalho

Nota 1: * Fator $=1-$ Local de Trabalho, 2 - Chefia, 3 - Equipe, $4-$ Falta de Suporte.

Nota 2: Método de extração: Análise do componente principal.

O primeiro fator estabelecido de "Local de Trabalho" teve um $\alpha$ de 0,82 ; o segundo fator "Chefia" gerou um $\alpha$ de 0,85 , sendo o de maior grau de confiabilidade; o terceiro fator "Equipe" teve um $\alpha$ de 0,79; e o quarto fator "Falta de Suporte" gerou um alfa de Cronbach de 0,65 , sendo considerado este o mais problemático devido o seu valor ser questionável, segundo George e Mallery (2003).

Tabela 12

Análises fatoriais dos 4 fatores - Suporte a Aprendizagem

\begin{tabular}{lcccc}
\hline \multicolumn{1}{c}{ Fator } & Média & Desvio Padrão & Assimetria & Curtose \\
\hline 1 - Local de Trabalho & 6,72 & 1,51 & 0,02 & $-0,72$ \\
$2-$ Chefia & 7,00 & 1,81 & $-0,80$ & 1,18 \\
$3-$ Equipe & 7,77 & 1,54 & $-1,16$ & 1,95 \\
$4-$ Falta de Suporte & 3,42 & 1,60 & 1,00 & 1,20 \\
\hline
\end{tabular}

Tendo os quatro fatores identificados na variável preditora de Suporte à Aprendizagem, segue-se para as análises das variáveis critério estabelecidas para esta pesquisa. 


\subsubsection{Análise fatorial do impacto de treinamento em amplitude}

O bloco de impacto de treinamento em amplitude do questionário ficou composto por 16 itens.

Ao analisar a matriz de correlações verificou-se que a correlação média é igual a 0,61 e o percentual de correlações com valores absolutos maiores que 0,3 é bem alto $(87,5 \%)$, indicando condições de fatorabilidade da matriz. A análise da matriz de correlação só apontou resultados alarmantes para o item 13, "Tive dificuldades em realizar este curso na modalidade de Educação a Distância”, único item que mostrou correlações baixas e não significativas com os demais.

Por outro lado, analisando a matriz anti-imagem, observa-se que os valores presentes na diagonal desta matriz são valores bem altos, sendo o menor valor encontrado igual a 0,75 .

A análise da matriz de comunalidades apresentou valores não tão próximos de 0 e nem tão próximos de 1 , indicando boas condições para a realização da análise fatorial.

Dois componentes apresentaram eigenvalues acima de um, sendo que o primeiro explicou $66,27 \%$ da variância e o segundo mais $6,96 \%$.

O KMO foi igual a 0,96, um valor bastante alto e satisfatório. Além disto, o teste de esfericidade de Bartlett apresentou um p-valor aproximadamente 0.

A configuração fatorial inicial sugeriu um primeiro fator com 15 itens da escala, sendo que o segundo fator seria composto apenas pelo item 13. Considerando que a configuração bifatorial não possuía qualquer embasamento teórico, e que a alocação de apenas um item para um fator prejudicaria características psicométricas da medida, optou-se pela extração de apenas um fator. 
Quando conduzida a análise fatorial com rotação Varimax, observou-se que apenas o item 13 não possuiu carga fatorial acima de 0,30 . Todos os outros itens obtiveram cargas entre 0,75 a 0,90 , conforme Tabela 13 .

\section{Tabela 13}

Cargas fatoriais da solução unifatorial da escala de Impacto de treinamento em amplitude

Item Fator

1 - Impact

As habilidades que aprendi na capacitação fizeram com que eu cometesse menos erros, em meu trabalho, em atividades relacionadas ao conteúdo do treinamento.

$\mathbf{0 , 9 0}$

A qualidade do meu trabalho melhorou nas atividades diretamente relacionadas ao conteúdo da capacitação.

A participação na capacitação serviu para aumentar minha motivação para o trabalho.

Após minha participação na capacitação, tenho sugerido, com mais frequência, mudanças nas rotinas de trabalho.

Utilizo, com frequência, em meu trabalho atual, o que foi ensinado na capacitação.

$\mathrm{O}$ curso realizado tornou-me mais receptivo às mudanças no trabalho.

A participação nessa capacitação aumentou minha autoconfiança. (Agora tenho mais

confiança na minha capacidade de executar meu trabalho com sucesso).

Aproveito as oportunidades que tenho para colocar em prática o que me foi ensinado na capacitação.

Quando aplico o que aprendi na capacitação, executo meu trabalho com maior segurança.

A qualidade do meu trabalho melhorou mesmo naquelas atividades que não pareciam estar relacionadas ao conteúdo da capacitação.

A capacitação que fiz beneficiou minha equipe de trabalho, que aprenderam comigo algumas novas habilidades.

Os testes, exercícios e/ou questões avaliativas a que me submeti durante o curso foram adequados.

Recordo-me bem dos conteúdos ensinados na capacitação.

Consegui estabelecer paralelos (confrontos) entre a teoria e a realidade / prática do conteúdo a que se referia este curso.

Os métodos e técnicas utilizados pelos instrutores / tutores foram adequados nesta capacitação.

Tive dificuldades em realizar este curso na modalidade de Educação a Distância.

Nota: Método de extração: Análise do componente principal.

O índice de confiabilidade da solução unifatorial se mostrou satisfatório, $(\alpha=0,95)$. 


\subsubsection{Análise fatorial do bloco de impacto em profundidade}

O questionário de impacto em profundidade contemplou dois cursos obrigatórios aos gerentes executivos e gerentes de Agência da Previdência Social, tendo 10 itens para cada curso, sendo 5 para aferir a importância e 5 para aferir a contribuição de cada curso no desempenho laboral do gestor. Ressalta-se que estes itens foram elaborados pela Organização em 2010, e estão sendo objeto de validação empírica nesta Dissertação.

Nas análises realizadas verificou-se que a medida de Kaiser-Meyer-Olkin para o curso de gestão estratégica é igual a 0,87 na escala de contribuição e 0,89 na escala de importância. No curso gestão de equipes o KMO correspondeu a 0,89 na escala de contribuição e 0,87 na escala de importância. Estes são valores altos e satisfatórios para a realização da análise fatorial. Além disto, o teste de esfericidade de Bartlett apresentou um p-valor aproximadamente 0 , em todas as escalas dos dois cursos selecionados, sendo um valor significativo.

A análise da matriz de comunalidade apresenta valores não tão próximos de 0 e nem tão próximos de 1, indicando condições para a realização da análise fatorial. A matriz de componentes identificada no bloco de impacto em profundidade para os cursos de gestão estratégica e gestão de equipes é bifatorial e está formada por dois fatores oriundos das escalas de importância e contribuição.

A fim de verificar indicadores de validade da escala de Impacto em Profundidade dos cursos de gestão estratégica e gestão de equipes procedeu-se a análise fatorial, sendo apresentados os resultados nas tabelas 14 e 15. 
Tabela 14

Cargas da solução do bloco de Impacto em Profundidade - Curso de Gestão Estratégica

\begin{tabular}{|lcc|}
\hline Item do Curso de Gestão Estratégica & $\begin{array}{c}\text { Fator da } \\
\text { Escala de } \\
\text { Importância }\end{array}$ & $\begin{array}{c}\text { Fator da } \\
\text { Escala de } \\
\text { Contribuição }\end{array}$ \\
\hline $\begin{array}{l}\text { Relato de que forma ocorre o alinhamento e o desdobramento das estratégias } \\
\text { organizacionais }\end{array}$ & 0,85 & 0,80 \\
$\begin{array}{l}\text { Discuto com a equipe o plano estratégico da Previdência Social } \\
\text { Viabilizo a aplicação de objetivos estratégicos em minha unidade de trabalho }\end{array}$ & 0,87 & 0,89 \\
$\begin{array}{l}\text { Implemento ações vinculadas aos direcionadores estratégicos da Previdência } \\
\text { Social }\end{array}$ & 0,90 & 0,91 \\
Promovo práticas de gestão estratégica em minha unidade de trabalho & 0,87 & 0,90 \\
\hline
\end{tabular}

Nota: Método de extração: Análise do componente principal.

Tabela 15

Cargas da solução do bloco de Impacto em Profundidade - Curso de Gestão de Equipes

\begin{tabular}{|lcc|}
\hline Item do Curso de Gestão de Equipes & $\begin{array}{c}\text { Fator da } \\
\text { Escala de } \\
\text { Importância }\end{array}$ & $\begin{array}{c}\text { Fator da } \\
\text { Escala de } \\
\text { Contribuição }\end{array}$ \\
\hline Causo a melhoria contínua da equipe de trabalho & 0,87 & 0,87 \\
Discuto ações mobilizadoras de desempenho com a equipe de trabalho & 0,89 & 0,89 \\
Organizo as condições ideais para a realização do trabalho em equipe & 0,88 & 0,91 \\
Avalio o desempenho da equipe & 0,90 & 0,92 \\
Estimulo no ambiente de trabalho a formação de novas lideranças & 0,82 & 0,90 \\
\hline
\end{tabular}

Nota: Método de extração: Análise do componente principal.

No curso de gestão estratégica um componente apresentou eingenvalue acima de um na escala de importância, explicando 77,64\%. Na escala de contribuição apresentou 76,15\% da variância, sendo, assim, aceitável, conforme Hair et al (2006).

No curso de gestão de equipes também um componente apresentou eingenvalue acima de um, sendo na escala de importância 76,19\% de variância explicada e nos itens relativos à contribuição 80,28\% de explicação.

No curso de gestão estratégica o índice de confiabilidade da solução na escala de importância, com 5 itens, se mostrou satisfatório, com alfa de Cronbach =0,93. Na escala de contribuição, também com os mesmos 5 itens, o $\alpha$ apresentou índice de 0,92 , mostrando-se 
também satisfatório.

No curso de gestão de equipes, para a escala de importância encontrou-se o alfa de Cronbach de 0,92 e na escala de contribuição, $\alpha=0,94$. Ambos são considerados satisfatórios.

\subsubsection{Análise fatorial do bloco de impacto em amplitude sobre importância do curso e domínio de competências do gerente de Agência da Previdência Social (APS)}

Não foi possível realizar a análise fatorial considerando-se as respostas dadas pelos 30 gerentes executivos em relação à importância percebida pelo curso ao desenvolvimento de competências e o quanto os cursos permitiram o domínio de competências profissionais relacionados ao trabalho. Isto porque não se encontrou variabilidade suficiente (amostra pequena).

No que se refere às respostas emitidas pelos gerentes de APS o bloco de impacto dos dois cursos sobre aquisição e expressão de competências apresentou um total de 34 itens (17 para aferir a importância e 17 para aferir a contribuição de cada competência requerida pelo INSS ao desempenho laboral do gestor).

A análise fatorial foi realizada para verificar a existência de possíveis fatores de segunda ordem nas escalas de importância e contribuição de cada competência.

Por meio da análise fatorial exploratória foram identificados dois fatores empíricos: importância atribuída aos cursos para o desenvolvimento de competências $(\mathrm{KMO}=0,87)$ e o domínio / expertise de competências derivadas das duas capacitações em análise (KMO = $0,87)$.

Estes são valores altos e satisfatórios. Além disto, o teste de esfericidade de Bartlett apresentou um p-valor aproximadamente 0 , em relação aos dois fatores, o que é considerado um valor significativo.

A análise da matriz de comunalidade apresentou valores não tão próximos de 0 e nem 
tão próximos de 1, indicando condições para a realização da análise fatorial. A fim de verificar indicadores de validade da escala de importância e de contribuição, do bloco de impacto em amplitude sobre competências do gerente de APS, procedeu-se à análise fatorial.

Na escala de importância (17 itens, $\alpha=0,87$ ), o fator identificado explicou $32 \%$ da variância. Na escala de contribuição (17 itens, $\alpha=0,88$ ), encontrou-se $34 \%$ da variância.

As cargas fatoriais obtidas estão apresentadas na Tabela 16.

Tabela 16

Cargas da solução unifatorial do bloco de Impacto de treinamento em amplitude sobre Competências do gerente de APS - escalas Importância e Contribuição

\begin{tabular}{lcc}
\hline Item de Competência do Gerente de APS & $\begin{array}{c}\text { Fator da } \\
\text { Escala de } \\
\text { Importância }\end{array}$ & $\begin{array}{c}\text { Fator da } \\
\text { Escala de } \\
\text { Contribuição }\end{array}$ \\
\hline Promover ações para o funcionamento da APS & 0,49 & 0,30 \\
Obter produtividade no trabalho & 0,55 & 0,40 \\
Buscar a qualidade nas decisões & 0,51 & 0,54 \\
Construir equipes de trabalho & 0,55 & 0,57 \\
Promover o desenvolvimento pessoal e profissional da equipe & 0,54 & 0,46 \\
Promover a disseminação e internalização dos valores da instituição & 0,59 & 0,58 \\
Mobilizar equipe para realização do trabalho & 0,46 & 0,61 \\
Avaliar o desempenho da equipe & 0,54 & 0,59 \\
Empenhar-se no auto-desenvolvimento & 0,49 & 0,65 \\
Promover a qualidade de vida no trabalho & 0,53 & 0,70 \\
Gerir talentos e competências & 0,53 & 0,61 \\
Promover a execução do atendimento com qualidade & 0,43 & 0,43 \\
Avaliar o resultado do atendimento & 0,62 & 0,54 \\
Promover ações para otimizar o atendimento & 0,64 & 0,70 \\
Obter informações necessárias a gestão da APS & 0,73 & 0,64 \\
Promover o armazenamento da informação e do conhecimento & 0,68 & 0,69 \\
Empenhar-se na disseminação de informações confiáveis & 0,68 & 0,73 \\
\hline No: & &
\end{tabular}

Nota: Método de extração: Análise do componente principal.

Observa-se que ambas escalas da Tabela 16 tem variações, porém apresentam algumas convergências no fator de importância e de contribuição, destacando-se o item de "promover a disseminação e internalização dos valores da instituição", "promover a execução do atendimento com qualidade" e "promover o armazenamento da informação e do conhecimento". 


\subsection{Modelos empíricos}

Apresentam-se, aqui, os resultados empíricos obtidos com a testagem dos modelos estatísticos de regressão. Como parte das variáveis explicativas se repete ao longo dos distintos modelos empíricos obtidos, optou-se por apresentar a Discussão dos resultados no Capítulo 6, a fim de não tornar exaustivos e repetitivos os argumentos que serão apresentados.

\subsubsection{Variável critério: impacto do treinamento em amplitude}

Com relação a variável critério impacto de treinamento em amplitude o modelo empírico final indicou que apenas Suporte à Aprendizagem do Local de Trabalho $(\beta=0,41)$ e da Chefia $(\beta=0,17)$ predisseram significativamente Impacto medido em Amplitude. Tal constatação vem ao encontro do que aponta Coelho Jr., Abbad, \& Todeschini (2005), onde a variável de suporte é, de fato, a que mais explica o impacto do treinamento. A Tabela 17 apresenta as informações.

Tabela 17

Resultados regressão múltipla impacto de treinamento em amplitude

\begin{tabular}{ccccc} 
Modelo & $\begin{array}{c}\text { Coeficientes não } \\
\text { padronizados }\end{array}$ & $\begin{array}{c}\text { Coeficientes } \\
\text { padronizados }\end{array}$ & $\mathbf{R}$ \\
\cline { 2 - 4 } & B & Modelo padrão & Beta & quadrado
\end{tabular}

1

(Constante) 2,59

2,59

0,43

$p<0,000$

Suporte Aprendizagem - Fator

Local de Trabalho

0,61

0,06

0,50

0,25

$p<0,000$

(Constante)

2
Local de Trabalho

Suporte Aprendizagem - Fator Chefia
2,12

0,51

0,46

0,07

0,17

0,06
0,17

$p<0,000$

$p<0,000$

0,41

0,27 
Utilizou-se do método de inserção dos fatores por etapas, tendo por critério os valores de $\mathrm{F}<0,05$. Na Tabela 17 é apresentado tal ocorrência, onde o primeiro preditor a ser inserido foi o Suporte à Aprendizagem no Local de Trabalho, com $\mathrm{R}^{2}=0,25, \mathrm{~B}=0,61, \beta=0,50, \mathrm{p}<$ 0,001. A seguir, foi inserido o preditor de Suporte à Aprendizagem da Chefia, obtendo-se uma alteração de $\mathrm{R}$ significativa, $\Delta \mathrm{R}^{2}=0,02, \mathrm{p}<0,005$.

\subsubsection{Componentes da regressão linear de impacto de treinamento em profundidade quanto importância do curso e domínio de competências desenvolvidas}

Impacto de treinamento em profundidade foi analisado considerando os dois cursos presentemente investigados (gestão estratégica e gestão de equipes). Este impacto foi analisado, aqui, em termos da importância e a contribuição de cada um dos dois cursos para o desenvolvimento de competências e posterior desempenho do gestor. O método de inserção de cada uma das variáveis antecedentes também foi por etapas (como anteriormente em 5.2.1), utilizando como critério de permanência no modelo os valores de $\mathrm{F}<0,05$.

\subsubsection{Modelo empírico para impacto de treinamento em profundidade (curso de Gestão Estratégica - escala de importância)}

O primeiro preditor inserido, conforme recomendação da literatura, por ser o mais importante preditor do domínio de competências laborais, foi o suporte da chefia $\left(R^{2}=0,13, B\right.$ $=0,13, \beta=0,36, p<0,001)$. Nenhuma das demais variáveis pesquisadas explicou esta variável critério. O modelo final indicou que apenas suporte à aprendizagem da chefia era capaz de predizer significativamente o impacto em profundidade no curso de gestão estratégica em termos de sua importância para o desenvolvimento de competências profissionais orientadas ao desempenho laboral do gestor. A Tabela 18 sintetiza as 
informações obtidas.

Tabela 18

Resultados Regressão Múltipla Impacto de treinamento em profundidade (curso Gestão Estratégica, importância do curso à aquisição e domínio de competências profissionais do gestor)

\begin{tabular}{|c|c|c|c|c|c|c|}
\hline & \multirow[t]{2}{*}{ Modelo } & \multicolumn{2}{|c|}{$\begin{array}{c}\text { Coeficientes não } \\
\text { padronizados }\end{array}$} & \multirow{2}{*}{$\begin{array}{c}\text { Coeficientes } \\
\text { padronizados }\end{array}$} & \multirow[t]{2}{*}{$\begin{array}{c}\mathbf{R} \\
\text { quadrado }\end{array}$} & \multirow[t]{2}{*}{ Sig. } \\
\hline & & B & Modelo padrão & & & \\
\hline \multirow[t]{2}{*}{1} & (Constante) & 2,20 & 0,15 & & & $\mathrm{p}<0,000$ \\
\hline & Suporte Aprendizagem - Fator Chefia & 0,13 & 0,02 & 0,36 & 0,13 & $\mathrm{p}<0,000$ \\
\hline
\end{tabular}

O curso de gestão estratégica foi realizado por gerentes executivos e gerentes de APS, demonstrando a importância que o fator de suporte da Chefia influencia na aquisição e domínio de competências profissionais para ambas das funções comissionadas.

\subsubsection{Modelo empírico para o impacto de treinamento em profundidade (curso de Gestão Estratégica, escala de contribuição)}

O primeiro preditor a ser inserido nesta regressão foi o suporte à aprendizagem da chefia $\left(R^{2}=0,14, B=0,14, \beta=0,37, p<0,001\right)$. A seguir, foram inseridas novas variáveis. Além do suporte da chefia, apenas "falta de suporte" contribuiu significativamente para o modelo. Desta forma, o modelo final indicou que o suporte à aprendizagem da chefia e a falta de suporte predisseram significativamente o impacto em profundidade no curso de gestão estratégica, em termos da sua contribuição percebida à aquisição e domínio de competências profissionais orientadas ao desempenho laboral do gestor. A Tabela 19 sintetiza estas informações. 
Tabela 19

Resultados Regressão Múltipla Impacto de treinamento em profundidade (curso Gestão Estratégica, contribuição percebida do curso à aquisição e domínio de competências profissionais do gestor)

\begin{tabular}{|c|c|c|c|c|c|c|}
\hline & \multirow[t]{2}{*}{ Modelo } & \multicolumn{2}{|c|}{$\begin{array}{c}\text { Coeficientes não } \\
\text { padronizados }\end{array}$} & \multirow{2}{*}{$\begin{array}{c}\begin{array}{c}\text { Coeficientes } \\
\text { padronizados }\end{array} \\
\text { Beta } \\
\end{array}$} & \multirow{2}{*}{$\begin{array}{c}\text { R } \\
\text { quadrado }\end{array}$} & \multirow[t]{2}{*}{ Sig. } \\
\hline & & B & Modelo padrão & & & \\
\hline \multirow[t]{2}{*}{1} & (Constante) & 2,06 & 0,15 & & & $\mathrm{p}<0,001$ \\
\hline & Suporte Aprendizagem - Fator Chefia & 0,14 & 0,02 & 0,37 & 0,14 & $\mathrm{p}<0,001$ \\
\hline \multirow{3}{*}{2} & (Constante) & 1,75 & 0,17 & & & $\mathrm{p}<0,001$ \\
\hline & Suporte Aprendizagem - Fator Chefia & 0,15 & 0,02 & 0,39 & & $\mathrm{p}<0,001$ \\
\hline & $\begin{array}{l}\text { Suporte Aprendizagem - Fator Falta de } \\
\text { Suporte }\end{array}$ & 0,08 & 0,02 & 0,18 & 0,17 & $\mathrm{p}<0,001$ \\
\hline
\end{tabular}

No quesito de contribuição do curso de gestão estratégica para a aquisição e domínio de competências, os gestores apontam para dois fatores de suporte que podem ser inibidores para sua aprendizagem, sendo a Chefia e a Falta de Suporte. Os participantes parecem discernir a importância do papel atribuído à chefia no provimento de suporte ao mesmo tempo que percebem haver falta de suporte por parte de outros componentes da estrutura organizacional (falta de suporte material, por exemplo). Pesquisas qualitativas são recomendadas no sentido de identificar-se quais são estes fatores de contexto e organizacionais que podem estar sendo percebidos como restritivos ao desempenho dos colaboradores.

\subsubsection{Modelo empírico para o impacto de treinamento em profundidade (curso de Gestão de Equipes - escala de importância)}

O único preditor identificado para esta variável critério foi o suporte à aprendizagem percebido no local de trabalho. Os resultados encontram-se dispostos na Tabela 20. 
Tabela 20

Resultados Regressão Múltipla Impacto de treinamento em profundidade (curso Gestão de Equipes, importância percebida do curso à aquisição e domínio de competências profissionais do gestor)

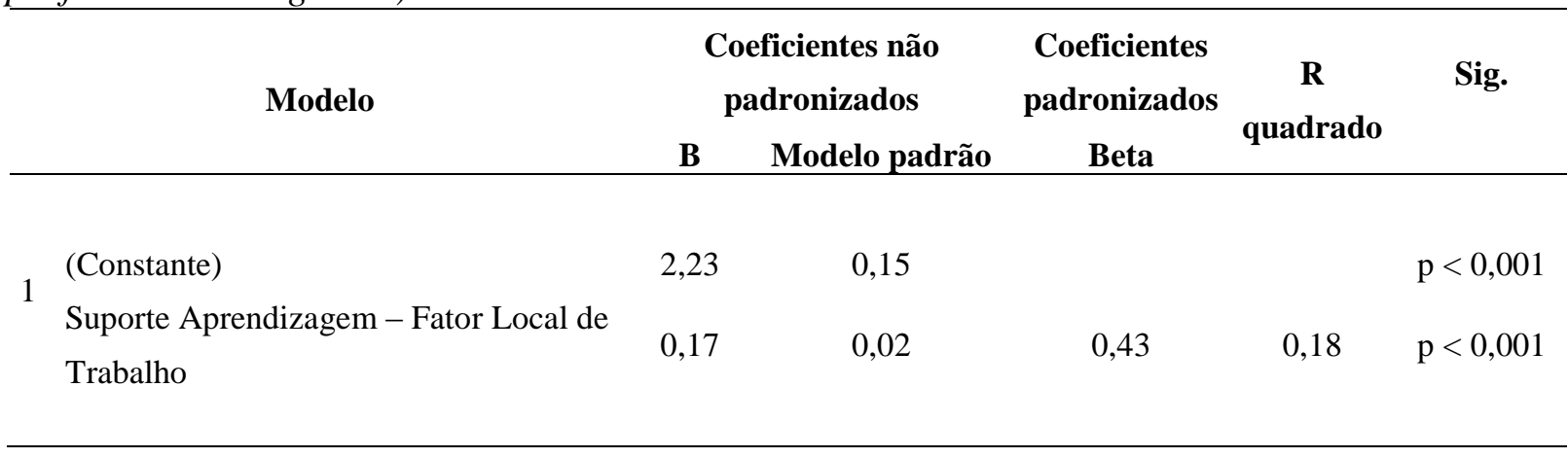

Neste curso de Gestão de Equipes denota-se que o fator local de trabalho tem considerável representatividade, divergindo do outro curso analisado de Gestão Estratégica que apontou para o fator de Chefia. Tal situação demonstra que de acordo com o tema e os objetivos do curso a percepção dos participantes pode ser modificada.

5.2.2.4 Modelo empírico para impacto de treinamento em profundidade (curso de Gestão de Equipes, escala de contribuição)

O único preditor que contribuiu de maneira estatisticamente significativa nesta regressão foi suporte à aprendizagem percebido no local de trabalho $\left(R^{2}=0,19, B=0,19, \beta=\right.$ $0,43, p<0,001)$. A Tabela 21 sintetiza as informações.

Tabela 21

Resultados Regressão Múltipla Impacto de treinamento em profundidade (curso Gestão de Equipes, contribuição percebida do curso à aquisição e domínio de competências profissionais do gestor)

\begin{tabular}{llcccc}
\hline \multirow{2}{*}{ Modelo } & \multicolumn{2}{c}{$\begin{array}{c}\text { Coeficientes não } \\
\text { padronizados }\end{array}$} & $\begin{array}{c}\text { Coeficientes } \\
\text { padronizados }\end{array}$ & $\begin{array}{c}\text { R } \\
\text { quadrado }\end{array}$ & Sig. \\
\cline { 2 - 5 } & B & Modelo padrão & Beta & \\
\hline $\begin{array}{l}\text { (Constante) } \\
\begin{array}{l}\text { Suporte Aprendizagem - Fator Local de } \\
\text { Trabalho }\end{array}\end{array}$ & 2,02 & 0,16 & & & $\mathrm{p}<0,001$ \\
& 0,19 & 0,02 & 0,43 & 0,19 & $\mathrm{p}<0,001$ \\
\hline
\end{tabular}


Semelhante ao resultado obtido na escala de importância - Tabela 20, a escala de contribuição também apresenta o fator Local de Trabalho como relevante para aquisição e domínio de competências. Apenas tem resultados diferentes quando comparado com o curso de Gestão Estratégica, que apresentou os fatores de Chefia e Falta de Suporte como sendo relevantes na escala de contribuição.

5.2.2.5 Modelo final de impacto de treinamento em amplitude sobre competências (escala de importância)

O único preditor foi de suporte à aprendizagem percebido no local de trabalho $\left(R^{2}=\right.$ $0,13, B=0,07, \beta=0,36, p<0,001)$. A Tabela 22 apresenta as informações sobre este modelo empírico.

Tabela 22

Resultados regressão múltipla impacto do treinamento em amplitude sobre competência do gerente de APS, importância percebida do curso à aquisição e domínio de competências profissionais do gestor

\begin{tabular}{lccccc}
\hline \multicolumn{1}{c}{ Modelo } & \multicolumn{2}{c}{$\begin{array}{c}\text { Coeficientes não } \\
\text { padronizados } \\
\text { Bodelo padrão }\end{array}$} & $\begin{array}{c}\text { Coeficientes } \\
\text { padronizados } \\
\text { Beta }\end{array}$ & $\begin{array}{c}\mathrm{R} \\
\text { quadrado }\end{array}$ & Sig. \\
\hline $\begin{array}{l}\text { (Constante) } \\
\begin{array}{l}\text { Suporte Aprendizagem - Fator Local de } \\
\text { Trabalho }\end{array}\end{array}$ & 3,11 & 0,07 & & & $\mathrm{p}<0,001$ \\
\hline
\end{tabular}

Ao observar as competências requeridas ao gerente de APS e os cursos obrigatórios que os mesmos participam, evidencia-se a importância do fator local de trabalho para a efetividade de tais ações de capacitação, não havendo representatividade dos demais fatores do suporte à aprendizagem neste quesito e aqui estabelecidos nesta pesquisa, a saber: suporte da chefia, suporte da equipe e falta de suporte. 
5.2.2.6 Modelo final de impacto de treinamento em amplitude sobre competências (escala de contribuição)

Também neste modelo, assim como o modelo anterior, o único preditor estatisticamente significativo obtido foi suporte à aprendizagem percebido no local de trabalho $\left(R^{2}=0,28, B=\right.$ $0,15, \beta=0,53, p<0,001)$. A Tabela 23 sintetiza as informações.

\section{Tabela 23}

Resultados regressão múltipla impacto do treinamento em amplitude sobre competências do gerente de APS, contribuição percebida do curso à aquisição e domínio de competências profissionais do gestor

\begin{tabular}{lccccc}
\hline \multicolumn{1}{c}{ Modelo } & $\begin{array}{c}\text { Coeficientes não } \\
\text { padronizados } \\
\text { Modelo padrão }\end{array}$ & $\begin{array}{c}\text { Coeficientes } \\
\text { padronizados } \\
\text { Beta }\end{array}$ & $\begin{array}{c}\text { R } \\
\text { quadrado }\end{array}$ & Sig. \\
\hline & 2,26 & 0,10 & & & \\
\hline $\begin{array}{l}\text { B Constante) } \\
\begin{array}{l}\text { Suporte Aprendizagem - Fator Local de } \\
\text { Trabalho }\end{array}\end{array}$ & 0,15 & 0,01 & 0,53 & 0,28 & $\mathrm{p}<0,001$ \\
\hline
\end{tabular}

O fator local de trabalho também esteve presente nos resultados do impacto em profundidade do curso de Gestão de Equipes, podendo ser assim um componente facilitador ou inibidor de aprendizagem e desempenho organizacional.

Em síntese, após a apresentação dos resultados empíricos tanto concernentes à evidência de validade do questionário utilizado e suas dimensões teóricas, bem como os modelos de regressão estatística, procedeu-se a análise do padrão de respostas entre os 291 respondentes, considerando-se a Unidade de lotação dos mesmos. Basicamente, procedeu-se à realização de ANOVA considerando-se como parâmetro duas funções: função comissionada de gerente executivo e função de gerente de APS. 


\subsection{Resultados do teste ANOVA}

A fim de analisar a possível influência de fatores contextuais sobre o padrão de respostas dadas pelos respondentes, optou-se por realizar a ANOVA. Primeiramente foram comparadas as médias das respostas dos itens de impacto de treinamento em amplitude entre os grupos de gerentes executivos e gerentes de APS. A amostra total continha 30 gerentes executivos e 261 gerentes de APS. Apesar de existir uma acentuada diferença no tamanho dos grupos, não foram observados resultados estatisticamente significativos para o teste de Levene, o que permite concluir que as variâncias entre os grupos foram homogêneas. A comparação de médias por meio da ANOVA mostrou um resultado não significativo, $F$ (1, 289) $=0,16, p=0,69$, o que permite concluir que gerentes de APS e gerentes executivos não diferiram quanto a avaliações emitidas relativas a impacto em amplitude.

Ao comparar os dois tipos de função em relação às avaliações de contribuição e importância do curso de Gestão Estratégica, foi identificado que gerentes de APS e gerentes executivos diferiram quanto a avaliações de importância do curso de gestão estratégica $(F(1$, 289) $=7,12, p=0,01$ ), e quanto às avaliações de contribuição do curso de gestão estratégica, $(F(1,289)=6,43, p=0,01)$.

A média de avaliações de gerentes de APS para importância do curso de gestão estratégica no desenvolvimento de suas competências foram menores $(M=3,10, D P=0,67$, Bca IC 95\% $[3,02 ; 3,18])$ do que em relação às avaliações dos gerentes executivos $(M=3,44$, $D P=0,61$, Bca IC $95 \%[3,22 ; 3,65])$.

A média de avaliações de contribuição de gerentes de APS também foi menor $(M=$ $3,02, D P=0,68$, Bca IC 95\% $[2,93 ; 3,10])$, do que em relação às médias de avaliações dos gerentes executivos $(M=3,35, D P=0,62$, Bca IC 95\% [3,10; 3,56]). As médias encontradas estão expostas na Figura 8. 


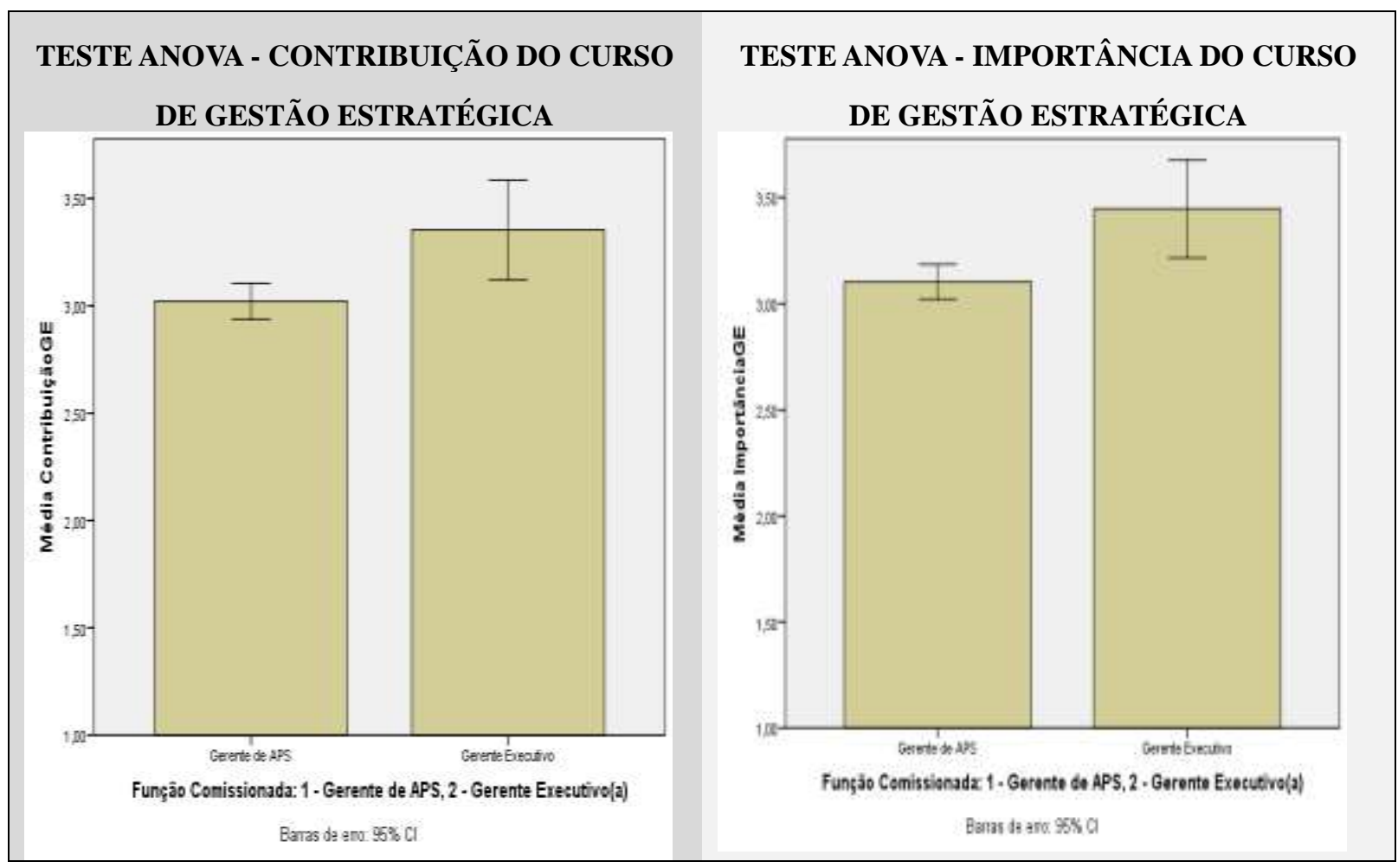

Figura 8. Gráfico comparativo de médias entre gerentes executivos e gerentes de APS quanto avaliações de contribuição e importância do curso de Gestão Estratégica.

Não foram identificadas diferenças significativas entre gerentes de APS e gerentes executivos quanto às avaliações de contribuição e importância do curso de Gestão de Equipes. Este resultado sinaliza homogeneidade nas percepções.

O próximo Capítulo apresenta a discussão dos achados empíricos aqui relatados. 


\section{Discussão dos Resultados}

Os modelos empíricos obtidos nesta Dissertação vão ao encontro da literatura científica sobre TD\&E ao demonstrarem a importância do suporte psicossocial à aprendizagem na predição de impacto de treinamento no trabalho (Alfandi, 2016; Galanou \& Priporas, 2009).

Nenhuma das variáveis pessoais e profissionais contribuíram de forma significativa aos modelos empíricos. Este resultado é curioso, mas vai ao encontro de Abbad e Carvalho (2006) e Yotamo (2014), que também não identificaram efeitos de variáveis desta natureza (gênero, faixa etária, grau de escolaridade e experiência na função pública) de forma significativa na predição de impacto.

Os indicadores psicométricos obtidos nas medidas presentemente discutidas apresentaram-se satisfatórios e assemelham-se com as medidas originais (como em Coelho Jr., 2004 e Pilati \& Abbad, 2005). Os dados sustentam evidências de validade interna nas medidas utilizadas.

O ambiente laboral é de suma importância ao impacto das ações de capacitação, e precisam já ser considerados na avaliação das necessidades de aprendizagem (Yotamo, 2014). Galanou e Priporas (2009) também identificaram que as capacitações contribuíram para aumento da produtividade, e que o nível de satisfação da equipe foi aumentado pelo treinamentoavaliado pelos autores. O impacto de treinamento no trabalho gera, de fato, contribuições efetivas à aquisição e domínio de competências profissionais de gestores (D’Netto, Bakas, Bordia, 2008).

Capacitações a distância são capazes de gerar impacto sobre o desempenho (Vargas, 2003). Segundo Joia e Costa (2007) é importante salientar que não existe um modelo ou uma fórmula única para garantir o sucesso dos programas de treinamento corporativos a distância. Cada empresa e cada programa de treinamento são únicos, com características específicas que devem ser observadas, para que seja possível adotar as estratégias corretas e atingir os 
objetivos desejados. Zerbini e Abbad (2010) afirmam que é preciso desenvolver uma cultura de avaliação dos efeitos destes cursos, visando ao aprimoramento do planejamento instrucional utilizado. Além disso, segundo tais autoras, a melhoria de cursos à distância pode estimular planejadores instrucionais a elaborarem objetivos de aprendizagem mais complexos e delinearem estratégias de ensino e avaliações de aprendizagem mais compatíveis com os mesmos.

A atuação gerencial deve ser capaz de prover e incentivar a aprendizagem (Coelho Jr. \& Mourão, 2011). A busca da mudança deve ser constante, com o propósito de desenvolver os indivíduos para que possam atuar ativamente nas suas rotinas laborais.

O suporte à aprendizagem é imprescindível, neste contexto, posto que os indivíduos podem ser os agentes provedores ou receptores do apoio de colegas e chefias. Ao encontro de Coelho Junior e Borges-Andrade (2011), identificou-se, aqui, que o suporte à aprendizagem prediz impacto, e este é capaz de influenciar no desenvolvimento de competências profissionais.

Merece destaque a variável preditora "falta de suporte à aprendizagem". Zerbini e Abbad (2005) sustentam que o papel da organização nesse caso seria o de oferecer apoio aos indivíduos e/ou cursos que promovam o desenvolvimento de estratégias de enfrentamento para essas situações.

Segundo Abbad e Borges - Andrade (2014), Balarin et al (2014) e Coelho Junior et. al. (2005), o suporte à aprendizagem provido no ambiente/local de trabalho usualmente refere-se às oportunidades para exposição de ideias de cada servidor; o tempo destinado para a busca de novas formas de executar o trabalho; a autonomia para argumentar sobre demandas da chefia; a tolerância a erros quando se tenta aplicar novos conhecimentos e habilidades; o incentivo a busca de novas aprendizagens; e a existência de recursos materiais, humanos, financeiros e/ou informacionais suficientes para a aplicação de novos conhecimentos e habilidades. As razões desta falta de suporte precisam ser compreendidas qualitativamente no âmbito do INSS. 
D’Netto, Bakas e Bordia (2008) também encontraram relações preditivas entre suporte do gerente de linha e oportunidade de usar, de forma efetiva, as ações de desenvolvimento gerencial. O suporte do alto nível gerencial apareceu como forte preditor da ligação com a estratégia, sendo esta última a melhor variável preditora da efetividade do desenvolvimento gerencial.

Em síntese, os resultados sugerem a necessidade de se investir maciçamente em ações gerenciais de provimento de suporte à aprendizagem, pois este é capaz de predizer impacto e influenciar o domínio de competências profissionais. Percebendo o ambiente organizacional como suportivo os trabalhadores conseguirão aplicar, em suas rotinas, as competências adquiridas em situação de treinamento.

É oportuno destacar que tal pesquisa foi realizada com gestores do INSS e para tanto tais resultados merecem uma reflexão em maior profundidade nesta autarquia, visando tornar a natureza da pesquisa téorica - empírica mais aplicável e útil ao público alvo selecionado e responsável por tais ações de capacitação. Deste modo será disponibilizado tal conteúdo na tentativa de gerar melhorias no processo educacional desta organização, podendo se implementar novas formas de avaliação somativa, mesmo se considerando que as avaliações respondidas nesta pesquisa tiveram resultados sempre positivos e favoráveis frente aos cursos obrigatórios selecionados. 


\section{Considerações Finais}

O objetivo geral desta Dissertação consistiu em verificar a influência do suporte à aprendizagem e dos treinamentos gerenciais ofertados a gestores do INSS sobre a aquisição e expressão de competências profissionais requeridas para o desempenho de suas funções. Como objetivos específicos, estabeleceu-se buscar evidências de validade interna e de construto das medidas relativas à suporte psicossocial à aprendizagem, impacto de treinamento em amplitude e em profundidade concernente à importância e efeitos do treinamento sobre a aquisição e expressão de competências gerenciais e, por fim, testar relações preditivas entre estas variáveis no âmbito de gestores do INSS.

Acredita-se que os objetivos foram plenamente atingidos. Identificaram-se evidências de validade interna nas medidas testadas, que apresentaram bons indicadores psicométricos. Também, identificou-se, empiricamente, que o suporte psicossocial provido à aprendizagem foi importante preditor às variáveis critério aqui testadas.

Destaca-se que foram utilizadas apenas medidas de autoavaliação, não havendo medidas de heteroavaliação. O uso de medidas de auto-relato pode ter sofrido a influência de vieses, especialmente leniência. Para se tentar evitar isto recomenda-se o uso de medidas de heteroavaliações (entre pares e chefia) como agenda de pesquisa.

O número de participantes $(\mathrm{N}=291)$ contemplou funcionários lotados no País inteiro pertencentes a duas funções distintas: gerentes executivos e gerentes de APS. De forma isolada, os gerentes executivos tiveram $29 \%$ de taxa de resposta, os gerentes de APS, $17 \%$. Uma possível justificativa para a baixa taxa de resposta pode ser a complexidade dos itens (mesmo após terem sido realizados os procedimentos de validação semântica) e a quantidade de itens do questionário utilizado. Mesmo assim, foi alcançado um número amostral satisfatório para as análises estatísticas aqui utilizadas. 
Os instrumentos de impactos em amplitude e em profundidade (importância e contribuição), bem como o instrumento de suporte à aprendizagem tiveram satisfatórias evidências de validade interna. Registre-se que os participantes manifestaram, no geral, percepções favoráveis em relação a todos os itens medidos, indicando que estes dois cursos (que são obrigatórios aos gerentes) parecem estar sendo adequados à sua clientela. Tais cursos parecem ser percebidos pelos egressos como úteis para o desempenho de suas tarefas gerenciais.

Os casos omissos inexistiram nesta pesquisa devido às configurações de coleta de dados adotadas no mesmo. O participante tinha de responder obrigatoriamente todos os itens para seguir adiante, sendo, ainda, opcional, apenas os campos de comentários. Além disso, só era possível o envio do instrumento com o seu preenchimento integral.

\subsection{Contribuições}

Talvez a maior contribuição deste estudo seja a identificação de três variáveis relativas a impacto de treinamento capazes de predizer significativamente a importância e a contribuição efetividade do treinamento no ambiente de trabalho. O impacto das duas capacitações analisadas a partir da importância destas capacitações à aquisição de competências profissionais de gestão e ao quanto tais capacitações propiciaram o domínio destas competências pode ser considerado a principal contribuição teórica.

A presente pesquisa também possibilitou a ampliação e diversificação de amostras nas investigações de impacto de treinamento nas organizações, contribuindo assim para aumentar a generalização dos resultados de pesquisas nacionais de TD\&E, conforme recomendam Coelho Junior e Abbad (2010). Outra contribuição refere-se aos índices de evidências de validade dos instrumentos de impacto do treinamento em amplitude e em profundidade para o contexto do INSS, conforme resultados e discussões aqui apresentadas. 
Outra contribuição não menos relevante é a amplitude da pesquisa realizada, envolvendo um público alvo distribuído em todas as unidades federativas do Brasil - tanto nas capitais como em municípios do interior, que foram convidados a participar da pesquisa. Pesquisas como a desenvolvida aqui nesta Dissertação, por meio de survey ainda não tinha sido até então realizada nestes moldes junto a autarquia pesquisada. Ressalta-se que, com esta pesquisa, já se percebem expectativas gerenciais em torno do planejamento e oferta de novas ações de capacitação no INSS.

Contribuições gerenciais também podem ser consideradas, especialmente quando se constata a necessidade de se desenvolver continuamente o ambiente de apoio e suporte psicossocial à aprendizagem.

\subsection{Limitações}

Uma limitação identificada, refere-se ao uso da estratégia de autoavaliação que, conforme já mencionado anteriormente, pode ter enviesado os resultados.

Outra limitação foi a disponibilização de um questionário bastante extenso para ser respondido pelo público gestor, cujo tempo disponível é concorrido no ambiente de trabalho. Pode ser que a amplitude do instrumento de pesquisa tenha gerado, por consequência, uma baixa participação na pesquisa, apesar das tentativas de sensibilização por correio eletrônico, telefonemas e divulgação junto aos gestores superiores.

No questionário disponibilizado houveram blocos com escalas do tipo Lickert com ponderações de 1 a 10 nos casos de impacto em amplitude e suporte a aprendizagem, sendo que nos blocos de impacto em profundidade e impacto em amplitude sobre competências houveram ponderações de 1 a 4, sendo recomendável a utilização de escalas com ponderações idênticas em todos os blocos, apesar de tais ocorrências não terem prejudicado as análises e resultados obtidos. 
O intervalo de tempo da conclusão dos treinamentos avaliados e da realização desta pesquisa também foi variado e bastante disperso (em média, dez meses). A falta de informações sobre cada turma (proporção de desistentes e evadidos por turma, por exemplo), o que poderia ter enriquecido na análise dos resultados (perfil de clientela e falta de informações sobre o levantamento das necessidades de capacitação, por exemplo) foi outra limitação verificada. As expectativas perante o treinamento, especialmente quanto ao seu potencial de aplicação ainda em fase pré-evento instrucional, também poderiam ter sido mensuradas. A mesma medida poderia ter sido aplicada pós - treinamento, e poderia ter sido verificado se as expectativas modificaram-se em virtude das ações instrucionais.

\subsection{Agenda de pesquisa}

De acordo com os resultados apresentados e discutidos, propõe-se a seguinte agenda de pesquisa para futuros estudos:

- Identificar fatores de contexto percebidos como de falta de suporte, especialmente se há alguma restrição à autonomia pela busca de novas aprendizagens informais ou alguma outra restrição ao impacto das ações de capacitação;

- Adotar-se abordagem de pesquisa mista, por meio de triangulação metodológica, evitando-se apenas a abordagem quantitativa para se investigar efeitos do impacto de treinamento sobre a aquisição e domínio de competências gerenciais (entrevistas em profundidade com esta clientela são amplamente recomendadas);

- Relacionar características do trabalho (job design) com a avaliação das necessidades de aprendizagem, especialmente em termos do alinhamento do perfil esperado do cargo de gestor em relação ao perfil real apresentado por eles;

- Buscar evidências de validade externa às medidas presentemente testadas, garantindo a melhoria contínua de sua precisão, generalidade e calibragem; 
- Investigar ações de aprendizagem informal, no ambiente laboral, que possam ter auxiliado na aquisição de competências gerenciais, em termos da identificação das estratégias de aprendizagem (especialmente busca de ajuda interpessoal); e

- Proceder à re-aplicação do instrumento construído e validado neste estudo em outras organizações que desenvolvam cursos de capacitação e metodologias instrucionais afins aos cursos presentemente avaliados, utilizando diferentes variáveis critério (por exemplo, desempenho de equipes ou desempenho organizacional, tentando-se verificar valor final das atividades de capacitação). 


\section{Referências}

Abbad, G. (1999). Um Modelo Integrado de Avaliação do Impacto do Treinamento no Trabalho - IMPACT (Tese de Doutorado, Universidade de Brasília, Brasília, Brasil).

Abbad, G. S. (2014). Necessidades e impactos de treinamento e programas educacionais no trabalho e nas organizações [Projeto de pesquisa apresentado ao CNPQ para renovação de bolsa de pesquisa]. Brasília, DF, Brasil.

Abbad, G., Pilati, R., \& Pantoja, M. J. (2003). Avaliação de treinamento: análise da literatura e agenda de pesquisa. Revista Administração, 38(3), 205-218.

Abbad, G. S. (2007). Educação à distância: o estado da arte e o futuro necessário. Revista do Serviço Público, 58, 100-110.

Abbad, G. S., \& Borges-Andrade, J. E. (2014). Aprendizagem humana em organizações e trabalho. Em: Zanelli, J. C., Borges-Andrade, J. E., \& Bastos, A. V. B. (Orgs.). Psicologia, Organizações e Trabalho no Brasil, (pp. 244-284). Porto Alegre: Artmed.

Abbad, G. S., \& Carvalho, R. S. (2006). Avaliação de treinamento a distância: reação, suporte, transferências e impactos no trabalho. Revista de Administração Contemporânea, 10(1), 95-116.

Abbad, G. S., Carvalho, R. S., \& Zerbini, T. (2006). Evasão em curso via internet: explorando variáveis explicativas. Revista de Administração de Empresas Eletrônica, 5(2).

Abbad, G. S., Coelho Jr., F. A., Freitas, I. A., \& Pilati, R. (2006). Medidas de suporte em avaliação de TD\&E. Em: Borges-Andrade, J. E., Abbad, G., Mourão, L., \& Colaboradores (Orgs.). Treinamento, Desenvolvimento e Educação em Organizações e Trabalho: fundamentos para a gestão de pessoas, (pp. 395-421). Porto Alegre: Artmed.

Abbad, G. S., Zerbini, T., Souza, D. B. L. (2010). Panorama das pesquisas em educação a distância no Brasil. Estudos de Psicologia, 15(3), 291-298. 
Abbad, G., et al. (2012). Impacto do treinamento no trabalho - medida em amplitude. Em: Abbad, G., et al (Orgs.). Medidas de Avaliação em Treinamento, Desenvolvimento e Educação, (pp. 145-162). Porto Alegre: Artmed.

Abbad, G. S., et al. (2012). Suporte à transferência de treinamento e suporte à aprendizagem. Em: Abbad, G., et al (Orgs.). Medidas de Avaliação em Treinamento, Desenvolvimento e Educação, (pp. 244-263). Porto Alegre: Artmed.

Abbad, G. S., et al. (2013). Aprendizagem em organizações e no trabalho. In: BORGES, L. O.; MOURÃO, L. (Org.). O trabalho e as organizações: atuações a partir da psicologia, (pp. 467-527). Porto Alegre: Artmed.

Aguinis, H, \& Kraiger, K. (2009). Benefits of training and development for individuals and teams, organizations, and society. Annual Review of Psychology, 60, 451-474.

Alfandi, A. M. (2016). Training Impact on the Performance of Employees "A Case of Jordanian Travel and Tourism Institutions". International Business Management, 10, 377-384.

Alliger, G. M., \& Janak, E. A. (1989). Kirpatrick’s levels of training criteria: thirty years later. Personal Psychology,42, 331-342.

Balarin, C. S., Zerbini, T., Martins, L. B. (2014). A relação entre suporte à aprendizagem e impacto de treinamento no trabalho. Revista Eletrônica de Administração, 20(2).

Bastos, A. V. B. (2006). Trabalho e qualificação: questões conceituais e desafios postos pelo cenário de reestruturação produtiva. Treinamento, Desenvolvimento e Educação em Organizações e Trabalho: fundamentos para a gestão de pessoas, (pp. 23-40). Porto Alegre: Artmed.

Bitencourt, C. C. (2004). A gestão de competências gerenciais e a contribuição da aprendizagem organizacional. Revista de Administração de Empresas, 44, 58-69. 
Bloom, B. S., Hastings, T., \& Madaus, G. (1983). Manual de avaliação formativa e somativa do aprendizado escolar. São Paulo: Pioneira.

Borges-Andrade, J. E. (1982). Avaliação somativa de sistemas instrucionais: integração de três propostas. Tecnologia Educacional, 11(46), 29-39.

Borges-Andrade, J. E. (2006). Avaliação integrada e somativa em TD\&E. Em: BorgesAndrade, J. E., Abbad, G., Mourão, L. \& Colaboradores (Orgs.). Treinamento, Desenvolvimento e Educação em Organizações e Trabalho: fundamentos para a gestão de pessoas, (pp. 343-358). Porto Alegre: Artmed.

Borges-Andrade, J. E., Abbad, G. S., Mourão, L. \& Colaboradores. (2006). Treinamento, desenvolvimento e educação em organizações e trabalho: fundamentos para a gestão de pessoas. Porto Alegre: Artmed.

Boyatzis, R. E. (1982). The competent management: a model for effective performance. New York: John Wiley.

Brandão, H. P., Borges-Andrade, J. E., Freitas, I. A., \& Vieira, F. T. (2010). Desenvolvimento e estrutura interna de uma escala de competências gerenciais. Psicologia: Teoria e Pesquisa, 26 (1), 171-182.

Bresser-Pereira, L. C. (1998). Reforma do Estado para a cidadania: a reforma gerencial brasileira na perspectiva internacional. Brasília: ENAP/Editora 34.

Burgess, J. R. D., \& Russel, J. E. A. (2003). The effectiveness of distance learning iniciatives in organizations. Journal of Vocational Behavior, 63, 289-303.

Campos, E. B. D. (2015). Competências empreendedoras: uma Avaliação no Contexto de Empresas Juniores Brasileiras. (Tese de Doutorado, Universidade de Brasília, Brasília, Brasil).

Carbone, P. P. (2009). Gestão por competências e gestão do conhecimento. (3a ed.). Rio de Janeiro: Editora FGV. 
Churchill, G. A., Jr. (1999). Marketing research: methodological foundations (7a ed.). Fort Worth: The Dryden Press.

Coelho Junior, F. A. (2004). Avaliação de Treinamento a Distância: Suporte à Aprendizagem e Impacto do Treinamento no Trabalho. (Dissertação de mestrado, Universidade de Brasília, Brasília, Brasil).

Coelho Junior, F. A. (2009). Suporte à aprendizagem, satisfação no trabalho e desempenho: um estudo multinível. (Tese de doutorado, Universidade de Brasília, Brasília, Brasil).

Coelho Junior, F. A., \& Abbad, G. (2010). Construção e validação de uma escala de avaliação de impacto em profundidade de um treinamento a distância em uma organização do setor bancário brasileiro. Revista Eletrônica de Administração - REad 16(1), 91-119.

Coelho Junior, F. A., \& Borges-Andrade, J. E. (2011). Efeitos de variáveis individuais e contextuais sobre desempenho individual no trabalho. Estudos de Psicologia, 16(2), 111-120.

Coelho Junior, F. A., \& Borges-Andrade, J. E. (2008). Uso do conceito de aprendizagem em estudos relacionados ao trabalho e organizações. Paidéia, 18(40),221-234.

Coelho Junior, F. A., \& Mourão, L. (2011). Suporte à aprendizagem informal no trabalho: uma proposta de articulação conceitual. Revista de Administração Mackenzie, 12(6), 224-253.

Coelho Junior, F. A., Gondim, S. M., Borges-Andrade, J. E., \& Faiad, C. (2012). O Comportamento Organizacional como campo científico: uma análise crítica. XXXVI EnANPAD, 1-13.

Coelho Junior, F. A., Abbad, G., \& Todeschini, K. C. (2005). Construção de validação de uma escala de suporte à aprendizagem no trabalho em uma instituição bancária brasileira. Revista Psicologia Organizações e Trabalho - rPOT, 5(2), 167-196. 
Colquitt, J., LePine, J., \& Noe, R. (2000). Toward an Integrative Theory of Training Motivation: A Meta-Analytic Path Analysis of 20 Years of Research. Journal of Applied Psychology, 85(5), 678-707.

Constituição da República Federativa do Brasil, de 5 de outubro de 1988. (2016). Brasília: Senado Federal, Texto consolidado até a Emenda Constitucional $\mathrm{n}^{\circ} 91$ de 18 de fevereiro de 2016.

Corrar, L. J., Paulo, E. \& Dias Filho, J. M. (2007). Análise Multivariada para os Cursos de Administração, Ciências Contábeis e Economia. São Paulo: Editora Atlas.

Creswell, J. W. (2010). Projeto de pesquisa: métodos qualitativo, quantitativo e misto (3a ed.). Porto Alegre: Artmed.

Damásio, B. F. (2012). Uso da análise fatorial exploratória em psicologia. Avaliação Psicológica, 11(2), 213-228.

Decreto n. 99.350, de 27 de junho de 1990. (1990). Cria o Instituto Nacional do Seguro Social (INSS) define sua estrutura básica e o Quadro Distributivo de Cargos e Funções do Grupo-Direção e Assessoramento Superiores de suas Unidades Centrais e dá outras providências.

Decreto $n$. 5.707, de 23 de fevereiro de 2006. (2006). Institui a Política e as Diretrizes para o Desenvolvimento de Pessoal da administração pública federal direta, autárquica e fundacional, e regulamenta dispositivos da Lei no 8.112, de 11 de dezembro de 1990.

Denhardt, R. B. (2012). Teorias da administração pública. São Paulo: Cengage Learning.

Deluiz, N. A. (2004). Boletim Técnico do SENAC. A Revista de Educação Profissional, 30 (3), 72-79.

D’Netto, B., Bakas, F., Bordia, P. (2008). Predictors of management development effectiveness: In australian perspective. International Journal of Training and Development, 12 (1), 2-23. 
Dutra, J. S. (2008). Competências: Conceitos e Instrumentos para a Gestão de Pessoas na Empresa Moderna. São Paulo: Atlas.

Elnaga, A., \& Imran, A. (2013). The Effect of Training on Employee Performance. European Journal of Business and Management, 5 (4).

Fachin, O. (2006). Fundamentos de metodologia. 5. ed. São Paulo: Saraiva.

Field, A. (2009). Descobrindo a Estatística usando o SPSS (2 ed.). Porto Alegre: Artmed.

Fleury, A., \& Fleury, M. T. L. (2000). Estratégias empresariais e formação de competências: um quebra-cabeça caleidoscópio da indústria brasileira. São Paulo: Atlas.

Freitas, H., Oliveira, M., Saccol, A. Z., \& Moscarola, J. (2000). O método de pesquisa survey. Revista de Administração, 35(3), 105-112.

Freitas, I. A., Borges-Andrade, J. E., Abbad, G. S., \& Pilati, R. (2006). Medidas de impacto de TD\&E no trabalho e nas organizações. Em: Borges-Andrade, J. E., Abbad, G., Mourão, L. \& Colaboradores (Orgs.). Treinamento, Desenvolvimento e Educação em Organizações e Trabalho: fundamentos para a gestão de pessoas, (pp. 489-504). Porto Alegre: Artmed.

Galanou, E., \& Priporas, C. V. (2009). A model for evaluating the effectiveness of middle managers' training courses: evidence from a major banking organization in Greece. International Journal of Training and Development, 13 (4), 221-246.

George, D. \& Mallery, P. (2003). SPSS for Windows step by step: A simple guide and reference (4th ed.). Boston: Allyn \& Bacon.

Gil, A. C. (2009). Como elaborar projetos de pesquisa. 4. ed. São Paulo: Atlas.

Goldstein, I. L. (1991). Training in work organizations. Em: Dunnette, D., \& Hough, L. M. (Eds.). Handbook of industrial and organizational psychology (2a ed., pp. 507-619). Palo Alto: Consulting Psych. 
Hair, Jr., Black, W. C., Babin, B. J., Anderson, R. E., \& Tatham, R. L. (2006). Multivariate Data Analysis NJ: Pearson Prentice Hall.

Hamblin, A. C. (1978). Avaliação e controle do treinamento. São Paulo: McGraw-Hill do Brasil.

Hoon, C. (2013). Meta-Synthesis of Qualitative Case Studies: An Approach to Theory Building. Organizational Research Methods, 16(4), 522-556.

Instituto Nacional do Seguro Social (2015). Boletim estatístico gerencial: INSS em Números Dezembro/2015. Brasília.

Instituto Nacional do Seguro Social (2015). Relatório de Gestão do INSS de 2014. Brasília.

Instituto Nacional do Seguro Social (2013). Resolução n. 291, de 17 de abril de 2013 Projeto Educacional do INSS. Brasília.

Joia, L. A., \& Costa, M. F. C. (2007). Fatores-chave de sucesso no treinamento corporativo a distância via web. Revista de Administração Pública, 41(4).

Kraiger, K.; Cavanagh, T. M. (2015). Training and personal development. Em Kraiger, K., Passmoore, J., Santos, N. R., \& Malvezzi, S. The Wiley Blackwell Handbook of The Psychology of Training, Development, and performance improvement (pp.227246).West Sussex: John Wiley \& Sons.

Kirkpatrick, D. L. (1976). Evaluation of training. Em: Craig, R. L. (Org.). Training and development handbook. New York: McGraw Hill.

Le Boterf, G. (1997). Construire la competence collective de l'entreprise. Gestion, 22(3).

Lei n. 8.029, de 12 de abril de 1990. (1990). Dispõe sobre a extinção e dissolução de entidades da administração Pública Federal, e dá outras providências.

Lei n. 13.346, de 10 de outubro de 2016. (2016). Dispõe sobre a extinção de cargos em comissão do Grupo-Direção e Assessoramento Superiores e a criação de funções de confiança denominadas Funções Comissionadas do Poder Executivo. 
Lima, G. A. B. (2010). Modelos de categorização: apresentando o modelo clássico e o modelo de protótipos. Perspectivas em Ciência da Informação, 15(2), 108-122.

Loiola, E., Néris, J. S., \& Bastos, A. V. B. (2006). Aprendizagem em organizações: mecanismos que articulam processos individuais e coletivos. Em: Borges-Andrade, J. E., Abbad, G., Mourão, L. \& Colaboradores (Orgs.). Treinamento, Desenvolvimento e Educação em Organizações e Trabalho: fundamentos para a gestão de pessoas, (pp. 115-136). Porto Alegre: Artmed.

Malvezzi, S. (2015). The history of training. Em: Kraiger, K., Passmore, J., Santos, N. R., \& Malvezzi, S. (Eds.). The Wiley Blacwell Handbook of The Psychology of Training, Development, and performance improvement (pp. 13-31). West Sussex: John Wiley \& Sons.

Mcclelland, D. C. (1973). Testing for competencies rather than for intelligence. American Psychologist, 28, 1-4.

Meneses, P. P. M., Coelho Junior, F.A., Ferreira, R. R., Paschoal, T., Silva Filho, A. I. (2014). A produção científica brasileira sobre a gestão de recursos humanos entre 2001 e 2010. RAM - Revista de Administração Mackenzie, 15(4), 110-134.

Mertens, L. (1996). Competencia laboral: sistemas, surgimiento y modelos. Montevideo: Cinterfor.

Ministério do Trabalho e Previdência Social (2015). Evolução Recente da Proteção Previdenciária e seus Impactos sobre o Nível de Pobreza. Informe da Previdência Social 27(11).

Noe, R. A., Clarke, A. D. M., \& Klein, H. J. (2014). Learning in the Twenty-FirstCentury Workplace. Annual Review of Organizational Psychology and Organizational Behavior, 1, pp. $245-275$. 
Pasquali, L. (2010). Testes referentes a construto: teoria e modelo de construção. Em: Pasquali, L., et al. Instrumentação Psicológica: fundamentos e práticas. Porto Alegre: Artmed.

Peci, A., Pieranti, O. P., \& Rodrigues, S. (2008). Governança e new public management: convergências e contradições no contexto brasileiro. Organizações \& Sociedade, 15 (46).

Pilati, R., \& Abbad, G. (2005). Análise fatorial confirmatória da escala de impacto do treinamento no trabalho. Psicologia: Teoria e Pesquisa, 21(1).

Ropé, F., \& Tanguy, L. (1997). Saberes e competências. Campinas: Papirus.

Sandberg, J. (1996). Human competence at work. Göteborg: BAS.

Sandberg, J. (2000). Understanding human competence at work: An interpretative Approach. The Academy of Management Journal, 43(1), 9-25.

Salas, E., \& Cannon-Bowers, J. A. (2001). The science of training: a decade of progress. Annual Review Psychology, 52, 471-499.

Santos, G. E. O. Cálculo amostral: calculadora on-line. Disponível em http://www.calculoamostral.vai.la. Acesso em: 13/11/2016.

Sijtsma, K. (2009). On the use, the misuse, and the very limited usefulness of Cronbach's alpha. Psychometrika, 74(1), 107-120.

Stufflebeam, D. (1978). Alternativas em avaliação educacional: um guia de auto-ensino para educadores. Em: M. Scriven e D. Stufflebeam (Eds.). Avaliação educacional (II): perspectivas, procedimentos e alternativas. Petrópolis: Vozes.

Sveiby, K. E. (1998). A nova riqueza das organizações. Rio de Janeiro: Rocco.

Tabachnick, B. G. \& Fidell, L. S. (2007). Using Multivariate Statistics (5th. ed.). Boston: Allyn and Bacon. 
Tannenbaum, S. I., \& Yukl, G. (1992). Training and development in work organizations. Annual Review of Psychology, 43, 399-441.

Tribunal de Contas da União (2013). Acórdão n. 3.023, do Tribunal de Contas da União TCU - Plenário. (2013). Avalia a situação da governança e da gestão de pessoas em amostra de organizações da Administração Pública Federal. Brasília.

Tribunal de Contas da União (2017). Acórdão n. 358, do Tribunal de Contas da União - TCU - Plenário. (2017). Avalia a situação atual e a evolução da governança e da gestão de pessoas na Administração Pública Federal. Brasília.

Vargas, M. R. M. (2003). Educação à distância no contexto da mudança organizacional. Em: Valle, S. M. L. (Org.). Mudança organizacional: teoria e gestão. Rio de Janeiro: FGV.

Vitória, D. M., (2014). Avaliação do Impacto do Treinamento no Trabalho (Dissertação de Mestrado). Universidade de Brasília, Brasília, Brasil.

Warr, P. B., Bird, M. W., \& Rackham, N. (1970). Evaluating of management training. Londres: Gower Press.

Yotamo, C. J. (2014). Avaliação de impacto de treinamento no desempenho de servidores públicos de Sofala em Moçambique (Dissertação de mestrado). Universidade de Brasília, Brasília, DF, Brasil.

Zarifian, P. (2001). Objetivo competência. São Paulo: Atlas.

Zerbini, T., \& Abbad, G. S. (2005). Impacto de treinamento no trabalho via internet. $R A E$ eletrônica, 4 (2), jul-dez.

Zerbini, T., \& Abbad, G. S. (2010). Qualificação profissional a distância: avaliação da transferência de treinamento. Paidéia, 20 (47), 313-323.

Zerbini, T., \& Abbad, G. S. (2010). Transferência de Treinamento e Impacto do Treinamento no Trabalho: Análise Crítica da Literatura. Revista Psicologia: Organizações e Trabalho, 10 (2), 97-111. 


\section{Apêndices}

Apêndice I - Pesquisas nacionais selecionadas sobre suporte à aprendizagem, competências organizacionais e impacto do treinamento no trabalho

\begin{tabular}{|c|c|c|c|c|}
\hline CATEGORIZAÇÃO & REFERÊNCIA & CONTEXTO & VARIÁVEIS & RESULTADOS \\
\hline $\begin{array}{l}\text { SUPORTE } \\
\text { APRENDIZAGEM }\end{array}$ & $\begin{array}{l}\text { Zerbini, T., Abbad, G.S. (2005). Impacto de } \\
\text { treinamento no trabalho via internet. RAE- } \\
\text { eletrônica, v. 4, n. } 2 \text {, jul-dez. }\end{array}$ & $\begin{array}{l}\text { Testar um modelo reduzido de } \\
\text { avaliação de Impacto de } \\
\text { Treinamento } \\
\text { no Trabalho. }\end{array}$ & $\begin{array}{l}\text { Análise do relacionamento entre as } \\
\text { variáveis preditoras referentes às } \\
\text { Características da Clientela, Reações } \\
\text { ao Treinamento, Falta de Suporte à } \\
\text { Transferência e à variável-critério } \\
\text { Impacto do Treinamento no Trabalho. }\end{array}$ & $\begin{array}{l}\text { Construção e validação de cinco novas } \\
\text { escalas de avaliação de treinamentos a } \\
\text { distância que possibilitaram o teste dos } \\
\text { modelos reduzidos de avaliação de } \\
\text { treinamento. Além disso, neste estudo foi } \\
\text { possível realizar validações estatísticas da } \\
\text { Escala de Impacto do Treinamento no } \\
\text { Trabalho, medidas em profundidade. }\end{array}$ \\
\hline $\begin{array}{l}\text { SUPORTE } \\
\text { APRENDIZAGEM }\end{array}$ & $\begin{array}{l}\text { Pantoja, M.J., Porto, J.B., Mourão, L., Borges- } \\
\text { Andrade, J.E. (2005). Valores, suporte } \\
\text { psicossocial e impacto do treinamento no trabalho. } \\
\text { Estudos de Psicologia, 10(2), pp. 255-265. }\end{array}$ & $\begin{array}{l}\text { Investigar a influência de } \\
\text { variáveis relacionadas às } \\
\text { características dos treinados, } \\
\text { mais especificamente, seus } \\
\text { valores individuais, bem como } \\
\text { de suas percepções acerca do } \\
\text { suporte organizacional à } \\
\text { transferência de treinamento, } \\
\text { sobre tal impacto. }\end{array}$ & $\begin{array}{l}\text { Investigar o poder preditivo dos } \\
\text { valores individuais e percepções de } \\
\text { suporte psicossocial à transferência de } \\
\text { treinamento como preditores do } \\
\text { impacto do treinamento no trabalho, } \\
\text { bem como, o efeito moderador dos } \\
\text { valores individuais sobre a relação } \\
\text { entre os suportes psicossocial e } \\
\text { material e o impacto do treinamento. }\end{array}$ & $\begin{array}{l}\text { Os resultados da análise de regressão } \\
\text { hierárquica indicaram que o suporte à } \\
\text { transferência e os valores individuais do } \\
\text { treinado estão significativamente } \\
\text { relacionadas ao impacto do treinamento } \\
\text { no trabalho. Mais especificamente, os } \\
\text { dados obtidos apontaram o suporte } \\
\text { psicossocial e o tipo motivacional } \\
\text { conservadorismo como importantes } \\
\text { preditores do impacto do treinamento no } \\
\text { trabalho. }\end{array}$ \\
\hline $\begin{array}{l}\text { SUPORTE } \\
\text { APRENDIZAGEM }\end{array}$ & $\begin{array}{l}\text { Cavazotte, F.S.C.N., Moreno Junior, V.A., \& } \\
\text { Turano, L.M. (2015). Cultura de aprendizagem } \\
\text { contínua, atitudes e desempenho no trabalho: uma } \\
\text { comparação entre empresas do setor público e } \\
\text { privado. Revista de Administração Pública, Rio de } \\
\text { Janeiro, v.49, n.6. }\end{array}$ & $\begin{array}{l}\text { Investiga a relação entre } \\
\text { cultura de aprendizagem } \\
\text { contínua, percepção de } \\
\text { oportunidades de crescimento } \\
\text { e desempenho individual, } \\
\text { comparando empresas do setor } \\
\text { público e privado. }\end{array}$ & $\begin{array}{l}\text { Existência de três variáveis } \\
\text { demográficas de controle: idade, sexo e } \\
\text { tempo na área; que foram inseridas em } \\
\text { todas as avaliações das relações causais } \\
\text { previstas no modelo proposto, } \\
\text { consideradas variáveis latentes: cultura } \\
\text { de aprendizagem contínua, } \\
\text { desempenho formal, oportunidades de } \\
\text { crescimento, cidadania organizacional. }\end{array}$ & $\begin{array}{l}\text { Confirma-se a proposição de que } \\
\text { empresas públicas tendem a apresentar, na } \\
\text { percepção de seus funcionários, culturas } \\
\text { menos voltadas para o aprendizado. } \\
\text { Parece fundamental que gestores se } \\
\text { preocupem com o desenvolvimento de um } \\
\text { ambiente que facilite comportamentos } \\
\text { ligados à promoção do conhecimento e da } \\
\text { aprendizagem nas organizações. }\end{array}$ \\
\hline $\begin{array}{l}\text { SUPORTE } \\
\text { APRENDIZAGEM }\end{array}$ & $\begin{array}{l}\text { Freitas, I.A., Borges-Andrade, J.E. (2004). } \\
\text { Construção e validação de escala de crenças sobre }\end{array}$ & $\begin{array}{l}\text { Aborda a construção e } \\
\text { validação da escala de crenças }\end{array}$ & \begin{tabular}{|lrr} 
Os itens relativos a crenças & sobre o \\
sistema de treinamento foram
\end{tabular} & \begin{tabular}{ll} 
Escala apresentou & \multicolumn{2}{c}{ indicadores } \\
psicométricos adequados & e todos os
\end{tabular} \\
\hline
\end{tabular}




\begin{tabular}{|c|c|c|c|c|}
\hline CATEGORIZAÇÃO & REFERÊNCIA & CONTEXTO & VARIÁVEIS & RESULTADOS \\
\hline & $\begin{array}{l}\text { o sistema treinamento. Estudos de Psicologia, v. 9, } \\
\text { n.3, set/dez, } 2004 .\end{array}$ & $\begin{array}{|lll|}\text { sobre } \quad \mathrm{o} & \text { sistema } & \mathrm{de} \\
\text { treinamento. } & & \end{array}$ & $\begin{array}{l}\text { construídos com base em três fontes: } \\
\text { (a) nas escalas de Cinismo } \\
\text { Organizacional; (b) nas crenças que as } \\
\text { pessoas possuem sobre treinamento; e } \\
\text { (c) no Modelo MAIS. }\end{array}$ & $\begin{array}{l}\text { fatores obtiveram índice de consistência } \\
\text { interna superiores a } 0,80 \text { (Pasquali, 2004). } \\
\text { O percentual de variância explicada pelo } \\
\text { instrumento foi de 51,3\%, índice } \\
\text { considerado muito bom para as ciências } \\
\text { sociais. }\end{array}$ \\
\hline $\begin{array}{l}\text { SUPORTE } \\
\text { APRENDIZAGEM }\end{array}$ & $\begin{array}{l}\text { Lacerda, E.R.M., Abbad, G. (2003). Impacto do } \\
\text { treinamento no trabalho: investigando variáveis } \\
\text { motivacionais e organizacionais como suas } \\
\text { preditoras. Revista de Administração } \\
\text { Contemporânea, vol. } 7, \mathrm{n}^{\circ} 4 \text {, out/dez. }\end{array}$ & $\mid \begin{array}{lcc}\text { Testar um } & \text { modelo } & \text { de } \\
\text { avaliação de } & \text { Impacto } & \text { do } \\
\text { Treinamento no Trabalho. } & \end{array}$ & $\begin{array}{l}\text { Relacionamento entre } \\
\text { dos participantes dos } \\
\text { (Motivaçásticas para Aprenamentos } \\
\text { Transferir e V Valor Instrumental), } \\
\text { Reações e Suporte à Transferência, } \\
\text { como variáveis antecedentes, e } \\
\text { Impacto do Treinamento no Trabalho, } \\
\text { como variável critério. }\end{array}$ & $\begin{array}{l}\text { Os resultados obtidos com a variável } \\
\text { Suporte Psicossocial como a melhor } \\
\text { preditora de Impacto do Treinamento no } \\
\text { Trabalho neste estudo, podem ser um } \\
\text { indício de generalidade. As contribuições } \\
\text { mais relevantes deste trabalho referem-se } \\
\text { à boa qualidade psicométrica da escala } \\
\text { construída de Valor Instrumental do } \\
\text { Treinamento e ao fato de essa variável ter } \\
\text { sido explicativa de impacto. }\end{array}$ \\
\hline $\begin{array}{l}\text { SUPORTE } \\
\text { APRENDIZAGEM }\end{array}$ & $\begin{array}{l}\text { Abbad, G.S., Gama, A.L.G., Borges-Andrade, J.E. } \\
\text { (2000). Treinamento: Análise do Relacionamento } \\
\text { da Avaliação nos Níveis de Reação, } \\
\text { Aprendizagem e Impacto no Trabalho. RAC, v.4, } \\
\text { n.3, pp. } 25-45 \text {, set-dez. }\end{array}$ & 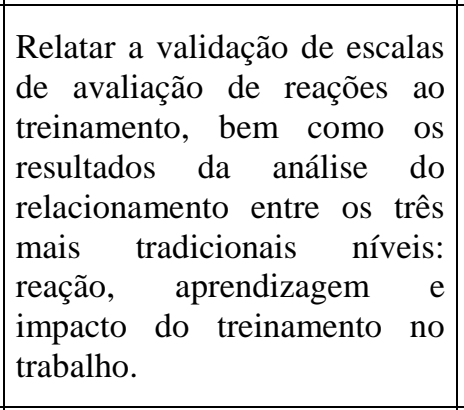 & $\begin{array}{l}\text { O impacto do treinamento no trabalho } \\
\text { pode depender fortemente do suporte à } \\
\text { transferência e de variáveis de reações } \\
\text { aos resultados do treinamento. Todos } \\
\text { os níveis de avaliação, ou variáveis } \\
\text { critério, parecem depender de certas } \\
\text { características da clientela e quase } \\
\text { todas de percepções de suporte } \\
\text { organizacional. }\end{array}$ & $\begin{array}{l}\text { As medidas de impacto, reação e retenção, } \\
\text { de modo geral, estão moderadamente } \\
\text { relacionadas entre si. A aprendizagem é a } \\
\text { única variável que não está } \\
\text { significativamente correlacionada com } \\
\text { todas as demais. A variável reações aos } \\
\text { resultados, aplicabilidade e expectativas } \\
\text { de suporte, entre as variáveis estudadas, é } \\
\text { a que está mais fortemente correlacionada } \\
\text { com as medidas de impacto. } \\
\end{array}$ \\
\hline $\begin{array}{l}\text { SUPORTE } \\
\text { APRENDIZAGEM }\end{array}$ & $\begin{array}{l}\text { Pilati,R., Borges-Andrade, J.E. (2005). Estratégias } \\
\text { para aplicação no trabalho do aprendido em } \\
\text { treinamento: proposiça conceitual e e } \\
\text { desenvolvimento de uma medida. Psicologia: } \\
\text { Reflexão e Crítica, v. } 18, \text { n. 2, mai/ago. }\end{array}$ & 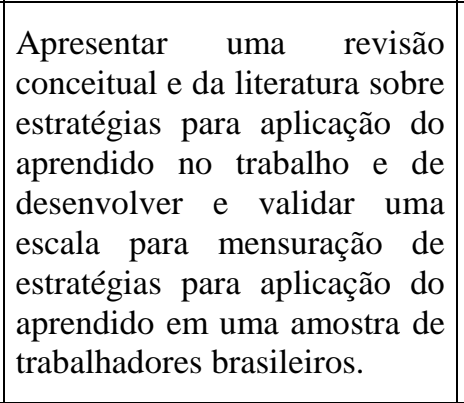 & 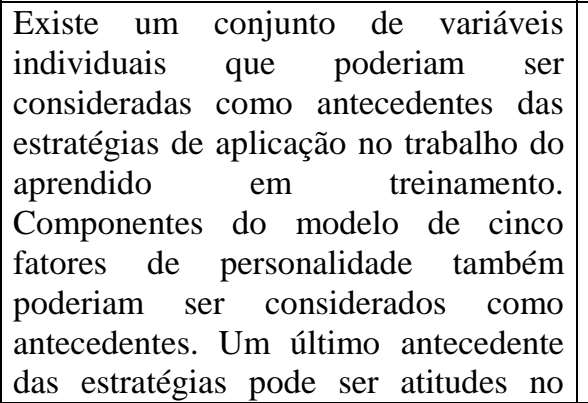 & $\begin{array}{l}\text { Foi realizada uma análise conceitual do } \\
\text { fenômeno e uma escala para sua } \\
\text { mensuração foi desenvolvida. A } \\
\text { escala foi aplicada em uma amostra de } \\
\text { trabalhadores e os dados submetidos a } \\
\text { análises para aferição da estrutura latente. } \\
\text { Os resultados corroboram os pressupostos } \\
\text { teóricos da análise conceitual, mas devem } \\
\text { ser realizados mais estudos para: a) } \\
\text { descrever melhor as características do }\end{array}$ \\
\hline
\end{tabular}




\begin{tabular}{|c|c|c|c|c|}
\hline CATEGORIZAÇÃO & REFERÊNCIA & CONTEXTO & VARIÁVEIS & RESULTADOS \\
\hline & & & $\begin{array}{|lrr|}\text { trabalho } & \text { (i.e.,satisfação, } \\
\text { comprometimento), tanto com relações } \\
\text { diretas como } & \text { com } & \text { relações } \\
\text { moderadoras. } & & \\
\end{array}$ & $\begin{array}{l}\text { fenômeno; e, b) relacioná-lo com } \\
\text { indicadores de resultado do treinamento } \\
\text { no trabalho. }\end{array}$ \\
\hline $\begin{array}{l}\text { SUPORTE À } \\
\text { APRENDIZAGEM }\end{array}$ & $\begin{array}{l}\text { Joia, L.A., Costa, M.F.C. (2007). Fatores-chave de } \\
\text { sucesso no treinamento corporativo a distância via } \\
\text { web. Revista de Administração Pública, v. } 41, \mathrm{n} \text {. } \\
4, \text { jul/ago. }\end{array}$ & $\begin{array}{l}\text { Investiga os fatores chaves de } \\
\text { sucesso, pela análise de dois } \\
\text { distintos programas de } \\
\text { treinamento a distância via } \\
\text { web, com a seguinte pergunta } \\
\text { de pesquisa:"Quais os fatores } \\
\text { críticos de sucesso para a } \\
\text { construção de programas } \\
\text { corporativos de treinamento a } \\
\text { distância baseados na web?". }\end{array}$ & $\begin{array}{l}\text { Realizada uma regressão linear } \\
\text { multivariada utilizando como variável } \\
\text { dependente o grau de atingimento dos } \\
\text { objetivos do programa de treinamento } \\
\text { e como variáveis independentes as } \\
\text { notas atribuídas pelos usuários a cada } \\
\text { uma dessas dimensões. Foram } \\
\text { analisados os níveis de significância de } \\
\text { cada um dos coeficientes associados a } \\
\text { cada uma das oito variáveis } \\
\text { independentes (cada uma das oito } \\
\text { dimensões analisadas), er foram } \\
\text { descartados os coeficientes que não } \\
\text { apresentavam evidência de correlação } \\
\text { linear com a variável dependente } \\
\text { (atingimento dos objetivos). } \\
\end{array}$ & $\begin{array}{l}\text { Identifica as efetivas causas para o } \\
\text { atingimento ou não dos objetivos dos } \\
\text { programas, de modo a permitir a } \\
\text { inferência dos fatores-chave de sucesso } \\
\text { para a implementação de programas de } \\
\text { treinamento corporativos a distância } \\
\text { baseados na web. }\end{array}$ \\
\hline $\begin{array}{l}\text { SUPORTE À } \\
\text { APRENDIZAGEM }\end{array}$ & $\begin{array}{l}\text { Borges-Andrade, J.E. (2002). Desenvolvimento de } \\
\text { medidas em avaliação de treinamento. Estudos de } \\
\text { Psicologia, 7, pp. 31-43. }\end{array}$ & 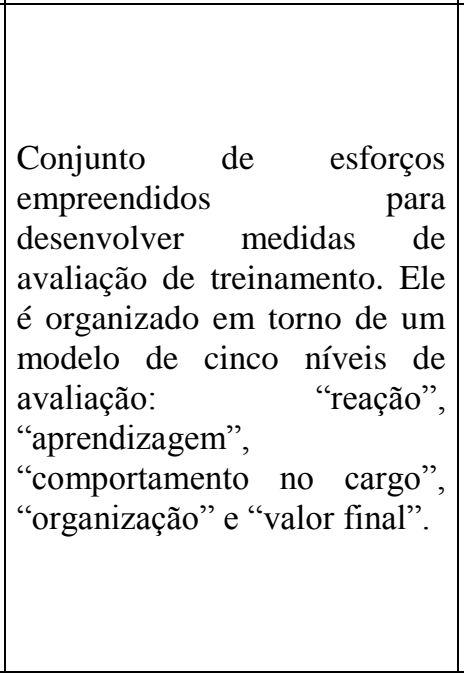 & 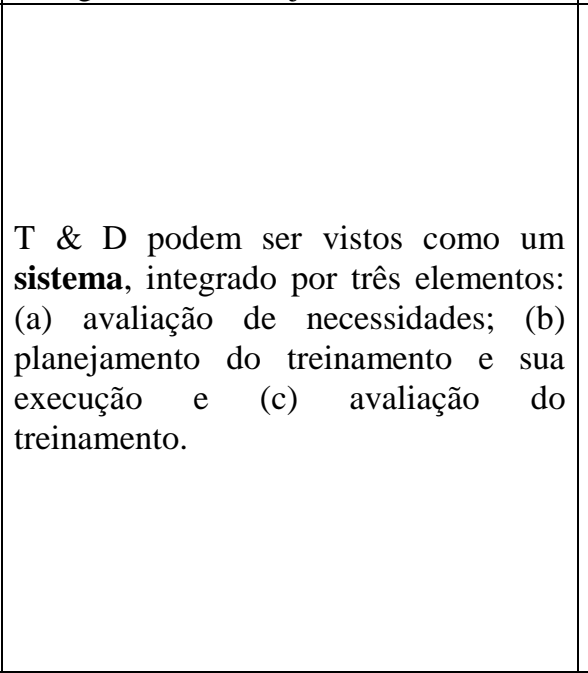 & $\begin{array}{l}\text { A necessidade da convivência com } \\
\text { diversas estratégias metodológicas de } \\
\text { avaliaçãa de treinamento foi reconhecida, } \\
\text { mas é preciso conhecer melhor os } \\
\text { condicionantes que levam a diferentes } \\
\text { escolhas metodológicas. Foram } \\
\text { mencionados e discutidos os instrumentos } \\
\text { e procedimentos que têm sido usados para } \\
\text { fazer avaliaçães, utilizando-se o modelo } \\
\text { de níveis de mensuração de Hamblin } \\
\text { (1978). Comparando-se os cinco níveis de } \\
\text { avaliação de treinamento, pode-se concluir } \\
\text { que houve mais avanços metodológicos nos } \\
\text { níveis de reação e de comportamento no } \\
\text { cargo e uma quase estagnação no nível de } \\
\text { aprendizagem. No nível de organização, já } \\
\text { se sabe o que deverá ser feito para }\end{array}$ \\
\hline
\end{tabular}




\begin{tabular}{|c|c|c|c|c|}
\hline CATEGORIZAÇÃO & REFERÊNCIA & CONTEXTO & VARIÁVEIS & RESULTADOS \\
\hline & & & & $\begin{array}{l}\text { desenvolver métodos, embora eles ainda } \\
\text { estejam raramente disponíveis. }\end{array}$ \\
\hline $\begin{array}{l}\text { SUPORTE } \\
\text { APRENDIZAGEM }\end{array}$ & $\begin{array}{l}\text { Carvalho, R. S.; Abbad, G. (2006). Avaliação de } \\
\text { treinamento a distância: reação, suporte à } \\
\text { transferência e impactos no trabalho. Revista de } \\
\text { Administração Contemporânea, v. 10, n. 1, pp. 95- } \\
116 .\end{array}$ & 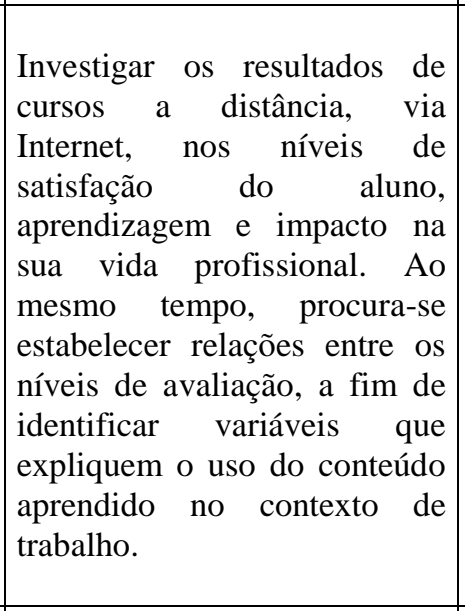 & $\begin{array}{l}\text { Avalia modelos de predição de três } \\
\text { variáveis critério: Escores de } \\
\text { Aprendizagem e Impacto do } \\
\text { Treinamento no Trabalho, medido em } \\
\text { Profundidade e em Amplitude. As } \\
\text { variáveis antecedentes dos modelos } \\
\text { integram os componentes de Reação, } \\
\text { Características da Clientela e Suporte à } \\
\text { Transferência }\end{array}$ & $\begin{array}{l}\text { Os resultados das análises indicaram que } \\
\text { os respondentes que percebem menos } \\
\text { suporte à abertura e manutenção de um } \\
\text { empreendimento obtêm escores mais altos } \\
\text { de impactos no trabalho. O } \\
\text { relacionamento negativo entre medidas de } \\
\text { suporte à transferência e impacto não foi } \\
\text { encontrado em relatos anteriores. O } \\
\text { resultado poderia ser explicado pelo fato } \\
\text { de o contexto do empreendedorismo } \\
\text { valorizar desafios. A falta de suporte, } \\
\text { sendo entendida como desafio, pode ter } \\
\text { sido valorizada pelos respondentes e vista } \\
\text { como estímulo à utilização dos novos } \\
\text { conhecimentos. }\end{array}$ \\
\hline $\begin{array}{l}\text { SUPORTE } \\
\text { APRENDIZAGEM }\end{array}$ & $\begin{array}{l}\text { Zerbini, T.; Abbad, G.S. (2010). Qualificação } \\
\text { profissional a distância: avaliação da transferência } \\
\text { de treinamento. Paidéia, v. 20, n. 47, set-dez, pp. } \\
\text { 313-323. }\end{array}$ & \begin{tabular}{|lrrr} 
Identificar & \multicolumn{2}{r}{ variáveis } \\
explicativas & da & aplicação & de \\
habilidades & ensinadas & aos \\
participantes & de um curso & de \\
qualificação & profissional & a \\
distância, via & internet. Foram \\
aplicadas & as & escalas, \\
submetidas & à validação \\
estatística: & Ambiente & de \\
Estudo e & Procedimentos & de \\
Interação, & Estratégias & de \\
Aprendizagem, Reação & aos \\
Procedimentos & Instrucionais, \\
Reação ao & Desempenho & do \\
Tutor e Transferência & de \\
Treinamento. & & \\
\end{tabular} & $\begin{array}{l}\text { Identificar variáveis preditoras de } \\
\text { Transferência de Treinamento, entre as } \\
\text { variáveis de características da clientela } \\
\text { (estratégias de aprendizagem), de } \\
\text { reações ao curso (procedimentos } \\
\text { instrucionais e desempenho do tutor)e e } \\
\text { de contexto (ambiente de estudo do } \\
\text { aluno e procedimentos de interação do } \\
\text { curso). }\end{array}$ & $\begin{array}{l}\text { Ocorrência de um maior poder explicativo } \\
\text { de variáveis individuais sobre resultados } \\
\text { de treinamentos, em comparação com } \\
\text { modelos de avaliação de treinamentos } \\
\text { presenciais. Destacam-se a utilização de } \\
\text { instrumentos validados; a revisão de } \\
\text { literatura da área de avaliação de } \\
\text { treinamento presencial e a distância em } \\
\text { psicologia instrucional e organizacional e } \\
\text { TD\&E; e o aprimoramento da estratégia } \\
\text { de coleta de dados realizada pela internet. }\end{array}$ \\
\hline $\begin{array}{l}\text { SUPORTE } \\
\text { APRENDIZAGEM }\end{array}$ & $\begin{array}{l}\text { Abbad, G.S., Zerbini, T., Souza, D.B.L. (2010). } \\
\text { Panorama das pesquisas em educação a distância } \\
\text { no Brasil. Estudos de Psicologia, 15(3), set/dez, } \\
\text { pp. 291-298. }\end{array}$ & $\begin{array}{|lrr|}\text { Descrever } & \text { brevemente } & 0 \\
\text { contexto e } & \text { o foco das } \\
\text { pesquisas sobre treinamentos a } \\
\text { distância (TAD) no Brasil, no }\end{array}$ & \begin{tabular}{|l} 
Há resultados indicando que, além de \\
variáveis do contexto de trabalho, \\
variáveis pessoais relacionadas à \\
família do estudante também afetam a
\end{tabular} & 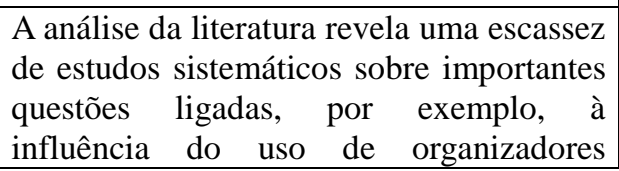 \\
\hline
\end{tabular}




\begin{tabular}{|c|c|c|c|c|}
\hline CATEGORIZAÇÃO & REFERÊECIA & CONTEXTO & VARIÁVEIS & RESULTADOS \\
\hline & & $\begin{array}{l}\text { período de } 2003 \text { a } 2009 \text {, a } \\
\text { partir de } \\
\text { bibliográfica e de dados do } \\
\text { Anuário Brasileiro Estatístico } \\
\text { de Educação Aberta e a } \\
\text { Distância (ABRAED). }\end{array}$ & 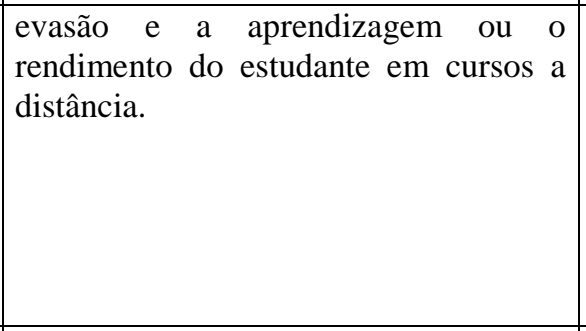 & $\begin{array}{l}\text { gráficos e mapas conceituais sobre a } \\
\text { aprendizagem, retenção, armazenagem, } \\
\text { recuperação de informações na memória e } \\
\text { na aplicação de novas habilidades no } \\
\text { trabalho, e à influência de diferentes } \\
\text { combinações de meios de ensino sobre a } \\
\text { memorização, a aprendizagem e a } \\
\text { transferência de aprendizagem. }\end{array}$ \\
\hline $\begin{array}{l}\text { SUPORTE } \\
\text { APRENDIZAGEM }\end{array}$ & $\begin{array}{l}\text { Abbad, G. S., Mourão, L. (2012). Avaliação de } \\
\text { necessidades de TD\&E: proposição de um novo } \\
\text { modelo. RAM, Rev. Adm. Mackenzie [online], } \\
\text { v.13, n.6, pp. 107-137. }\end{array}$ & $\begin{array}{l}\text { Este artigo apresenta um } \\
\text { modelo de avaliação de } \\
\text { necessidades, r mesmo } \\
\text { existindo outro bem conhecido } \\
\text { e ainda em uso, visto que as } \\
\text { pesquisas em avaliação de } \\
\text { necessidades, encontradas em } \\
\text { revisões da literatura de } \\
\text { psicologia organizacional e do } \\
\text { trabalho, ainda naro } \\
\text { desenvolveram metodologias } \\
\text { capazes de detectar } \\
\text { necessidades de grupos, } \\
\text { equipes e/ou processos } \\
\text { organizacionais. }\end{array}$ & $\begin{array}{l}\text { Como primeira etapa, o modelo sugere } \\
\text { a definição dos objetivos da ANT e a } \\
\text { avaliação de necessidades no nível da } \\
\text { organização. Após a detecção dessas } \\
\text { necessidades, é possível identificar em } \\
\text { quais macroprocessos, unidades, } \\
\text { cargos estão lotadas as pessoas (quem } \\
\text { deve ser treinado) que precisarão } \\
\text { desenvolver tais competências. A ANT } \\
\text { deve facilitar a classificação das } \\
\text { necessidades de treinamento em termos } \\
\text { de complexidade, grau de } \\
\text { internalização ou de automatização. }\end{array}$ & $\begin{array}{l}\text { O modelo de ANT proposto vai além da } \\
\text { análise de tarefas e de pessoas, incluindo } \\
\text { também o nível organizacional e de grupo. } \\
\text { Da forma como desenhado, } \\
\text { seguindo-se as nove etapas estabelecidas, } \\
\text { ele permitirá fornecer as informações } \\
\text { necessárias ao desenho de situações de } \\
\text { aprendizagem e de treinamento que } \\
\text { possam promover o desenvolvimento de } \\
\text { complexas competências, valorizadas pelo } \\
\text { mundo do trabalho. }\end{array}$ \\
\hline $\begin{array}{l}\text { SUPORTE } \\
\text { APRENDIZAGEM }\end{array}$ & $\begin{array}{l}\text { Balarin, C.S., Zerbini, T., Martins, L.B. (2014). A } \\
\text { relação entre suporte à aprendizagem e impacto de } \\
\text { treinamento no trabalho. Revista Eletrônica de } \\
\text { Administração, v. } 20, \text { n. 2, Porto Alegre, mai/ago. }\end{array}$ & $\begin{array}{l}\text { Avaliar a relação entre uma } \\
\text { variável contextual, Suporte à } \\
\text { Aprendizagem, e o Impacto de } \\
\text { Treinamento no Trabalho, } \\
\text { medido em amplitude. }\end{array}$ & $\begin{array}{l}\text { Estudou-se a relação entre as variáveis: } \\
\text { Suporte à Aprendizagem - percepção } \\
\text { de apoio e suporte psicossocial à } \\
\text { aprendizagem natural ou induzida no } \\
\text { ambiente de trabalho, e Impacto } \\
\text { do Treinamento no Trabalho - } \\
\text { influência do que foi aprendido em } \\
\text { ações de TD\&E no desempenho geral, } \\
\text { nas atitudes e motivação do indivíduo. }\end{array}$ & $\begin{array}{l}\text { Indicaram correlação entre Suporte à } \\
\text { Aprendizagem e o Impacto de } \\
\text { Treinamento no Trabalho e ainda que a } \\
\text { aprendizagem natural pode estar } \\
\text { correlacionada aos resultados das ações de } \\
\text { TD\&E, enfatizando ainda mais o poder do } \\
\text { contexto organizacional nesses resultados. }\end{array}$ \\
\hline $\begin{array}{l}\text { SUPORTE } \\
\text { APRENDIZAGEM }\end{array}$ & $\begin{array}{l}\text { Abbad, G.S., Pilati, R., Pantoja, M.J. (2003). } \\
\text { Avaliação de treinamento: análise da literatura e } \\
\text { agenda de pesquisa. Revista de Administração } \\
U S P \text {, v. } 38, \text { n.3, pp. 205-218, São Paulo, }\end{array}$ & $\begin{array}{l}\text { Análise da produção científica } \\
\text { e tecnológica nacional e } \\
\text { estrangeira na área de } \\
\text { avaliação de treinamento, }\end{array}$ & $\begin{array}{l}\text { A contribuição de variáveis relativas as } \\
\text { características individuais na } \\
\text { explicação de impacto é pequena } \\
\text { quando comparada aquela exercida por }\end{array}$ & $\begin{array}{l}\text { Uma das importantes conclusões é o papel } \\
\text { central exercido pelo suporte à } \\
\text { transferência na explicação do impacto do } \\
\text { treinamento no trabalho. Urge revisar as }\end{array}$ \\
\hline
\end{tabular}




\begin{tabular}{|c|c|c|c|c|}
\hline CATEGORIZAÇÃO & REFERÊNCIA & CONTEXTO & VARIÁVEIS & RESULTADOS \\
\hline & jul/ago/set. & $\begin{array}{l}\text { visando identificar pontos de } \\
\text { avanços teóricos r e } \\
\text { metodológico obtidos, bem } \\
\text { como eventuais lacunas } \\
\text { presentes nas linhas de } \\
\text { pesquisa. }\end{array}$ & $\begin{array}{|lllll|}\begin{array}{l}\text { variáveis } \\
\text { suporte. }\end{array} & \text { relacionadas a clima } & \text { e } \\
\end{array}$ & $\begin{array}{l}\text { tecnologias de levantamento das } \\
\text { necessidades de treinamento. }\end{array}$ \\
\hline $\begin{array}{ll}\text { SUPORTE } & \grave{A} \\
\text { APRENDIZAGEM } & \end{array}$ & $\begin{array}{l}\text { Coelho Jr, F.A., Mourão, L. (2011). Suporte à } \\
\text { aprendizagem informal no trabalho: uma proposta } \\
\text { de articulação conceitual. RAM - Revista de } \\
\text { Administração Mackenzie, São Paulo, v. 12, n. } 6 \text {, } \\
\text { pp. 224-253, nov/dez. }\end{array}$ & $\begin{array}{l}\text { Propor um modelo teórico } \\
\text { baseado no ordenamento das } \\
\text { etapas de suporte psicossocial } \\
\text { à aprendizagem informal, } \\
\text { segundo as características e as } \\
\text { qualidades das distintas etapas } \\
\text { do conceito de aprendizagem } \\
\text { informal do trabalho. }\end{array}$ & $\begin{array}{l}\text { Torna-se importante investigar como se } \\
\text { dá o suporte psicossocial à } \\
\text { aprendizagem informal no trabalho, a } \\
\text { partir do contato interpessoal entre } \\
\text { colegas, pares e chefias, e como tal } \\
\text { suporte pode ser gerenciado } \\
\text { estrategicamente de forma a maximizar } \\
\text { o desempenho ou os resultados no } \\
\text { trabalho. }\end{array}$ & $\begin{array}{l}\text { Destaca-se a originalidade do trabalho no } \\
\text { sentido de evidenciar as diferentes fases } \\
\text { do processo de aprendizagem informal no } \\
\text { trabalho e o suporte que pode ser dado em } \\
\text { cada uma dessas etapas. Assim, espera-se } \\
\text { que a proposta teórica desse modelo, com } \\
\text { a classificação do conceito de suporte à } \\
\text { aprendizagem, seja o primeiro passo na } \\
\text { sistematização desse conceito, posto que } \\
\text { essa variável de apoio vem sendo } \\
\text { considerada como uma das principais } \\
\text { preditoras de impacto de treinamento no } \\
\text { trabalho e desempenho. }\end{array}$ \\
\hline $\begin{array}{ll}\text { SUPORTE } & \grave{A} \\
\text { APRENDIZAGEM } & \end{array}$ & $\begin{array}{l}\text { Coelho Jr, F.A., Borges-Andrade, J.E. (2011). } \\
\text { Efeitos de variáveis individuais e contextuais } \\
\text { sobre desempenho individual no trabalho. Estudos } \\
\text { de Psicologia, Natal, v.16, n.2, pp. 111-120, } \\
\text { mai/ago. }\end{array}$ & $\begin{array}{l}\text { Identificar quais variáveis do } \\
\text { contexto organizacional } \\
\text { otimizam a ocorrência de } \\
\text { aprendizagem entre os } \\
\text { indivíduos e facilitam novos } \\
\text { desempenhos no ambiente de } \\
\text { trabalho por meio do apoio } \\
\text { organizacional à inovação, } \\
\text { experimentação e e } \\
\text { desenvolvimento profissional } \\
\text { de seus integrantes. }\end{array}$ & $\begin{array}{l}\text { As variáveis antecedentes investigadas, } \\
\text { isoladas ou em interação, } \\
\text { corresponderam à idade, gênero, cargo, } \\
\text { grau de escolaridade, tempo de serviço } \\
\text { e percepção de suporte à } \\
\text { aprendizagem, medidas no nível } \\
\text { individual e de contexto, e satisfação } \\
\text { no trabalho, de nível individual. }\end{array}$ & $\begin{array}{l}\text { Pode-se afirmar, analisando o modelo } \\
\text { multinível final, que a relação teórica } \\
\text { hipotetizada entre suporte à aprendizagem } \\
\text { e desempenho foi confirmada } \\
\text { empiricamente. As percepções coletivas } \\
\text { de suporte informal à aprendizagem, } \\
\text { enquanto variável de contexto, foram } \\
\text { capazes de predizer desempenho. Este é o } \\
\text { achado mais consistente e importante } \\
\text { deste artigo. }\end{array}$ \\
\hline $\begin{array}{ll}\text { SUPORTE } & \grave{A} \\
\text { APRENDIZAGEM }\end{array}$ & $\begin{array}{l}\text { Coelho Jr, F.A., Abbad, G.S., Vasconcelos, L.C. } \\
\text { (2008). Análise da relação entre variáveis de } \\
\text { clientela, suporte à aprendizagem e impacto de } \\
\text { treinamento a distância. RAC Eletrônica, v.2, n. } 1 \text {, } \\
\text { art. 6, pp. 88-104, jan/abr. }\end{array}$ & $\begin{array}{lrr}\text { Investiga } & \text { o relacionamento } \\
\text { entre características da } & \text { cas da } \\
\text { clientela e variáveis relativas à } \\
\text { organização r } \\
\text { psicossocial à aprendizagem) } \\
\text { na predição de impacto de um }\end{array}$ & \begin{tabular}{|l} 
Elaborado um modelo reduzido de \\
avaliação, empírico, baseado \\
principalmente nos Modelos MAIS e \\
IMPACT. Serão investigadas as \\
variáveis subsistema (área de lotação) \\
do indivíduo e suporte à aprendizagem
\end{tabular} & $\begin{array}{l}\text { Ressalta-se que tanto o instrumento de } \\
\text { suporte à aprendizagem quanto o de } \\
\text { impacto de treinamento no trabalho } \\
\text { apresentaram índices psicométricos } \\
\text { válidos. }\end{array}$ \\
\hline
\end{tabular}




\begin{tabular}{|c|c|c|c|c|}
\hline CATEGORIZAÇÃO & REFERÊNCIA & CONTEXTO & VARIÁVEIS & RESULTADOS \\
\hline & & $\begin{array}{|lll|}\begin{array}{l}\text { treinamento } \\
\text { trabalho. }\end{array} & \text { distância } & \text { no } \\
\end{array}$ & $\begin{array}{l}\text { e seu poder de explicação de impacto } \\
\text { de treinamento no trabalho. }\end{array}$ & \\
\hline $\begin{array}{l}\text { COMPETÊNCIAS } \\
\text { PROFISSIONAIS }\end{array}$ & $\begin{array}{l}\text { Moura, M.C.C., Bitencourt, C.C. (2006). A } \\
\text { articulação entre estratégia e o desenvolvimento de } \\
\text { competências gerenciais. RAE Eletrônica, São } \\
\text { Paulo, v.5, n. } 1 \text {, jan/jun. }\end{array}$ & 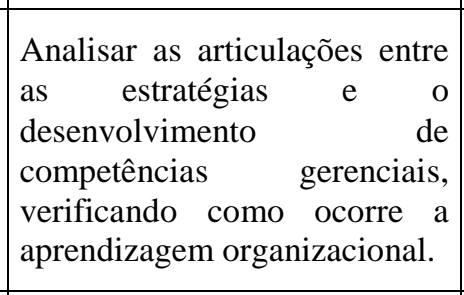 & \begin{tabular}{|l} 
O método utilizado foi estudo de caso \\
único, de caráter exploratório, de uma \\
empresa de serviços, em \\
mapeadas as estratégias adotadas pela \\
empresa, identificam-se as demandas \\
de desenvolvimento gerencial para \\
cada período.
\end{tabular} & $\begin{array}{l}\text { Os resultados obtidos sinalizam como a } \\
\text { aplicação de estratégias organizacionais } \\
\text { pode gerar necessidades de } \\
\text { desenvolvimento de novas competências } \\
\text { gerenciais, tendo em vista as atribuições e } \\
\text { responsabilidades que passam a ser } \\
\text { assumidas pelos gestores. }\end{array}$ \\
\hline $\begin{array}{l}\text { COMPETÊNCIAS } \\
\text { PROFISSIONAIS }\end{array}$ & $\begin{array}{l}\text { Maciel, C.O., \& Camargo C. (2013). } \\
\text { Sobrequalificação no trabalho e sua influência } \\
\text { sobre atitudes e comportamentos. Revista de } \\
\text { Administração Contemporânea, Curitiba, v.17, } \\
\text { n.2. }\end{array}$ & $\begin{array}{llrr}\text { Verificar } & \text { a } & \text { influência } & \text { da } \\
\text { sobrequalificação } & \text { percebida } \\
\text { no trabalho } & \text { sobre } & \text { satisfação, } \\
\text { intenção } & \text { de } & \text { saíla } & \text { e } \\
\text { cooperaçãa } & \text { do } & \text { indivíduo } & \text { na } \\
\text { organização. } & & \end{array}$ & $\begin{array}{l}\text { Sobrequalificação, Satisfação e e } \\
\text { Intenção de Saída são as variáveis de } \\
\text { atitudes; e a Cooperação, a variável } \\
\text { comportamental. }\end{array}$ & $\begin{array}{l}\text { Considerando as dimensões } \\
\text { sobrequalificação, a insatisfação do } \\
\text { funcionário, a intenção de saída e a baixa } \\
\text { cooperação, essas são resultados da } \\
\text { comparação que o indivíduo faz entre suas } \\
\text { habilidades e as oportunidades de } \\
\text { desenvolvimento providas pela } \\
\text { organização. Assim, as dimensões da } \\
\text { sobrequalificação apresentam-se como } \\
\text { constructos importantes para ampliação das } \\
\text { investigações acerca das interaçõ entre } \\
\text { elementos atitudinais e comportamentais. }\end{array}$ \\
\hline \begin{tabular}{|l} 
COMPETÊNCIAS \\
PROFISSIONAIS
\end{tabular} & $\begin{array}{l}\text { Carnasciali, A.M.S., \& Bulgacov, S. (2014). } \\
\text { Recursos e } \text { Competências Organizacionais } \\
\text { Distribuídos na Saúde Pública. Revista de } \\
\text { Administraçâao Contemporânea, Curitiba, v.18, } \\
\text { n.6. }\end{array}$ & 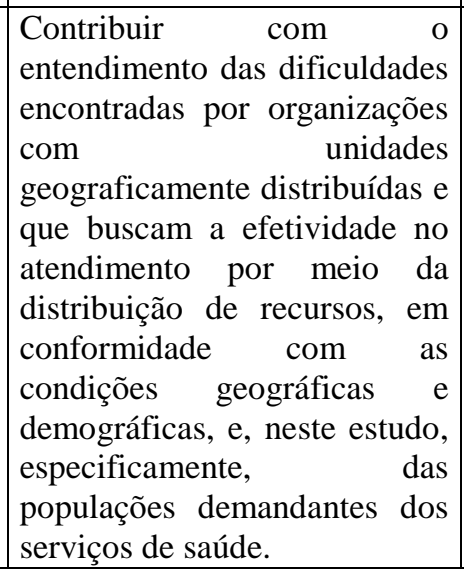 & $\begin{array}{l}\text { Análise do desenvolvimento dos } \\
\text { condicionantes da gestão de recursos e } \\
\text { competências, bem com a análise do } \\
\text { desenvolvimento do SIG - Sistema de } \\
\text { Informações Geográficas. }\end{array}$ & $\begin{array}{l}\text { Utilização da Visão Baseada em Recursos } \\
\text { (VBR) associada ao SIG, como elementos } \\
\text { de análises, possibilita a identificação dos } \\
\text { recursos estratégicos para um adequado } \\
\text { atendimento dos propósitos das UMS - } \\
\text { Unidades Municipais de Saúde de Curitiba, } \\
\text { Pr,, sendo imprescindível a identificação } \\
\text { das necessidades da população, seu perfil } \\
\text { socioeconômico, bem como a sua } \\
\text { distribuição espacial. }\end{array}$ \\
\hline
\end{tabular}




\begin{tabular}{|c|c|c|c|c|}
\hline CATEGORIZAÇÃO & REFERÊNCIA & CONTEXTO & VARIÁVEIS & RESULTADOS \\
\hline $\begin{array}{l}\text { COMPETÊNCIAS } \\
\text { PROFISSIONAIS }\end{array}$ & $\begin{array}{l}\text { Leite, J.B.D., Porsse, M.C.S. (2003). Competição } \\
\text { baseada em competências e aprendizagem } \\
\text { organizacional: em busca da vantagem } \\
\text { competitiva, Revista de Admin. Contemporânea, } \\
\text { v.7, no especial, Curitiba. }\end{array}$ & \begin{tabular}{|lrr}
$\begin{array}{l}\text { Aprofundar a discussão da } \\
\text { Teoria da }\end{array}$ \\
Baseada em Competição \\
Esta abordagem, que propõe \\
combinar duas perspectivas da \\
teoria estratégica (Escola de \\
Posicionamento Estratégico e \\
Teoria Baseada em Recursos), \\
reconhece os níveis de \\
incerteza que envolvem a a \\
mudança estratégica, assim \\
como a importância dos \\
processos de criação de \\
conhecimento e aprendizagem \\
organizacional.
\end{tabular} & 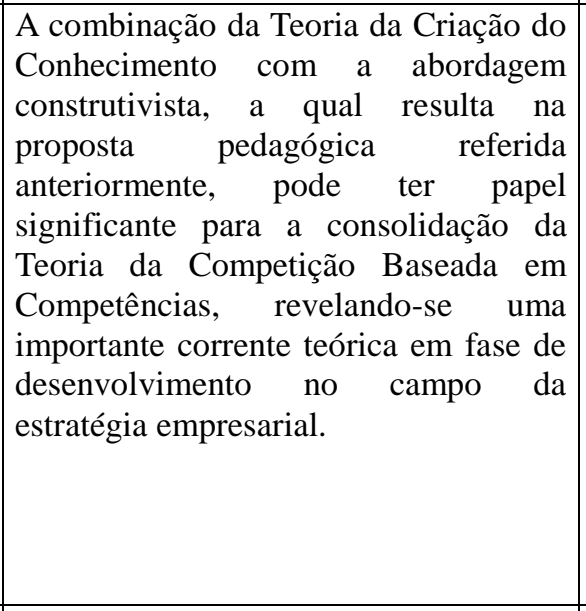 & $\begin{array}{l}\text { Procurou aprofundar a análise da nova } \\
\text { Teoria da Competição Baseada em } \\
\text { Competências, que emergiu no início dos } \\
\text { anos noventa, com o propósito de integrar } \\
\text { as Teorias da Organização Industrial e a } \\
\text { Baseada em Recursos. Considerando-se } \\
\text { que a fonte de vantagem competitiva reside } \\
\text { na aplicação do conhecimento pela } \\
\text { organização, a identificação e a utilização } \\
\text { das melhores práticas indicam que está } \\
\text { sendo pavimentado o caminho para um } \\
\text { desempenho organizacional superior. }\end{array}$ \\
\hline $\begin{array}{l}\text { COMPETÊNCIAS } \\
\text { PROFISSIONAIS }\end{array}$ & $\begin{array}{l}\text { Miguel, L.A.P., Teixeira, M.L.M. (2009). Valores } \\
\text { organizacionais e criação do conhecimento } \\
\text { organizacional inovador. Revista de Admin. } \\
\text { Contemporânea, v.13, n.1, Curitiba, Jan./Mar. }\end{array}$ & 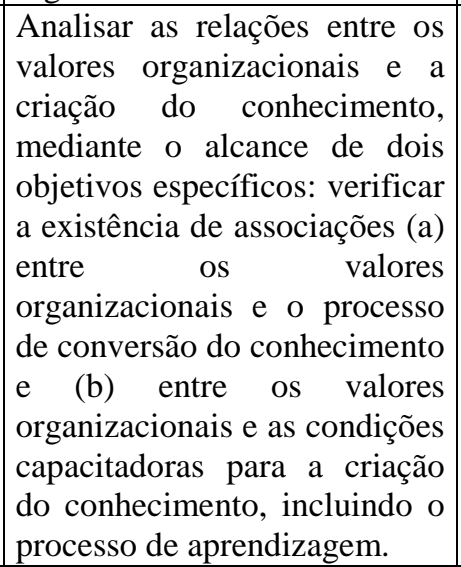 & $\begin{array}{l}\text { A pesquisa caracterizou-se como } \\
\text { exploratório-descritiva e empregou o } \\
\text { método quantitativo, coletando dados } \\
\text { mediante questionário fechado, do qual } \\
\text { fez parte um bloco formado por valores } \\
\text { organizacionais e outro composto por } \\
\text { assertivas relativas à criação do } \\
\text { conhecimento, além de um terceiro } \\
\text { destinado a variáveis demográficas. } \\
\text { Visando à redução do número de } \\
\text { variáveis da escala de Criação do } \\
\text { Conhecimento } \\
\text { utilizou-se a rotação VARIMAX com } \\
\text { extração de componentes principais. }\end{array}$ & $\begin{array}{l}\text { Os resultados evidenciaram indícios de } \\
\text { corroboração da hipótese proposta para o } \\
\text { estudo, uma vez que foi desenvolvido em } \\
\text { uma amostra não-probabilística, o que } \\
\text { demanda aprofundar em outros estudos a } \\
\text { relação entre valores organizacionais e } \\
\text { criação do conhecimento. }\end{array}$ \\
\hline $\begin{array}{l}\text { COMPETÊNCIAS } \\
\text { PROFISSIONAIS }\end{array}$ & $\begin{array}{l}\text { Mascarenhas, A.O., Vasconcelos, F.C., } \\
\text { Vasconcelos, I. F.G. (2005). Impactos da } \\
\text { tecnologia na gestão de pessoas - um estudo de } \\
\text { caso. Revista de Admin. Contemporânea, v.9, n.1 } \\
\text { Curitiba, Jan./Mar. }\end{array}$ & $\begin{array}{l}\text { Discutir os impactos } \text { da } \\
\text { tecnologia da informação e o } \\
\text { seu papel estratégico no } \\
\text { contexto de transição da } \\
\text { gestão de pessoas. }\end{array}$ & $\begin{array}{l}\text { O estudo de caso, apresentado neste } \\
\text { projeto, é do tipo incorporado, isto é, a } \\
\text { investigação foi dividida em algumas } \\
\text { subunidades de análise, ao invés de um } \\
\text { estudo que examinasse apenas a } \\
\text { natureza global do fenômeno. }\end{array}$ & $\begin{array}{l}\text { A informatização e a reorganização da } \\
\text { gestão de pessoas permitiram que os } \\
\text { profissionais de RH passassem a executar } \\
\text { outras funções no contexto organizacional. } \\
\text { As antigas funções operacionais, que } \\
\text { demandavam grande quantidade de } \\
\text { recursos e tempo dos profissionais, }\end{array}$ \\
\hline
\end{tabular}




\begin{tabular}{|c|c|c|c|c|}
\hline CATEGORIZAÇÃO & REFERÊNCIA & CONTEXTO & VARIÁVEIS & RESULTADOS \\
\hline & & & & $\begin{array}{l}\text { deixaram de estar no centro das } \\
\text { responsabilidades da área, e foram } \\
\text { substituídas pelas preocupações com } \\
\text { questões mais estratégicas. }\end{array}$ \\
\hline $\begin{array}{l}\text { COMPETÊNCIAS } \\
\text { PROFISSIONAIS }\end{array}$ & $\begin{array}{l}\text { Souza-Silva, J.C. (2009). Condições e desafios ao } \\
\text { surgimento de comunidades de prática em } \\
\text { organizações. Rev. adm. Empresas, v.49, n.2, São } \\
\text { Paulo, Abril /Junho. }\end{array}$ & 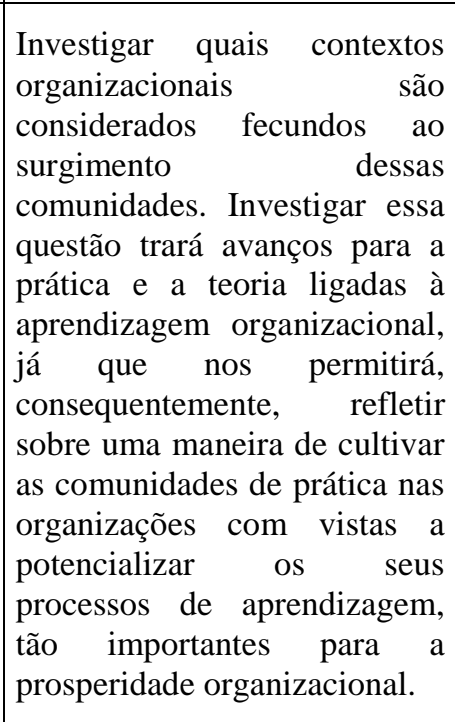 & $\begin{array}{l}\text { Estudo de caso múltiplo e a análise de } \\
\text { discurso } \\
\text { como estratégias metodológicas para } \\
\text { levar a cabo esse estudo empírico. }\end{array}$ & $\begin{array}{l}\text { Além da carência de valores e crenças } \\
\text { ligados à valorização da aprendizagem } \\
\text { socioprática, encontramos, na fala dos } \\
\text { entrevistados da maioria das faculdades } \\
\text { pesquisadas, a carência de valores e } \\
\text { crenças de valorização ao elemento } \\
\text { humano, que também tem o poder de } \\
\text { impedir a geração de condições ao } \\
\text { surgimento de comunidades de prática, } \\
\text { favorecendo o desengajamento afetivo dos } \\
\text { indivíduos. esta pesquisa propõe que } \\
\text { existência de uma cultura organizacional } \\
\text { de aprendizagem socioprática fomenta o } \\
\text { desenvolvimento de relações mais afetivas } \\
\text { e intimistas entre as pessoas, além da } \\
\text { compreensão do potencial das interações } \\
\text { socioprofissionais para o processo de } \\
\text { aprendizagem. }\end{array}$ \\
\hline $\begin{array}{l}\text { COMPETÊNCIAS } \\
\text { PROFISSIONAIS }\end{array}$ & $\begin{array}{l}\text { Celia, M.; Loiola, E. (2001). Aprendendo a } \\
\text { aprender: análise de três estudos de caso em } \\
\text { aprendizagem organizacional a partir do } \\
\text { construtivismo. Organizações e Sociedade, v.8, } \\
\text { n.22, pp. 1-15. }\end{array}$ & $\begin{array}{l}\text { Estabelecer nexos entre } \\
\text { abordagens do ensino e da } \\
\text { aprendizagem, mais familiares } \\
\text { ao campo da Educação, e as } \\
\text { teorias da aprendizagem } \\
\text { organizacional. Identifica, na } \\
\text { abordagem cognitivista da } \\
\text { aprendizagem organizacional, } \\
\text { a tendência a analisar o } \\
\text { fenômeno organizacional } \\
\text { enquanto rocion processo } \\
\text { socialmente construído pela } \\
\text { interação entre atores } \\
\text { relevantes, infundindo vida }\end{array}$ & $\begin{array}{l}\text { Investigar as formas pelas quais as } \\
\text { organizações desenvolvem framework } \\
\text { ou paradigmas, a partir dos quais as } \\
\text { suas próprias experiências são } \\
\text { interpretadas, o que põe em relevo a } \\
\text { problemática das representações, ou } \\
\text { seja, a possibilidade de desacordos em } \\
\text { torno do significado da experiência, da } \\
\text { história. }\end{array}$ & $\begin{array}{l}\text { A análise dos três estudos de caso tende a } \\
\text { confirmar as lacunas e problemas relativos } \\
\text { à } \\
\text { incapacidade, ainda persistente, de } \\
\text { relacionar dialeticamente indivíduo e } \\
\text { contexto. A teoria do ensino-aprendizagem } \\
\text { que ancora esta análise inspira a } \\
\text { revalorização dos espaços onde } \\
\text { concretamente se dão os processos, } \\
\text { sugerindo que questões relevantes para o } \\
\text { conhecimento como conteúdo, processo e } \\
\text { forma são fatores-chave para a } \\
\text { aprendizagem. }\end{array}$ \\
\hline
\end{tabular}




\begin{tabular}{|c|c|c|c|c|}
\hline CATEGORIZAÇÃO & REFERÊNCIA & CONTEXTO & VARIÁVEIS & RESULTADOS \\
\hline & & $\begin{array}{|lcr|}\text { própria } & \text { à } & \text { organização, em } \\
\text { oposição } & \text { ao } & \text { tradicional } \\
\text { construto } & \text { de } & \text { organização } \\
\text { como entidade racional. }\end{array}$ & & \\
\hline \begin{tabular}{|l} 
COMPETÊNCIAS \\
PROFISSIONAIS
\end{tabular} & $\begin{array}{l}\text { Meirelles, D.S., \& Camargo, A.A.B. (2014). } \\
\text { Capacidades Dinâmicas: O Que São e Como } \\
\text { Identificá-las? Revista de Administração } \\
\text { Contemporânea, Curitiba, v.18, n.spe. }\end{array}$ & 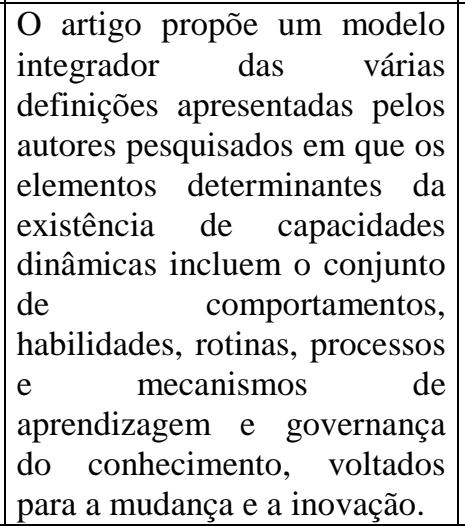 & $\begin{array}{l}\text { As capacidades dinâmicas são baseadas } \\
\text { no tripé: processos (rotinas ou padrões } \\
\text { de práticas correntes e aprendizado), } \\
\text { posições (ativos, estrutura de } \\
\text { governança, base de consumidores e } \\
\text { relações externas com fornecedores e } \\
\text { parceiros) e trajetória (histórico de } \\
\text { decisões e oportunidades tecnológicas } \\
\text { e de mercado). }\end{array}$ & $\begin{array}{l}\text { Foi definida uma classificação para } \\
\text { capacidades dinâmicas divididas em duas } \\
\text { visões. A primeira visão é definida como } \\
\text { um conjunto de comportamentos, } \\
\text { habilidades e capacidades organizacionais } \\
\text { que, quando combinadas, criam } \\
\text { capacidades dinâmicas na organização. A } \\
\text { segunda visão define que capacidades } \\
\text { dinâmicas são processos e rotinas que as } \\
\text { organizações devem usar para poderem se } \\
\text { adaptar e manter vantagens competitivas. }\end{array}$ \\
\hline $\begin{array}{l}\text { COMPETÊNCIAS } \\
\text { PROFISSIONAIS }\end{array}$ & $\begin{array}{l}\text { Do Amaral, H.K. (2006). Desenvolvimento de } \\
\text { competências de servidores na administração } \\
\text { pública brasileira. Revista do Serviço Público, } \\
\text { v.57, n. 4, Brasília. }\end{array}$ & 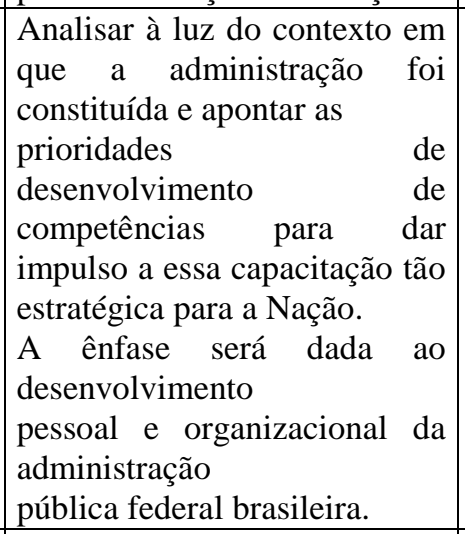 & $\begin{array}{l}\text { A moderna gestão de pessoas assenta- } \\
\text { se em um tripé estratégico: gestão por } \\
\text { competências; democratização das } \\
\text { relações de trabalho para gerar } \\
\text { ambientes adequados à inovação; e } \\
\text { qualificação intensiva das equipes de } \\
\text { trabalho, incluindo o uso de tecnologia } \\
\text { da informação. }\end{array}$ & $\begin{array}{l}\text { O perfil que os Especialistas em Políticas } \\
\text { Públicas e Gestão Governamental, deverão } \\
\text { ter no futuro é serem capazes de avaliar } \\
\text { riscos, fazer julgamentos com precisão e } \\
\text { agilidade, reconhecer problemas e } \\
\text { interesses, gerenciar diversidade de atores } \\
\text { envolvidos, negociar e gerenciar acordos, } \\
\text { repactuar regras, conhecer mercados, } \\
\text { escutar, ter consciência dos limites, } \\
\text { escolher técnicas, métodos e tecnologias e } \\
\text { gerenciar ajustes. }\end{array}$ \\
\hline \begin{tabular}{|l} 
COMPETÊNCIAS \\
PROFISSIONAIS
\end{tabular} & $\begin{array}{l}\text { Ghedine, T., Testa, M.G., Freitas, H.M.R. (2008). } \\
\text { Educação a distância via internet em grandes } \\
\text { empresas brasileiras. Revista de Administração de } \\
\text { Empresas, v. } 48, \text { n. 4, São Paulo, Out/Dez. }\end{array}$ & $\begin{array}{l}\text { Identificar as características } \\
\text { das iniciativas de Educação a } \\
\text { Distância via Internet em } \\
\text { grandes empresas privadas } \\
\text { brasileiras. }\end{array}$ & \begin{tabular}{|l} 
A pesquisa realizada possui natureza \\
exploratório-descritiva. O orarter \\
exploratório do estudo deriva da \\
inexistência de uma base conceitual \\
consolidada sobre EAD na área \\
organizacional . Por outro lado, as
\end{tabular} & 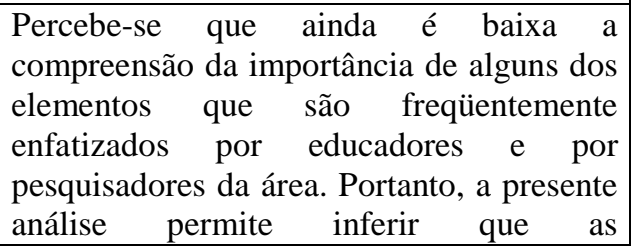 \\
\hline
\end{tabular}




\begin{tabular}{|c|c|c|c|c|}
\hline CATEGORIZAÇÃO & REFERÊNCIA & CONTEXTO & VARIÁVEIS & RESULTADOS \\
\hline & & & $\begin{array}{l}\text { principais características das iniciativas } \\
\text { de EADI foram levantadas em uma } \\
\text { estrutura de coleta de dados típica de } \\
\text { um estudo descritivo. }\end{array}$ & \begin{tabular}{|l|} 
possibilidades da EADI não são \\
plenamente exploradas. Um dos prováveis \\
motivos para essa realidade está no foco de \\
muitas das iniciativas implementadas e \\
analisadas: a redução de custos. \\
\end{tabular} \\
\hline $\begin{array}{l}\text { COMPETÊNCIAS } \\
\text { PROFISSIONAIS }\end{array}$ & $\begin{array}{l}\text { Silva, F.M., Mello, S.P.T. (2011). A noção de } \\
\text { competência na gestão de pessoas: reflexões a } \\
\text { partir de casos do setor público. Revista do } \\
\text { Serviço Público, v. } 62 \text { n. } 2 \text {, pp. 167-183, Brasília, } \\
\text { abr/jun. }\end{array}$ & 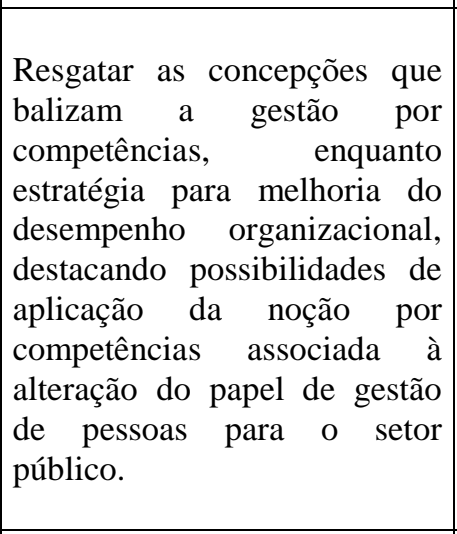 & \begin{tabular}{|l|} 
Estudos recentes apresentam a \\
competência em pelo menos duas \\
grandes perspectivas, estando cada \\
uma delas atrelada a um eixo \\
conceitual . O primeiro refere-se à \\
dimensão estratégica das organizações, \\
provocando um debate importante para \\
o desenvolvimento da competitividade. \\
O segundo eixo conceitual, que debate \\
as competências, é associado a práticas \\
próprias de gestão de pessoas, como \\
seleção, desenvolvimento, avaliação e \\
remuneração.
\end{tabular} & $\begin{array}{l}\text { Pode-se dizer que o sucesso no } \\
\text { desenvolvimento } \\
\text { da gestão por competências também está } \\
\text { em reconhecer que, por ser uma abordagem } \\
\text { com foco nas pessoas, se trata de um } \\
\text { processo evolucionário com } \\
\text { eventos planejados e espontâneos que } \\
\text { visam transformar comportamentos e } \\
\text { atitudes, o que leva tempo e exige } \\
\text { paciência ao longo das ações } \\
\text { organizacionais do dia a dia. }\end{array}$ \\
\hline $\begin{array}{l}\text { IMPACTO DO } \\
\text { TREINAMENTO } \\
\text { NO TRABALHO }\end{array}$ & $\begin{array}{l}\text { Fleury, M.T.L., Fleury, A. (2001). Construindo o } \\
\text { conceito de competência. Rev. adm. } \\
\text { Contemporânea, v.5. n. spe, Curitiba. }\end{array}$ & $\begin{array}{l}\text { Recuperar o debate térico a } \\
\text { respeito da noção de } \\
\text { competência, explicitando o } \\
\text { conceito em seus vários níveis } \\
\text { de } \\
\text { relacionando-o à estratégáaia, e } \\
\text { aos processos de de } \\
\text { aprendizagem organizacional. }\end{array}$ & 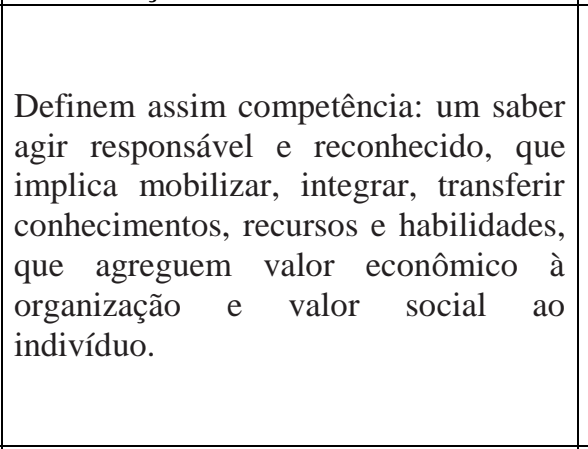 & $\begin{array}{l}\text { A noção de competência, explorada neste } \\
\text { texto, lança luz sobre um aspecto } \\
\text { importante: se por um lado, agrega valor } \\
\text { econômico à organização, por outro não } \\
\text { menos relevante deve agregar valor social } \\
\text { ao indivíduo, ou seja, as pessoas, ao } \\
\text { desenvolverem competências essenciais } \\
\text { para o sucesso da organização, estão } \\
\text { também investindo em si mesmas, não só } \\
\text { como cidadãos organizacionais, mas como } \\
\text { cidadãos do próprio país e do mundo. }\end{array}$ \\
\hline $\begin{array}{l}\text { IMPACTO DO } \\
\text { TREINAMENTO } \\
\text { NO TRABALHO }\end{array}$ & $\begin{array}{l}\text { Loiola, E., Bastos, A.V.B. (2003). A produção } \\
\text { acadêmica sobre aprendizagem organizacional no } \\
\text { Brasil. Rev. adm. contemporânea, v.7, n. 3, } \\
\text { Curitiba, July/Sept. }\end{array}$ & 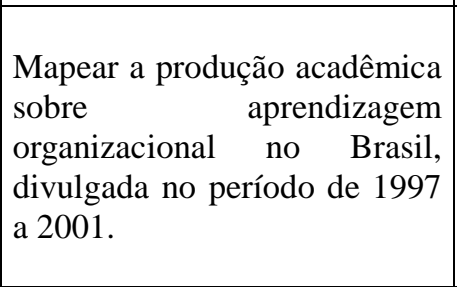 & $\begin{array}{|lrrr|}\text { A seleção das } & \text { fontes } & \text { de } & \text { pesquisa } \\
\text { buscou } & \text { assegurar a cobertura } & \text { dos } \\
\text { periódicos nacionais mais expressivos, } \\
\text { assim como de anais de dois dos mais } \\
\text { importantes } & \text { encontros } & \text { de } \\
\text { pesquisadores, } & \text { acadêmicos } & \text { e } \\
\text { consultores } & \text { no } & \text { campo } & \text { da }\end{array}$ & $\begin{array}{l}\text { Evidenciou-se, mais uma vez, a bifurcação } \\
\text { do campo entre duas abordagens - } \\
\text { organizações que aprendem e } \\
\text { aprendizagem organizacional, assim como } \\
\text { a prevalência de literatura estrangeira, } \\
\text { notadamente produzida por autores } \\
\text { posicionados nos Estados Unidos. }\end{array}$ \\
\hline
\end{tabular}




\begin{tabular}{|c|c|c|c|c|}
\hline CATEGORIZAÇÃO & REFERÊNCIA & CONTEXTO & VARIÁVEIS & RESULTADOS \\
\hline & & & Administração. & \\
\hline $\begin{array}{l}\text { IMPACTO DO } \\
\text { TREINAMENTO } \\
\text { NO TRABALHO }\end{array}$ & $\begin{array}{l}\text { De Souza, Y. S. (2004). Organizações de } \\
\text { aprendizagem ou aprendizagem organizacional. } \\
\text { RAE electronica, v.3, n.1, São Paulo, Jan./June. }\end{array}$ & $\begin{array}{l}\text { Chamar à atenção para } \\
\text { possibilidades } \\
\text { desenvolvimento e otimização } \\
\text { de processos de aprendizagem } \\
\text { organizacional, levando-se em } \\
\text { conta as realidades } \\
\text { culturais dociais e } \\
\text { organizacionais. contextos }\end{array}$ & 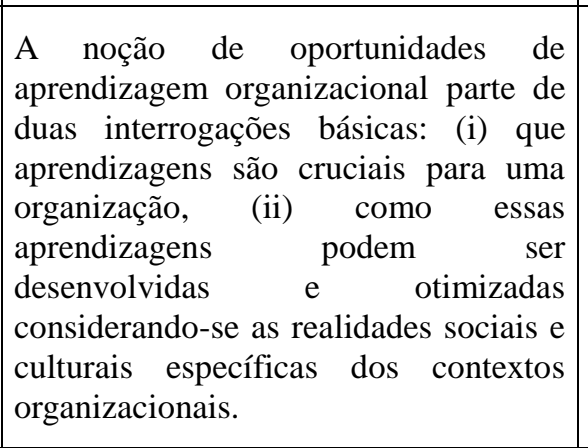 & $\begin{array}{l}\text { Existem caminhos para a prática da } \\
\text { aprendizagem organizacional que não se } \\
\text { restringem às idéias de A quinta disciplina } \\
\text { de Peter Senge e sua proposição das } \\
\text { organizações de aprendizagem. Com a } \\
\text { noção de oportunidades de aprendizagem } \\
\text { organizacional aqui proposta, pretendemos } \\
\text { designar momentos e situações que, jás } \\
\text { inscritos na cultura e nas formas } \\
\text { privilegiadas de ação da organização, são } \\
\text { propícios à aprendizagem. }\end{array}$ \\
\hline $\begin{array}{l}\text { IMPACTO DO } \\
\text { TREINAMENTO } \\
\text { NO TRABALHO }\end{array}$ & $\begin{array}{l}\text { Fernandes, B.H.R.; Fleury, M.T.L.; Mills, J. } \\
\text { (2006). Construindo o diálogo entre competência, } \\
\text { recursos e desempenho organizacional. Revista de } \\
\text { Administração de Empresas, v.46, n. 4, São Paulo, } \\
\text { Oct./Dec. }\end{array}$ & 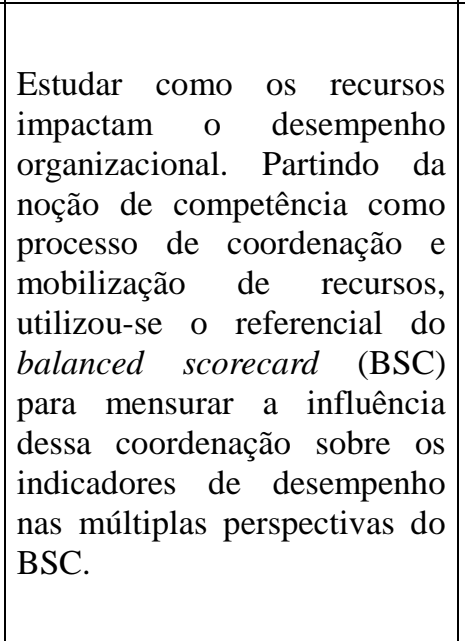 & $\begin{array}{l}\text { Procurou-se entender que recursos e } \\
\text { indicadores os membros das } \\
\text { organizações em } \\
\text { estudo julgavam importantes para a } \\
\text { obtenção de exito no desempenho, } \\
\text { cobrindo todas as perspectivas do BSC. }\end{array}$ & $\begin{array}{l}\text { Em geral, as variáveis estão } \\
\text { correlacionadas. A competência foco em } \\
\text { resultado parece resultar da coordenação } \\
\text { dos recursos satisfação dos empregados e } \\
\text { densidade de recursos. Outros detalhes que } \\
\text { apareceram na análise foram: o grau de } \\
\text { competência profissional, segundo a forma } \\
\text { medida pela empresa, não apresentou } \\
\text { associação com variáveis de desempenho; } \\
\text { os fatores ambientais relacionados ao } \\
\text { consumo residencial apareceram como o } \\
\text { mais forte determinante da performance; a } \\
\text { satisfação dos empregados demonstrou } \\
\text { associação com metas de processos } \\
\text { internos, com metas financeiras e com a } \\
\text { satisfação dos consumidores. }\end{array}$ \\
\hline $\begin{array}{l}\text { IMPACTO DO } \\
\text { TREINAMENTO } \\
\text { NO TRABALHO }\end{array}$ & $\begin{array}{l}\text { Pilati,R., Abbad, G. (2005). Análise fatorial } \\
\text { confirmatória da escala de impacto do treinamento } \\
\text { no trabalho. Psicologia: Teoria e Pesquisa, } \\
\text { Brasília, v.21, n.1. }\end{array}$ & $\begin{array}{l}\text { Testar a estrutura empírica de } \\
\text { um instrumento de impacto do } \\
\text { treinamento no } \\
\text { trabalho por meio de } \\
\text { modelagem por equações } \\
\text { estruturais. }\end{array}$ & $\begin{array}{l}\text { Notoriamente, a literatura aponta que } \\
\text { os indicadores de resultado do } \\
\text { treinamento no trabalho dos indivíduos } \\
\text { são descritos pelos conceitos r de } \\
\text { transferência de aprendizagem } \\
\text { impacto do treinamento no trabalho. }\end{array}$ & $\begin{array}{l}\text { Foi realizada uma AFC do instrumento de } \\
\text { impacto do treinamento no trabalho de } \\
\text { Abbad (1999) em uma ampla amostra. } \\
\text { Esse resultado permitiu a indicação de } \\
\text { elementos para o aprimoramento da escala } \\
\text { e também a confirmação, por meio de uma } \\
\text { técnica confirmatória de análise de dados, }\end{array}$ \\
\hline
\end{tabular}




\begin{tabular}{|c|c|c|c|c|}
\hline CATEGORIZAÇÃO & REFERÊNCIA & CONTEXTO & VARIÁVEIS & RESULTADOS \\
\hline & & & & $\begin{array}{l}\text { da estrutura empírica unidimensional do } \\
\text { mesmo, corroborando com sua estrutura } \\
\text { teórica proposta por Abbad (1999). Esses } \\
\text { resultados auxiliam na descrição dos } \\
\text { fenômenos relacionados à mudança } \\
\text { individual provocada pelo treinamento, } \\
\text { proporcionando aprimoramento dos } \\
\text { modelos explicativos do fenômeno. }\end{array}$ \\
\hline \begin{tabular}{|l} 
IMPACTO DO \\
TREINAMENTO \\
NO TRABALHO
\end{tabular} & $\begin{array}{l}\text { Antonello, C.S., Godoy, A.S. (2010). A } \\
\text { encruzilhada da aprendizagem organizacional: } \\
\text { uma visão multiparadigmática. Revista de } \\
\text { Administração Contemporânea, v.14, n. } 2, \\
\text { Curitiba, Apr. }\end{array}$ & $\begin{array}{l}\text { Utilizando-se uma análise de } \\
\text { inspiração } \\
\text { multiparadigmática, as } \\
\text { contribuições identificadas } \\
\text { foram agrupadas em cinco } \\
\text { campos que apresentam } \\
\text { alguns temas e questões } \\
\text { recorrentes. Esta análise } \\
\text { aponta quatro questões } \\
\text { (relacionadas ao nível de } \\
\text { análise, resultados da } \\
\text { aprendizagem, mudanças e } \\
\text { processos de aprendizagem), } \\
\text { que o conceito de AO deve } \\
\text { superar para tornar-ser } \\
\text { significativo. }\end{array}$ & $\begin{array}{l}\text { Em função da evolução das teorias e } \\
\text { adotando-se um olhar capaz de } \\
\text { acomodar diversas representações da } \\
\text { temática, acredita-se que seja possível } \\
\text { identificar quatro características da } \\
\text { AO, que precisam ser mais discutidas, } \\
\text { incorporadas e/ou resgatadas para uma } \\
\text { compreensão do fenômeno e para o } \\
\text { delineamento de um conceito de AO } \\
\text { que fundamente seu estudo empírico. }\end{array}$ & $\begin{array}{l}\text { A proposta da abordagem da aprendizagem } \\
\text { baseada em práticas focaliza } \\
\text { predominantemente a prática como } \\
\text { atividade e seu papel nos processos de } \\
\text { aprendizagem. abordagem da } \\
\text { aprendizagem baseada em práticas está } \\
\text { preocupada em compreender como o } \\
\text { conhecimento é produzido ou transformado } \\
\text { por meio de sujeitos com e/ou em atividade } \\
\text { e, não necessariamente, como o } \\
\text { atingimento de metas pode representar que } \\
\text { ocorreu aprendizagem. }\end{array}$ \\
\hline \begin{tabular}{|l} 
IMPACTO DO \\
TREINAMENTO \\
NO TRABALHO
\end{tabular} & $\begin{array}{l}\text { Bahry, C.P., \& Tolfo, S.R. (2007). Mobilização de } \\
\text { competências nas atividades profissionais dos } \\
\text { egressos de um programa de formação e } \\
\text { aperfeiçoamento. Revista de Administraçâa } \\
\text { Pública, Rio de Janeiro, v.41, n.1. }\end{array}$ & $\begin{array}{l}\text { Identifica a percepção dos } \\
\text { funcionários egressos do } \\
\text { Programa de Formação e } \\
\text { Aperfeiçoamento em Nível } \\
\text { Superior do Banco do Brasil, } \\
\text { titulados mestres ou doutores, } \\
\text { sobre a mobilização, nos } \\
\text { cargos em que estão alocados, } \\
\text { das competências } \\
\text { desenvolvidas nos programas } \\
\text { de pós-graduação onde } \\
\text { obtiveram a titulação. }\end{array}$ & $\begin{array}{l}\text { A pesquisa, descritiva, utilizou uma } \\
\text { abordagem metodológica qualitativa e } \\
\text { quantitativa. A coleta de dados foi feita } \\
\text { por meio de pesquisa documental e de } \\
\text { questionário. A população foi } \\
\text { composta pelos funcionários que } \\
\text { participaram do programa e já haviam } \\
\text { retornado ao trabalho. }\end{array}$ & $\begin{array}{l}\text { Foi possível demonstrar que os principais } \\
\text { conhecimentos desenvolvidos pelos } \\
\text { funcionários egressos, durante a } \\
\text { permanência no programa, foram relativos } \\
\text { a saberes acadêmicos, bem como a técnicas } \\
\text { e métodos de pesquisa e ensino. Esses } \\
\text { conhecimentos demonstram congruência } \\
\text { com o tipo de formação que o programa } \\
\text { proporciona aos egressos. }\end{array}$ \\
\hline
\end{tabular}




\begin{tabular}{|c|c|c|c|c|}
\hline CATEGORIZAÇÃO & REFERÊNCIA & CONTEXTO & VARIÁVEIS & RESULTADOS \\
\hline $\begin{array}{l}\text { IMPACTO DO } \\
\text { TREINAMENTO } \\
\text { NO TRABALHO }\end{array}$ & $\begin{array}{l}\text { Abbad, G. S.; Corrêa, V. P.; Meneses, P. P. M. } \\
\text { (2010). Avaliação de treinamentos a distância: } \\
\text { relações entre estratégias de aprendizagem e } \\
\text { satisfação com o treinamento. Revista de } \\
\text { Administração Mackenzie, v. 11, n. 2, art. } 69 \text {, pp. } \\
\text { 43-67. }\end{array}$ & $\begin{array}{l}\text { Análise da relação entre o uso } \\
\text { de } \quad \text { estratégias } r \quad \text { de } \\
\text { aprendizagem e a } \\
\text { com o treinamento }\end{array}$ & $\begin{array}{l}\text { Realizada no Ministério Público do } \\
\text { Trabalho, esta } \\
\text { exploratória eraisa, de natureza } \\
\text { procedimentos baseada em em } \\
\text { quantitativos, contemplou uma série de } \\
\text { cursos de natureza e complexidade } \\
\text { diferenciadas sob responsabilidade da } \\
\text { instituição referida. }\end{array}$ & 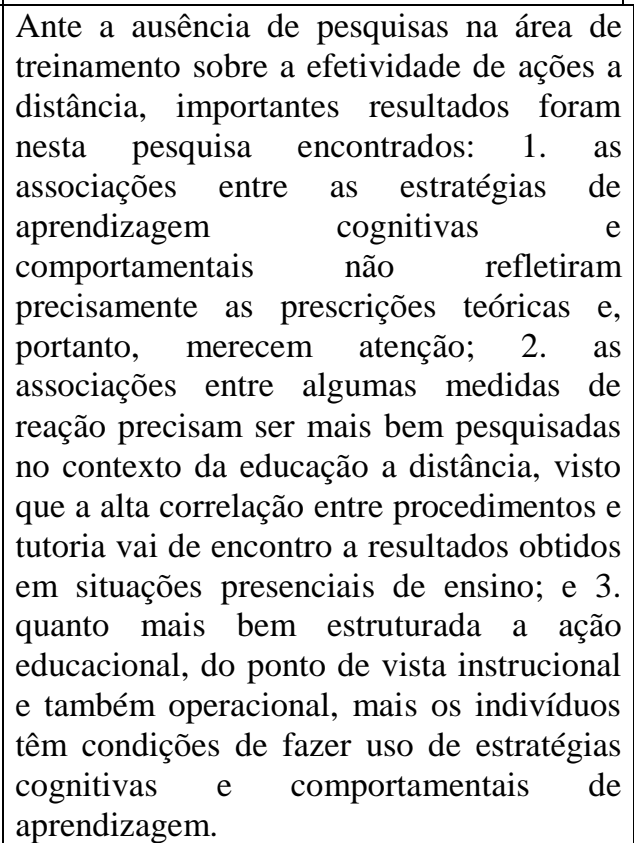 \\
\hline $\begin{array}{l}\text { IMPACTO DO } \\
\text { TREINAMENTO } \\
\text { NO TRABALHO }\end{array}$ & $\begin{array}{l}\text { Camillis, P.K., Antonello, C.S. (2010). Um estudo } \\
\text { sobre os processos de aprendizagem dos } \\
\text { trabalhadores que não exercem função gerencial. } \\
\text { Revista de Administração Mackenzie, v.11, n. } 2 \text {, } \\
\text { São Paulo, Mar/Apr. }\end{array}$ & $\begin{array}{l}\text { Contribuir para os escassos } \\
\text { estudos sobre aprendizagem } \\
\text { que considerem outros níveis } \\
\text { da hierarquia organizacional, } \\
\text { além de trazer subsídios aos } \\
\text { profissionais que atuam na } \\
\text { área de desenvolvimento de } \\
\text { recursos humanos para a } \\
\text { elaboração de uma análise } \\
\text { crítica sobre as atuais práticas } \\
\text { e a posterior formulação de } \\
\text { políticas na área, que possam } \\
\text { ser condizentes com a } \\
\text { realidade da organização onde } \\
\text { estão inseridos. }\end{array}$ & $\begin{array}{l}\text { Os dados foram coletados por meio de } \\
\text { entrevistas semiestruturadas, baseadas } \\
\text { em roteiro previamente preparado, } \\
\text { porém com flexibilidade para ordenar, } \\
\text { formular e aprimorar as perguntas } \\
\text { durante a entrevista. A análise foi feita } \\
\text { por meio da técnica de análise de } \\
\text { conteúdo, procurando identificar } \\
\text { presença ou ausência de uma } \\
\text { característica (ou um conjunto) e } \\
\text { descobrir os núcleos de sentido que } \\
\text { compõem uma comunicação, a fim de } \\
\text { verificar a ocorrência e a relevância } \\
\text { desses núcleos (categorias de análise), } \\
\text { com base na análise do relato de cada }\end{array}$ & $\begin{array}{l}\text { Foi possível identificar e descrever os tipos } \\
\text { de processos de aprendizagem que ocorrem } \\
\text { no local de trabalho de um grupo de } \\
\text { trabalhadores que não ocupam } \\
\text { papéis/cargos/funções gerenciais. Alguns } \\
\text { desses processos foram considerados mais } \\
\text { usuais e mais eficientes pelos pesquisados, } \\
\text { principalmente os informais. Os resultados } \\
\text { aqui discutidos foram apresentados na } \\
\text { forma de agrupamento de categorias, } \\
\text { porém interdependentes e dinâmicas. }\end{array}$ \\
\hline
\end{tabular}




\begin{tabular}{|c|c|c|c|c|}
\hline CATEGORIZAÇÃO & REFERÊNCIA & CONTEXTO & VARIÁVEIS & RESULTADOS \\
\hline & & & sujeito pesquisado. & \\
\hline $\begin{array}{l}\text { IMPACTO DO } \\
\text { TREINAMENTO } \\
\text { NO TRABALHO }\end{array}$ & $\begin{array}{l}\text { Remor, L.C., Miranda, A.C.D., Santos, N., Steil, } \\
\text { A.V., Remor, C.A.M. (2010). Esquecimento } \\
\text { organizacional e suas consequências no processo } \\
\text { de aprendizagem organizacional. Revista de } \\
\text { Administração Pública, v.44, n.3, Rio de Janeiro, } \\
\text { May/June. }\end{array}$ & $\begin{array}{l}\text { Revisão da literatura sobre o } \\
\text { tema } \\
\text { organizacional" esquecimento } \\
\text { consequências no processo de } \\
\text { aprendizagem organizacional. } \\
\text { O objetivo da revisão é } \\
\text { mostrar a importância } \\
\text { atribuída ao esquecimento } \\
\text { organizacional, considerando } \\
\text { que ele interfere no processo } \\
\text { da aprendizagem. }\end{array}$ & $\begin{array}{l}\text { A metodologia utilizada para este } \\
\text { artigo foi o levantamento bibliográfico. } \\
\text { Foram pesquisados em diversas bases } \\
\text { de dados termos relativos ao tema } \\
\text { "esquecimento organizacional". Nas } \\
\text { tabelas estão os termos pesquisados, } \\
\text { em que índices foram procurados e } \\
\text { documentos recuperados. Destaca-se } \\
\text { que a base Scielo apresenta títulos de } \\
\text { periódicos que não têm acesso livre. } \\
\text { Assim, o mesmo título foi procurado } \\
\text { no portal da Capes. }\end{array}$ & $\begin{array}{l}\text { Considerando que a memória é importante } \\
\text { como armazenamento e preservação do } \\
\text { conhecimento e até para a sua constituição, } \\
\text { é necessário certo esquecimento. Fica a } \\
\text { questão de por que o esquecimento, na } \\
\text { literatura, parece ter ficado em segundo } \\
\text { plano. A aprendizagem organizacional, } \\
\text { como também o esquecimento ligado à } \\
\text { memória organizacional, parte do processo } \\
\text { de aprendizagem, torne-se um campo } \\
\text { favorável para pesquisas. }\end{array}$ \\
\hline $\begin{array}{l}\text { IMPACTO DO } \\
\text { TREINAMENTO } \\
\text { NO TRABALHO }\end{array}$ & $\begin{array}{l}\text { Fernandes, B.H.R., Fleury, M.T.L., Mills, J. } \\
\text { (2006). Construindo o diálogo entre competência, } \\
\text { recursos e desempenho organizacional. Revista de } \\
\text { Administração de Empresas, v.46, n. 4, São Paulo, } \\
\text { Oct./Dec. }\end{array}$ & $\begin{array}{l}\text { Estudar como os recursos } \\
\text { impactam o desempenho } \\
\text { organizacional. Partindo da } \\
\text { noção de competência como } \\
\text { processo de coordenação e } \\
\text { mobilização de recursos, } \\
\text { utilizou-se o referencial do } \\
\text { balanced scorecard (BSC) } \\
\text { para mensurar a infl uência } \\
\text { dessa coordenação sobre os } \\
\text { indicadores de desempenho } \\
\text { nas múltiplas perspectivas do } \\
\text { BSC. }\end{array}$ & $\begin{array}{l}\text { Foram estabelecidas as seguintes } \\
\text { etapas: (a) definir, com os integrantes } \\
\text { da empresa, uma competência } \\
\text { organizacional para as URs e seus } \\
\text { recursos componentes, utilizando a } \\
\text { metodologia arquitetura de } \\
\text { competências e recursos; (b) definir } \\
\text { resultados e indicadores importantes } \\
\text { que as unidades deveriam buscar } \\
\text { dentro de cada perspectiva do BSC; (c) } \\
\text { estabelecer, por meio de mapas } \\
\text { causais, as ligações entre recursos e } \\
\text { indicadores de performance; (d) coletar } \\
\text { dados junto aos sistemas de informação } \\
\text { da empresa, quando já } \\
\text { monitorados, ou desenvolver e aplicar } \\
\text { instrumento de coleta específico no } \\
\text { caso de dados não disponíveis; (e) } \\
\text { aplicar técnicas de análise fatorial } \\
\text { visando identificar fatores (ou variáveis } \\
\text { reduzidas) que explicassem parte } \\
\text { significativa da variância em cada }\end{array}$ & $\begin{array}{l}\text { Tais constatações apontam para a } \\
\text { necessidade de aprofundar estudos sobre a } \\
\text { relação entre competências / recursos } \\
\text { organizacionais e performance, tema deste } \\
\text { artigo. Em particular, tais estudos deveriam } \\
\text { privilegiar os seguintes aspectos: (a) } \\
\text { avaliar a performance em suas múltiplas } \\
\text { perspectivas simultaneamente; e (b) incluir } \\
\text { outros recursos ou direcionadores da } \\
\text { performance, como competências } \\
\text { individuais, ativos tangíveis, satisfação, } \\
\text { etc., além das práticas de RH. }\end{array}$ \\
\hline
\end{tabular}




\begin{tabular}{|c|c|c|c|c|}
\hline CATEGORIZAÇÃO & REFERÊNCIA & CONTEXTO & VARIÁVEIS & RESULTADOS \\
\hline & & & $\begin{array}{l}\text { perspectiva do BSC; e (f) conduzir } \\
\text { análises de regressão para verificar } \\
\text { associações entre variáveis reduzidas, } \\
\text { fossem elas recursos ou indicadores } \\
\text { de performance. }\end{array}$ & \\
\hline \begin{tabular}{|l} 
IMPACTO DO \\
TREINAMENTO \\
NO TRABALHO
\end{tabular} & $\begin{array}{l}\text { Meneses, P.P.M., Abbad, G.S. (2003). Preditores } \\
\text { individuais e situacionais de auto e } \\
\text { heteroavaliação de impacto do treinamento no } \\
\text { trabalho. } R A C \text {, Ediçãa Especial, pp. 185-204. }\end{array}$ & $\begin{array}{l}\text { Esse trabalho fundamenta-se } \\
\text { na premissa de que qualquer } \\
\text { indivíduo é capaz de aprender } \\
\text { e transferir suas novas } \\
\text { habilidades para situações de } \\
\text { trabalho, desde que o desenho } \\
\text { instrucional e as condições de } \\
\text { apoio à aprendizagem e à } \\
\text { transferência o estimulem a } \\
\text { engajar-se nesse processo de } \\
\text { mudança comportamental. }\end{array}$ & $\begin{array}{l}\text { Os seguintes instrumentos foram } \\
\text { utilizados: Auto-eficácia, Locus de } \\
\text { Controle, Motivação para o } \\
\text { Treinamento, Impacto em Amplitude } \\
\text { do Treinamento no Trabalho e Suporte } \\
\text { à Transferência. }\end{array}$ & $\begin{array}{l}\text { Apesar de a principal questão deste estudo } \\
\text { estar relacionada à contribuição de } \\
\text { variáveis individuais na predição de } \\
\text { impacto de treinamento, os resultados } \\
\text { mostraram que não são essas variáveis as } \\
\text { principais preditoras de impacto. Quando } \\
\text { medidas de avaliação auto-referente } \\
\text { compuseram o modelo de regressão em } \\
\text { conjunto com medida referentes a } \\
\text { aspectos externos e não relacionados à } \\
\text { personalidade ou ao estilo pessoal, apenas } \\
\text { as avaliações do ambiente organizacional } \\
\text { explicaram significativamente o impacto } \\
\text { do treinamento no trabalho. }\end{array}$ \\
\hline
\end{tabular}


Apêndice II - Pesquisas internacionais selecionadas sobre suporte à aprendizagem, competências organizacionais e impacto do treinamento no trabalho

\begin{tabular}{|c|c|c|c|c|}
\hline CATEGORIZAÇÃO & AUTOR & CONTEXTO & VARIÁVEIS & RESULTADOS \\
\hline $\begin{array}{l}\text { SUPORTE } \\
\text { APRENDIZAGEM }\end{array}$ & $\begin{array}{l}\text { Velada, R., Caetano, A., } \\
\text { Michel, J.W., Lyons, B. D., } \\
\text { Kavanagh, M. J. (2007). The } \\
\text { effects of training design, } \\
\text { individual characteristics and } \\
\text { work environment on transfer } \\
\text { of training. International } \\
\text { Journal of Training and } \\
\text { Development, v. 11, n. 4, pp. } \\
\text { 282-294. }\end{array}$ & $\begin{array}{l}\text { Total de } 182 \text { gerentes de uma grande } \\
\text { rede de supermercados em Portugal. } \\
\text { Treinamentos ocorridos em nove } \\
\text { mercados da rede, com duração de um } \\
\text { mês, relacionados a atendimento ao } \\
\text { cliente, segurança, prevenção e higiene } \\
\text { laboral. }\end{array}$ & $\begin{array}{l}\text { Variável critério ou dependente: } \\
\text { transferência de treinamento; } \\
\text { Variáveis preditoras ou } \\
\text { independentes: Desenho do } \\
\text { treinamento, auto-eficácia, } \\
\text { retenção de treinamento, suporte } \\
\text { do supervisor e feedback. }\end{array}$ & $\begin{array}{l}\text { Os resultados confirmaram as hipóteses de } \\
\text { predição de todas as variáveis, inclusive do } \\
\text { feedback de outras pessoas da organização, mas } \\
\text { rejeitaram o suporte do supervisor como preditor. } \\
\text { Os autores argumentaram que a não participação } \\
\text { de suporte do supervisor poderia ser explicada } \\
\text { pelo enfoque exclusivo de suporte pós- } \\
\text { treinamento (reforço positivo e reuniões) adotado } \\
\text { em sua pesquisa e que poderia ter havido efeito } \\
\text { mais forte dessa variável sobre a transferência se } \\
\text { tivessem sido investigadas também as } \\
\text { intervenções do supervisor no período pré- } \\
\text { treinamento e durante a sua execução. }\end{array}$ \\
\hline $\begin{array}{l}\text { SUPORTE } \\
\text { APRENDIZAGEM }\end{array}$ & $\begin{array}{l}\text { Burke, L.A.; Hutchins, H.M. } \\
\text { (2007). Training Transfer: An } \\
\text { Integrative Literature Review. } \\
\text { Human Resource } \\
\text { Development Review. v. 6; pp. } \\
\text { 263-297. }\end{array}$ & $\begin{array}{l}\text { Total de } 170 \text { artigos a respeito de } \\
\text { transferência de treinamento. Os } \\
\text { autores tiveram como foco } \\
\text { investigações empíricas e meta- } \\
\text { análises, particularmente aquelas } \\
\text { publicadas em periódicos relevantes } \\
\text { nas últimas décadas. }\end{array}$ & $\begin{array}{l}\text { Variável critério ou dependente: } \\
\text { Transferência de treinamento; } \\
\text { Variáveis preditoras ou } \\
\text { independentes: características da } \\
\text { clientela, desenho/entrega da } \\
\text { instrução e aspectos do ambiente } \\
\text { de trabalho. }\end{array}$ & $\begin{array}{l}\text { Variáveis que demonstraram influência moderada } \\
\text { ou significativa na transferência de treinamento: - } \\
\text { Referentes às características da clientela: } \\
\text { habilidade cognitiva, auto-eficácia, motivação } \\
\text { pré-treinamento, afetividade negativa, abertura } \\
\text { para novas experiências, utilidade percebida, } \\
\text { planejamento da carreira, comprometimento } \\
\text { organizacional. - Desenho/entrega da instrução: } \\
\text { Objetivos de aprendizagem, relevância do } \\
\text { conteúdo, feedback e prática, modelagem } \\
\text { comportamental, exemplos baseados em erros } \\
\text { (mostrar o que não deve ser feito) - Propriedades } \\
\text { do ambiente de trabalho: clima para transferência, } \\
\text { suporte do supervisor, suporte dos pares. }\end{array}$ \\
\hline $\begin{array}{l}\text { SUPORTE } \\
\text { APRENDIZAGEM }\end{array}$ & $\begin{array}{l}\text { Tziner A., Fisher, M., Senior, } \\
\text { T. \& Weiberg, J. (2007). } \\
\text { Effects on } \\
\text { Characteristics on Trainee } \\
\text { Effetiveness. International } \\
\text { Journal of selection and } \\
\text { Assessement. v.15, n.2, } \\
\text { pp.167-174. }\end{array}$ & $\begin{array}{l}\text { Pesquisa realizada com } 130 \\
\text { funcionários de uma indústria de } \\
\text { grande porte israelense que } \\
\text { desempenharam uma variedade de } \\
\text { trabalhos operacionais e técnicos. } \\
\text { Todos eles participaram de um } \\
\text { treinamento com duração de } 2 \text { meses, } \\
\text { com foco na manutenção e atualização }\end{array}$ & $\begin{array}{l}\text { Variáveis critério ou dependentes: } \\
\text { Avaliação de desempenho no } \\
\text { trabalho pelo supervisor } \\
\text { (comportamento no cargo) e } \\
\text { prova final do curso } \\
\text { (aprendizagem). } \\
\text { preditoras ou independentes: } \\
\text { Auto-eficácia, motivação para }\end{array}$ & $\begin{array}{l}\text { Motivação para aprender e orientação para } \\
\text { aprendizagem } \\
\text { apresentaram maiores } \\
\text { contribuições para a predição da aprendizagem e } \\
\text { desempenho no cargo. Quando mediado por } \\
\text { motivação para aprender, o clima para } \\
\text { transferência de treinamento apresentou } \\
\text { correlação positiva com da aprendizagem e } \\
\text { desempenho no cargo. }\end{array}$ \\
\hline
\end{tabular}




\begin{tabular}{|c|c|c|c|c|}
\hline CATEGORIZAÇÃO & AUTOR & CONTEXTO & VARIÁVEIS & RESULTADOS \\
\hline & & $\begin{array}{lll}\text { de } & \text { conhecimentos } & \text { técnico- } \\
\text { profissionais. } & \end{array}$ & $\begin{array}{l}\text { aprender, conscienciosidade, } \\
\text { orientação para o objetivo da } \\
\text { aprendizagem, orientação para o } \\
\text { desempenho e interesse pelo } \\
\text { curso (instrumentalidade) e clima } \\
\text { organizacional } \\
\text { psicossocial e clima paporte } \\
\text { transferência). }\end{array}$ & \\
\hline $\begin{array}{l}\text { SUPORTE } \\
\text { APRENDIZAGEM }\end{array}$ & $\begin{array}{l}\text { D'Netto, B., Bakas, F., } \\
\text { Bordia, P. (2008). Predictors } \\
\text { of management development } \\
\text { effectiveness: In australian } \\
\text { perspective. International } \\
\text { Journal of Training and } \\
\text { Development. v.12, n.1, pp. 2- } \\
\text { 23. }\end{array}$ & $\begin{array}{l}\text { O estudo envolveu } 206 \text { gerentes de } 153 \\
\text { das } 200 \text { maiores empresas da Austrália, } \\
\text { que participaram de cursos de } \\
\text { desenvolvimento gerencial nos últimos } \\
\text { dois anos. }\end{array}$ & $\begin{array}{l}\text { Variável critério ou dependente: } \\
\text { efetividade do desenvolvimento } \\
\text { gerencial. Variáveis preditoras ou } \\
\text { independentes: Componentes } \\
\text { antecedentes (fase pré- } \\
\text { treinamento): a cultura de } \\
\text { aprendizagem organizacional, a } \\
\text { iniciativa individual, o suporte do } \\
\text { alto nível gerencial e a ligação } \\
\text { com a estratégia organizacional. } \\
\text { Componentes pós-programa: } \\
\text { avaliação do programa, suporte } \\
\text { gerencial de linha e oportunidades } \\
\text { de usar os novos conhecimentos. }\end{array}$ & $\begin{array}{l}\text { Foi encontrada correlação positiva direta entre } \\
\text { suporte do gerente de linha e oportunidade de usar } \\
\text { com a efetividade do desenvolvimento gerencial. } \\
\text { O suporte do alto nível gerencial apareceu como } \\
\text { forte preditor da ligação com a estratégia, sendo } \\
\text { esta última a maior variável preditora da } \\
\text { efetividade do desenvolvimento gerencial. }\end{array}$ \\
\hline $\begin{array}{ll}\text { SUPORTE } & \grave{A} \\
\text { APRENDIZAGEM }\end{array}$ & $\begin{array}{l}\text { Burke, L. A., Hutchins, H. M. } \\
\text { (2008). A Study of Best } \\
\text { Practices in Training Transfer } \\
\text { and Proposed Model of } \\
\text { Transfer. Human Resource } \\
\text { Development Quarterly, v. 19, } \\
\text { n.2, pp. 107- 128. }\end{array}$ & $\begin{array}{l}\text { Total de } 139 \text { membros de uma sessão } \\
\text { da American Society of Training and } \\
\text { Development -ASTD localizada em } \\
\text { uma grande cidade norteamericana. } \\
\text { Participantes apresentaram experiência } \\
\text { média em TD\&E de } 14,5 \text { anos e cerca } \\
\text { de } 48 \% \text { dos com diploma de mestrado. } \\
\text { Dados coletados a respeito das } \\
\text { melhores práticas organizacionais para } \\
\text { apoiar a transferência de treinamento e } \\
\text { apresentar proposta de modelo. }\end{array}$ & $\begin{array}{l}\text { Variável critério ou dependente: } \\
\text { transferência de treinamento. } \\
\text { Variáveis preditoras ou } \\
\text { independentes: Características do } \\
\text { aprendiz; Desenho da instrução e } \\
\text { forma de entrega; Características } \\
\text { do instrutor Ambiente de } \\
\text { trabalho. }\end{array}$ & $\begin{array}{l}\text { Estratégias usadas no ambiente de trabalho foram } \\
\text { as mais recorrentes (49\%), seguidas de } \\
\text { características do desenho e do desenvolvimento } \\
\text { da instrução }(46 \%) \text {. Contrariando a literatura, o } \\
\text { suporte oriundo do instrutor (48\%) exerceu maior } \\
\text { influência do que aquele ofertado pelo superior } \\
\text { imediato }(25 \%) \text { na transferência de treinamento. } \\
\text { Os participantes informaram que o período } \\
\text { imediatamente após o treinamento é o mais } \\
\text { crucial para a transferência. A partir dos achados, } \\
\text { as autoras propõem um refinamento dos modelos } \\
\text { atuais de transferência como forma de ampliar a } \\
\text { teoria de desenvolvimento de recursos humanos } \\
\text { na área de treinamento. }\end{array}$ \\
\hline
\end{tabular}




\begin{tabular}{|c|c|c|c|c|}
\hline CATEGORIZAÇÃO & AUTOR & CONTEXTO & VARIÁVEIS & RESULTADOS \\
\hline $\begin{array}{l}\text { SUPORTE } \\
\text { APRENDIZAGEM }\end{array}$ & $\begin{array}{l}\text { Galanou, E., Priporas, C. V. } \\
(2009) . \text { A model for } \\
\text { evaluating the effectiveness of } \\
\text { middle managers' training } \\
\text { courses: evidence from a } \\
\text { major banking organization in } \\
\text { Greece. International Journal } \\
\text { of Training and Development, } \\
\text { v. 13, n. 4, pp. 221-246. }\end{array}$ & $\begin{array}{l}\text { Total de } 190 \text { gerentes de nível } \\
\text { intermediário do Emporiki Bank (uma } \\
\text { das maiores organizações do setor } \\
\text { bancário da Grécia) que participaram } \\
\text { de cursos de gestão (duração de 40h) } \\
\text { oferecidos pelo Banco (relacionados } \\
\text { aos temas de gestão administrativa, } \\
\text { planejamento de vendas, controle, } \\
\text { planejamento e organização das } \\
\text { operações, motivação, comunicação e } \\
\text { relacionamento com o público). }\end{array}$ & $\begin{array}{l}\text { Variáveis critério ou dependentes: } \\
16 \text { variáveis distribuídas nos } 6 \\
\text { níveis: 1) reações ao processo de } \\
\text { treinamento: expectativas quanto } \\
\text { ao curso, conteúdo do curso e } \\
\text { condições técnicas; } \\
\text { aprendizagem: conhecimento; } 3 \text { ) } \\
\text { comportamento no trabalho: } \\
\text { valores, envolvimento no } \\
\text { trabalho, comprometimento } \\
\text { organizacional e satisfação no } \\
\text { trabalho; 4) desempenho no } \\
\text { trabalho: criatividade, assiduidade } \\
\text { e recompensas; 5) efeitos no } \\
\text { grupo: o nível de satisfação da } \\
\text { equipe (moral), adaptabilidade e } \\
\text { estabilidade; 6) efeitos sociais: } \\
\text { auto-realização e segurança. } \\
\text { Variável preditora ou } \\
\text { independente: Treinamentos. }\end{array}$ & $\begin{array}{l}\text { Os autores concluem que os cursos contribuíram } \\
\text { para desenvolver o conhecimento dos gerentes; } \\
\text { que as atitudes em relação à satisfação com o } \\
\text { trabalho não foram significativamente afetadas. } \\
\text { Os cursos contribuíram para aumento da } \\
\text { produtividade, assiduidade e criatividade. O nível } \\
\text { de satisfação da equipe foi aumentado pelo } \\
\text { treinamento, enquanto a estabilidade da equipe } \\
\text { não foi modificada. Quanto a efeitos sociais, os } \\
\text { resultados foram positivos, apesar de não se } \\
\text { relacionarem a segurança. Resumo: O modelo de } \\
\text { avaliação proposto suporta a noção que o } \\
\text { treinamento analisado impactou o trabalho por } \\
\text { meio da alteração da qualidade do trabalho, } \\
\text { devido a melhoria do conhecimento, das } \\
\text { habilidades e das atitudes necessárias para o } \\
\text { desempenho. }\end{array}$ \\
\hline $\begin{array}{l}\text { SUPORTE } \\
\text { APRENDIZAGEM }\end{array}$ & $\begin{array}{l}\text { Blume, B., Ford, K., Baldwin, } \\
\text { T., Huang, J. (2010). Transfer } \\
\text { of Training: A Meta-Analytic } \\
\text { Review. Journal of } \\
\text { Management, v.36, n. 4, pp. } \\
\text { 1065-1105. }\end{array}$ & $\begin{array}{l}\text { Meta-análise de } 89 \text { estudos a respeito } \\
\text { de predição de impacto de treinamentos } \\
\text { e transferência de treinamento. Dos } 89 \\
\text { estudos, 58 foram artigos de } \\
\text { periódicos, } 5 \text { artigos de conferências, } \\
24 \text { dissertações e } 2 \text { manuscritos. } 85 \% \\
\text { dos artigos eram dos estados Unidos e } \\
\text { Canadá. Dos } 89 \text { estudos, } 24 \text { eram } \\
\text { cursos de pós-graduação, } 12 \text { MBA, } 21 \\
\text { cursos para gerentes e supervisores e } \\
32 \text { cursos para treinandos diversos. }\end{array}$ & $\begin{array}{l}\text { Variável critério ou dependente: } \\
\text { Transferência de treinamento. } \\
\text { Variáveis preditoras ou } \\
\text { independentes: Características da } \\
\text { clientela (habilidade cognitiva e } \\
\text { experiência), motivação para } \\
\text { aprender, conscienciosidade, } \\
\text { suporte para a transferência } \\
\text { (subdividido nos constructos de } \\
\text { suporte de pares e supervisores, } \\
\text { clima para transferência e } \\
\text { restrições organizacionais) e } \\
\text { natureza dos treinamentos. }\end{array}$ & $\begin{array}{l}\text { Os resultados confirmam } \text { o relacionamento } \\
\text { positivo entre transferência de treinamento e } \\
\text { habilidade cognitiva, conscienciosidade, } \\
\text { motivação para aprender e suporte para } \\
\text { transferência. Especificamente, motivação e } \\
\text { suporte organizacional estão fortemente } \\
\text { relacionados com transferência de treinamento de } \\
\text { outras habilidades "open skills" o que não ocorre } \\
\text { em treinamentos com o objetivo de desenvolver } \\
\text { habilidades "closed skills". Clima para } \\
\text { transferência demonstrou o relacionamento mais } \\
\text { consistente com transferência de treinamento, } \\
\text { quando comparado com outros componentes do } \\
\text { ambiente laboral. }\end{array}$ \\
\hline $\begin{array}{l}\text { SUPORTE } \\
\text { APRENDIZAGEM }\end{array}$ & $\begin{array}{l}\text { Chiaburu, D.S., Dam, K.V., } \\
\text { Hutchins, H.M. (2010). Social } \\
\text { Support in the Workplace and } \\
\text { Training Transfer: A A }\end{array}$ & $\begin{array}{l}\text { Total de } 111 \text { empregados de uma } \\
\text { grande empresa norte-americana que } \\
\text { frequentaram um treinamento voltado } \\
\text { para institucionalização de um clima de }\end{array}$ & \begin{tabular}{llr}
\multicolumn{2}{l}{ Variável critério ou dependente: } \\
transferência & de treinamento; \\
Variáveis & preditoras & ou \\
independentes: & Suporte & Social \\
\end{tabular} & $\begin{array}{l}\text { Achado corroborou a hipótese de que auto- } \\
\text { eficácia, motivação para transferir e orientação } \\
\text { para metas de aprendizagem estão relacionadas } \\
\text { com transferência de treinamento. Suporte }\end{array}$ \\
\hline
\end{tabular}




\begin{tabular}{|c|c|c|c|c|c|}
\hline \multicolumn{2}{|l|}{ CATEGORIZACCÃO } & \multicolumn{2}{|l|}{ AUTOR } & VARIÁVEIS & RESULTADOS \\
\hline & & $\begin{array}{l}\text { longitudinal analysis. } \\
\text { International Journal of } \\
\text { Selection and Assessment, v. } \\
\text { 18, n. 2, pp. 187-200. }\end{array}$ & $\begin{array}{l}\text { excelência na prestação de serviços } \\
\text { para os clientes externos e internos do } \\
\text { público-alvo. }\end{array}$ & \begin{tabular}{llr} 
(Organizacional e & Gerencial); \\
Auto-eficácia; & Orientação por \\
metas de & \multicolumn{2}{c}{ aprendizagem } \\
(estratégias & cognitivas & no \\
treinamento); & Motivação para \\
transferir. & & \\
& &
\end{tabular} & $\begin{array}{l}\text { Gerencial demonstrou ser um preditor de } \\
\text { transferência consistente e também, apresentou } \\
\text { um relacionamento mais forte com fatores } \\
\text { individuais que influenciam a transferência do } \\
\text { treinamento, quando comparado ao Suporte } \\
\text { Organizacional. }\end{array}$ \\
\hline $\begin{array}{ll}\text { IMPACTO } & \mathrm{L} \\
\text { TREINAMENTO } & \mathrm{I} \\
\text { TRABALHO } & \end{array}$ & & $\begin{array}{l}\text { Chiaburu, D.S., Sawyer, K.B., } \\
\text { Thoroughgood, C.N. (2010). } \\
\text { Transfering More than } \\
\text { Learned in Training: } \\
\text { Employees, and managers' } \\
\text { (over)generalization of skills. } \\
\text { International Journal of } \\
\text { Selection and Assessment, v. } \\
18, \text { n. 4, pp. 380-393. }\end{array}$ & $\begin{array}{l}\text { Total de } 71 \text { avaliações de egressos e } 37 \\
\text { avaliações de seus respectivos } \\
\text { supervisores. Alunos participaram de } \\
\text { um treinamento presencial (in } \\
\text { company, } 1 \text { a } 2 \text { dias) ofertado por seu } \\
\text { empregador (empresa norte-americana } \\
\text { de logística). O objetivo foi investigar } \\
\text { vieses (estimativas exageradas) nas } \\
\text { auto e heteroavaliações em avaliações } \\
\text { sobre transferência de treinamento. }\end{array}$ & $\begin{array}{l}\text { Variável dependente: estimação } \\
\text { de transferência de treinamento. } \\
\text { Variáveis independentes : Traços } \\
\text { de personalidade dos Big Five } \\
\text { (conscienciosidade, cortesia, } \\
\text { estabilidade emocional, abertura } \\
\text { para experiências e extroversão), } \\
\text { visibilidade das habilidades sexo, } \\
\text { nível de escolaridade, idade, } \\
\text { tempo na empresa, tempo no } \\
\text { cargo, significância entre pré e } \\
\text { pós teste. }\end{array}$ & $\begin{array}{l}\text { Abertura para experiências e extroversão não } \\
\text { foram preditores significativos de transferência. } \\
\text { Por outro lado, egressos de treinamento mais } \\
\text { conscientes do que sentem ou do que fazem, mais } \\
\text { corteses e emocionalmente estáveis estão mais } \\
\text { suscetíveis a reportar estimativas exageradas de } \\
\text { transferência. Foi demonstrado que outras } \\
\text { dimensões como insegurança e perfeccionismo } \\
\text { acentuaram a influência da conscienciosidade dos } \\
\text { treinandos. Para remediar esse efeito, sugere-se } \\
\text { alertar os empregados com estes traços de } \\
\text { personalidade sobre prováveis vieses antes da } \\
\text { aplicação de questionários que venham aferir } \\
\text { transferência de treinamento. }\end{array}$ \\
\hline $\begin{array}{l}\text { SUPORTE } \\
\text { APRENDIZAGEM }\end{array}$ & À & $\begin{array}{l}\text { Ismail, A., Mohamed, H. A., } \\
\text { Sulaiman, A. Z., Sabhi, S. } \\
\text { (2010). Supervisor's Role as } \\
\text { an Antecedent of Training } \\
\text { Transfer and Motivation to } \\
\text { Learn in Training Programs. } \\
\text { Acta Universitatis Danubius, } \\
\text { n.2, pp. 18-38. }\end{array}$ & $\begin{array}{l}\text { Total de } 110 \text { servidores públicos de } \\
\text { uma agência de infra-estrutura e } \\
\text { desenvolvimento da Malásia egressos } \\
\text { de treinamentos presenciais (in } \\
\text { company). }\end{array}$ & \begin{tabular}{|lrr} 
Variável & dependente: \\
transferência de & treinamento; \\
motivação para & aprender. \\
Variáveis independentes : Suporte \\
Gerencial Estilo de & Comunicação \\
Gerencial &
\end{tabular} & $\begin{array}{l}\text { Suporte Gerencial esteve significativamente } \\
\text { correlacionado com transferência de treinamento, } \\
\text { confirmando seu poder preditivo. Entretanto, os } \\
\text { dados apontaram, uma correlação não } \\
\text { significativa entre o Suporte Gerncial e a } \\
\text { motivação para aprender. Estilo de Comunicação } \\
\text { Gerencial esteve significativamente } \\
\text { correlacionado com motivação para aprender e } \\
\text { com transferência de aprendizagem. }\end{array}$ \\
\hline $\begin{array}{l}\text { SUPORTE } \\
\text { APRENDIZAGEM }\end{array}$ & À & $\begin{array}{l}\text { Martin, H. J. }(2010) . \\
\text { Workplace Climate and Peer } \\
\text { Support as Determinants of } \\
\text { Training Transfer. Human } \\
\text { Resource } \\
\text { Quarterly, v. } 21 \text { Development } \\
104.1, \text { pp.87- } \\
104 .\end{array}$ & $\begin{array}{l}\text { Total de } 237 \text { gerentes que frequentaram } \\
\text { treinamento ofertado por uma grande } \\
\text { empresa norte-americana do setor } \\
\text { produtivo. O treinamento durou } 12 \\
\text { semanas e foi planejado para } \\
\text { desenvolver preparar a transição para o } \\
\text { papel de gerentes de processo, } \\
\text { transferindo tarefas de supervisão } \\
\text { diárias para grupos de trabalho auto- }\end{array}$ & $\begin{array}{l}\text { Variável critério ou dependente: } \\
\text { transferência de treinamento } \\
\text { Variáveis preditoras ou } \\
\text { independentes: clima no ambiente } \\
\text { de trabalho Suporte dos pares. }\end{array}$ & $\begin{array}{l}\text { Suporte de colegas pode ser benéfico para superar } \\
\text { os efeitos de um clima negativo. Egressos de } \\
\text { treinamentos que atuavam em ambientes com } \\
\text { clima negativo, mas que contavam com suporte } \\
\text { advindo de colegas, alcançaram mesmo grau de } \\
\text { transferência de treinamento que aqueles que } \\
\text { trabalhavam em ambientes com clima positivo. } \\
\text { Devido a não disponibilização de dados da } \\
\text { pesquisa de clima da organização, clima no }\end{array}$ \\
\hline
\end{tabular}




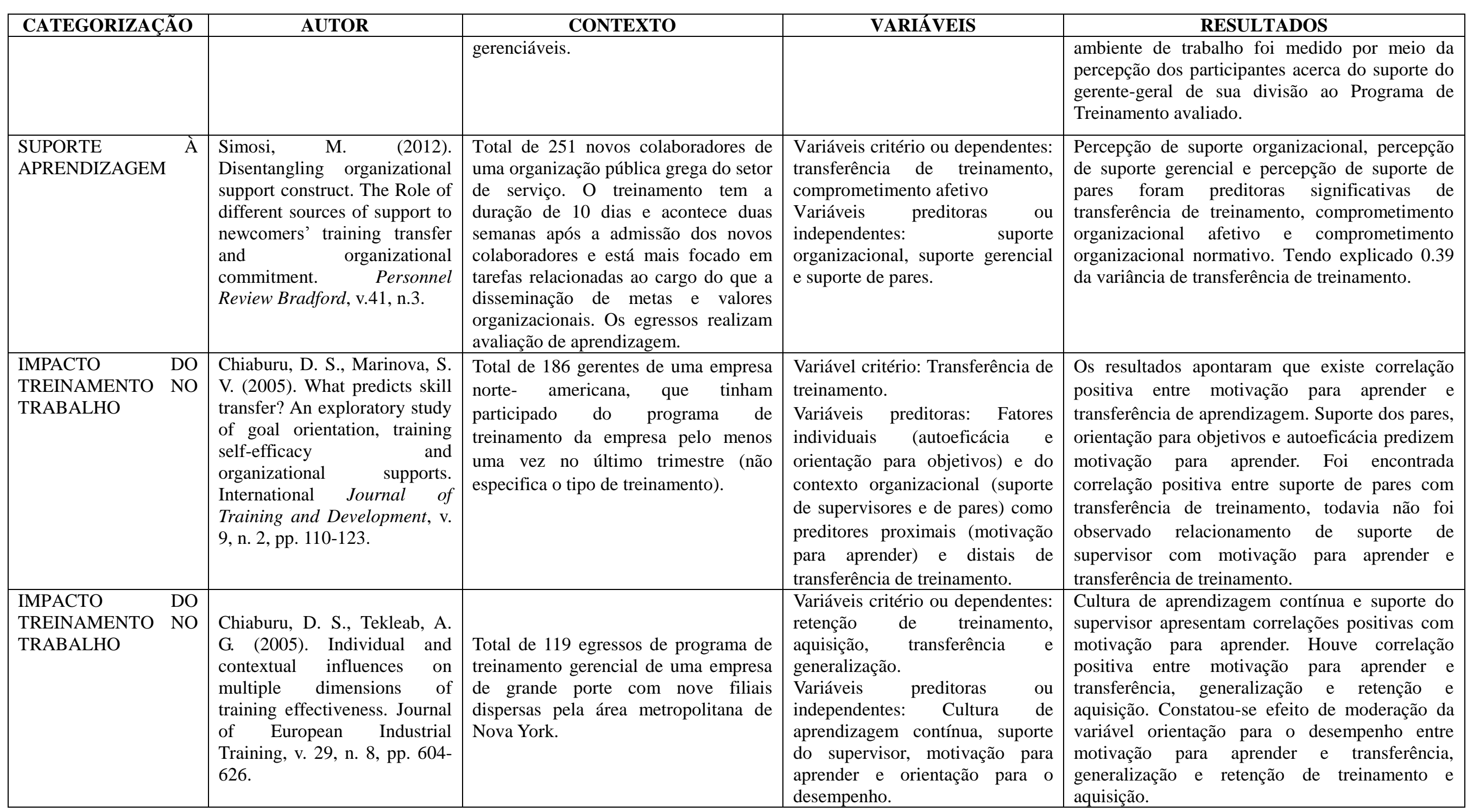




\begin{tabular}{|c|c|c|c|c|}
\hline CATEGORIZAÇÃO & AUTOR & CONTEXTO & VARIÁVEIS & RESULTADOS \\
\hline $\begin{array}{ll}\text { SUPORTE } & \grave{A} \\
\text { APRENDIZAGEM }\end{array}$ & $\begin{array}{l}\text { Kirwan, C., Birchall, D. } \\
\text { (2006). Transfer of learning } \\
\text { from management } \\
\text { development programmes: } \\
\text { testing the Holton model. } \\
\text { International Journal of } \\
\text { Training and Development, v. } \\
\text { 10, n. 4, pp. 252-268. }\end{array}$ & $\begin{array}{l}\text { Pesquisa aplicada no serviço de saúde } \\
\text { da Irlanda, coma participação de } 112 \\
\text { gerentes de enfermagem, que } \\
\text { tinham participado pelo menos de um } \\
\text { dos quatro treinamentos de } \\
\text { desenvolvimento } \\
\text { gerencial (duração de } 12 \text { dias). }\end{array}$ & $\begin{array}{l}\text { Variáveis critério ou dependentes: } \\
\text { Motivação para transferir e } \\
\text { capacidade pessoal para transferir. } \\
\text { Variáveis preditoras ou } \\
\text { independentes: Suporte dos pares, } \\
\text { suporte gerencial, oportunidade } \\
\text { de usar, feedback e coaching }\end{array}$ & $\begin{array}{l}\text { Motivação foi predita por suporte dos pares, } \\
\text { oportunidade de usar e feedback e coaching. } \\
\text { Capacidade pessoal para transferir foi predita por } \\
\text { oportunidade de usar e suporte gerencial. Neste } \\
\text { estudo, a força preditora das variáveis de suporte } \\
\text { foi mais uma vez comprovada. }\end{array}$ \\
\hline $\begin{array}{ll}\text { IMPACTO } & \text { DO } \\
\text { TREINAMENTO } & \text { NO } \\
\text { TRABALHO } & \end{array}$ & $\begin{array}{l}\text { Tharenou, P., Saks, A. M., } \\
\text { Moore, C. (2007). A review } \\
\text { and critique of research on } \\
\text { training and organizational- } \\
\text { level outcomes. Human } \\
\text { Resource Management } \\
\text { Review, n. 17, pp. 251-273. }\end{array}$ & $\begin{array}{l}\text { Meta -análise de } 67 \text { estudos a respeito } \\
\text { de resultados de treinamentos em nível } \\
\text { organizacional publicados em diversos } \\
\text { periódicos (não especifica tipos de } \\
\text { treinamento). }\end{array}$ & 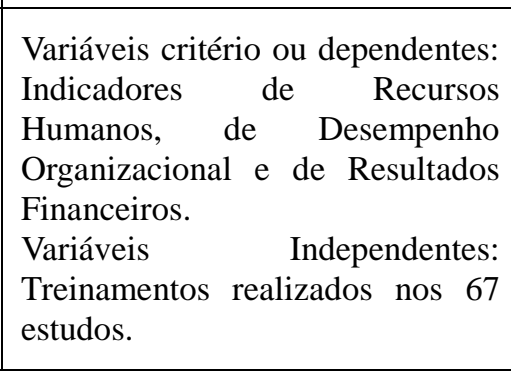 & $\begin{array}{l}\text { Treinamento está positivamente relacionado a } \\
\text { resultados de Recursos Humanos e desempenho } \\
\text { organizacional, mas é muito fraco o } \\
\text { relacionamento com resultado financeiro. } \\
\text { Os resultados de desempenho organizacional que } \\
\text { apresentaram maior correlação com treinamento } \\
\text { foram qualidade e produtividade (na verdade, } \\
\text { produtividade está relacionada a resultados } \\
\text { financeiros). }\end{array}$ \\
\hline $\begin{array}{ll}\text { IMPACTO } & \text { DO } \\
\text { TREINAMENTO } & \text { NO } \\
\text { TRABALHO } & \end{array}$ & $\begin{array}{l}\text { Powell, K. S., Yalcin, S. } \\
\text { (2010). Managerial training } \\
\text { effectiveness }- \text { A } \quad \text { meta- } \\
\text { analysis } 1952-\quad 2002 . \\
\text { Personnel Review, v. } 39 \text {, n. } 2 \text {, } \\
\text { pp. 227-241. }\end{array}$ & $\begin{array}{l}\text { A pesquisa inclui estudos sobre } \\
\text { efetividade de treinamento no período } \\
\text { entre } 1952 \text { e } 2002 .\end{array}$ & $\begin{array}{l}\text { Variável Critérios: efetividade dos } \\
\text { programas de treinamento por } \\
\text { década }(50,60,70,80.90 \text { e } \\
\text { 2000). } \\
\text { Variáveis Independentes: reação, } \\
\text { aprendizagem, comportamento e } \\
\text { resultados. }\end{array}$ & $\begin{array}{l}\text { Conclui-se que os programas de treinamento, } \\
\text { disponibilizados na literatura, não foram tão } \\
\text { efetivos como o esperado. Apenas os estudos das } \\
\text { décadas de } 1960 \quad(0,27) \text { e de } 1970 \quad(0,38) \\
\text { apresentaram correlações significantes e positivas } \\
\text { com os resultados organizacionais. }\end{array}$ \\
\hline $\begin{array}{ll}\text { IMPACTO } & \text { DO } \\
\text { TREINAMENTO } & \text { NO } \\
\text { TRABALHO } & \end{array}$ & 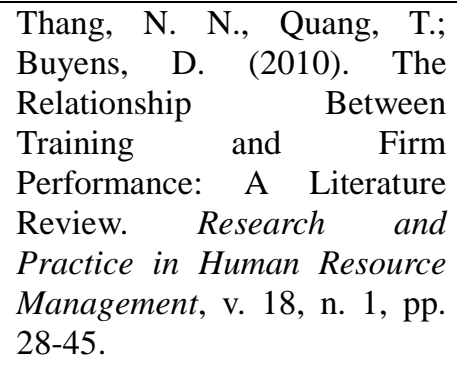 & $\begin{array}{l}\text { Revisão sobre pesquisas publicadas } \\
\text { entre } 1991 \text { a } 2007 \text {, que tem avaliado a } \\
\text { relação entre treinamento e } \\
\text { desempenho das empresas. }\end{array}$ & $\begin{array}{l}\text { Variável Critério: desempenho } \\
\text { organizacional (financeiros e não- } \\
\text { financeiros). Independentes: } \\
\text { Variáveis trabadores, } \\
\text { conhecimento dos trabalhadores } \\
\text { atitude, capital investido, } \\
\text { estratégia organizacional. }\end{array}$ & $\begin{array}{l}\text { A análise indica que a relação entre treinamento e } \\
\text { desempenho pode ser mediada pelas variáveis de } \\
\text { conhecimento dos trabalhadores e atitude. Por } \\
\text { outro lado, o capital investido e a estratégia } \\
\text { organizacional moderam a relação entre } \\
\text { treinamento e desempenho. }\end{array}$ \\
\hline
\end{tabular}




\section{Apêndice III - Questionário aos gerentes executivos e gerentes de Agência da}

\section{Previdência Social}

\section{Apresentação:}

Sr(a) Gerente:

Bem vindo ao preenchimento do Questionário de Autoavaliação!

Esta é uma pesquisa acadêmica, voluntária, que tem como objetivo principal verificar os treinamentos à distância do INSS obrigatórios aos gerentes.

A pesquisa encontra-se estruturada para verificar o suporte interpessoal e material existente à aprendizagem no trabalho; o impacto gerado pelo aproveitamento da capacitação no trabalho; o alinhamento destas capacitações com as competências necessárias definidas para o exercício da função de gerente executivo e gerente de APS.

Para que a pesquisa atinja o resultado desejado, é importante que as suas respostas reflitam o que você realmente pensa e que as questões sejam respondidas na íntegra.

Suas respostas serão analisadas em conjunto com outras obtidas nesta pesquisa e a elas será dado tratamento confidencial, com análises e publicações de valores numéricos e estatísticos, na forma de estudo acadêmico.

Como forma de estímulo e agradecimento, os participantes que concluírem integralmente este questionário e informarem o email de cadastro e contato no final da pesquisa, estarão participando de um sorteio de um cheque presente da FNAC www.fnac.com.br - no valor de $\mathrm{R} \$ 325,00$ (trezentos e vinte e cinco reais), que poderá ser utilizado na compra de qualquer produto oferecido no site. O sorteio será feito por meio dos emails cadastrados, podendo ser um email válido não institucional e que não lhe identifique nesta pesquisa, de forma aleatória para os questionários preenchidos integralmente até o dia 10 de agosto de 2016.

Atenciosamente,

Leovanir Dieter D. Richter

Estudante de Mestrado em Administração - Universidade de Brasília leovanir@yahoo.com.br / fone: 61-98120-3988

Brasília - DF, 2015 / 2016.

Pesquisa autorizada conforme Despacho Decisório no 324/DGP/INSS, publicado no Boletim de Serviço nº 137,

\section{Termo de Consentimento} de 19 de julho de 2016.

Confirmo que li e entendi as informações relativas a esta pesquisa e que concordo em participar.

( ) Sim ( ) Não. Em caso negativo, justifique se possível: 


\section{Impacto em Amplitude dos Cursos de Formação Continuada para Gestores}

Selecione o último Curso concluído e manifeste-se em relação às questões abaixo utilizando a seguinte escala:

Discordo Totalmente <== (1) (2) (3) (4) (5) (6) (7) (8) (9) (10) ==> Concordo Totalmente

Quanto mais próximo de (1) for sua marcação, significa que você DISCORDA da afirmação do item.

Quanto mais próximo de (10) for sua marcação, significa que você CONCORDA com a afirmação do item.

\begin{tabular}{|c|c|c|}
\hline $\begin{array}{ll}\text { Últim } \\
\text { Temp }\end{array}$ & $\begin{array}{l}\text { Curso a Distância Concluído: } \\
\text { transcorrido em meses, desde o término deste curso: }\end{array}$ & - Grau de Percepção e \\
\hline Item & Questão & \\
\hline 3.1 & Utilizo, com frequência, em meu trabalho atual, o que foi ensinado na capacitação. & (1) (2) (3) (4) (5) (6) (7) (8) (9) (10) \\
\hline 3.2 & Aproveito as oportunidades que tenho para colocar em prática o que me foi ensinado na capacitação. & (1) (2) (3) (4) (5) (6) (7) (8) (9) (10) \\
\hline 3.3 & $\begin{array}{l}\text { As habilidades que aprendi na capacitação fizeram com que eu cometesse menos erros, em meu trabalho, em atividades relacionadas ao conteúdo do } \\
\text { treinamento. }\end{array}$ & (1) (2) (3) (4) (5) (6) (7) (8) (9) (10) \\
\hline 3.4 & Recordo-me bem dos conteúdos ensinados na capacitação. & (1) (2) (3) (4) (5) (6) (7) (8) (9) (10) \\
\hline 3.5 & Quando aplico o que aprendi na capacitação, executo meu trabalho com maior segurança. & (1) (2) (3) (4) (5) (6) (7) (8) (9) (10) \\
\hline 3.6 & A qualidade do meu trabalho melhorou as atividades diretamente relacionadas ao conteúdo da capacitação. & (1) (2) (3) (4) (5) (6) (7) (8) (9) (10) \\
\hline 3.7 & A qualidade do meu trabalho melhorou mesmo naquelas atividades que não pareciam estar relacionadas ao conteúdo da capacitação. & (1) (2) (3) (4) (5) (6) (7) (8) (9) (10) \\
\hline 3.8 & A participação na capacitação serviu para aumentar minha motivação para o trabalho. & (1) (2) (3) (4) (5) (6) (7) (8) (9) (10) \\
\hline 3.9 & $\begin{array}{l}\text { Minha participação nessa capacitação aumentou minha auto-confiança. (Agora tenho mais confiança na minha capacidade de executar meu trabalho com } \\
\text { sucesso) }\end{array}$ & (1) (2) (3) (4) (5) (6) (7) (8) (9) (10) \\
\hline 3.10 & Após minha participação na capacitação, tenho sugerido, com mais frequência, mudanças nas rotinas de trabalho. & (1) (2) (3) (4) (5) (6) (7) (8) (9) (10) \\
\hline 3.11 & O curso realizado tornou-me mais receptivo às mudanças no trabalho. & (1) (2) (3) (4) (5) (6) (7) (8) (9) (10) \\
\hline 3.12 & A capacitação que fiz beneficiou minha equipe de trabalho, que aprenderam comigo algumas novas habilidades. & (1) (2) (3) (4) (5) (6) (7) (8) (9) (10) \\
\hline 3.13 & Tive dificuldades em realizar este curso na modalidade de Educação a Distância. & (1) (2) (3) (4) (5) (6) (7) (8) (9) (10) \\
\hline 3.14 & Os métodos e técnicas utilizados pelos instrutores / tutores foram adequados nesta capacitação. & (1) (2) (3) (4) (5) (6) (7) (8) (9) (10) \\
\hline 3.15 & Consegui estabelecer paralelos (confrontos) entre a teoria e a realidade/prática do conteúdo a que se referia este curso. & (1) (2) (3) (4) (5) (6) (7) (8) (9) (10) \\
\hline 3.16 & Os testes, exercícios e/ou questões avaliativas a que me submeti durante o curso foram adequados. & (1) (2) (3) (4) (5) (6) (7) (8) (9) (10) \\
\hline
\end{tabular}

3.17 Na conclusão deste Curso a Distância você realizou a Avaliação de Reação: ( ) Sim （ ） Não. Justifique se possível: 


\section{Impacto em Profundidade dos Cursos de Formação Continuada para Gestores}

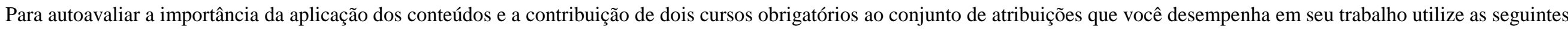
escalas:

IMPORTÂNCIA DO CURSO PARA O MEU

\section{DESEMPENHO PROFISSIONAL}

(1) = Nenhuma Importância / Não se aplica (importância irrelevante)

(2) = Pouca Importância

(3) = Média Importância

(4) = Alta Importância (ação imprescindível)

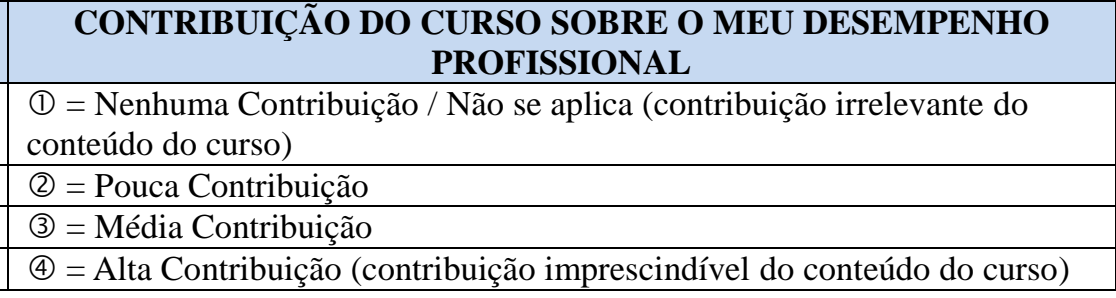

\begin{tabular}{|c|c|c|c|}
\hline \multirow{3}{*}{$\begin{array}{l}\text { Nenhuma (1) (2) (3) (4) Imprescindível } \\
\text { IMPORTÂNCIA PARA O MEU } \\
\text { DESEMPENHO }\end{array}$} & \multirow{2}{*}{\multicolumn{2}{|c|}{$\begin{array}{l}\text { 4.5 Curso: Gestão Estratégica } \\
\text { Tempo transcorrido em meses, desde o término deste curso: }\end{array}$}} & \multirow{3}{*}{$\begin{array}{c}\text { Nenhuma (1) (2) (3) (4) Decisiva } \\
\text { CONTRIBUIÇÃO DO } \\
\text { CURSO SOBRE O MEU } \\
\text { DESEMPENHO }\end{array}$} \\
\hline & & & \\
\hline & Item & Questão & \\
\hline (1) (2) (3) (4) & 4.5 .1 & Relato de que forma ocorre o alinhamento e o desdobramento das estratégias organizacionais. & (1) (2) (3) (4) \\
\hline (1) (2) (3) (4) & 4.5 .2 & Discuto com a equipe o plano estratégico da Previdência Social. & (1) (2) (3) (4) \\
\hline (1) (2) (3) (4) & 4.5 .3 & Viabilizo a aplicação de objetivos estratégicos em minha unidade de trabalho. & (1) (2) (3) (4) \\
\hline (1) (2) (3) (4) & 4.5 .4 & Implemento ações vinculadas aos direcionadores estratégicos da Previdência Social. & (1) (2) (3) (4) \\
\hline (1) (2) (3) (4) & 4.5 .5 & Promovo práticas de gestão estratégica em minha unidade de trabalho. & (1) (2) (3) (4) \\
\hline
\end{tabular}

\begin{tabular}{|c|c|c|c|}
\hline Nenhuma (1) (2) (3) (4) Imprescindível & \multirow{2}{*}{\multicolumn{2}{|c|}{$\begin{array}{l}\text { 4.6 Curso: Gestão de Equipes } \\
\text { Tempo transcorrido em meses, desde o término deste curso: }\end{array}$}} & \multirow{3}{*}{$\begin{array}{c}\text { Nenhuma (1) (2) (4) Decisiva } \\
\text { CONTRIBUIÇÃO DO } \\
\text { CURSO SOBRE O MEU } \\
\text { DESEMPENHO }\end{array}$} \\
\hline \multirow{2}{*}{$\begin{array}{l}\text { IMPORTÂNCIA PARA O MEU } \\
\text { DESEMPENHO }\end{array}$} & & & \\
\hline & Item & Questão & \\
\hline (1) (2) (3) (4) & 4.6 .1 & Causo a melhoria contínua da equipe de trabalho. & (1) (2) (3) (4) \\
\hline (1) (2) (3) (4) & 4.6 .2 & Discuto ações mobilizadoras de desempenho com a equipe de trabalho. & (1) (2) (3) (4) \\
\hline (1) (2) (3) (4) & 4.6 .3 & Organizo as condições ideais para a realização do trabalho em equipe. & (1) (2) (3) (4) \\
\hline (1) (2) (3) (4) & 4.6 .4 & Avalio o desempenho da equipe. & (1) (2) (3) (4) \\
\hline (1) (2) (3) (4) & 4.6 .5 & Estimulo a formação de novas lideranças no ambiente de trabalho. & (1) (2) (3) (4) \\
\hline
\end{tabular}




\section{Suporte à Aprendizagem}

Manifeste sua percepção quanto ao estímulo do ambiente organizacional para participação em capacitações e o uso de novos conhecimentos, utilizando a seguinte escala:

Discordo Totalmente $<==$ (1) (2) (3)(4) (5) (6) (7) (8) (9) (10) ==> Concordo Totalmente

Quanto mais próximo de (1) for sua marcação, significa que você DISCORDA da afirmação do item. Quanto mais próximo de (1) for sua marcação, significa que você CONCORDA com a afirmação do item.

5.1 Na minha unidade de trabalho ...

Item

\begin{tabular}{|l|l|l}
\hline 5.1 .1 \\
\hline 5.12
\end{tabular}

5.1 .2

5.1 .3

5.1 .4

5.1 .5

5.1 .6

5.1 .7

5.1 .8

Há oportunidade para exposição de ideias de cada servidor

Há tempo destinado para a busca de novas formas de executar o trabalho

O excesso de trabalho impede a participação em capacitações

Há autonomia para argumentar as demandas da chefia

Há troca de informações sobre a aplicação de novos conhecimentos e habilidades

Há tolerância a erros quando se tenta aplicar novos conhecimentos e habilidades

As tentativas de aplicação de novos conhecimentos e habilidades são ignorados

Há incentivo a busca de novas aprendizagens

5.1 .9

Há recursos materiais, humanos, financeiros e/ou informacionais suficientes para a aplicação de novos conhecimentos e habilidades

- Grau de Percepção e Concordância + (1) (2) (3) (4) (5)(6)(7)(8) (9) (10) (1) (2) (3) (4) (5) (6) (7) (8) (9) (10)

(1) (2) (3) (4) (5) (6) (7) (8) (9) (10 (1) (2) (3) (4)(5)(6)(7)(8) (9)(1) (1) (2) (3) (4) (5) (6) (7) (8) (9)(11) (1) (2) (3) (4) (5)(6)(7)(8) (9) (1) (1) (2) (3) (4) (5) (6) (7) (8) (9) (11) (1) (2) (3) (4) (5) (6) (7) (8) (9) (10 (1) (2) (3) (4) (5) (6) (7) (8) (9) (10

5.2 Meu gestor imediato ...

Item

5.2 .1

Estabelece objetivos de trabalho que me motivam a aplicar novos conhecimentos e habilidades

Me estimula a aplicar novos conhecimentos e habilidades no ambiente de trabalho

Assume comigo os riscos de tentar novas formas de realizar o trabalho

Leva em conta minhas ideias quando diferente das dele

Inibe o uso das minhas novas habilidades no trabalho

Me elogia quando aplico novos conhecimentos e habilidades

Ignora as mudanças que eu proponho em função do que aprendi em capacitação

Me dá liberdade para decidir sobre como desenvolver minhas tarefas

5.2 .8

Está disponível para tirar minhas dúvidas sobre o uso de novos conhecimentos e habilidades

5.2 .9

Grau de Percepção e Concordância +

(1) (2) (3) (4) (5) (6) (7) (8) (9) (10)

(1) (2) (3) (4) (5) (6) (7) (8) (9) (1)

(1) (2) (3) (4) (5) (6) (7) (8) (9) (10

(1) (2) (3) (4) (5) (6) (7) (8) (9) (10)

(1)(2) (3) (4) (5) (6) (7) (8) (9) (10)

(1) (2) (3) (4) (5) (6) (7) (8) (9) (10

(1) (2) (3) (4) (5) (6) (7) (8) (9) (1)

(1) (2) (3) (4) (5) (6) (7) (8) (9) (11)

(1) (2) (3) (4) (5) (6) (7) (8) (9) (10) 


\begin{tabular}{|c|c|c|}
\hline \multicolumn{2}{|c|}{5.3 No relacionamento com a equipe de trabalho ... } & \multirow{2}{*}{ - Grau de Percepção e Concordância + } \\
\hline Item & & \\
\hline 5.3 .1 & Há espaço para orientação quando existem dificuldades para aplicar novos conhecimentos e habilidades & (1) (2) (3) (4) (5) (6) (7) (8) (9) (10) \\
\hline 5.3 .2 & Há reconhecimento quando aplicadas novas habilidades e conhecimentos & (1) (2) (3) (4) (5) (6) (7) (8) (9) (10) \\
\hline 5.3 .3 & Há estímulo para busca de novos conhecimentos e habilidades voltados ao trabalho & (1) (2) (3) (4) (5) (6) (7) (8) (9) (10) \\
\hline 5.3 .4 & Me criticam negativamente quando erro ao aplicar novos conhecimentos e habilidades no trabalho & (1) (2) (3) (4) (5) (6) (7) (8) (9) (10) \\
\hline 5.3 .5 & Sentem-se ameaçados quando aplico novos conhecimentos e habilidades no trabalho & (1) (2) (3) (4) (5) (6) (7) (8) (9) (10) \\
\hline
\end{tabular}

\section{GERENTE EXECUTIVO(A) - Autoavaliação de Competências para o Desempenho Profissional}

São elencadas as competências necessárias à gestão da Gerência Executiva, conforme Resolução no 134/INSS/PRES, onde você Gerente Executivo(a) está convidado a se manifestar a respeito.

Para autoavaliar a importância da aplicação destas competências em seu desempenho profissional e a contribuição dos cursos obrigatórios no desenvolvimento de cada competência ao conjunto de atribuições que você desempenha em seu trabalho, utilize as seguintes escalas:

\section{IMPORTÂNCIA DA COMPETENCIA PARA O MEU DESEMPENHO}

CONTRIBUIÇÃO DOS CURSOS PARA O DESENVOLVIMENTO DAS COMPETÊNCIAS

(1) = Nenhuma Importância / Não se aplica (competência irrelevante)

(2) = Pouca Importância

(3) = Média Importância

(4) = Alta Importância (competência imprescindível)

(1) = Nenhuma Contribuição / Não se aplica (contribuição irrelevante sobre a competência)

(2) = Pouca Contribuição

(3) = Média Contribuição

(4) = Alta Contribuição (contribuição imprescindível sobre a competência)

Sendo hoje Gerente de Agência da Previdência Social desconsidere este tópico de pesquisa e responda o próximo item.

\begin{tabular}{|c|c|c|c|}
\hline \multicolumn{4}{|c|}{ Último Curso a Distância Concluído: } \\
\hline \multicolumn{4}{|c|}{ Tempo transcorrido em meses, desde o término deste curso: } \\
\hline Nenhuma (1) (2) (3) (4) Imprescindível & \multirow{2}{*}{\multicolumn{2}{|c|}{$\begin{array}{l}\text { 6.1 Aponte a importância da competência para o seu desempenho profissional e a } \\
\text { contribuição dos cursos obrigatórios no desenvolvimento de cada competência } \\
\text { requerida a função de Gerente Executivo(a): }\end{array}$}} & Nenhuma (1) (2) (3) (4) Decisiva \\
\hline \multirow{2}{*}{$\begin{array}{c}\text { IMPORTÂNCIA DA } \\
\text { COMPETENCIA PARA O MEU } \\
\text { DESEMPENHO PROFISSIONAL }\end{array}$} & & & \multirow{2}{*}{$\begin{array}{l}\text { CONTRIBUIÇÃO DO CURSO CONCLUÍDO PARA } \\
\text { O DESENVOLVIMENTO DAS COMPETÊNCIAS }\end{array}$} \\
\hline & Item & Unidade de Competência ao(à) Gerente Executivo(a) & \\
\hline (1) (2) (3) (4) & 6.1 .1 & Contribuir para a elaboração do Planejamento Estratégico & (1) (2) (3) (4) \\
\hline (1) (2) (3) (4) & 6.1 .2 & Viabilizar os objetivos estratégicos do INSS & (1) (2) (3) (4) \\
\hline (1) (2) (3) (4) & 6.1 .3 & Representar o INSS junto à sociedade & (1) (2) (3) (4) \\
\hline (1) (2) (3) (4) & 6.1 .5 & Mobilizar a equipe para a realização do trabalho & (1) (2) (3) (4) \\
\hline (1) (2) (3) (4) & 6.1 .6 & Empenhar-se no auto-desenvolvimento & (1) (2) (3) (4) \\
\hline (1) (2) (3) (4) & 6.1 .7 & Promover o desenvolvimento pessoal e profissional dos servidores & (1) (2) (3) (4) \\
\hline (1) (2) (3) (4) & 6.1 .8 & Promover a qualidade de vida no trabalho & (1) (2) (3) (4) \\
\hline
\end{tabular}




\begin{tabular}{|c|c|c|c|}
\hline (1) (2) (3) (4) & 6.1 .9 & Garantir o funcionamento da Gerência Executiva & (1) (2) (3) (4) \\
\hline (1) (2) (3) (4) & 6.1 .10 & Buscar a qualidade das decisões & (1) (2) (3) (4) \\
\hline (1) (2) (3) (4) & 6.1 .11 & Demonstrar resolutividade nas situações de trabalho & (1) (2) (3) (4) \\
\hline (1) (2) (3) (4) & 6.1 .12 & Promover ações de responsabilidade socioambiental & (1) (2) (3) (4) \\
\hline (1) (2) (3) (4) & 6.1 .13 & Viabilizar condições de trabalho adequadas & (1) (2) (3) (4) \\
\hline (1) (2) (3) (4) & 6.1 .14 & Promover a qualidade do atendimento & (1) (2) (3) (4) \\
\hline (1) (2) (3) (4) & 6.1 .15 & Avaliar o desempenho das APS & (1) (2) (3) (4) \\
\hline (1) (2) (3) (4) & 6.1 .16 & Obter informações necessárias à gestão da Gerência Executiva & (1) (2) (3) (4) \\
\hline (1) (2) (3) (4) & 6.1 .17 & Garantir a disseminação de informações confiáveis & (1) (2) (3) (4) \\
\hline
\end{tabular}

\section{GERENTE DE AGÊNCIA DA PREVIDÊNCIA SOCIAL (APS) - Autoavaliação de Competências para o Desempenho Profissional}

São elencadas as competências necessárias à gestão da Agência da Previdência Social, conforme Resolução n ${ }^{\circ} 15 / \mathrm{INSS} / \mathrm{PRES}$, onde você Gerente de APS está convidado a se manifestar a respeito.

Para autoavaliar a importância da aplicação destas competências em seu desempenho profissional e a contribuição dos cursos obrigatórios no desenvolvimento de cada competência ao conjunto de atribuições que você desempenha em seu trabalho, utilize as seguintes escalas:

\section{IMPORTÂNCIA DA COMPETÊNCIA PARA O MEU DESEMPENHO}

(1) = Nenhuma Importância / Não se aplica (competência irrelevante)

(2) = Pouca Importância

(3) = Média Importância

(4) = Alta Importância (competência imprescindível)

Sendo hoje Gerente Executivo(a) desconsidere este tópico de pesquisa e responda o próximo item.

\section{CONTRIBUIÇÃO DOS CURSOS PARA O DESENVOLVIMENTO DAS COMPETÊNCIAS}

(1) = Nenhuma Contribuição / Não se aplica (contribuição irrelevante sobre a competência)

(2) = Pouca Contribuição

(3) = Média Contribuição

(4) = Alta Contribuição (contribuição imprescindível sobre a competência)

Último Curso a Distância Concluído:

Tempo transcorrido em meses, desde o término deste curso:

\section{Nenhuma (1) (2) (3) (4) Imprescindível}

IMPORTÃNCIA DA

COMPETÊNCIA PARA O MEU

DESEMPENHO PROFISSIONAL

(1) (2) (3) (4)

(1) (2) (3) (4)

(1) (2) (3) (4)

(1) (2) (3) (4)

(1) (2) (3) (4)

(1) (2) (3) (4)

(1) (2) (3) (4)
Nenhuma (1) (2) (3) (4) Decisiva contribuição dos cursos obrigatórios no desenvolvimento de cada competência requerida a função de Gerente de APS :

\begin{tabular}{|l|l|}
\hline Item & Unidade de Competência ao(à) Gerente de APS \\
\hline 7.1 .1 & Promover aços para ofuncionamento daPS \\
\hline
\end{tabular} Promover ações para o funcionamento da APS

Obter produtividade no trabalho Buscar a qualidade nas decisões

Construir equipes de trabalho

Promover o desenvolvimento pessoal e profissional da equipe

Promover a disseminação e internalização dos valores da instituição

Mobilizar equipe para realização do trabalho
CONTRIBUIÇÃO DOS CURSOS PARA O DESENVOLVIMENTO DAS COMPETÊNCIAS

\begin{tabular}{|l|} 
(1) (2) (3) (4) \\
(1) (2) (3) (4) \\
(1) (2) (3) (4) \\
(1) (2) (3) (4) \\
(1) (2) (3) (4) \\
(1) (2) (3) (4) \\
\hline (1) (2) (3) (4)
\end{tabular}




\begin{tabular}{|l|l|l|l|}
\hline (1) (2) (3) (4) & 7.1 .8 & Avaliar o desempenho da equipe & (1) (2) (3) (4) \\
\hline (1) (2) (3) (4) & 7.1 .9 & Empenhar-se no auto-desenvolvimento & (1) (2) (3) (4) \\
\hline (1) (2) (3) (4) & 7.1 .10 & Promover a qualidade de vida no trabalho & (1) (2) (3) (4) \\
\hline (1) (2) (3) (4) & 7.1 .11 & Gerir talentos e competências & (1) (2) (3) (4) \\
\hline (1) (2) (3) (4) & 7.1 .12 & Promover a execução do atendimento com qualidade & (1) (2) (3) (4) \\
\hline (1) (2) (3) (4) & 7.1 .13 & Avaliar o resultado do atendimento & (1) (2) (3) (4) \\
\hline (1) (2) (3) (4) & 7.1 .14 & Promover ações para otimizar o atendimento & (1) (2) (3) (4) \\
\hline (1) (2) (3) (4) & 7.1 .15 & Obter informações necessárias a gestão da APS & (1) (2) (3) (4) \\
\hline (1) (2) (3) (4) & 7.1 .16 & Promover o armazenamento da informação e do conhecimento & (1) (2) (3) (4) \\
\hline (1) (2) (3) (4) & 7.1 .17 & Empenhar-se na disseminação de informações confiáveis & (1) (2) (3) (4) \\
\hline
\end{tabular}




\section{Solicitações de Capacitação}

8.1 Você solicita capacitações para sua formação profissional?

( ) Sim, como e quais? ( ) Não Justifique se possível:

8.2 Você solicita capacitações para a formação profissional de sua equipe de trabalho?

( ) Sim, como e quais? ( ) Não Justifique se possível:

\section{Capacitações do Substituto Imediato}

9.1 O seu substituto imediato realizou os sete cursos obrigatórios para gestores?
( ) $\operatorname{Sim}$
( ) Não
( ) Parcialmente
( ) Não sei

\section{Perfil do Gestor}

10.1 Cargo: ( ) Técnico do Seguro Social

( ) Analista do Seguro Social

( ) Outro:

10.2 Função Comissionada: ( ) Gerente Executivo ( ) Gerente de APS

10.2.1 Sendo Gerente de APS, indique a Unidade da Federação e o Porte de sua Agência:

( ) Sigla da Unidade da Federação （ ） Porte da APS (Tipo A, B ou C)

10.3 Sexo: ( ) Feminino ( ) Masculino

10.4 Faixa de Idade:

( ) De 18 a $20 \operatorname{anos}($ ) De 21 a $30 \operatorname{anos}$ ( ) De 31 a 40 anos

( ) De 41 a 50 anos ( ) De 51 a 60 anos ( ) Acima de 60 anos

10.5 Escolaridade:
( ) Ensino Fundamental
( ) Ensino Médio
( ) Superior Incompleto
( ) Superior Completo
( ) Especialização / MBA
( ) Mestrado / Doutorado

10.6 Exerce o cargo de Servidor Público no INSS :

( ) Há menos de 1 ano ( ) Entre 1 e 3 anos

( ) Entre 3 e 5 anos ( ) Entre 5 e 10 anos

( ) Há mais de 10 anos

10.7 Exerce a função de Gerente a quanto tempo:
( ) Há menos de 1 ano
( ) Entre 1 e 3 anos
( ) Entre 3 e 5 anos
( ) Entre 5 e 10 anos
( ) Há mais de 10 anos 
10.8 A Unidade onde exerce o seu trabalho é vinculada à:

( ) I - Superintendência Sudeste - São Paulo

( ) II - Superintendência Sudeste - Belo Horizonte

( ) III - Superintendência Sul - Florianópolis

( ) IV - Superintendência Nordeste - Recife

( ) V - Superintendência Norte / Centro-Oeste - Brasília

10.9 Quantidade de Agentes Públicos em sua Unidade de Gestão:

( ) Servidores Públicos

( ) Estagiários

( ) Terceirizados

10.10 Email de cadastro e contato para fins de sorteio de um cheque presente de $\mathrm{R} \$ 325,00$ da Fnac para os que preencheram integralmente o questionário até 10 de agosto de 2016:

email para cadastro e contato:

\section{ESPAÇO LIVRE}

Utilize este para espaço para se manifestar a respeito desta pesquisa e considere a importância das capacitações para o desempenho do seu trabalho.

Enfim, ficamos gratos por sua valiosa colaboração e participação.

Comentários: 


\section{Apêndice IV - Conceitos relacionados a Competência}

\section{Conceitos relacionados a competência}

Autor Definição de Competência(s)

Abbad e Borges-

Andrade (2004)

Amaro (2008)

Ansorena Cao (1996, como citado em

Trujillo, 2000)

Araújo (2009)

Bergenhenegouwen (1996)

Boog (1991, como citado em Campos et al., 2008)

Boyatzis (1982)

Brandão e

BorgesAndrade (2007)

Brophy e Kiely (2002)

Burnett e Dutsch (2006)

Carbone, Brandão, Leite, e Vilhena, (2005, como citado em Mutti, 2008)

Cheetam e Chivers, (2005, como citado em De Coi et al., 2007)

Ducci (1996)
Competência é uma combinação de conhecimentos, habilidades e atitudes (CHAs) que um indivíduo mobiliza para alcançar um determinado propósito no trabalho.

Competência profissional é entendida como os conhecimentos, as habilidades e as atitudes que são mobilizados pelos trabalhadores para a realização de uma ação específica.

Competência é uma habilidade ou atributo pessoal da conduta do sujeito, que se pode definir como característica de seu comportamento, e, sob as quais, o comportamento orientado para a tarefa pode se classificar de forma lógica e confiável.

Competência refere-se ao conjunto de conhecimentos, habilidades e atitudes (isto é, conjunto de capacidades humanas) que justificam um alto desempenho, acreditandose que os melhores desempenhos estão fundamentados na inteligência humana e na personalidade das pessoas.

Competências individuais dizem respeito a características fundamentais da personalidade que são inerentes às ações das pessoas em relação a todos os tipos de tarefas e situações; especialidades e habilidades; motivos e qualidades.

O conceito de competência está ligado à qualidade de quem é capaz de apreciar e resolver certo assunto, fazer determinada coisa; significa capacidade, habilidade, aptidão e idoneidade.

Competência é uma característica subjacente de um indivíduo (que pode ser um motivo, traço, habilidade, aspecto de sua autoimagem, papel social, ou conjunto de conhecimentos) causalmente relacionados a efetividade e/ou desempenho superior no trabalho.

Competência representa um conjunto de conhecimentos, habilidades e atitudes necessários para exercer certa atividade e, também o desempenho expresso pelo indivíduo em termos de comportamentos adotados no trabalho e realizações decorrentes.

Competências são habilidades, conhecimentos, comportamentos e atitudes requeridas para desempenhar um papel de forma efetiva.

Competência se refere a características subjacentes a um indivíduo relacionadas ao trabalho (ex: habilidades, conhecimentos, atitudes, crenças, motivos e traços) que o possibilitam ter um desempenho bem sucedido no trabalho, em que "bem sucedido" é entendido como estando em consonância com as funções estratégicas da organização (ex: visão, missão, singularidade, orientação para o futuro, sucesso, ou sobrevivência).

Competências são combinações sinérgicas de conhecimentos, habilidades e atitudes, expressas pelo desempenho profissional dentro de determinado contexto organizacional, que agregam valor às pessoas e às organizações.

Competência é o desempenho efetivo dentro de um domínio/contexto em diferentes níveis de proficiência.

A competência é mais do que a soma de todos esses componentes (conhecimentos, habilidades, destrezas e atitudes): é uma síntese que resulta de combinação, interação e prática de tais componentes em uma situação real, enfatizando o resultado e não o 


Autor Definição de Competência(s)

insumo.

Durrand (1998)

Dutra, Hipólito e Silva (2000)

Fleury e Fleury (2001)

Freitas e Brandão (2006)

Gilbert (1978, como citado em Brandão, 2009)

Gomes (2003, como citado em Freire, 2010)

Haerem (1998)

Hoffmann (1999)

Lawler III (1994)

Le Boterf (1994, como citado em Fleury e Fleury (2001)

Le Boterf (1999 como citado em Brandão, 2006)

Le Boterf (2003)

McClelland e Dailey (1972, como citado em Kilimnik \& Sant" Anna, 2006)

McLagan (1997)
Competência diz respeito ao conjunto de conhecimentos, habilidades e atitudes interdependentes e necessários à consecução de determinado propósito, dentro de um contexto organizacional específico.

Competência é a capacidade da pessoa em gerar resultados dentro dos objetivos estratégicos e organizacionais da empresa.

Competência é definida como um saber agir responsável e reconhecido, que implica mobilizar, integrar, transferir conhecimentos, recursos, habilidades, que agreguem valor econômico à organização, e valor social ao indivíduo.

Competências podem ser entendidas como combinações sinérgicas de conhecimentos, habilidades e atitudes, expressas pelo desempenho profissional dentro de um contexto organizacional, que agregam valor a pessoas e organizações.

Competência é expressa em função do desempenho ou comportamento da pessoa no trabalho.

Competência é constituída de várias habilidades articuladas e direcionadas à ação solucionadora, em uma determinada situação.

Competência é a habilidade e a vontade de transformar conhecimento em resultados práticos.

Competências são definidas como desempenho observável, padrão ou qualidade do resultado do desempenho da pessoa, e os atributos subjacentes a uma pessoa.

Competências são características demonstráveis de um indivíduo, que incluem conhecimentos, habilidades e comportamentos ligados diretamente com o desempenho.

Competência é um saber agir responsável e que é reconhecido pelos outros. Implica saber como mobilizar, integrar e transferir os conhecimentos, recursos e habilidades, num contexto profissional determinado. A competência não reside nos recursos (saberes, conhecimentos, capacidades, habilidades) a serem mobilizados, mas na própria mobilização desses recursos.

A competência da pessoa é decorrente da aplicação conjunta, no trabalho, de conhecimentos, habilidades e atitudes (saber, saber-fazer, saber-ser). São manifestadas em ações ou comportamentos executados em determinadas atividades ou tarefas.

A competência é uma ação ou um conjunto de ações finalizado sobre uma utilidade, sobre uma finalidade que tem um sentido para o profissional que terão um impacto sobre os desempenhos realizados. Para que haja competência, é preciso que haja colocação em jogo de um repertório de recursos (conhecimentos, capacidades cognitivas, capacidades relacionais, etc.).

Competência é um conjunto de características individuais observáveis, como conhecimentos, habilidades, objetivos e valores, capazes de predizer e/ou causar um desempenho efetivo ou superior no trabalho ou em outras situações da vida.

Uma competência é o agrupamento de conhecimentos, habilidades e atitudes interrelacionados que se correlacionam com a efetividade do desempenho no trabalho, que pode ser medido e avaliado, e que pode ser aperfeiçoado através de treinamento e desenvolvimento.

Competências são conhecimentos, habilidades, capacidade ou característica associada 


\begin{tabular}{ll}
\hline Autor & \multicolumn{1}{c}{ Definição de Competência(s) } \\
\hline $\begin{array}{l}\text { com alto desempenho no trabalho, como resolução de problema, pensamento analítico } \\
\text { ou liderança. }\end{array}$
\end{tabular}

Murray (2003)

As competências pessoais englobam atributos, habilidades e comportamentos de pessoas para desempenhar uma função ou tarefa de um trabalho em sentido designado, mas superior.

Nisembaum (2000, como citado em Bruno-Faria e Brandão, 2003)

Nordhaug (1998, como citado em Lima \& Borges-Andrade, 2006)

Parry (1996)

Perrenoud (2001, como citado em Kilimnik, Sant ${ }^{\text {e }}$ Anna, \& Luz, 2004)

Perrenoud (1997)

Perrenoud (2002)

Rabaglio (2001, como citado em Campos et al., 2008)

Rodríguez \& Feliú (1996, como citado em Trujillo, 2000)

Ruas et al. (2005)

Ruas (1999, como citado em Porto, 2001)

Sant'Anna (2002)

Sargis (2000, como citado em Miranda, 2004)

Sparrow (1997, como citado em Vakola, Soderquist \& Prastacos, 2007)
Competências representam combinações sinérgicas de conhecimentos, habilidades e atitudes, expressas pelo desempenho profissional, dentro de determinado contexto organizacional.

Competência é o composto de conhecimentos, habilidades e atitudes humanas que podem servir a propósitos produtivos em organizações.

Competências são um agrupamento de conhecimentos, habilidades e atitudes (CHA) que afeta a maior parte do trabalho de uma pessoa (um papel ou responsabilidade), que se correlacionam com desempenho no trabalho, que podem ser mensuradas considerando padrões bem aceitos, e que possam ser melhoradas através de treinamento e desenvolvimento.

Competência é a capacidade de um indivíduo de mobilizar o todo ou parte de seus recursos cognitivos e afetivos para enfrentar situações complexas, o que exige a conceituação precisa desses recursos, das relações que devem ser estabelecidas entre eles e da natureza do "saber mobilizar".

Competência é uma capacidade de agir eficazmente em um determinado tipo de situação, apoiada em conhecimentos, mas sem limitar-se a eles.

A competência é uma aptidão para dominar um conjunto de situações e de processos complexos agindo com discernimento.

Competência envolve um conjunto de conhecimentos, habilidades e comportamentos que o indivíduo precisa desempenhar com eficácia para determinadas tarefas e em qualquer situação.

Competências são conjuntos de conhecimentos, habilidades, disposições e condutas que possui uma pessoa, e que a permite a realização exitosa de uma atividade.

Competência é a capacidade de mobilizar, integrar e colocar em ação conhecimentos, habilidades e formas de atuar do indivíduo com a finalidade de atingir e/ou superar desempenhos esperados pela organização.

Competência é a capacidade de mobilizar e aplicar conhecimentos e capacidades numa condição particular, aonde se colocam recursos e restrições próprias à situação específica.

Competência é a resultante da combinação de múltiplos saberes: saber-fazer, saberagir, saber-ser - capazes de propiciarem respostas com bom êxito, por parte dos indivíduos, aos desafios advindos dos processos de reestruturação e modernização produtiva em voga.

Competência é a capacidade de mobilizar um conjunto de recursos com o objetivo de realizar uma atividade.

Competência é o repertório comportamental das pessoas, isto é, seus conjuntos de padrões comportamentais que se relacionam com o desempenho no trabalho e distingue desempenho excelente de mediano. 
Autor

Definição de Competência(s)

Sparrow e Bognanno

(1994, como citado em

Brandão \& Guimarães, 2001)

Spencer e Spencer

Stuart e Lindsay

Sveiby $(1998$, como citado em Okimoto, 2004)

Swieringa e Wierdsma (1995, como citado em Porto, 2001)

Tejada Fernández (1999)

Trujillo (2000)

Vakola, Soderquist e Prastacos (2007)

Vasconcelos, Cavalcante e Monte (2011)

Wynne e Stringer (1997, como citado em Brophy \& Kiely, 2002)

Zarifian (2008)

Zarifian (1996, como citado em Lima e Borges-Andrade (2006)
Competências representam atitudes identificadas como relevantes para a obtenção de alto desempenho em um trabalho específico ao longo de uma carreira profissional ou no contexto de uma estratégia corporativa.

Competências são características subjacentes ao indivíduo que se relacionam causalmente a um padrão de eficácia e/ou a um desempenho superior em um trabalho ou situação.

Competência é uma declaração de valor atribuído a outro dentro de uma organização em particular; o valor que é colocado em um gerente que é capaz de desempenhar e "ser" de maneira que são altamente valorizadas e exigidas pela organização.

A competência de um indivíduo é formada por cinco elementos mutuamente dependentes: o conhecimento explícito, habilidades, experiências, julgamentos de valor e rede social.

Competência se refere não só ao que as pessoas sabem e compreendem, mas também pelo que podem fazer (capacidades), o que tem vontade de fazer e o que são (personalidade e atitudes).

Competência refere-se a funções, tarefas e atuação de um profissional; incumbência para desenvolver, adequada e idoneamente, suas funções de trabalho; suficiência, que é resultado e objetivo de um processo de capacitação e qualificação.

Uma competência é o que faz com que a pessoa seja competente para realizar um trabalho ou uma atividade exitosa por si mesmos, o que pode significar a conjugação de conhecimentos, habilidades, disposições e condutas específicas. Se falha algum destes aspectos, e os mesmos se requerem para alcançar algo, já não é mais competente.

Uma competência individual relacionada ao trabalho é o conjunto subjacente de padrões de comportamento de um empregado relacionados a efetividade e/ou ao desempenho superior no trabalho, atuando tanto no nível individual quanto coletivo (efetividade/ desempenho superior ambos no trabalho solitário e no interpessoal), e que proporcionam à organização em que são implementadas e aplicadas, vantagens competitivas sustentáveis.

Uma competência pode ser entendida como o conjunto de conhecimentos, habilidades e atitudes que contribuem para que haja resposta adequada às demandas do trabalho que um indivíduo exerce.

Competências são coisas que as pessoas tem que ser, saber e fazer, para alcançar os resultados requeridos no seu trabalho.

A competência é o "tomar iniciativa" e o "assumir responsabilidade" do indivíduo diante de situações profissionais com as quais se depara. A competência é um entendimento prático de situações que se apoia em conhecimentos adquiridos e os transforma na medida em que aumenta a diversidade das situações.

Competência é assumir responsabilidades frente a situações laborais complexas e desenvolver uma atitude reflexiva sobre trabalho, que permita ao profissional lidar com eventos inéditos, surpreendentes, de natureza singular. 


\section{Anexo I - Competências do gerente de Agência da Previdência Social (APS)}

\begin{tabular}{|c|c|c|}
\hline $\begin{array}{l}\text { Papéis } \\
\text { chave }\end{array}$ & $\begin{array}{l}\text { Unidades de } \\
\text { Competências }\end{array}$ & Desempenhos competentes \\
\hline \multirow{12}{*}{ 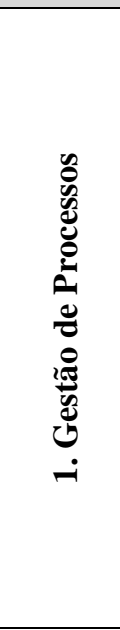 } & \multirow{5}{*}{$\begin{array}{l}\text { 1.1 Promover ações } \\
\text { para o funcionamento } \\
\text { da APS }\end{array}$} & 1.1.1. Gerenciar contratos e serviços \\
\hline & & 1.1.2. Negociar melhores condições de trabalho com diferentes instâncias \\
\hline & & $\begin{array}{l}\text { 1.1.3. Acompanhar e ajustando os recursos disponíveis ao funcionamento } \\
\text { da APS }\end{array}$ \\
\hline & & 1.1.4. Gerir custos operacionais \\
\hline & & $\begin{array}{l}\text { 1.1.5. Interagir com diferentes instâncias com vistas ao funcionamento da } \\
\text { APS }\end{array}$ \\
\hline & \multirow{3}{*}{$\begin{array}{l}1.2 \text { Obter } \\
\text { Produtividade no } \\
\text { Trabalho }\end{array}$} & $\begin{array}{l}\text { 1.2.1. Distribuir as tarefas de acordo com o volume, a natureza, a } \\
\text { complexidade e o quadro de pessoal }\end{array}$ \\
\hline & & 1.2.2. Administrar situações imprevistas e excepcionalidades \\
\hline & & 1.2.3. Monitorar o fluxo de trabalho \\
\hline & \multirow{4}{*}{$\begin{array}{l}1.3 \text { Buscar a Qualidade } \\
\text { nas decisões }\end{array}$} & 1.3.1. Coletar as informações necessárias \\
\hline & & 1.3.2. Analisar e avaliando as informações coletadas \\
\hline & & 1.3.3. Estimular a participação da equipe \\
\hline & & 1.3.4. Avaliar as consequências da tomada de decisão \\
\hline \multirow{32}{*}{ 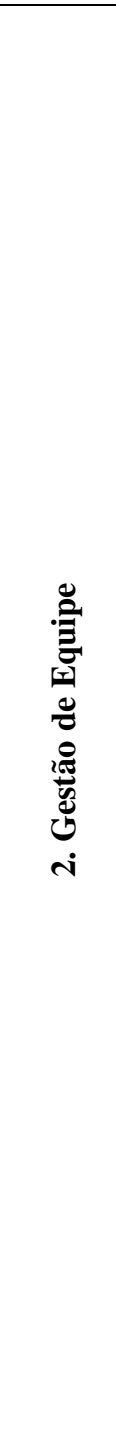 } & \multirow{6}{*}{$\begin{array}{l}\text { 2.1 Construir Equipe } \\
\text { de Trabalho }\end{array}$} & 2.1.1. Identificar habilidades dos servidores \\
\hline & & $\begin{array}{l}\text { 2.1.2. Distribuir as tarefas da APS de acordo com as habilidades dos } \\
\text { servidores }\end{array}$ \\
\hline & & 2.1.3. Buscar a integração dos servidores \\
\hline & & 2.1.4. Respeitar as diferenças individuais \\
\hline & & 2.1.5. Administrar conflitos \\
\hline & & 2.1.6. Valorizar a imagem da Instituição \\
\hline & \multirow{6}{*}{$\begin{array}{l}\text { 2.2 Promover o } \\
\text { Desenvolvimento } \\
\text { Pessoal e Profissional } \\
\text { da Equipe }\end{array}$} & 2.2.1. Orientar a equipe a buscar capacitação e Autodesenvolvimento \\
\hline & & 2.2.2. Favorecer o compartilhamento de conhecimentos e Experiências \\
\hline & & 2.2.3. Criar oportunidades de aprendizagem \\
\hline & & 2.2.4. Reconhecer e valorizando o trabalho realizado \\
\hline & & 2.2.5. Identificar causas de insuficiência de desempenho \\
\hline & & 2.2.6. Propor ações para correção de insuficiência de desempenho \\
\hline & \multirow{3}{*}{\begin{tabular}{|l|} 
2.3 Promover a \\
Disseminação e \\
Internalização dos \\
Valores da Instituição \\
\end{tabular}} & 2.3.1. Estabelecer padrões de conduta no trabalho \\
\hline & & 2.3.2. Acompanhar a observância dos padrões acordados \\
\hline & & 2.3.3. Liderar pelo exemplo \\
\hline & \multirow{4}{*}{$\begin{array}{l}\text { 2.4 Mobilizar Equipe } \\
\text { para a Realização do } \\
\text { Trabalho }\end{array}$} & 2.4.1. Compartilhar os direcionadores estratégicos com a equipe \\
\hline & & 2.4.2. Explicitar as metas e objetivos a serem alcançados \\
\hline & & 2.4.3. Estabelecer comunicação eficaz \\
\hline & & 2.4.4. Identificar dificuldades e buscar soluções \\
\hline & \multirow{3}{*}{\begin{tabular}{|l|}
2.5 Avaliar o \\
Desempenho da \\
Equipe \\
\end{tabular}} & 2.5.1. Analisar os resultados \\
\hline & & 2.5.2. Reconhecer e valorizando o trabalho realizado \\
\hline & & 2.5.3. Propor ações de melhoria \\
\hline & \multirow{4}{*}{$\begin{array}{l}\text { 2.6 Empenhar-se no } \\
\text { Auto } \\
\text { Desenvolvimento }\end{array}$} & 2.6.1. Buscar capacitação \\
\hline & & 2.6.2. Assumir desafios \\
\hline & & 2.6.3. Manter-se atualizado diante das mudanças tecnológicas \\
\hline & & 2.6.4. Informar-se sobre as diretrizes e padrões de atendimento do INSS \\
\hline & \multirow{5}{*}{$\begin{array}{l}\text { 2.7 Promover a } \\
\text { Qualidade de Vida no } \\
\text { Trabalho }\end{array}$} & $\begin{array}{l}\text { 2.7.1. Identificar sinais que possam caracterizar doenças no trabalho e } \\
\text { propondo encaminhamentos }\end{array}$ \\
\hline & & 2.7.2. Estabelecer condições adequadas de estrutura no trabalho \\
\hline & & 2.7.3. Zelar pelo clima organizacional \\
\hline & & 2.7.4. Valorizar o trabalho realizado \\
\hline & & 2.7.5. Orientar para a segurança do trabalho \\
\hline & 2.8 Gerir Talentos e & 2.8.1. Mapear as habilidades e conhecimento dos servidores \\
\hline
\end{tabular}




\begin{tabular}{|c|c|c|}
\hline $\begin{array}{l}\text { Papéis } \\
\text { chave }\end{array}$ & $\begin{array}{l}\text { Unidades de } \\
\text { Competências }\end{array}$ & Desempenhos competentes \\
\hline & Competências & 2.8.2. Divulgar as informações do Portal de Competências \\
\hline \multirow{16}{*}{ 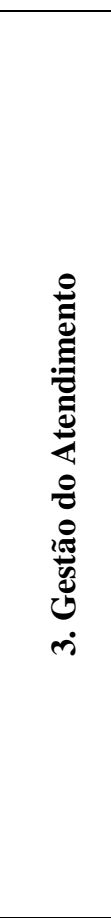 } & \multirow{8}{*}{$\begin{array}{l}3.1 \text { Promover a } \\
\text { Execução do } \\
\text { Atendimento com } \\
\text { Qualidade }\end{array}$} & $\begin{array}{l}\text { 3.1.1. Divulgar internamente as diretrizes e padrões de atendimento do } \\
\text { INSS }\end{array}$ \\
\hline & & $\begin{array}{l}\text { 3.1.2. Mobilizar os servidores para agir de acordo com as diretrizes e } \\
\text { padrões }\end{array}$ \\
\hline & & 3.1.3. Buscar recursos necessários para a realização do Atendimento \\
\hline & & $\begin{array}{l}\text { 3.1.4. Adotar providências em função do conhecimento da demanda (perfil, } \\
\text { necessidades, informações cadastrais dos cidadãos) }\end{array}$ \\
\hline & & 3.1.5. Propor novos critérios de atendimento em conjunto com a equipe \\
\hline & & 3.1.6. Divulgar os serviços do INSS aos cidadãos \\
\hline & & 3.1.7. Analisar as informações dos sistemas gerenciais de forma crítica \\
\hline & & $\begin{array}{l}\text { 3.1.8. Administrar conflitos com o cidadão, de forma conciliadora e } \\
\text { imparcial }\end{array}$ \\
\hline & \multirow{5}{*}{$\begin{array}{l}\text { 3.2 Avaliar o } \\
\text { Resultado do } \\
\text { Atendimento }\end{array}$} & 3.2.1. Verificar o cumprimento das metas \\
\hline & & 3.2.2. Identificar pontos restritivos \\
\hline & & $\begin{array}{l}\text { 3.2.3. Verificar causas de extrapolação de prazo de conclusão dos } \\
\text { processos }\end{array}$ \\
\hline & & 3.2.4. Verificar a qualidade das decisões \\
\hline & & $\begin{array}{l}\text { 3.2.5. Verificar o cumprimento da agenda e demais serviços não } \\
\text { agendáveis }\end{array}$ \\
\hline & \multirow{3}{*}{$\begin{array}{l}\text { 3.3 Promover Ações } \\
\text { para otimizar o } \\
\text { Atendimento }\end{array}$} & 3.3.1. Propor ajustes em acordo com a equipe (ambiente interno) \\
\hline & & 3.3.2. Propor soluções ao nível estratégico do INSS \\
\hline & & 3.3.3. Propor soluções para reclamações do cidadão \\
\hline \multirow{14}{*}{ 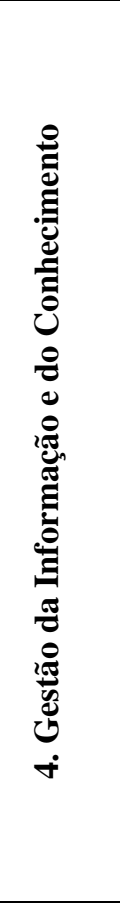 } & \multirow{4}{*}{$\begin{array}{l}4.1 \text { Obter } \\
\text { Informações } \\
\text { necessárias à Gestão } \\
\text { da APS }\end{array}$} & 4.1.1. Acompanhar alterações de normas internas e legislação pertinente \\
\hline & & $\begin{array}{l}\text { 4.1.2. Analisar as informações dos sistemas, periodicamente, de forma } \\
\text { crítica }\end{array}$ \\
\hline & & 4.1.3. Identificar o perfil da demanda \\
\hline & & 4.1.4. Acompanhar informações sobre a Instituição (internas e externas) \\
\hline & \multirow{4}{*}{$\begin{array}{l}\text { 4.2 Promover o } \\
\text { armazenamento da } \\
\text { Informação e do } \\
\text { Conhecimento }\end{array}$} & $\begin{array}{l}\text { 4.2.1. Identificar com a equipe os locais onde a informação e o } \\
\text { conhecimento está armazenado (banco de dados, na mente das pessoas, } \\
\text { arquivos, processos de trabalho) }\end{array}$ \\
\hline & & 4.2.2. Criar meios de armazenamento do conhecimento retido pelas pessoas \\
\hline & & $\begin{array}{l}\text { 4.2.3. Orientar o registro das informações, em local próprio, para consultas } \\
\text { posteriores }\end{array}$ \\
\hline & & 4.2.4. Manter o arquivo organizado \\
\hline & \multirow{6}{*}{$\begin{array}{l}\text { 4.3 Empenhar-se na } \\
\text { Disseminação de } \\
\text { Informaçôes } \\
\text { Confiáveis }\end{array}$} & $\begin{array}{l}\text { 4.3.1. Viabilizar o compartilhamento de informações, conhecimentos e } \\
\text { experiências }\end{array}$ \\
\hline & & $\begin{array}{l}\text { 4.3.2. Atender às solicitações do público interno e externo (cidadãos e } \\
\text { órgãos representativos da sociedade) }\end{array}$ \\
\hline & & $\begin{array}{l}\text { 4.3.3. Divulgar à equipe alterações de normas internas e legislação } \\
\text { pertinente }\end{array}$ \\
\hline & & 4.3.4. Participar do Programa de Educação Previdenciária \\
\hline & & 4.3.5. Divulgar resultados alcançados pela APS \\
\hline & & $\begin{array}{l}\text { 4.3.6. Planejar a rotatividade de pessoal para transferência do } \\
\text { conhecimento }\end{array}$ \\
\hline
\end{tabular}




\section{Anexo II - Competências do gerente executivo}

\begin{tabular}{|c|c|c|}
\hline $\begin{array}{l}\text { Papéis } \\
\text { chave }\end{array}$ & $\begin{array}{l}\text { Unidades de } \\
\text { Competências }\end{array}$ & Desempenhos competentes \\
\hline \multirow{8}{*}{ 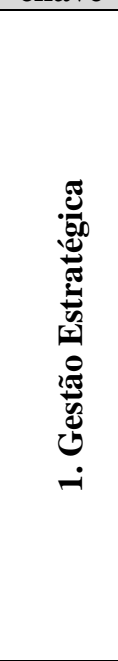 } & \multirow{2}{*}{$\begin{array}{l}\text { 1.1 Contribuir para a } \\
\text { elaboração do } \\
\text { Planejamento } \\
\text { Estratégico } \\
\text { do INSS }\end{array}$} & $\begin{array}{l}\text { 1.1.1 Fornecer informações sobre o ambiente interno de suas unidades de } \\
\text { atendimento }\end{array}$ \\
\hline & & 1.1.2 Fornecer informações sobre o cenário externo de sua Jurisdição \\
\hline & \multirow{4}{*}{$\begin{array}{l}\text { 1.2.Viabilizar a } \\
\text { realização } \\
\text { dos objetivos } \\
\text { estratégicos } \\
\text { do INSS }\end{array}$} & $\begin{array}{l}\text { 1.2.1 Contribuir para a elaboração do Plano Anual de Ação na sua } \\
\text { jurisdição }\end{array}$ \\
\hline & & $\begin{array}{l}\text { 1.2.2 Considerar os reflexos dos ambientes interno e externo no } \\
\text { funcionamento das APS }\end{array}$ \\
\hline & & 1.2.3 Coordenar a execução do Plano Anual de Ação na sua jurisdição \\
\hline & & $\begin{array}{l}\text { 1.2.4 Mobilizar a equipe para a realização do trabalho em consonância com } \\
\text { a missão do INSS }\end{array}$ \\
\hline & \multirow{2}{*}{$\begin{array}{l}1.3 \text { Representar o INSS } \\
\text { junto à sociedade }\end{array}$} & $\begin{array}{l}\text { 1.3.1 Interagir com o judiciário, órgãos de controle e sociedade organizada, } \\
\text { com vistas à redução de demandas judiciais }\end{array}$ \\
\hline & & $\begin{array}{l}\text { 1.3.2 Receber demandas e articulando soluções com vistas à melhoria do } \\
\text { atendimento previdenciário }\end{array}$ \\
\hline \multirow{23}{*}{ 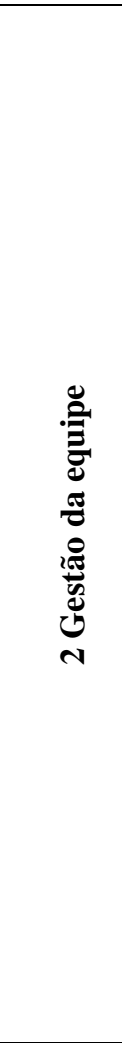 } & \multirow{5}{*}{$\begin{array}{l}\text { 2.1 Construir a equipe } \\
\text { de } \\
\text { trabalho }\end{array}$} & 2.1.1 Respeitar as diferenças individuais \\
\hline & & 2.1.2 Buscar a integração dos servidores \\
\hline & & 2.1.3 Administrar conflitos \\
\hline & & 2.1.4 Estimular o diálogo \\
\hline & & 2.1.5 Valorizar a imagem do INSS \\
\hline & \multirow{3}{*}{$\begin{array}{l}2.2 \text { Mobilizar a equipe } \\
\text { para } \\
\text { a realização do trabalho }\end{array}$} & 2.2.1 Explicitar as metas a serem alcançadas \\
\hline & & 2.2.2 Reconhecer dificuldades e buscando soluções. \\
\hline & & 2.2.3 Acompanhar e valorizando seu desempenho. \\
\hline & \multirow{3}{*}{$\begin{array}{l}2.3 \text { Empenhar-se no } \\
\text { autodesenvolvimento }\end{array}$} & 2.3.1 Buscar capacitação \\
\hline & & 2.3.2 Assumir desafios \\
\hline & & 2.3.3 Manter-se atualizado diante das mudanças tecnológicas \\
\hline & \multirow{7}{*}{$\begin{array}{l}\text { 2.4 Promover o } \\
\text { desenvolvimento } \\
\text { pessoal e } \\
\text { profissional dos } \\
\text { servidores }\end{array}$} & 2.4.1 Orientar a buscar capacitação e o auto-desenvolvimento \\
\hline & & 2.4.2 Favorecer o compartilhamento de conhecimentos e experiências. \\
\hline & & 2.4.3 Criar oportunidades de aprendizagem. \\
\hline & & 2.4.4 Identificar causas de insuficiência de desempenho. \\
\hline & & 2.4.5 Fornecer feedback \\
\hline & & 2.4.6 Propor ações para a correção de insuficiência de Desempenho \\
\hline & & $\begin{array}{l}\text { 2.4.7 Orientar a conduta dos servidores quanto aos valores reconhecidos } \\
\text { pelo INSS, tais como ética, respeito, transparência }\end{array}$ \\
\hline & \multirow{5}{*}{$\begin{array}{l}2.5 \text { Promover a } \\
\text { qualidade } \\
\text { de vida no trabalho }\end{array}$} & $\begin{array}{l}\text { 2.5.1 Identificar sinais de doenças no trabalho e propondo } \\
\text { Encaminhamentos }\end{array}$ \\
\hline & & 2.5.2 Estabelecer condições físicas de trabalho adequadas \\
\hline & & 2.5.3 Zelar pelo clima organizacional \\
\hline & & 2.5.4 Valorizar o trabalho realizado \\
\hline & & 2.5.5 Orientar para a segurança no trabalho \\
\hline \multirow{12}{*}{ 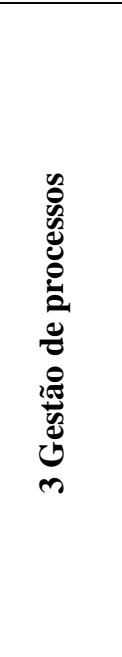 } & \multirow{5}{*}{$\begin{array}{l}\text { 3.1 Garantir o } \\
\text { funcionamento da } \\
\text { Gerência Executiva }\end{array}$} & 3.1.1 Identificar as necessidades das áreas \\
\hline & & 3.1.2 Administrar situações imprevistas e excepcionalidades \\
\hline & & $\begin{array}{l}\text { 3.1.3 Verificar o andamento dos processos relativos a orçamento, finanças, } \\
\text { contabilidade, recursos humanos, benefícios e atendimento }\end{array}$ \\
\hline & & $\begin{array}{l}\text { 3.1.4 Verificar os processos relativos às demandas judiciais e respectivos } \\
\text { desdobramentos. }\end{array}$ \\
\hline & & 3.1.5 Respeitar os princípios da administração pública (limpe) \\
\hline & \multirow{3}{*}{$\begin{array}{l}\text { 3.2 Buscar a qualidade } \\
\text { das Decisões }\end{array}$} & 3.2.1 Estimular a participação da equipe \\
\hline & & 3.2.2 Coletar as informações necessárias \\
\hline & & 3.2.3 Avaliar a situação e as consequências da decisão \\
\hline & \multirow{3}{*}{$\begin{array}{l}\text { 3.3 Demonstrar } \\
\text { resolutividade nas } \\
\text { situações de trabalho }\end{array}$} & $\begin{array}{l}\text { 3.3.1 Interagir com diferentes instâncias (outras gerências, } \\
\text { superintendências) }\end{array}$ \\
\hline & & 3.3.2 Articular soluções no âmbito da gerência executiva \\
\hline & & $\begin{array}{l}\text { 3.3.3 Negociar melhores condições de trabalho com as instâncias e } \\
\text { entidades competentes }\end{array}$ \\
\hline & 3.4 Promover ações de & 3.4.1 Disseminar os princípios da ecoeficiência \\
\hline
\end{tabular}




\begin{tabular}{|c|c|c|}
\hline $\begin{array}{l}\text { Papéis } \\
\text { chave }\end{array}$ & $\begin{array}{l}\text { Unidades de } \\
\text { Competências }\end{array}$ & Desempenhos competentes \\
\hline & $\begin{array}{l}\text { responsabilidade } \\
\text { socioambiental }\end{array}$ & 3.4.2 Divulgar as práticas adotadas em sua jurisdição \\
\hline \multirow{8}{*}{ 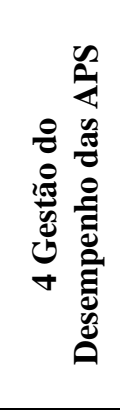 } & \multirow{2}{*}{$\begin{array}{l}4.1 \text { Viabilizar } \\
\text { condições de } \\
\text { trabalho adequadas }\end{array}$} & 4.1.1 Propiciar infra-estrutura satisfatória \\
\hline & & 4.1.2 Fornecer condições para capacitação do quadro de Pessoal \\
\hline & \multirow{2}{*}{$\begin{array}{l}\text { 4.2 Promover a } \\
\text { qualidade } \\
\text { do atendimento }\end{array}$} & 4.2.1 Divulgar as diretrizes e padrões de atendimento do INSS \\
\hline & & 4.2.2 Mobilizar os gerentes de APS para o atingimento das Metas \\
\hline & \multirow{4}{*}{$\begin{array}{l}\text { 4.3 Avaliar o } \\
\text { desempenho } \\
\text { das APSs }\end{array}$} & 4.3.1 Acompanhar o atingimento das metas \\
\hline & & 4.3.2 Acompanhar o volume de processos represados \\
\hline & & 4.3.3 Verificar os indicadores dos sistemas \\
\hline & & 4.3.4 Verificar a adequação do quadro de pessoal \\
\hline \multirow{11}{*}{ 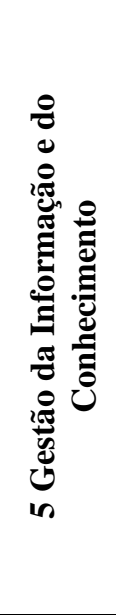 } & \multirow{4}{*}{$\begin{array}{l}\text { 5.1 Obter informações } \\
\text { necessárias à gestão da } \\
\text { Gerência Executiva }\end{array}$} & $\begin{array}{l}\text { 5.1.1 Acompanhar alterações de normas internas e legislação } \\
\text { previdenciária }\end{array}$ \\
\hline & & $\begin{array}{l}\text { 5.1.2 Analisar as informações dos sistemas periodicamente, de forma } \\
\text { crítica }\end{array}$ \\
\hline & & 5.1.3 Buscar informações sobre a jurisdição e a clientela \\
\hline & & 5.1.4 Acompanhar noticiário sobre o INSS \\
\hline & \multirow{7}{*}{$\begin{array}{l}5.2 \text { Garantir a } \\
\text { disseminação de } \\
\text { informações confiáveis }\end{array}$} & $\begin{array}{l}\text { 5.2.1 Viabilizar o compartilhamento de informações, conhecimentos e } \\
\text { experiências }\end{array}$ \\
\hline & & $\begin{array}{l}\text { 5.2.2 Divulgar à equipe alterações de normas internas e legislação } \\
\text { previdenciária }\end{array}$ \\
\hline & & 5.2.3 Divulgar índices alcançados pelas APS e Gerência Executiva \\
\hline & & 5.2.4 Repassar temas de interesse do INSS \\
\hline & & 5.2.5 Atender às solicitações do público externo \\
\hline & & 5.2.6 Atender às solicitações internas \\
\hline & & 5.2.7 Participar do Programa de Educação Previdenciária \\
\hline
\end{tabular}

